Material Recovery \& Waste Form Development 2015 Accomplishments

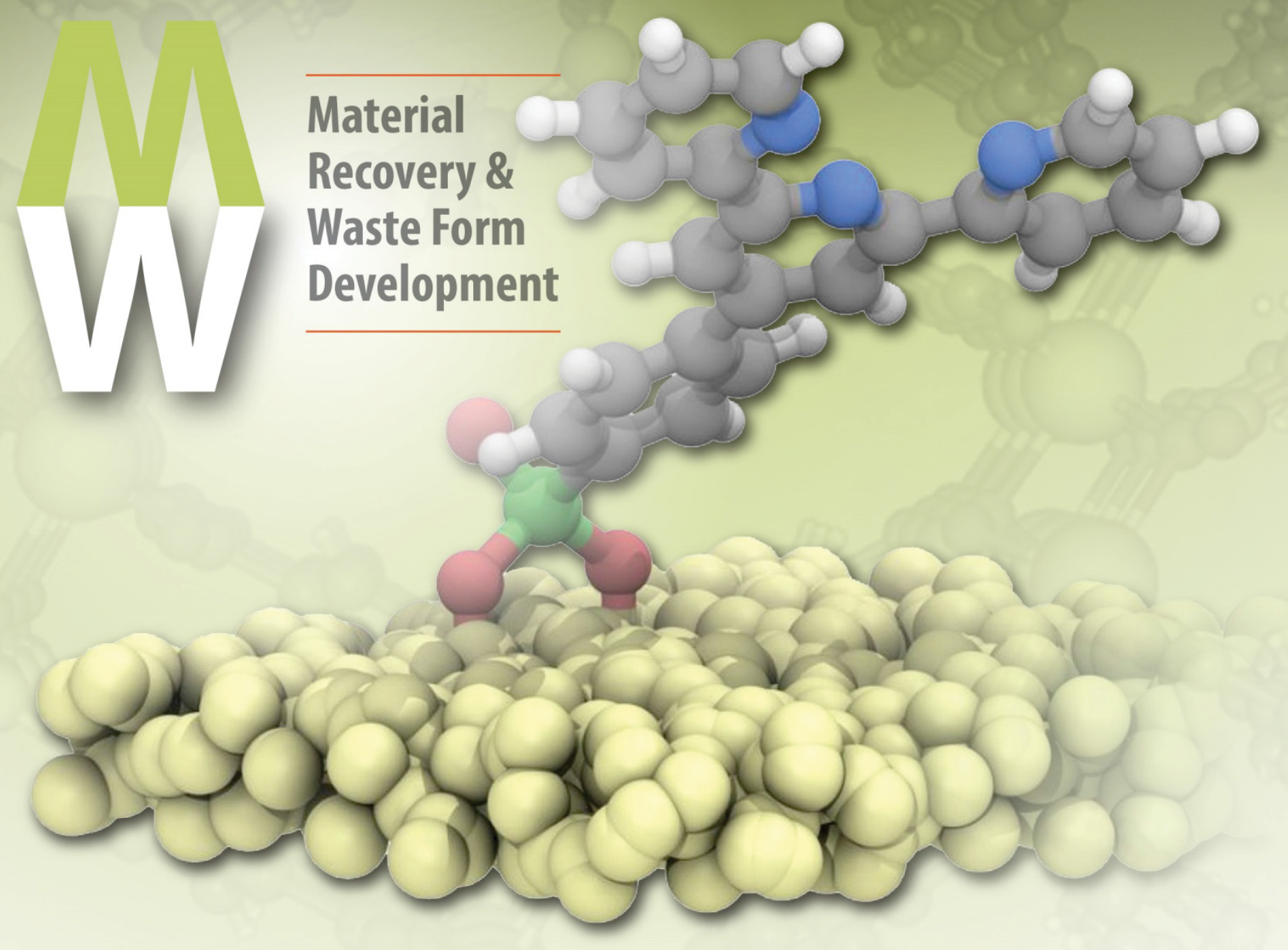




\section{About the Cover}

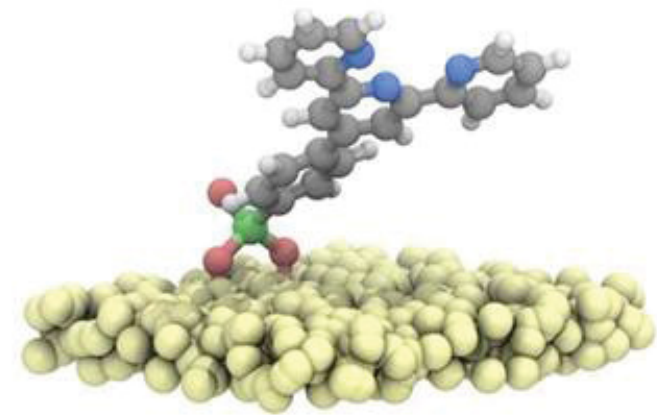

Experiments were designed to test the hypothesis that binding of Am(III) at the electrode surface facilitates electron transfer to the electrode. This figure illustrates the attachment of an americiumselective terpyridine ligand to the $n \mathrm{ITO}$ surface. This figure is from a manuscript accepted for publication in Science.

The background is a solid-state packing of a new MOF with an active site shown in blue. In an effort to develop advanced materials with improved Xenon (Xe) and Krypton ( $\mathrm{Kr}$ ) adsorption capacity and selectivity, a new metal organic framework (MOF) was recently synthesized from inexpensive starting material that forms a one dimensional channel with average cross section of $5.9 \AA \times 5.8 \AA$. The outstanding Xe capacity under simulated conditions with and without water vapor makes this new MOF a leading candidate for separating the $\mathrm{Xe} / \mathrm{Kr}$ from nuclear re-processing applications.

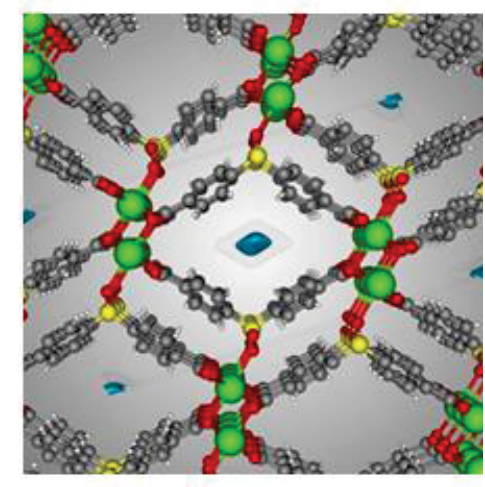

\section{DISCLAIMER}

This information was prepared as an account of work sponsored by an agency of the U.S. Government. Neither the U.S. Government nor any agency thereof, nor any of their employees, makes any warranty, expressed or implied, or assumes any legal liability or responsibility for the accuracy, completeness, or usefulness, of any information, apparatus, product, or process disclosed, or represents that its use would not infringe privately owned rights. References herein to any specific commercial product, process, or service by trade name, trade mark, manufacturer, or otherwise, does not necessarily constitute or imply its endorsement, recommendation, or favoring by the U.S. Government or any agency thereof. The views and opinions of authors expressed herein do not necessarily state or reflect those of the U.S. Government or any agency thereof. 
FCRD-MRWFD-2016-000001

INL/EXT-15-37053

\title{
Material Recovery and Waste Form Development FY-15 Accomplishments Report
}

\author{
FCRD-MRWFD-2016-000001
}

INL/EXT-15-37053

November 2, 2015

Idaho National Laboratory Idaho Falls, Idaho 83415

http://www.inl.gov

Prepared for the

U.S. Department of Energy

Office of Nuclear Energy

Under DOE Idaho Operations Office

Contract DE-AC07-05ID14517 
This page intentionally left blank. 


\section{FUEL CYCLE RESEARCH AND DEVELOPMENT}

\section{MATERIAL RECOVERY AND WASTE FORM DEVELOPMENT FY-15 ACCOMPLISHMENTS REPORT}

FCRD-MRWFD-2016-000001

INL/EXT-15-37053

November 2, 2015

Compiled and edited by:

Lori Braase (lori.braase@inl.gov)

W. Edgar May (ed.may@inl.gov)

INL Systems Analyses

Approved by:

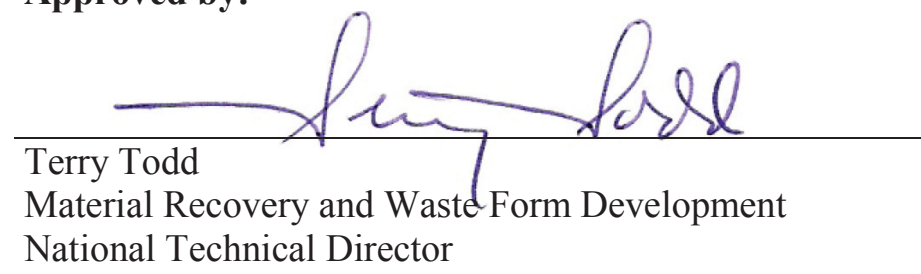


This page intentionally left blank. 


\section{CONTENTS}

1. MRWFD CAMPAIGN MANAGEMENT AND INTEGRATION …............................................ 3

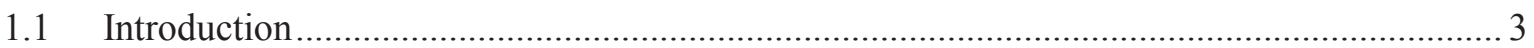

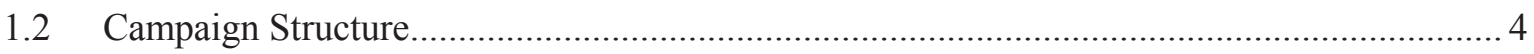

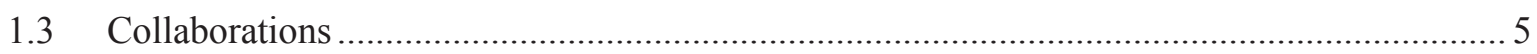

2. REFERENCE TECHNOLOGIES AND ALTERNATIVES _...................................................... 15

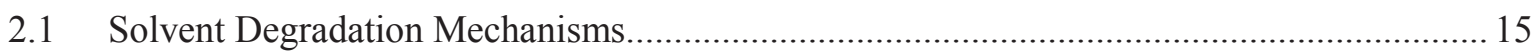

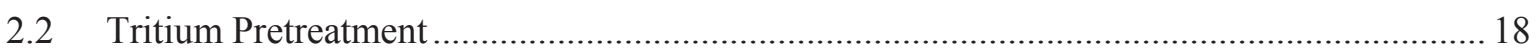

2.3 Tritium Separation from High-Volume Dilute Aqueous Streams....................................... 20

2.4 Tritium Separation from Dilute Aqueous Solutions ...................................................... 21

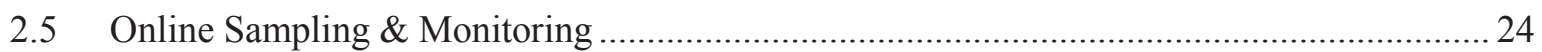

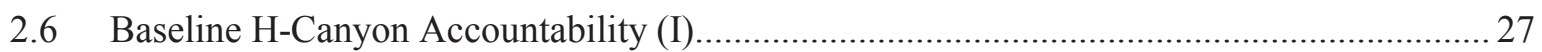

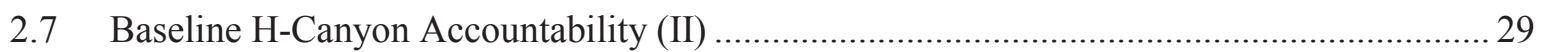

2.8 Lab-scale Testing of Reference Processes (I) ....................................................................... 30

2.9 Lab-Scale Testing of Reference Processes (II) .................................................................... 33

2.10 Lab-Scale Testing of Reference Processes (III) .................................................................... 35

2.11 Lab-Scale Testing of Reference Processes (IV)..................................................................... 38

3. SIGMA TEAM FOR ADVANCED ACTINIDE RECYCLE .................................................... 47

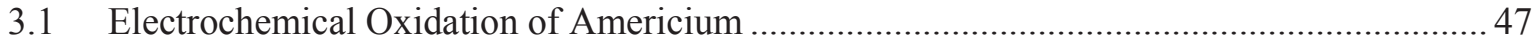

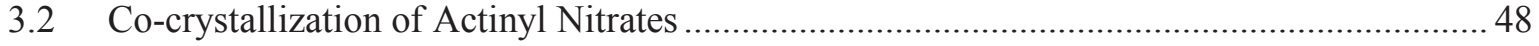

3.3 ALSEP Process Development for An/Ln Separation......................................................... 50

3.4 Fundamental Chemistry of TALSPEAK-Based Systems ….............................................. 53

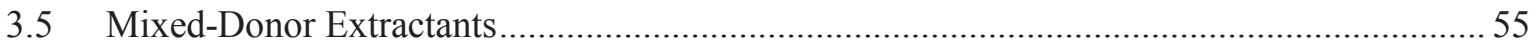

3.6 Theoretical Prediction of Am(III)/Eu(III) Selectivity ....................................................... 57

3.7 Define \& Document Reference Flowsheet ......................................................................... 61

4. SIGMA TEAM FOR OFF-GAS CAPTURE AND IMMOBILIZATION ..................................... 67

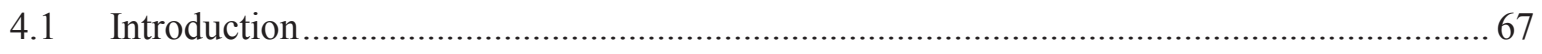

4.2 Preliminary Evaluation of Exchange of Hydrogen Isotopes in the Structure of a

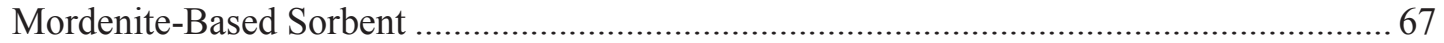

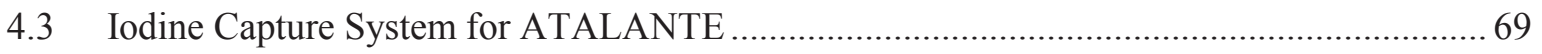

4.4 Methyl Iodide and Iodine Adsorption in Deep Beds........................................................ 71

4.5 Silver-Functionalized Silica-Aerogels: Progress Towards a Mechanically Robust

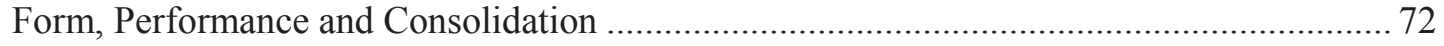

4.6 Results of $\mathrm{Kr} / \mathrm{Xe}$ multi column Adsorption tests .............................................................. 74

4.7 Effects of Functionalization of MOFs on $\mathrm{Kr} / \mathrm{Xe}$ Capture, Separation, and Stability............. 76 


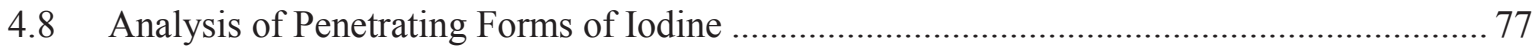

4.9 Scale-Up of GCM Materials for Iodine Waste Forms …....................................................... 79

4.10 Vessel Off-Gas Testing of Silver Exchanged Mordenite ........................................................ 80

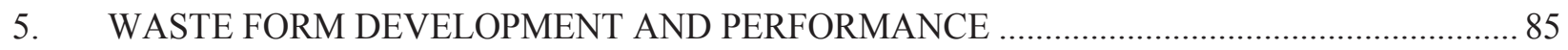

5.1 Characterization of Ceramic Produced from a Cold Crucible Induction Melter Test............85

5.2 Glass Ceramic Waste Form Development for Fission Products from Used Nuclear

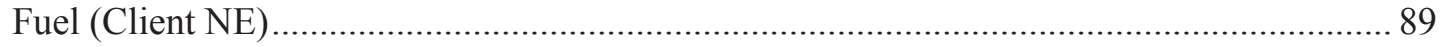

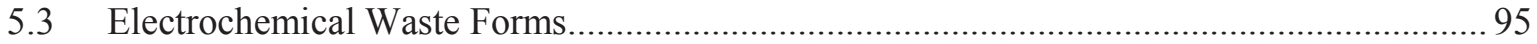

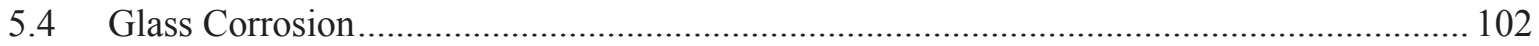

5.5 Advanced Waste Forms (Zirconium Recycle) ................................................................... 110

5.6 First-Principles Modeling of Hydrolysis Reactions ............................................................ 113

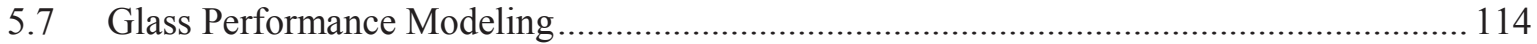

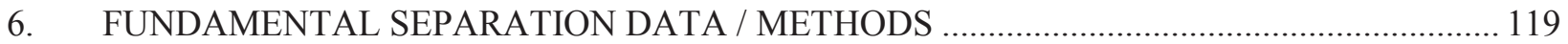

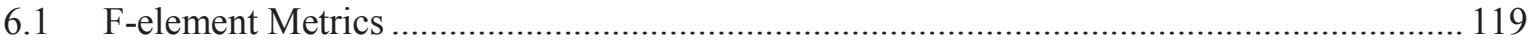

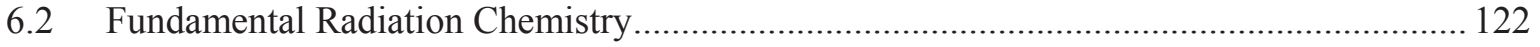

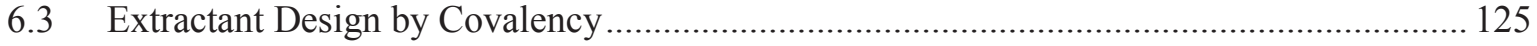

6.4 Separation Process Thermodynamics and Kinetics: Development of Microfluidic Devices for Solvent Extraction Studies and Radioanalytical Applications ......................... 127

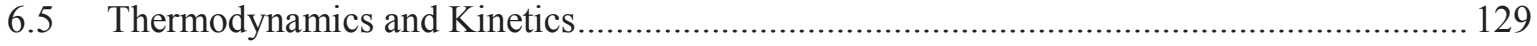

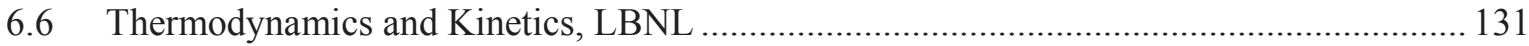

6.7 Theoretical Prediction Stability Constants of Lanthanum Lactate Complexes in Solution and Exploratory Calculations of Spectroscopic Properties of M-DTPA Complexes

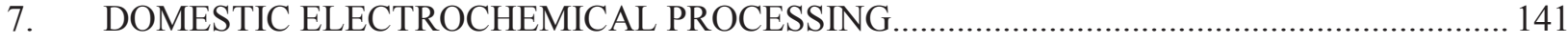

7.1 Development of Engineering-Scale Co-Deposition Cathode.............................................. 141

7.2 AC Voltammetry for Quantitative Analysis of Actinides in Molten Fluoride Salts ........... 142

7.3 U/TRU Codeposition and Fluoride Salt Studies ................................................................ 145

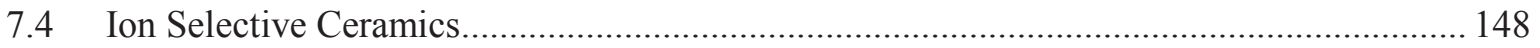

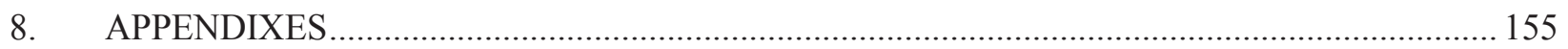

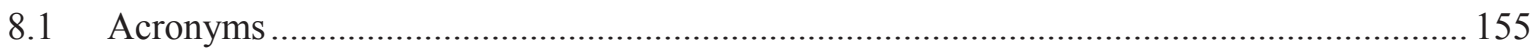

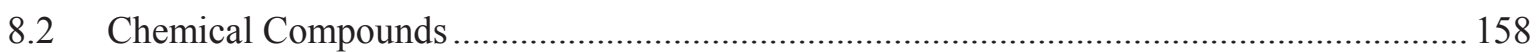

8.3 Nuclear Energy University Project (NEUP) Grants......................................................... 160

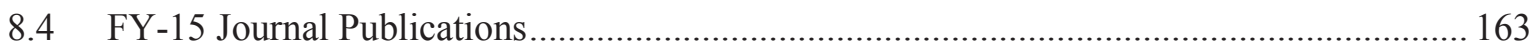




\section{FIGURES}

1. Structures of compounds used in the advanced TALSPEAK process................................... 15

2. Schematic of a closed-loop recirculation system for the pretreatment of light-water reactor (LWR) used fuel to remove tritium, iodine, and krypton.

3. Schematic diagram of the in situ dissolution of the used fuel powder prepared by a head-end process for the subsequent aqueous separation of fissile components - part of a process to recycle used reactor fuel.

4. Clear solution obtained by direct extraction of $\mathrm{UO}_{3}$ in $\mathrm{TBP} /$ dodecane.

5. Schematic of the membrane separation system

6. (A) Microfluidic chip for use in solvent extraction; (B) Schematic of the Raman Microscope-video probe adjacent to the microfluidic cell shown with the laser focus within the microchannels of the mixing chamber....

7. Lewis Cell instrumented with UV/vis/NIR probes for kinetic measurements during extraction/ separation processes

8. Detailed overview of process monitoring and control system ..............................................22

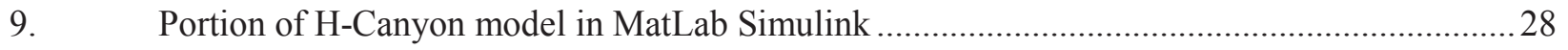

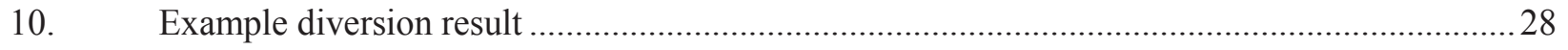

11. Distributions of $\mathrm{U}, \mathrm{Zr}$, and $\mathrm{Tc}$ in $2.83 \mathrm{M} \mathrm{HNO}_{3}$, separately and combined, (E1) contacted with organic phase of $30 \%$ TBP in dodecane. The organic phase (loaded U, $\mathrm{Zr}$, or both in organic) is contacted with $\mathrm{Tc}$ in $2.83 \mathrm{M} \mathrm{HNO}_{3}(\mathrm{E} 2)$.

12. Distributions of $\mathrm{U}, \mathrm{Zr}, \mathrm{Mo}, \mathrm{Ru}$, and $\mathrm{Tc}$ with and without varied concentrations of fluoride present in the form of $\mathrm{NaF}$.

13. $\mathrm{Tc}$ and $\mathrm{Zr}$ in $2.83 \mathrm{M} \mathrm{HNO}_{3}$, where $\mathrm{Zr}$ is contacted with $30 \% \mathrm{TBP} /$ kerosene............................ 35

14. Iodine loading behavior of $\mathrm{NO}_{2}$-aged $\mathrm{AgNO}_{3}$-impregnated alumina .......................................36

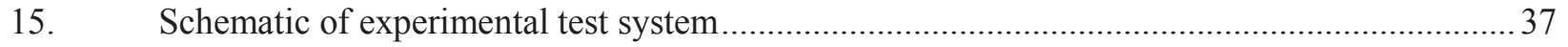

16. Chemical structures of the TALSPEAK (HDEHP) and Advanced TALSPEAK (HEH[EHP]) extractants.

17. Chemical structures of the aqueous-phase complexant and buffers used in the Advanced TALSPEAK system.

18. a) Extraction of $\mathrm{Ln}(\mathrm{III})$ from $0.6 \mathrm{~mol} / \mathrm{L}$ citrate $+0.125 \mathrm{~mol} / \mathrm{L}$ HEDTA at $\mathrm{pH}=2.6$ into $1.0 \mathrm{~mol} / \mathrm{L} \mathrm{HEH}[\mathrm{EHP}] / n$-dodecane. b) Comparison of the $\mathrm{Sm}, \mathrm{Eu}$, and Gd extraction data for the $0.6 \mathrm{~mol} / \mathrm{L}$ citrate $+0.125 \mathrm{~mol} / \mathrm{L}$ HEDTA at $\mathrm{pH}=2.6$ system to those for the $0.2 \mathrm{~mol} / \mathrm{L}$ citrate $+0.125 \mathrm{~mol} / \mathrm{L}$ HEDTA at $\mathrm{pH}=3.1$ system.

19. Time dependence of $\mathrm{Am}(\mathrm{III})$ and $\mathrm{Ln}(\mathrm{III})$ extraction from aqueous solution containing $0.25 \mathrm{~mol} / \mathrm{L} \mathrm{NTA}$ and $0.2 \mathrm{~mol} / \mathrm{L}$ citrate into $1 \mathrm{~mol} / \mathrm{L} \mathrm{HEH}[\mathrm{EHP}]$ in $\mathrm{n}$-dodecane. The initial $\mathrm{pH}$ of the aqueous phase was 3.11 .

20. A terpyridine ligand bound to an indium tin oxide particle on an electrode surface via a phosphonic acid linker. 
21. Concentration of Am species in solution (left) as measured by visible spectroscopy in a $50 \mathrm{~cm}$ waveguide (right) over time during a controlled-potential electrolysis of initially $84 \mu \mathrm{M} \mathrm{Am}(\mathrm{III})$ at $2.25 \mathrm{~V}$ vs $\mathrm{Ag} / \mathrm{AgCl}$. The working electrode was a ligand-modified high-surface-area $n \mathrm{ITO}$, with a Pt foil counter electrode and a $\mathrm{Ag} / \mathrm{AgCl}$ wire reference electrode. The aqueous electrolyte was $0.1 \mathrm{M}$ nitric acid and $0.95 \mathrm{M}$ sodium nitrate. (Right) Initial and final electronic spectra measured in a $1 \mathrm{~cm}$ path-length cuvette and modeled with Gaussian functions.

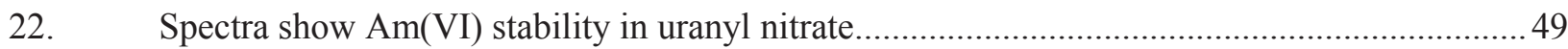

23. Component extractants and aqueous components used in the ALSEP process........................50

24. Separation factors for $\mathrm{Ln}(\mathrm{III}) / \mathrm{Am}(\mathrm{III})$ and distribution ratios of Am(III) at the Am-strip step using a modified centrifugal contactor with increased mixing residence time. Organic phase: 0.045 M T2EHDGA/0.6 M HEH[EHP]. Aqueous phase: $0.125 \mathrm{M}$ HEDTA/0.2 M citrate, $\mathrm{pH} 2.81 . T=21 \pm 2{ }^{\circ} \mathrm{C}$.

25. Application of actinide stripping agent in TALSPEAK-MME Ln/Am separation system. Aqueous phase: $7.01 \mathrm{mM} \mathrm{N}$-methylpiperidine dipicolinic acid, $0.1 \mathrm{M}$ glycine, pH 2.55. Organic phase: $0.4 \mathrm{M}$ (HEH)EHP and $0.4 \mathrm{M}$ Cyanex 923 in $n$-dodecane.

26. Luminescence $\left(\mathrm{Eu}^{3+}\right)$ and absorption $\left(\mathrm{Am}^{3+}\right)$ spectroscopy determination of thermodynamic parameters confirming the existence of mixed M(Mal)(HEDTA) ${ }^{2-}$ complexes in malonate buffered Advanced TALSPEAK. Left: 99.8 mM HEDTA titrated into $1.98 \mathrm{mM} \mathrm{Eu}^{3+}, 0.500 \mathrm{M}$ malonate. Right: $25.0 \mathrm{mM}$ HEDTA titrated into $0.818 \mathrm{mM} \mathrm{Am}^{3+}, 0.600 \mathrm{M}$ malonate.

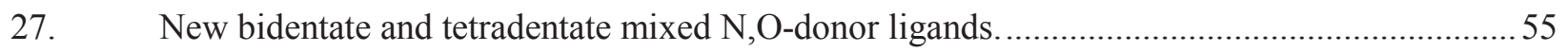

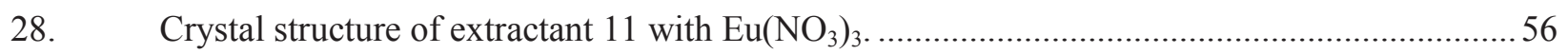

29. Optimized structures for aqueous 1:1 metal ion-ligand complexes stabilized in the nine-

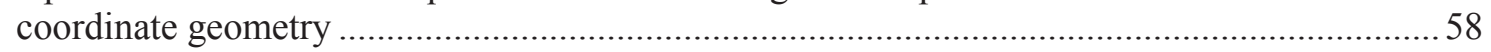

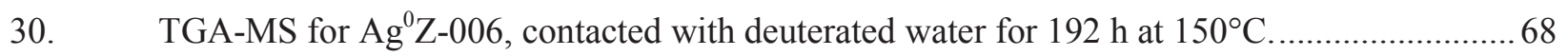

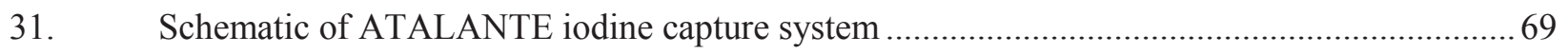

32. Photograph of the individual components of the iodine capture system. ............................... 70

33. Practical iodine capacity and $\mathrm{Ag}$ utilization of $\mathrm{AgZ}$ sorbent for $\mathrm{CH}_{3} \mathrm{I}$ adsorption from

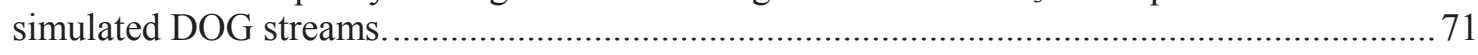

34. HIP-consolidated iodine-loaded silver-functionalized silica aerogel. White and light gray areas represent AgI inclusions dispersed in the silica matrix (dark areas)....................... 73

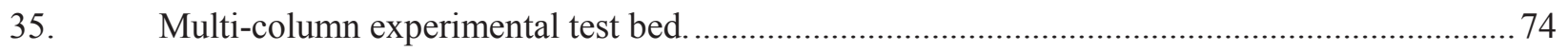

36. Solid-state packing of a new MOF with active site is shown in blue (left). The singlecolumn breakthrough experiments using a gas mixture with $400 \mathrm{ppm} \mathrm{Xe}, 40 \mathrm{ppm} \mathrm{Kr}$, $78 \% \mathrm{~N}_{2}, 21 \% \mathrm{O}_{2}, 0.9 \% \mathrm{Ar}, 0.03 \% \mathrm{CO}_{2}$ in $40 \%$ relative humidity

37. Optical images of the fired GCMs.(left column) GCM containing $20 \mathrm{wt} \% \mathrm{INL} \mathrm{CH}_{3} \mathrm{I}-$

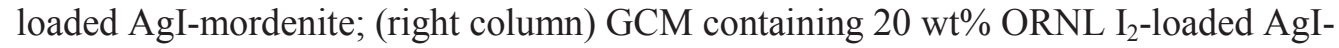
moredenite.

38. Sorption of $\mathrm{CH}_{3} \mathrm{I}$ onto $\mathrm{Ag}^{0} \mathrm{Z}$ under prototypical VOG conditions

39. Summary of primary phase abundances in core samples compared to estimated abundances based on feed composition and target phase assemblage. 


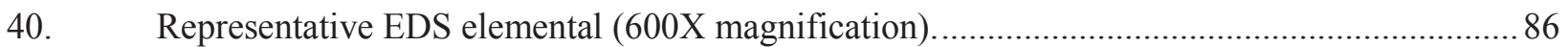

41. SAED pattern inset corresponds to the phase in which the inset is located. .87

42. Sequence of high-resolution TEM images as a function of doses/irradiation of zirconolite phase (Ca-Zr-Ti-Nd-Fe-O) in a multi-phase ceramic waste form sample. Corresponding fast Fourier transforms (FFT) are shown inset. 88

43. First-order component effect on viscosity at temperatures of $1350{ }^{\circ} \mathrm{C}$ (left) and $1250{ }^{\circ} \mathrm{C}$ (right). 90

44. Phase I Normalized Concentration Based on Boron through 448 Days 91

45. Normalized Release (7-day) Based on Boron for Phase I and Phase II Glass Ceramics Compared to EA Glass

46. Backscattered electron micrographs of $\mathrm{C} 1$ morphology; a) crystal-to-glass corrosion (halo around crystals) after SPFT testing at $7000 \times, b$ ) oxyapatite cluster with powellite and glass inside $\mathrm{C} 1$ at $1000 \times$. Oxyapatite within the superstructure all grow at the same crystallographic orientation.

47. Normalized elemental release of $\mathrm{B}$ as a function of $\mathrm{q} / \mathrm{s}$ and canister centerline cooling rate $(4 \times, 1 \times$, and $0.25 \times)$ for glass ceramic $\mathrm{C} 1$.

48. STEM-EDS analysis of oxyapatite-to-glass interface in centroid sample after SPFT testing: a) image with HAADF detector, b) elemental dot map of interface, c) component line scan from elemental map, and d) component elemental compositions.

49. Mechanical properties evolution of SPFT glass ceramic as a function of distance from surface.

50. Microstructure of ACWF-N2 .96

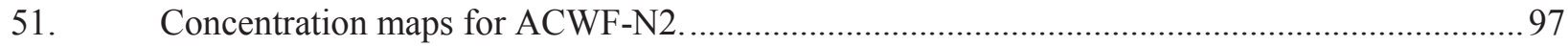

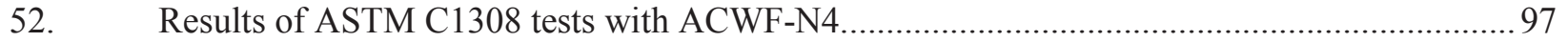

53. Release behaviors of (a) boron and (b) cesium for ACWF materials and standard CWF.........98

54. Potentiodynamic scans showing benefits of (a) Mo, Cr, and Ni, and (b) Ru and Pd to corrosion resistance of HT-9, and (c) metallic fuel wastes in HT-9 based RAW 3 materials

55. (a) PD for bare surface of a 316L-based MWF in acidic brine, (b) current density over time at $250 \mathrm{mV}$, (c) pits formed in intermetallic phases during potentiostatic experiment, and (d) EIS analyses of surface before and after test.

56. Schematic of glass corrosion process (from Vienna et al. 2013)

57. Stainless steel vessel for in-situ Raman spectroscopy of solutions contacting corroding glass.

58. Time-dependent Raman spectra of the solution contacting corroding EA glass at $90^{\circ} \mathrm{C}$. Glass was added to system at 35 hours

59. Time dependent volatization of cladding alloy component (derived from Ref. 1)

60. Color changes over time from nonradioactive $\mathrm{Kg}$-scale chlorination test......

61. New metal test equipment for hot cell tests with 100-500g UNF cladding per test. 
62. Hydrolysis reaction barriers (top row) and reaction energies (bottom row) calculated with first-principles methods for different reaction conditions.

63. Illustration of energy barriers along $\mathrm{Na}+-\mathrm{H}+$ exchange barrier calculated with firstprinciples methods

64. Model fits with the RR, GM, and GRAAL models to SON68 data published by Frugier et al. (Ref. 1) and obtained from a static test at $90^{\circ} \mathrm{C}$ and $200 \mathrm{~m}^{-1}$.

65. Model fit with GRAAL to CJ1 data from Gin et al. 2012 (Ref.2) obtained from a static test at $90^{\circ} \mathrm{C}, 8000 \mathrm{~m}^{-1}$, and $\mathrm{pH}=9$.

66. Model fit with GRAAL to ISG data from Gin et al. 2015 (Ref. 3) obtained from a static test at $\mathrm{SiO}_{2}$ (am) saturation and with pH jump to 11.5 at 209 days.

67. (a) Absorption spectra of $\mathrm{Am}^{3+}$ collected at varying concentrations in $2.0 \mathrm{M} \mathrm{HClO}_{4}$, inset: Beer-Lambert relationship determined using the maximum absorption for the 503 nm peak. (b) The dependence of the molar absorptivity for the $503 \mathrm{~nm}$ peak on the concentration of $\mathrm{HClO}_{4}$.

68. Spectrophotometric investigation of trivalent americium complexation with EDTA-BA, $\mathrm{T}=20 \pm 1{ }^{\circ} \mathrm{C}, \mathrm{I}=2.0 \mathrm{M}$ sodium perchlorate

69. Stripping tests for ${ }^{241} \mathrm{Am}$ and ${ }^{147} \mathrm{Pm}$ from 0.033 $\mathrm{M} \mathrm{T}_{2}$ EHDGA/0.5 M HEH[EHP] using $0.02 \mathrm{M}$ EDTA-DA in $0.5 \mathrm{M}$ Malonate at $\mathrm{pH} 3.0, \mathrm{~T}=25^{\circ} \mathrm{C}$. The vortex mixer was set to $3600 \mathrm{rpm}$.

70. The four possible products of ether linkage rupture for the unsymmetrical MeTODGA......... 123

71. Mass spectra for unirradiated DEHBA (top) and $\gamma$-irradiated to an absorbed dose of 203 kGy (bottom).

72. The radio-bleaching of methylene blue using ${ }^{243} \mathrm{Am}$ as an $\alpha$-source.

73. Synthetic steps for the preparation of new extractant design 2 in gram quantities.

74. Plot of distribution ratios (between the organic and aqueous phase - logD) against $\mathrm{pH}$ of the aqueous phase, for the 'rationally-designed' tethered extractant 2.

75. Solid-state structure of $\mathrm{Am}^{\mathrm{III}}\left[\mathrm{S}_{2} \mathrm{P}\left(\mathrm{C}_{12} \mathrm{H}_{6}{ }^{\mathrm{t}} \mathrm{Bu}_{2}\right)\right]_{4}{ }^{1-}$, an anionic tetrakis complex of $\mathrm{Am}(\mathrm{III})$ with 2 .

76. ANL microfluidic solvent extraction system.

77. (a) Observed Am back-extraction rates for HDEHP, HEH[EHP] and Bis-2ethylhexyl Phosphinic acid with 10mM DTPA/Malonate, $\mathrm{pH} 2.78,1 \mathrm{M}$ IS; (b) $\mathrm{pH}$ dependence for Am and Ln back-extraction rate constants by $0.75 \mathrm{M}$ HEH[EHP] from $25 \mathrm{mM}$ DTPA/ $0.5 \mathrm{M}$ citrate.

78. Fitted dodecane stopped-flow kinetics measured across the absorbance range of 450$675 \mathrm{~nm}$. Measured absorbance change fitted to standard consecutive kinetic model (A $\rightarrow \mathrm{B} \rightarrow \mathrm{C})$....

79. (a) results of the FTIR measurements on this system; (b) thermograms obtained from isothermal titration calorimetry experiments

80. Spectrophotometric titration of $\mathrm{NpO}_{2}{ }^{+} / \mathrm{HEDTA}$ complexation. $I=1.0 \mathrm{M} \mathrm{NaClO}_{4}$. (A) Initial solution in cuvette: $2.100 \mathrm{~mL} ; \mathrm{n}_{\mathrm{H}}=0.6201 \mu \mathrm{mol}, \mathrm{n}_{\mathrm{Np}}=0.5366 \mu \mathrm{mol}$; Titrant: $1.512 \mathrm{mM}$ HEDTA/ $0.3949 \mathrm{mM} \mathrm{H}^{+}$. (B) Initial solution in cuvette: $2.125 \mathrm{~mL} ; \mathrm{n}_{\mathrm{H}}$ $=4.366 \mu \mathrm{mol}, \mathrm{n}_{\mathrm{Np}}=0.5359 \mu \mathrm{mol}, \mathrm{n}_{\mathrm{L}}=1.249 \mu \mathrm{mol}$. Titrant: $0.01 \mathrm{M} \mathrm{NaOH}$. (C) Initial 
solution in cuvette: $2.150 \mathrm{~mL} ; \mathrm{n}_{\mathrm{H}}=8.113 \mu \mathrm{mol}, \mathrm{n}_{\mathrm{Np}}=0.5357 \mu \mathrm{mol}, \mathrm{n}_{\mathrm{L}}=2.498 \mu \mathrm{mol}$. Titrant: $0.015 \mathrm{M} \mathrm{NaOH}$. (D) Initial solution in cuvette: $2.100 \mathrm{~mL} ; \mathrm{n}_{\mathrm{H}}=0.6180 \mu \mathrm{mol}$, $\mathrm{n}_{\mathrm{Np}}=0.5344 \mu \mathrm{mol}$. Titrant: $4.902 \mathrm{mM}$ HEDTA/4. $454 \mathrm{mM} \mathrm{H}^{+}$.

81. Calorimetric titration of $\mathrm{NpO}_{2}{ }^{+} / \mathrm{HEDTA}\left(t=25^{\circ} \mathrm{C}, I=1.0 \mathrm{M} \mathrm{NaClO}_{4}\right)$. (Upper):

thermogram (left y axis) and total reaction heat (right y axis); (Lower) total reaction heat (right y axis; experimental data; dashed line, fit) and speciation of $\mathrm{Np}(\mathrm{V})$ (left y axis; solid lines) versus the volume of the titrant.

82. Representative potentiometric titrations for U(VI)/HEDTA complexation. (upper) $25^{\circ} \mathrm{C}$, In cup: $14.44 \mathrm{~mL}, 0.0221 \mathrm{mmol} \mathrm{U}(\mathrm{VI}), 0.0507 \mathrm{mmol}$ HEDTA, $0.1771 \mathrm{mmol} \mathrm{H}$; titrant: $0.1003 \mathrm{mM} \mathrm{NaOH}$; (lower) $70^{\circ} \mathrm{C}$, In cup: $14.31 \mathrm{~mL}, 0.0221 \mathrm{mmol} \mathrm{U}(\mathrm{VI})$, $0.0255 \mathrm{mmol} \mathrm{L}, 0.1016 \mathrm{mmol} \mathrm{H}$, titrant: $0.1003 \mathrm{mM} \mathrm{NaOH}$.

83. Calorimetric titration of U(VI)/HEDTA complexation at $25 \mathrm{oC}$. I $=1.0 \mathrm{M} \mathrm{NaClO} 4$.

Stepwise heat and corresponding speciation.

84. Comparison of cyclic voltammograms plotted in LiF-NaF-KF (grey curve) and in LiF-

NaF-KF-UF 4 (1.08wt\%) (black line) at $525^{\circ} \mathrm{C}$; WE: W, CE:Mo, RE: W-QRE;

$\boldsymbol{v}=100 \mathrm{mV} / \mathrm{s}$

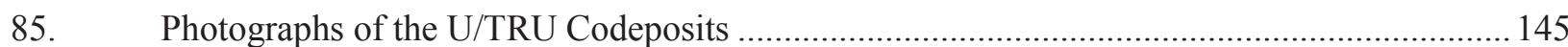

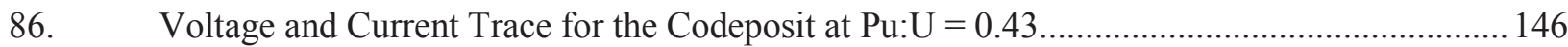

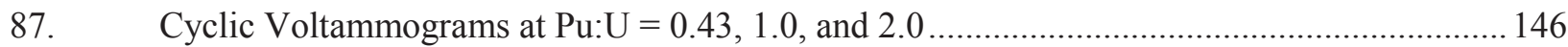

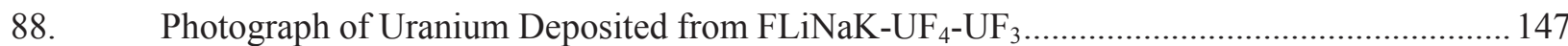

89. Cyclic Voltammograms in FLiNaK salt mixtures of $\mathrm{UF}_{4}, \mathrm{UF}_{3}$, and $\mathrm{UF}_{3}-\mathrm{LaF}_{3} \ldots \ldots \ldots \ldots \ldots \ldots \ldots . . . . . . . .147$

90. Schematic of process to use a closed-end ceramic tube to isolate Cs-contamination from LiCl-KCl molten salt

91. (a) A closed-end ceramic tube (4 cm diameter) and (b) sheets, discs, and cylinders made from NaSICON ceramics. Images from Ceramatec, Inc.

\section{TABLES}

1. Test results for modified distillation system. 22

2. Results from the determination of tritium in reactor cladding test specimens .........................38

3. Ratios of the percent precipitation of different TRU species with respect to $\mathrm{UO}_{2}{ }^{2+} \ldots \ldots \ldots \ldots \ldots . . . . . . . .49$

4. Preliminary distribution ratios and SFs of $\mathrm{Am}(\mathrm{III}) / \mathrm{Eu}(\mathrm{III})$ using ligands 10,11 , and $12 \ldots \ldots . . .56$

5. Calculated and measured selectivities in the solvent extraction of $\mathrm{Am}^{3+}$ and $\mathrm{Eu}^{3+}$

$(\mathrm{kcal} / \mathrm{mol})$. Computed selectivities are obtained as the changes in the free energies for reaction 1a $\left(\Delta \Delta G_{\text {ext }}(\mathrm{Am} / \mathrm{Eu})\right)$. $^{\mathrm{a}}$

6. Predicted and experimental differences in complexation free energies of $\mathrm{O}$ - and $\mathrm{N}$ donor ligands with $\mathrm{Am}^{3+}$ and $\mathrm{Eu}^{3+}$ ions in aqueous solution $(\mathrm{kcal} / \mathrm{mol})$. Computed selectivities are obtained as the changes in the free energies for reaction $2 \mathrm{a}$

$\left(\Delta \Delta G_{\text {compl }}(\mathrm{Am} / \mathrm{Eu})\right.$ 58

7. $\mathrm{Xe} / \mathrm{Kr}$ concentrations from sample bombs 74

8. Measured elemental concentrations (wt. \%) in the bulk CCIM sample. .85 


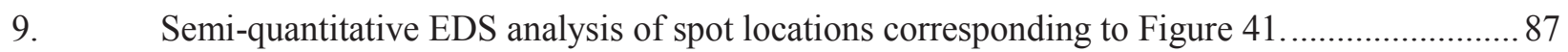

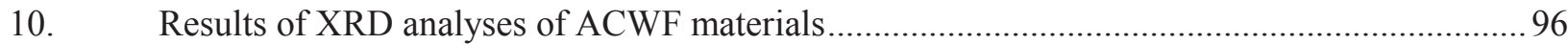

11. Thermodynamic parameters for the complexation of $\mathrm{NpO}_{2}{ }^{+} / \mathrm{HEDTA}, I=1.00 \mathrm{M}$ $\mathrm{NaClO}_{4}, \mathrm{t}=25^{\circ} \mathrm{C}$.

12. Thermodynamic parameters for reactions 4,5 , and $6, \mathrm{I}=1.0 \mathrm{M} \mathrm{NaClO}_{4}$. (a) van't Hoff, (b) calorimetry.

13. Calculated Free Energies $\left(\mathrm{kcal} \cdot \mathrm{mol}^{-1}\right)$ of hydration for 1-3 in aqueous solution.

14. Calculated free energies $\left(\mathrm{kcal} \cdot \mathrm{mol}^{-1}\right)$ and stability constants for $\mathrm{La}^{3+}$-lac complexation based on reaction 4 . 
Management and Integration

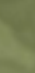


This page intentionally left blank. 


\section{MRWFD CAMPAIGN MANAGEMENT AND INTEGRATION}

\subsection{Introduction}

The Material Recovery and Waste Form Development (MRWFD) Campaign under the U.S. Department of Energy (DOE) Fuel Cycle Technologies (FCT) Program is responsible for developing advanced separation and waste form technologies to support the various fuel cycle options defined in the $D O E$ Nuclear Energy Research and Development Roadmap, Report to Congress, April 2010. The fiscal year (FY) 2015 Accomplishments Report provides a highlight of the results of the research and development (R\&D) efforts performed within MRWFD in FY-15. Each section contains an overview of the activities, results, technical point of contact, applicable references, and documents produced during the fiscal year.

This report briefly outlines campaign management and integration activities, but primarily focuses on the many technical accomplishments made during FY-15. The campaign continued to utilize an engineering driven-science-based approach to maintain relevance and focus.

MRWFD management and integration activities included international collaboration activities (France, China, Japan, European Union, and the International Atomic Energy Agency [IAEA]), integration activities with other campaigns, (Advanced Fuels, Used Fuel Disposition, Fuel Cycle Options, and Material Protection, Accountancy and Control Technology), and integration with DOE Office of Environmental Management (EM).

Technical accomplishments are reported under the following R\&D categories:

- Reference Technologies and Alternatives

- Sigma Team for Advanced Actinide Recycle

- Sigma Team for Off-Gas Capture and Immobilization

- Fundamental Separation Data/Methods

- Waste Form Development and Performance

- Domestic Electrochemical Processing.

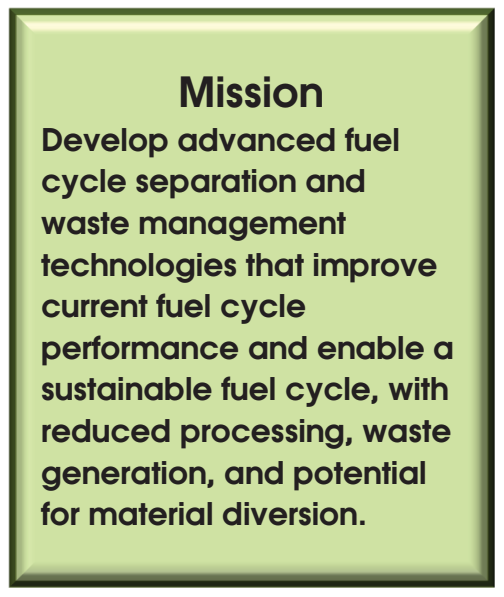

\section{Mission}

The Material Recovery and Waste Form Development Campaign applies expertise and technical capabilities to a wide array of applications. This campaign now also leverages its expertise by working with others in areas such as environmental remediation, national security missions, as well as civilian nuclear applications. The mission of MRWFD is to:

Develop advanced fuel cycle separation and waste management technologies that improve current fuel cycle performance and enable a sustainable fuel cycle, with minimal processing, waste generation, and potential for material diversion.

Mission implementation is outlined in the Material Recovery and Waste Form Development Campaign Implementation Plan, issued in November 2012. A revision will be made following issuance of a new Nuclear Energy Roadmap expected in FY-16. 


\section{Objectives}

- Develop technologies that support the current once-through fuel cycle and have near-term potential application

- Develop a fundamental and practical understanding of methods for the separation of uranium and transuranic elements from used nuclear fuel (UNF)

- Develop a fundamental and practical understanding of the factors affecting performance of advanced waste forms

- Develop and demonstrate enabling technologies to separate and immobilize gaseous fission products from UNF treatment

- Demonstrate predictable performance of advanced waste forms and processes with greatly improved cost and performance.

\section{Challenges}

- Separation of trivalent actinides from lanthanides.

- Capture and immobilization of off-gas constituents of UNF, including iodine, krypton, tritium and potentially carbon in a cost-effective manner meeting current US regulations

- Development of separation technologies and waste forms is interrelated to the types of fuels being processed, the types of fuels being fabricated, and the reactors used to burn recycled fuels

- Measuring waste form lifetimes in a laboratory is impossible considering they are on the order of hundreds of thousands to millions of years

- Proliferation risk assessment of separation technologies is very subjective and must be done in the context of the entire fuel cycle (mining to disposal).

\subsection{Campaign Structure}

The campaign is organized in a flat structure to facilitate cross-campaign integration. Federal Project Directors are responsible for oversight and approval of all MRWFD work activities. The National Technical Director (NTD) and Deputy NTDs are responsible for work prioritization, integration, and management.

Campaign leadership consists of:

- National Technical Director, Dr. Terry Todd, Idaho National Laboratory (INL)

- Deputy National Technical Director, Dr. John Vienna, Pacific Northwest National Laboratory (PNNL)

- Director, NE-51, Office of Systems Engineering and Integration, Dr. Patricia Paviet, Department of Energy Office of Nuclear Energy (DOE-NE)

- Federal Project Director, Dr. James Bresee, DOE-NE

- Federal Project Director, Domestic Electrochemical Separations Technology, Dr. Stephen Kung, DOE-NE 
- Federal Project Director, Waste Forms and Sigma Team for Off-Gas Capture and Immobilization, Ms. Kimberly Gray, DOE-NE.

\subsection{Collaborations}

\section{T. A. Todd, Idaho National Laboratory, J. D. Vienna, Pacific Northwest National Laboratory}

DOE Office of Environmental Management (EM) Collaboration

A long-standing interaction exists between the DOE Office of Nuclear Energy (NE) and the DOE Office of Environmental Management (EM), particularly in the areas of separations, waste forms, and disposal research. Many laboratory researchers work jointly for NE and EM, and many of the program objectives are similar. This close collaboration was formalized in 2011 by a Memorandum of Understanding (MOU) between The Department of Energy Office of Environmental Management and The Department of Energy Office of Nuclear Energy for Used Nuclear Fuel and Radioactive Waste Management and Processing Research and Development. The MOU, signed by Assistant Secretaries P. Lyons and I. Triay in March 2011, describes a policy of collaborative research and highlights several collaborative research tasks.

Three joint DOE NE-EM-National Nuclear Security Administration nuclear separations technologies workshops were held to identify common needs and requirements in separations as well as opportunities for partnerships between the three offices. The first such workshop was held in July 2011, the second in September 2012, and the third in December 2012. The outcome of these workshops were documented in meeting reports (the first published in 2012, the second in 2013, and the third in early 2014) and in a joint roadmap that describes the individual and collaborative research areas that will be pursued as part of this joint effort. The roadmap was drafted and is due to be issued in FY-16.

A joint EM-NE-International glass corrosion study that started in 2010 was continued through 2015 (as described below).

\section{IAEA-DOE Collaboration}

The United States has a long history of nuclear energy research and development (R\&D) collaboration with the international community through the International Atomic Energy Agency (IAEA). Specific areas of MRWFD collaboration in FY-15 include:

- Participation in an international workshop on "Challenges in Reprocessing of Fast Reactor Fuels"

- Participation in the "Consultancy Meeting on Advanced Fuel Cycle for Waste Burden Minimization"

- Participation in the Coordinated Research Project, "Processing Technologies for High-Level Waste, Formulation of Matrices, and Characterization of Waste Forms."

- Participation in the preliminary study, "Waste from Innovative Types of Reactors and Fuel Cycles."

These collaborations share methods, technologies, and research among practitioners from the member states. As such, there is a distinct advantage to campaign participation in that researchers gain valuable insight into the results from a wide range of member states that can be leveraged in conducting campaign R\&D. 


\section{EU-DOE Collaboration}

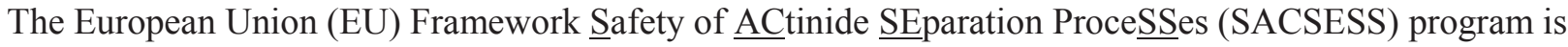
a 3-year effort that follows the very successful EU Actinide reCycling by SEParaTion (ACSEPT) program that ran for the four previous years and developed and demonstrated a number of new minor actinide separation processes. This program includes most of the leading European separation experts from the Commissariat à l'Énergie Atomique (CEA) in France; National Nuclear Laboratory (NNL) in the United Kingdom (UK); Forschungszentrum Juelich, Karlsruhe Institute of Technology, and the Institute for Transuranium Elements in Germany; Chalmers University in Sweden; and Czech Technical University and the Nuclear Research Institute in the Czech Republic, along with about 15 other European Universities.

MRWFD personnel participated in the first SACSESS International Workshop held in Warsaw, Poland in April, 2015 and a workshop on solvent extraction kinetics in Edinburg, Scotland, in September 2015. Additionally, SACSESS researchers were invited to participate in the "Radical Behavior" workshop held at INL in July 2015, focused on research involving radiation chemistry.

A number of tests in the area of solvent degradation were conducted at the INL in support of the SACESS Collaboration and are reported under the "Solvent Degradation Mechanisms" section (page 15).

\section{CEA-DOE Collaboration}

The United States and France share a long history of nuclear energy R\&D collaboration, particularly in the area of separations and waste management. Plans for Waste Forms in FY-15 were to contribute together on an international consensus on a source-term model for radionuclide release from glass.

- CEA and PNNL have co-organized a broad international collaboration in the field of glass corrosion (6 countries involved).

- A joint paper titled, "The fate of silicon during glass corrosion under alkaline conditions: A mechanistic and kinetic study with the International Simple Glass," was published in the peer reviewed Geochimica et Cosmochimica Acta journal (v. 151, 68-85) with four authors each from CEA and PNNL. In this seminal paper involving isotopic tracing, it was shown that the amorphous alteration layer is not a precipitate resulting from the hydrated silica saturation, but instead is a reconstructed version of the glass structure from which the most weakly bonded cations $(\mathrm{Na}, \mathrm{Ca}$ and $\mathrm{B})$ have been released. Additionally, the transport of water and dissolving ions appears not to be impeded by this layer. After a period of stable, slow (Stage II) dissolution, the glass dissolution was artificially prodded into accelerated "Stage III" behavior by increasing the $\mathrm{pH}$. The dissolution rate at $\mathrm{pH} 11.5$ was two orders of magnitude higher than Stage II rate, likely due to both the hydrolysis of the silicate network promoted by $\mathrm{OH}$ - and the precipitation of zeolites. These findings are proving to be critical to the development of an improved rate prediction model.

- In late August, a draft report was submitted to satisfy milestone M4FT-15PN0307138 that details the synthesis of ISG and serves as a collection of the characterization and corrosion work performed on the ISG glass to date. ${ }^{1}$ The document sources more than twelve institutions, including a large amount of CEA-generated information. The data collection includes information from the mundane (density, composition) to the advanced (atom-probe structure, phase separation studies, nuclear magnetic resonance (NMR) and Raman spectra). The document, after a DOE review, will be reviewed by all the submitting institutions before final issue. It will be an invaluable resource to the international glass corrosion community. It is expected that, through closely coupled theory, experimental, and modeling, the work performed on the ISG 
composition will help to provide understanding of key mechanisms at different time periods, ultimately resulting in the development of robust corrosion models that can predict the extent of glass alteration throughout the lifetime of a geologic repository.

- Future objectives include joint publications, further studies on the coupling of near-field conditions (effect of groundwater composition, effect of $\mathrm{Fe}$ and $\mathrm{Fe}$-corrosion products) to the understanding gained in the first phase, and staff exchanges (Joe Ryan to CEA-Marcoule and Benjamin Parruzot to Washington State University).

DOE and CEA have both invested heavily for more than 30 years in the development of nuclear waste glass technology. Sharing of data, methods and models will benefit both nations in order to still improve the science and technology of waste vitrification.

Significant Accomplishments:

- Unpublished glass property-composition databases were exchanged and discussed. A database of 100 glass compositions with up to eight properties was received by the U.S. and a database of over 1,000 glass compositions with up to five properties were sent to CEA. The data from CEA are applicable directly to glasses being developed for commercial fuel reprocessing while most of the data from the U.S. were based on tank waste immobilization.

- Initial evaluation of shared data sets and models (prediction of models for other datasets, comparison of component effects, etc.) have been completed. A meeting was held at PNNL in June 2015 to discuss the initial results from data and model evaluations. Relatively good agreement were found between model predictions and measured properties for some datasets. The effects of most components on properties were found to be similar across many datasets; however, some component effects were distinctly different between datasets. The reasons for these differences are still being investigated.

- Tour of laboratories at CEA (October 2014) and PNNL (June 2015) allowed for discussion and comparison of similarities and differences in glass fabrication and testing methods. Most methods were similar between the two laboratories. It was agreed to further discuss methods after exchange of written experimental procedures.

Statistical approaches to experimental design and property modeling were discussed and compared. The approach to layered design was discussed and agreed to be further investigated for application by CEA.

Future plans:

- Continue to share and evaluate glass property data and models

- Discuss results from evaluation of property data and models [web conference] (December 2015)

- Exchange experimental methods associated with shared data (viscosity [including which standards are used], electrical conductivity, $\mathrm{r}_{1 \mathrm{y}}, \mathrm{PCT}$, soxhlet, and SPFT)(November 2015)

- Discuss collaboration on spinel and nepheline formation (May to June 2016)

- Discuss possibility for jointly developing alternative property model forms (outside of linear and partial quadratic mixture models currently deployed by both sites) (December 2015).

- Discuss possibility of collaboration on noble metal settling (March 2016) 
- Discuss possibility of joint publication on statistical methods in nuclear waste glass (March 2016)

- Discuss possibility of joint publication on glass property data and model comparisons (December 2015)

- Discuss possibility of joint publication on powellite formation in waste glasses (March 2016)

- Discuss possibility of collaboration on phase separation and crystallization in high-Mo glasses to determine if CEA can collaborate with US-UK project (October 2015).

DOE and CEA are collaborating on joint research projects in areas related to separations, on benchmarking of minor actinide separation processes, and on discussion for possibly performing separation flowsheet tests on used nuclear fuel in the ATALANTE facility at Marcoule. Separations collaborative research is ongoing on:

- Degradation mechanisms of extraction molecules

- Online process monitoring

- Capture of volatile off-gas constituents

- Better understanding of the mechanisms of extraction molecule selectivity for minor actinides.

Technical meetings on solvent degradation took place between national experts in Warsaw (April 2015) and INL (July 2015). Samples of butyramide extractants were sent from CEA to INL for irradiation and irradiated samples were returned to CEA for analysis. Jessica Drader is completing a postdoc appointment at the CEA Marcouleon radiolysis and complexation of degradation products. The benchmarking of minor actinide separation processes is a collaboration topic that began in FY-14. In FY-15, a common set of parameters were established to compare technologies (e.g. fuel type, burnup, separation targets, etc.) as well as a set of evaluation criteria were agreed to between CEA and DOE. Flowsheets are being developed for comparison and modeling with each countries respective solvent extraction simulation code (AMUSE and PAREX).

A collaborative project on acid concentration measurements is underway between CEA and PNNL researchers. Strong acid measurements are being made on small volume samples using Raman spectroscopy. This pathway provides advancements of a technique for in-line, real-time process measurements of acid and $U$ concentrations on the microfluidic scale, which will simultaneously reduce the volume of waste, dose-to-staff performing these measurements, and response time of analysis.

Significant effort was invested in the design and fabrication of an iodine abatement system to be installed on the dissolver off-gas line at the ATALANTE facility in Marcoule. This is discussed in detail in the Off-Gas Sigma Team section of this report.

Collaboration on near-real-time, online monitoring of aqueous processes made significant progress in FY-15 and is reported in detail on pages 23-27.

\section{JAEA-DOE Collaboration}

Collaboration with Japan on separations technology is carried out by the Civil Nuclear Working Group (CNWG), chartered under the United States - Japan Bilateral Commission on Civil Nuclear Cooperation. Japanese technical participation in the activities of the working group is primarily from the Japan Atomic Energy Agency (JAEA), with occasional involvement of the Central Research Institute of the Electric Power Industry (CRIEPI). The responsible Japanese agency is the Ministry of Education, Culture, Sports, Science and Technology. 
The third meeting of the CNWG as well as a Steering Committee meeting was held at Argonne National Laboratory, in January 2015 to review action plans and initiate discussions on detailed collaboration topics. Three areas relative to MRWFD are part of the collaboration, aqueous separation from oxide fuels, borosilicate glass corrosion, and uranium extraction from seawater.

The objective of the aqueous separation from oxide fuels activity is to share technical results and perform joint research activities on methods to separate minor actinides from lanthanides and select fission products (e.g. cesium) from used nuclear fuel. In 2015, plans were made to ship branched alkylamide extractants to INL for testing with Am(VI) extraction and a researcher from JAEA is planning to visit INL and participate in testing of Am(VI) extraction in January 2016. The objective of the borosilicate glass corrosion activity is to improve the understanding of the mechanisms and rates controlling the release of radionuclides in a range of geologic disposal environments. Detailed plans for three tasks were finalized and experimental work was initiated. Progress was promoted through three technical expert meetings and results published in a joint research article. The U.S. participated in reviews of Japanese spent nuclear fuel disposal and underground research laboratory related programs in 2014. A joint research study was performed by researchers at Kyushu University, JAEA, and PNNL to determine the impacts of silica concentration in solution on the corrosion rates of an international reference glass and the resulting surface structures.

The objective of the uranium extraction from seawater activity is to jointly pursue the development of uranium extraction from unconventional resources, with a focus on harvesting uranium from seawater. This collaboration has been ongoing for a few years and has been very productive. Three collaborative tasks were identified: (1) Seawater uranium extraction technology cost analysis, (2) Adsorbent materials development by radiation induced graft polymerization, and (3) Marine testing of uranium recovery systems.

The objective of the borosilicate glass dissolution study is to improve the understanding of the mechanisms governing glass dissolution in different geological environments, leading to a robust and defensible model for calculating long term radionuclide releases under potential disposal conditions. Near term cooperation will focus on (1) identification of alteration rate acceleration mechanism and conditions, (2) investigation of the protective nature of glass alteration layers in closed or open systems, and (3) development of fully-coupled reactive transport models to consider the impacts of disposal environments on long-term rate.

In FY-15 a series of joint experiments were performed on glass corrosion test samples. Japanese colleagues performed micro-channel flow through tests as a function of silica saturation in solution to generate test specimens and performed micro-Raman spectroscopy on those specimen. PNNL performed profilometry and nano-SIMS on the samples to give full special and chemical images. A joint paper will be completed in FY-16, as well as future work. This testing and the associated draft research article meet a Joint DOE-JAEA milestone in the CNWG collaboration.

\section{Six-Nation Collaboration on Long-Term Performance of Glass}

DOE is co-leading a six-nation collaborative effort to develop the technical basis for an international consensus nuclear waste glass corrosion rate model along with CEA (France) and JAEA (Japan). Belgium (SCK-CEN), France (CEA, Subatech), Germany (University of Bonn), Japan (JAEA, Kyushu University, Tokyo University), the United Kingdom (NNL, Sheffield University, Serco), and the United States (ANL, Alfred University, Oak Ridge National Laboratory (ORNL), PNNL, Pennsylvania State University [PSU], Savannah River National Laboratory [SRNL], University of North Texas, [UNT], Washington State University [WSU]) are participating in the collaboration. 
Although the international community agrees on which phenomena occur during glass alteration, insufficient data is available on their rates to understand which control long-term performance under which disposal conditions. These processes include:

- Ion exchange between solid glass and solution

- Surface-controlled reaction

- Transport of ions to and from reacting glass surface

- Impact of alteration product formation.

A joint paper summarizing the current state of understanding and remaining challenges was issued by the study co-leads in fiscal year $2014 .^{2}$ This article and a previous one ${ }^{3}$ describe the focus of the collaborative efforts. In addition there are specific detailed bilateral agreements describing scope and milestones with CEA and JAEA.

Representatives from the six major partners shared data, techniques, and theories at an international workshop associated with a major conference in May in Miami, Florida. A report from the international team summarizing there most recent results on the international standard glass was compiled by the team and will be issued in $2015 .^{3}$

An international workshop to compare potential analytical models of long-term performance of glass and outline a method to develop consensus on those models was held in November 2014 in Tokyo. Each nation presented the glass alteration models currently used in their performance assessments along with near-term plans for updating models.

\section{References}

1. Kaspar, T.C. and J.V. Ryan, 2015, "Summary of Experiments and Modeling of the International Simple Glass,” FCRD-MRWFD-2015-000683, PNNL.

2. Vienna, J. D., J. V. Ryan, S. Gin, and Y. Inagaki, 2013, "Current Understanding and Remaining Challenges in Modeling Long-Term Degradation of Borosilicate Nuclear Waste Glasses," International Journal of Applied Glass Science, 4(4), 283-294.

3. Gin, S., A. Abdelouas, L. J. Criscenti, W. L. Ebert, K. Ferrand, T. Geisler, M. T. Harrison, Y. Inagaki, S. Mitsui, K. T. Mueller, J. C. Marra, C. G. Pantano, E. M. Pierce, J. V. Ryan, J. M. Schofield, C. I. Steefel, and J. D. Vienna, 2013, “An International Initiative on Long-Term Behavior of High-Level Nuclear Waste Glass," Materials Today, 16(6), 243-248.

\section{AREVA-JNFL-DOE Collaboration on lodine Management}

DOE, AREVA, and laboratory personnel have continued to explore several ideas for follow-on collaborations as a result of the site visits facilitated by AREVA to the Rokkasho and La Hague facilities that would draw upon AREVA's experience and could possibly be accomplished under the existing Advisory and Assistance Contract [A\&AC DE NE 0000291 (IDIQ Task 10)] or similar mechanism.

An Excel model of the pathway for the four primary volatile radionuclides was developed and shared (Jubin, 2015). This tool provides a means to evaluate the "critical" releases pathways that are thought to control the overall plant emissions. AREVA was to populate the spreadsheet with available data from LaHague and from JNFL for review in early FY-15, but this activity was placed on hold temporarily. 
Pending results of that analysis, follow-on discussions are planned with the intent of (1) identifying means to gain a better understanding of the iodine pathways through the reprocessing plants, (2) the speciation of the iodine and (3) how the speciation is related to the iodine emitted from the facility. Initial discussions with AREVA indicate it may be possible to install a sampling system to specifically allow the determination of iodine species, i.e., elemental, organic (and specific organic iodide compounds), and/or particulate released at the main stack. Such studies would potentially lead to the installation of additional monitoring and sampling equipment on the main stack as well as reviewing historic stack data.

Comparable data requests directed to JNFL, a partner of AREVA, and from Energy Solutions would be equally valuable and might be accomplished under a similar approach.

\section{References}

Jubin, R. T., 2015, “A Brief User's Guide to the Excel ${ }^{\circledR}$-Based DF Calculator,” FCRD-MRWFD-2015000627 (ORNL/SPR-2015/493).

\section{China-DOE Collaboration}

The China-United States Bilateral Civil Nuclear Energy Cooperation Action Plan, signed in Vienna, Austria on September 18, 2007, is a programmatic commitment for both countries to further facilitate joint long term R\&D collaborative activities in advanced civilian nuclear technologies. Presently, seven technical working groups have been established and organized under the U.S.-China Nuclear Energy Action Plan cooperation framework. They are (1) Advanced Separation Technologies, (2) Fast Reactor Technologies, (3) Advanced Fuels and Materials Development, (4) Safeguards and Physical Protection Technologies, (5) Nuclear Safety Enhancement, (6) Spent Fuel Storage and Repository Sciences, and (7) High Temperature Reactor Technologies.

\section{Major Accomplishments, Ongoing and Future Activities}

The co-chairs and technical experts met several times in the past three years to discuss topics related to head-end tritium capture, including requirements and regulatory issues, and iodine waste forms. Future information exchange meetings will continue to focus on iodine management. Topics to be discussed are near- and long-term separations approaches, lab test protocols, data requirements to support future collaboration, and updates on recent developments. Potential topics for joint projects include: iodine capture from dilute off-gas streams, iodine distribution and speciation, and iodine waste forms for aqueous-based processes.

The Separation Technologies Working Group under the auspices of the U.S.-China Bilateral Civil Nuclear Energy Cooperation Action Plan Agreement met at Oak Ridge National Laboratory on January 14-15, 2015. The technical content of the meeting was focused on the management of iodine during the course of spent fuel reprocessing operations and on the exploration of other topics of mutual interest. It was agreed that when considering the next steps for this collaboration the topics selected should be of mutual interest and be part of on-going funded work within the respective organizations.

Iodine will be the primary initial focus of near term collaboration. In the area of iodine capture, zeolite based sorbents and alternate sorbents will be considered as well as methods for the capture of elemental and organic iodides. A draft document describing the technical scope for the proposed collaborative work on iodine capture and on iodine waste forms was prepared and exchanged by both the U.S. and China sides. This will form the bases for discussions at the Eighth Joint Technical Working Groups Meeting under the U.S.-China Bilateral Civil Nuclear Energy Cooperative Action Plan. This is scheduled for October 27-29, 2015 in Qingdao, China. 
This page intentionally left blank. 


\section{Reference Technologies and Alternatives}


This page intentionally left blank. 


\section{REFERENCE TECHNOLOGIES AND ALTERNATIVES}

\subsection{Solvent Degradation Mechanisms}

\section{R. Peterman and J. D. Law, INL}

Separating the minor actinide elements (americium and curium) from the fission product lanthanides is an important step in closing the nuclear fuel cycle. Isolating the minor actinides will allow transmuting them to short-lived or stable isotopes in fast reactors, thereby reducing the long-term hazard associated with these elements. ${ }^{1,2}$ A two-step method has been investigated by the MRWFD program to separate the minor actinides from acidic high-level waste (HLW). The first step involves coextracting the lanthanides and minor actinides using the transuranic extraction (TRUEX) process. ${ }^{3}$ The second step uses the Trivalent Actinide-Lanthanide Separations by Phosphorus-reagent Extraction from Aqueous Complexes (TALSPEAK) process to separate the minor actinides from the lanthanides. ${ }^{4,5}$ The tandem TRUEXTALSPEAK approach has been demonstrated on irradiated fuel at a laboratory scale. ${ }^{6}$ However, the TALSPEAK process suffers the disadvantage of slow extraction kinetics and high sensitivity to the aqueous phase $\mathrm{pH}$. To overcome these disadvantages, a variation of the TALSPEAK process has been proposed which replaces the traditionally used bis(2- ethylhexyl)phosphoric acid (HDEHP) extractant with HEH[EHP]. ${ }^{7}$ This is referred to as an Advanced TALSPEAK process. The INL is studying the impacts of gamma radiolysis on the Advanced TALSPEAK flowsheet. In addition, the aqueous phase complexant and buffer used in traditional TALSPEAK are replaced with the combination of $\mathrm{N}-(2-$ hydroxyethyl)ethylenediamine-N,N',N'-triacetic acid (HEDTA) and citric acid (CA). The structures of these compounds are shown in Figure 1.

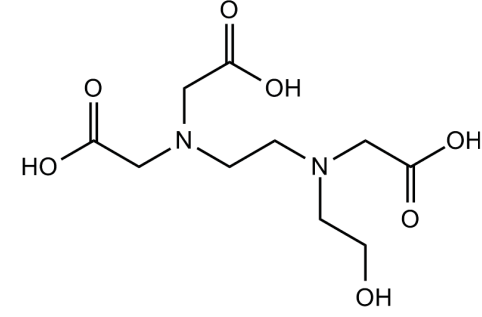

$\mathrm{N}$-(2-hydroxyethyl)ethylenediamine-N,N',N'-triacetic acid (HEDTA)

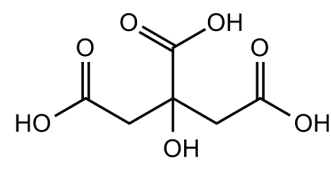

Citric acid

(CA)

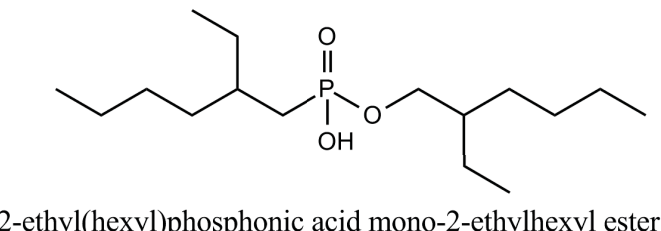

(HEH[EHP])

Figure 1. Structures of compounds used in the advanced TALSPEAK process.

The key advantages of switching to the HEH[EHP] extractant are reported to be: less dependence of the process performance on the aqueous solution $\mathrm{pH}$, more predictable extraction behavior, and more rapid extraction kinetics. The Advanced TALSPEAK process is being considered as a candidate to replace conventional TALSPEAK in the MRWFD full recycle case study.

In order to evaluate the possible impacts of gamma radiolysis upon the efficacy of the Advanced TALSPEAK flowsheet, aqueous and organic phases corresponding to the extraction section of the proposed flowsheet were irradiated in the INL test loop under an ambient atmosphere and the irradiated 
organic phase was subsequently processed through the INL solvent reconditioning loop. Samples of the irradiated aqueous and organic phases were spiked with americium and europium radiotracers and distribution ratios $\left(\mathrm{D}_{\mathrm{Am}}\right.$ and $\left.\mathrm{D}_{\mathrm{Eu}}\right)$ were determined as a function of absorbed dose. A suite of analytical techniques were employed to determine the variation in composition as a function of absorbed $\gamma$-dose and in some cases identify the radiolytically produced species.

The Advanced TALSPEAK solvent (1 M HEH[EHP] in dodecane) and aqueous phase (0.125 M HEDTA and $0.2 \mathrm{M}$ citrate at $\mathrm{pH}=3.7$ ) were irradiated in two experiments to a total of approximately $440 \mathrm{kGy}$ absorbed dose and an additional radiolysis experiment exposed the solvent to a total of $730 \mathrm{kGy}$ absorbed dose. Measurement of americium and europium distribution ratios demonstrated minimal solvent degradation occurred as a result of the gamma irradiation. The formation of several unknown degradation products was detected by various analytical techniques such as gas chromatography, ion chromatography, and electrospray ionization mass spectrometry. While the extent of the formation of radiolytic degradation products was small, understanding the processes leading to their formation is an important aspect of the successful application of the Advanced TALSPEAK process to recovery of minor actinide species. Analysis of the irradiated aqueous and organic phases demonstrated that the observed small increases of the values of $\mathrm{D}_{\mathrm{Am}}$ and $\mathrm{D}_{\mathrm{Eu}}$ (and the corresponding decrease in the europium/americium separation factor) following gamma irradiation in the test loop were likely due to the destruction of the aqueous soluble hold-back reagent, HEDTA.

In addition to the study of the potential impacts of gamma radiolysis upon an Advanced TALSPEAK flowsheet, a collaborative research program between the DOE-NE MRWFD Campaign and the European Union (EU) Safety of Actinide Separation Processes (SACSESS) program was established during 2015. One component of this collaboration was the evaluation of the radiolytic stability of a Selective ActiNide Extraction (SANEX) separation process, which utilized a TODGA-based organic solvent and an aqueous phase containing the hydrophilic complexing reagent, $\mathrm{SO}_{3}$-Ph-BTP. To best simulate process conditions, this experiment was irradiated in the radiolysis/hydrolysis test loop located at the INL.

Two test loop irradiations were performed. The first irradiation involved an organic phase comprised of $0.2 \mathrm{M} N, N, N$,,$N$ '-tetraoctyl diglycolamide (TODGA) $/ 5 \%$ octanol/dodecane in contact with a $4.5 \mathrm{M}$ $\mathrm{HNO}_{3}$ aqueous phase. The second irradiation utilized the same organic phase composition, but the aqueous phase was replaced with a solution containing $0.018 \mathrm{M} \mathrm{SO}_{3}$-Ph-BTP dissolved in $0.35 \mathrm{M} \mathrm{HNO}_{3}$. For both irradiation experiments, stable strontium, ruthenium, and neodymium were added to the aqueous phases.

Following preliminary static irradiation of the TODGA solvent in contact with the acidic aqueous phase, the TODGA solvent was irradiated in contact with the acidic aqueous phase in the INL test loop. The solvent was irradiated to a total absorbed $\gamma$-dose of $878 \mathrm{kGy}$. The analyses of the samples generated during this irradiation have not been completed as of this writing. At this time, the distribution ratios of americium, europium and cerium have been determined for selected samples from early and late in the irradiation, representing low- and high-absorbed doses. As was noted for the static irradiation experiment, no statistically significant variation in the measured distribution ratios of americium, cerium, or europium occurred.

The EU has developed an aqueous-soluble sulfonated $\mathrm{BTP}\left(\mathrm{SO}_{3}-\mathrm{Ph}-\mathrm{BTP}\right)$ to serve as an actinide selective hold-back reagent for the innovative SANEX separation process. The radiolytic stability of the $\mathrm{SO}_{3}-\mathrm{Ph}-$ BTP was evaluated by irradiating a mixture of $0.018 \mathrm{M} \mathrm{SO}_{3}$-Ph-BTP dissolved in $0.35 \mathrm{M} \mathrm{HNO}_{3}$ and 0.2 M TODGA / 5\% octanol in n-dodecane in the INL test loop. The mixture was irradiated to a total absorbed dose of $174 \mathrm{kGy}$. Over the course of the irradiation, significant changes in the appearance of the $\mathrm{SO}_{3}$-Ph-BTP containing aqueous phase occurred. Prior to irradiation, the aqueous phase had a deep, winered color. After exposure to approximately $12 \mathrm{kGy}$ absorbed dose, the aqueous phase had darkened 
significantly. After $\sim 100 \mathrm{kGy}$ absorbed dose, the aqueous phase was essentially black. Since significant radiolytic degradation was expected, distribution ratios were determined only for three low-absorbed dose and one high-absorbed dose samples.

The measured americium and lanthanide $\left(\mathrm{Ce}\right.$ and $\mathrm{Eu}$ ) distribution ratios for the irradiated $\mathrm{SO}_{3}-\mathrm{Ph}-\mathrm{BTP}$ solvent system did not exhibit a dependence upon absorbed dose consistent with significant radiolytic degradation of the $\mathrm{SO}_{3}-\mathrm{Ph}-\mathrm{BTP}$ ligand. At zero absorbed dose $\mathrm{D}_{\mathrm{Am}}=0.045$, but $\mathrm{D}_{\mathrm{Am}}$ increases to only 0.063 at $174 \mathrm{kGy}$ absorbed dose. Similarly, there was only a minor increase in the extraction efficiency of europium and cerium. Thus, in spite of the dramatic visual effect on the irradiated solution the separation factors between the actinide and these two lanthanides were essentially unchanged over this absorbed dose range. Separation factors $\left({ }^{\mathrm{Ce}} \mathrm{S}_{\mathrm{Am}}\right.$ and $\left.{ }^{\mathrm{Eu}} \mathrm{S}_{\mathrm{Am}}\right)$ calculated from the measured distribution, also, exhibited little dependence upon the absorbed gamma dose.

\section{References}

1. M. J. Hudson, L. M. Harwood, D. M. Laventine, F. W. Lewis, "Use of Soft Heterocyclic N-Donor Ligands To Separate Actinides and Lanthanides," Inorganic Chemistry 52(7), 2013: 3414-3428.

2. T. A. Todd, "Separation Research for Advanced Nuclear Fuel Cycles," Nuclear Energy and the Environment; C.M. Wai, B.J. Mincher, Eds., American Chemical Society, 2010, 13-18.

3. E. P. Horwitz, D. G. Kalina, H. Diamond, G. F. Vandegrift, W. W. Schulz, "The TRUEX Process - A Process for the Extraction of the Transuranic Elements from Nitric Acid Wastes Utilizing Modified PUREX Solvent, Solvent Extraction and Ion Exchange 3, 1985: 75-109.

4. B. Weaver and F. A. Kappelmann, 1968, "Preferential Extraction of Lanthanides Over Trivalent Actinides by Monoacidic Organophosphates from Carboxylic Acids And from Mixtures of Carboxylic And Aminopolyacetic Acids," Journal of Inorganic and Nuclear Chemistry 30, 1968: 263-272.

5. M. Nilsson and K. L. Nash, 2007, "A Review of the Development and Operational Characteristics of the TALSPEAK Process," Solvent Extraction and Ion Exchange 25(6), 2007: 665-701.

6. C. Pereira, G. F. Vandegrift, M. C. Regalbuto, A. Bakel, D. Bowers, A. V. Gelis, A.S. Hebden, D. Stepinski, Y. Tsai, J. J. Laidler, 2007, "Lab-Scale Demonstration of the UREX+1a Process Using Spent Nuclear Fuel," Waste Management 2007, Tucson, AZ, February 25 - March 1, 2007.

7. J. C. Braley, T. S. Grimes, and K. L. Nash, 2011, "Alternatives to HDEHP and DTPA for Simplified TALSPEAK Separations,” Industrial \& Engineering Chemistry Research 51(2), 2011: 629-638.

\section{Publications}

Zarzana, C. A., D. R. Peterman, G. S. Groenewold, L. G. Olson, R. G. McDowell, W. F. Bauer, and S. J. Morgan, "Investigation of the Impacts of Gamma Radiolysis on an Advanced TALSPEAK Separation," Separations Science and Technology, accepted 2015.

\section{Reports}

Peterman, D. R., 2014, "Re-Design Test Loop in Order to Increase Effective Gamma Dose," FCRDMRWFD-2015-000568, December 23, 2014, INL.

Peterman, D. R. and B. J. Mincher, 2015, "Support SACSESS Collaboration," FCRD-MRWRD-2015000569, September 15, 2015, INL.

Peterman, D. R., L. G. Olson, R. G. McDowell, G. S. Groenewold, C. A. Zarzana, W. F. Bauer, S. J. Morgan, 2014, "Investigation of the Impacts of Gamma Radiolysis on an Advanced TALSPEAK Separation,” FCRD-SWF-2014-000205, August 15, 2014, INL. 


\subsection{Tritium Pretreatment}

\section{G. D. Delcul, B. B. Spencer, and R. D. Hunt, ORNL}

A dry pretreatment process based on the oxidation of used nuclear fuel (UNF) is being studied for the removal and capture of tritium and iodine prior to the fuel dissolution step. The process converts oxide fuel into a fine powder at low temperature with oxygen and nitrogen dioxide $\left(\mathrm{NO}_{2}\right)$ as a shuttling agent. The powder product can be selected to be triuranium octoxide $\left(\mathrm{U}_{3} \mathrm{O}_{8}\right)$, uranium trioxide $\left(\mathrm{UO}_{3}\right)$, or a nitrated form of uranium by adjusting the processing conditions. The $\mathrm{UO}_{3}$ dissolves readily in $\mathrm{HNO}_{3}$ without gas evolution, allowing for a very fast "fumeless" dissolution that can produce higher concentrations of uranyl nitrate at lower acidities than may be obtained from direct dissolution of uranium dioxide $\left(\mathrm{UO}_{2}\right)$. Therefore, the dissolution time can be shortened from several hours to minutes while also reducing the volume and acid concentration of the dissolver solution and generating a dissolver product with higher actinide concentration. The latter advantage potentially translates into smaller tankage and less volume of residual raffinate waste, decreased facility footprint, and reduced facility cost. Both the $\mathrm{UO}_{3}$ and the nitrated form can be readily dissolved in an organic solvent (e.g., tributyl phosphate [TBP]), leaving behind most of the fission products that remain insoluble, potentially reducing the volume of the high-acid raffinate waste stream.

The overall goal is to develop the process to a technology-readiness level sufficient to design and estimate the cost of an engineering-scale implementation. This work advances this goal by exploring potential flow sheet options and implications as they relate to fission product partitioning. Figure 2 and Figure 3 show schematics of a combined tritium/iodine pretreatment process using $\mathrm{NO}_{2}$ oxidation integrated with an in situ dissolver system.

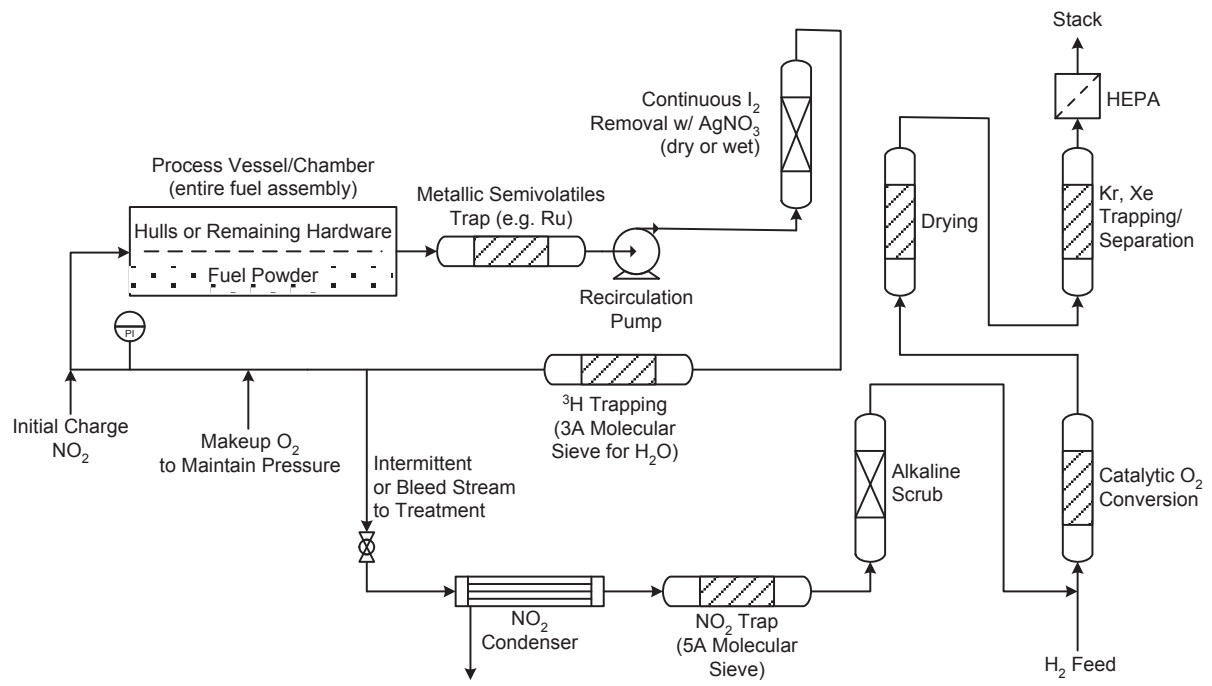

Figure 2. Schematic of a closed-loop recirculation system for the pretreatment of light-water reactor (LWR) used fuel to remove tritium, iodine, and krypton.

To present, all of the major tenets of the process to convert from pellets to oxide or nitrate have been tested and successfully corroborated at kilogram scale with surrogate materials. In-line trapping of iodine and water, and direct extraction by TBP of either the oxide or nitrate forms, has been tested at lab scale with surrogate materials (Figure 4). 


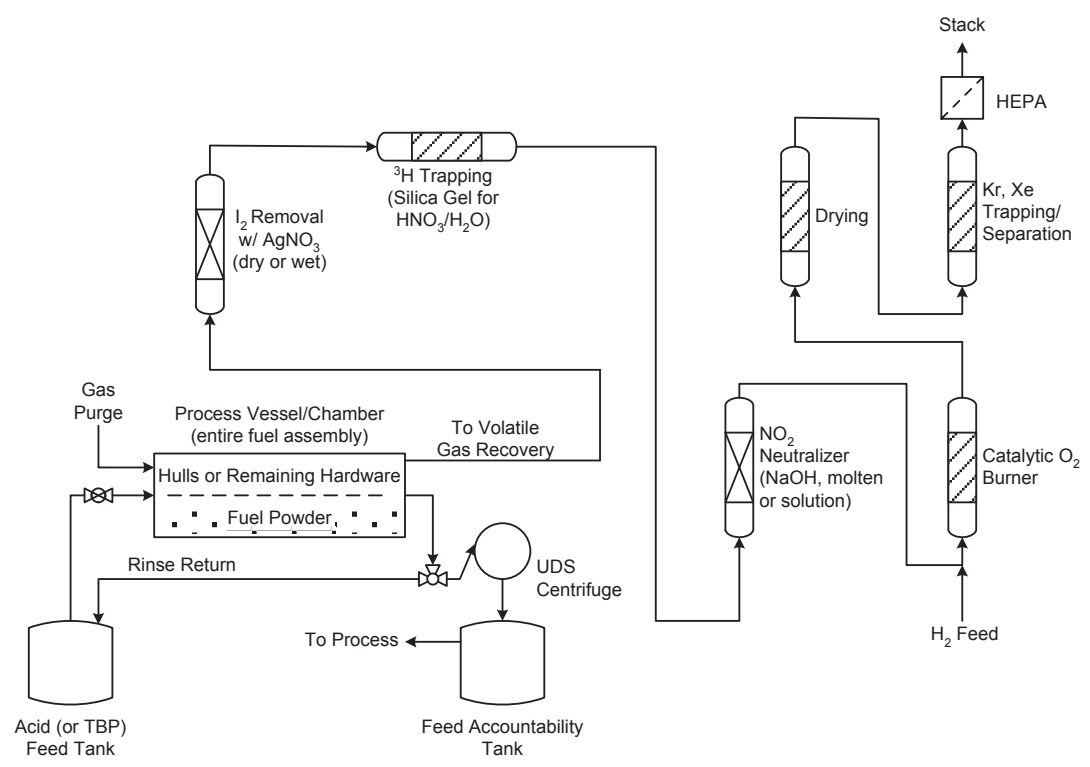

Figure 3. Schematic diagram of the in situ dissolution of the used fuel powder prepared by a head-end process for the subsequent aqueous separation of fissile components-part of a process to recycle used reactor fuel.

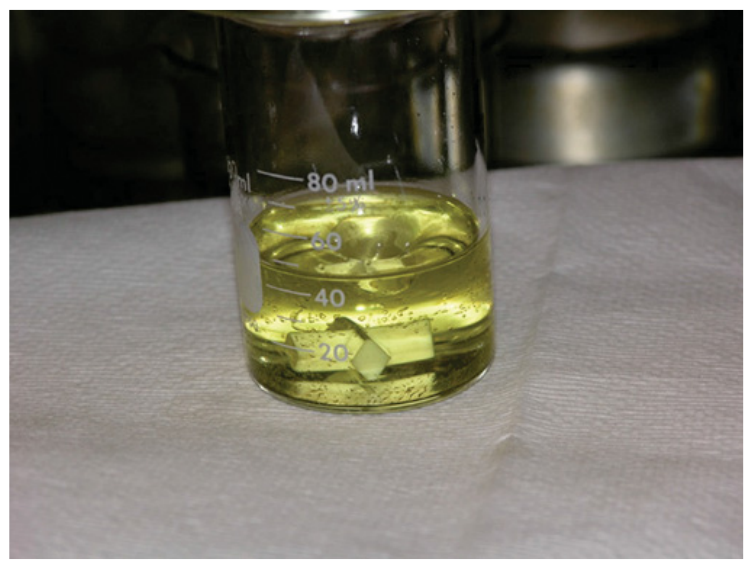

Figure 4. Clear solution obtained by direct extraction of $\mathrm{UO}_{3}$ in $\mathrm{TBP} /$ dodecane

A main focus area was centered on understanding the parameters governing the nitration process that resulted in a significant reduction of the processing time (total overall process 4 to $6 \mathrm{~h}$ from fuel to nitrate product). Other significant efforts included extending the direct TBP extraction avoiding acid dissolution to the $\mathrm{UO}_{3}$ oxide product (in addition to the previous direct extraction of the nitrate product), determining the fate of selected fission products with surrogate materials, constructing a prototype kilogram-scale metal reactor suitable for hot-cell operation, and demonstrating the complete process with $1 \mathrm{~kg}$ of green $\mathrm{UO}_{2}$ pellets pressed with embedded simulated fission products.

\section{Patents}

Bhave, R. R., M. M. DeBusk, G. D. DelCul, L. H. Delmau, and C. K. Narula, 2015, U.S. Patent No. 8,999,168, "Supported Liquid Inorganic Membranes for Nuclear Waste Separation," April 7, 2015.

DelCul, G. D., B. B. Spencer, R. D. Hunt, and R. T. Jubin, 2015, "Direct Dissolution and Extraction of Voloxidized Nuclear Fuel,” DOE S-NUMBER: S-138,094, Patent disclosure filed January 15, 2015. 


\subsection{Tritium Separation from High-Volume Dilute Aqueous Streams}

\section{R. Bhave and B. B. Spencer, ORNL}

The release of tritium (as tritiated water [HTO]) from nuclear facilities into the environment is required to be controlled by the US EPA. A novel option of utilizing molecular sieve membranes to preferentially separate tritium from high-volume dilute HTO-bearing aqueous streams was evaluated to address this issue.

The proof of principle research was performed for the separation and concentration of deuterated water (HDO). Molecular sieve zeolite membranes were synthesized and evaluated to separate and concentrate HDO from ordinary water $\left({ }^{1} \mathrm{H}_{2} \mathrm{O}\right.$, more commonly written $\left.\mathrm{H}_{2} \mathrm{O}\right)$. HDO was used as the non-radioactive simulant for HTO. Several silicoaluminophosphate (SAPO-34) molecular sieve zeolite membranes were synthesized and characterized with gas and vapor permeation measurements. The pervaporation process performance was evaluated for the separation and concentration of deuterated water.

The SAPO-34 seed crystals and membrane were characterized by X-ray diffraction (XRD), and the synthesized membranes were tested for single-gas permeation in which the driving force is a pressure gradient. These data were used to calculate the membrane permeance and selectivity from a single-gas permeation unit. This was helpful to determine the desirable membrane properties in terms of selectivity and presence of defects.

Several process and membrane parameters were evaluated. These include concentration of $\mathrm{D}_{2} \mathrm{O}(200$ $10,000 \mathrm{ppm})$, operating temperature $\left(25-60^{\circ} \mathrm{C}\right)$ and membrane thickness $(5 \mathrm{vs} 10 \mathrm{~mm})$. The permeate pressure was maintained constant and ranged from 50-60 microns of $\mathrm{Hg}(0.05-0.06$ Torr). The feed volume was approximately $50 \mathrm{~mL}$. Results show the preferential permeation of HDO through the membrane resulting in a substantially higher concentration of HDO in permeate as compared to the feed concentration. Separation factors calculated from the measured deuterium concentrations ranged from about 0.3 to 18.8 , depending on membrane properties and operating conditions. A higher selectivity was obtained at lower operating temperature indicating the adsorption of HDO is stronger at lower temperatures. The SAPO-34 membrane with $5 \mu \mathrm{m}$ thickness was observed to be of better quality and integrity compared to the $10 \mu \mathrm{m}$ thick SAPO membrane.

In order to verify that the SAPO-34 zeolite membrane layer is responsible for the observed separation of deuterated water, experiments were performed with a bare alumina support without the presence of the membrane layer. These results confirm that no selectivity was observed for HDO over water vapor in the absence of the SAPO-34 membrane layer.

Similar performance would be expected with tritiated water compared to deuterated water due to the slightly higher molecular weight of HTO. These results are very encouraging and demonstrate the potential of zeolite membranes to separate and concentrate deuterated and tritiated water. An invention disclosure was filed at ORNL (IDSA 3549), which describes the selective separation and concentration of deuterated and tritiated water.

Based on the results of the experimental runs to date, it is evident that zeolite membranes show a high separation factor. Experiments with tritiated water are being planned to demonstrate the suitability of zeolite membranes for the separation and concentration of tritium from tritiated water. Optimization of membrane synthesis is on-going to further improve selectivity and vapor permeance. Experimental plans also include evaluation of modified membranes such as zeolite LTA (Linde type A) and cation (e.g., Co and $\mathrm{Cs}$ ) exchanged zeolite membranes to increase vapor transport while maintaining high selectivity for $\mathrm{D}_{2} \mathrm{O}$ over $\mathrm{H}_{2} \mathrm{O}$. In the future, more effort will also be directed to develop a better understanding of the 
mechanism for the separation of deuterated water along with the investigation of adsorption and transport of $\mathrm{D}_{2} \mathrm{O}$ through the zeolite membrane layer.

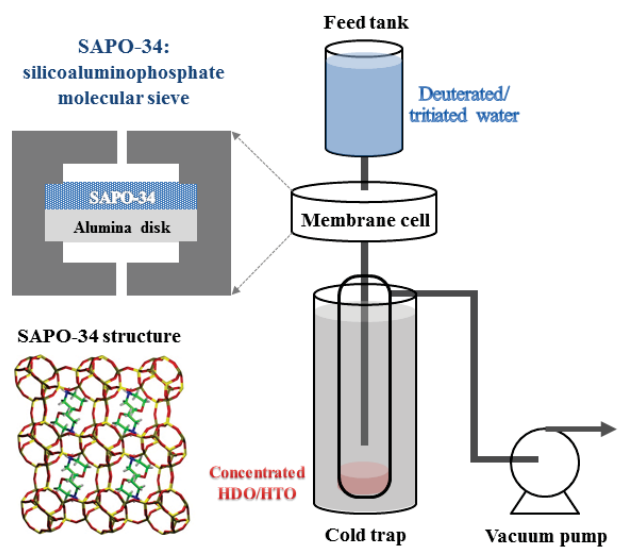

Figure 5. Schematic of the membrane separation system

\subsection{Tritium Separation from Dilute Aqueous Solutions}

\section{G. J. Sevigny and R. K. Motkuri, PNNL}

The objective of this study is to demonstrate the separation efficiency of graphene oxide (GOx) membranes in proof-of-principle tests to remove low concentration tritium from large volumes of tritiumcontaminated water in an effort to reuse or discharge the water to the environment. The removed tritium could be concentrated in a much smaller volume (e.g., 1/100th). If successful, the final embodiment would be a multi-stage membrane separation that would remove tritium from large volumes without the huge energy demand needed for electrolyzed water in the catalyzed electrochemical exchange (CECE) process.

In order to demonstrate the feasibility of GOx membrane-based isotopic water separation, PNNL demonstrated the relative transport rate and separation efficiencies of $\mathrm{H}_{2} \mathrm{O}, \mathrm{D}_{2} \mathrm{O}$, and $\mathrm{HTO}$.

First, the relative transport rate at room temperature was measured using the mass loss over time of GOx membrane-covered containers of $\mathrm{H}_{2} \mathrm{O}, \mathrm{D}_{2} \mathrm{O}$, and a mixture of the two isotopic compounds. Second, PNNL used an existing membrane test system to quantify the relative permeability of $\mathrm{H}_{2} \mathrm{O}$ and $\mathrm{D}_{2} \mathrm{O}$. Third, a modified distillation system was used to determine separation efficiency for the hydrogen isotopes. The system was modified to include a membrane for transporting steam through at an elevated temperature based on pressure difference.

For the first set of test, GOx membranes were fitted onto the opening of a $20 \mathrm{~mL}$ glass vial into which $10 \mathrm{~g}$ of $\mathrm{D}_{2} \mathrm{O}, \mathrm{H}_{2} \mathrm{O}$, and $\mathrm{D}_{2} \mathrm{O} / \mathrm{H}_{2} \mathrm{O}$ mixture were loaded. Results showed that $\mathrm{H}_{2} \mathrm{O}$ permeated faster than $\mathrm{D}_{2} \mathrm{O}$ for all types of GOx membranes. GOx membranes with nanoflake size (about $100 \mathrm{~nm}$ ) did not show a membrane thickness effect. However, a membrane thickness dependence on selectivity was observed for the larger flake size SKU-HCGO-W. The average separation factor based on permeation rate of $\mathrm{D}_{2} \mathrm{O}$ divided by $\mathrm{H}_{2} \mathrm{O}$ was about 0.93 with a low of 0.87 .

The permeation rate test was performed with a 2- $\mu$ m-thick cast Asbury membrane using mixed gas permeability testing with zero air (highly purified atmosphere) and with air humidified with either $\mathrm{H}_{2} \mathrm{O}$ or 
$\mathrm{D}_{2} \mathrm{O}$ to a nominal $50 \%$ relative humidity. The membrane permeability for both $\mathrm{H}_{2} \mathrm{O}$ and $\mathrm{D}_{2} \mathrm{O}$ was high with low rates for $\mathrm{N}_{2}$ and $\mathrm{O}_{2}$ that were near the system measurement limit. The $\mathrm{H}_{2} \mathrm{O}$ vapor permeation rate was $5.9 \times 10^{2} \mathrm{cc} / \mathrm{m}^{2} / \mathrm{min}\left(1.2 \times 10^{-6} \mathrm{~g} / \mathrm{min}-\mathrm{cm}^{2}\right)$, which is typical for graphene oxide membranes.

To demonstrate the feasibility of such isotopic water separation through $\mathrm{GO}_{\mathrm{X}}$ laminar membranes, an experimental setup was constructed to use pressure-driven separation by heating the isotopic water mixture at one side of the membrane to create steam while cooling the other side. Several membranes were tested and were prepared using different starting materials and by different pretreatment methods. The tests were performed with $\mathrm{D}_{2} \mathrm{O}$ and $\mathrm{T}_{2} \mathrm{O}$ enriched water.

For this study, the GOx membranes were prepared via modified Hummer's method. ${ }^{1}$ The first set of experiments was performed by using the GOx membrane where the graphene oxide was purchased from Aldrich and named "GOx-A. The second set of experiments was performed by using the PNNL-improved method, named "GOx-BC .

The transport rates in this study were slow, partially because of the small size of the filter used. The slow rate may be compensated by using larger pressure differentials or different operating temperatures. The initial setup consisted mostly of glassware, so the evaporator temperature could not be manipulated above $100^{\circ} \mathrm{C}$ due to concerns about internal pressure limits. Subsequently, an improved, second stainless steel setup was constructed with a reservoir connected to the condenser through the membrane and the results are presented in Table 1.

Table 1. Test results for modified distillation system

\begin{tabular}{lccccc} 
& Temp & Membrane & $\% \mathrm{D}_{2} \mathrm{O}$ & $\mathrm{g} / \mathrm{min}-\mathrm{cm}^{2}$ & $\begin{array}{c}\text { Outlet/Inlet } \\
\text { concentration }\end{array}$ \\
\hline RKM-1 & & & 1.00 \\
RKM-3 & $88-95^{\circ} \mathrm{C}$ & BC-GOx A & 10 & $5.22 \mathrm{E}-05$ & 0.82 \\
Bruce 1 & $90-95^{\circ} \mathrm{C}$ & BC-GOx A & 10 & $5.85 \mathrm{E}-03$ & 0.92 \\
RKM-5 & $88-95^{\circ} \mathrm{C}$ & BC-GOx improved & 10 & $4.57 \mathrm{E}-05$ & 0.82 \\
RKM-7Asbu & $88-95^{\circ} \mathrm{C}$ & BC-GOx & 10 & $6.09 \mathrm{E}-05$ & 0.81 \\
RKM-9 & $88-95^{\circ} \mathrm{C}$ & BC-GOx & 3 & $6.61 \mathrm{E}-05$ & 0.51 \\
RKM-11 & $110-115^{\circ} \mathrm{C}$ & Asbury & 2 & $3.90 \mathrm{E}-04$ & 0.91 \\
RKM-12 & $110-115^{\circ} \mathrm{C}$ & Asbury & 2 & $4.4 \mathrm{E}-04$ & 0.98 \\
RKM-14 & $88-95^{\circ} \mathrm{C}$ & New BC-GOx & 2 & $4.6 \mathrm{E}-05$ & 0.36 \\
RKM-15 & $110-115^{\circ} \mathrm{C}$ & Retested RKM-14 & 2 & $5.8 \mathrm{E}-04$ & 0.40 \\
Trit-1,2,3 & $110-115^{\circ} \mathrm{C}$ & BC-GOx & $1 \mathrm{mCi} / 1$ & & $0.38-0.64$ \\
Permeation & $23^{\circ} \mathrm{C}$ & Asbury & 0 & $4.75 \mathrm{E}-05$ & $\mathrm{NA}$ \\
using RGA & & & & \\
\hline
\end{tabular}

\section{a. Original solution}

A rough estimate of cost of the current technology was prepared as an indication of potential viability of the process and compared to the combined electrolysis and catalytic exchange (CECE) process. The relative process costs were based on the rough size of facility to accommodate the large surface area of the membranes and the energy needed to evaporate the water. The cost estimate was based on the initial separation factor of 0.6 for tritium. The water treatment costs ranged from $\$ 60 / \mathrm{L}$ to $\$ 180 / \mathrm{L}$. Capitalization of the building over 10 years was the largest cost factor. The cost for a CECE process system is estimated to be $\$ 2 / \mathrm{L}$ to $\$ 20 / \mathrm{L}$. Recent tests near the end of year showed better separation efficiencies that would reduce the cost. The membrane treatment costs could also be reduced with higher permeation rates, and compact membrane system designs. 


\section{Conclusions}

Based on the testing performed and the economic analyses, the following conclusions can be made.

- The large flake GOx membranes have higher separation efficiencies than the small flake material.

- The single-stage separation efficiency for tritiated water was demonstrated at 0.38-0.64 tritium outlet to tritium inlet concentration.

- Deuterium values showed values

- Permeation rate of water vapor through membrane was approximately $5 \mathrm{E}-5 \mathrm{~g} / \mathrm{min}-\mathrm{cm}^{2}$

- Membrane durability with direct water contact reduces membrane strength

- The current footprint and system size requirements are such that improvements are required to advance the technology. Areas of improvements include better separation factor and additional improvements in methods for increasing the membrane strength, and permeation rate.

- Facility costs are most significant factor for this technology and estimated costs are higher than CECE technology without improvements to surface area per unit volume or increased processing rates.

\section{References}

1. N. I. Kovtyukhova, P. J. Ollivier, B. R. Martin, T. E. Mallouk, S. A. Chizhik, E. V. Buzaneva, and A. D. Gorchinskiy, "Layer-by-Layer Assembly of Ultrathin Composite Films from Micron-Sized Graphite Oxide Sheets and Polycations," Chemistry of Materials 11, 1999: 771-778.

\section{Publications}

Frost, A., W. Bratton, 2015, "Design Analysis of Tritium Graphene Oxide Membrane System," KURBATT04-001-RPT-001, Rev A, Kurion, Richland, WA.

Sevigny, G. J., R. K. Motkuri, D. W. Gotthold, L. S. Fifield PNNL, A. P. Frost, W. Bratton, Kurion, 2015, "Separation of Tritiated Water Using Graphene Oxide Membrane," FCRD-MRWFD-2015000773, PNNL-24411. 


\subsection{Online Sampling \& Monitoring}

\section{S. A. Bryan and A. J. Casella, PNNL}

Spectroscopic-based approaches were investigated for real-time, on-line monitoring of fuel cycle processes. The overall objective of this task is to obtain the fundamental information needed for the design of on-line, real-time, process spectroscopic instrumentation for use in monitoring and controlling fuel reprocessing flowsheets. The methods used to monitor these processes must be robust (require little or no maintenance) and able to withstand harsh environments (e.g., high radiation fields and aggressive chemical matrices). The capability for continuous on-line monitoring provides the benefits of enhanced: accountability of fissile materials, control of the process flowsheet, information on flow parameters, solution composition, and chemical speciation, enhanced performance and reduction of worker dose by eliminating the need for traditional analytical "grab samples," improvement of operational and criticality safety, and reduced opportunity for human error.

The first area of focus for FY-15 was associated with the international collaboration between the Laboratory of Analysis and Material Metrology (LAMM) of the Commissariat à l'Énergie Atomique (CEA), in Marcoule France and PNNL. The purpose of the collaboration between LAMM and PNNL is to advance the technology for innovative in-situ analytical measurements of lanthanides and actinides in solvent extraction media, the conceptual design is shown in Figure 6. The initial focus is the application of PNNL Raman spectroscopic method for determination metals/pH/acid measurements using a LAMM integrated optics sensor for analysis of volumes on the microscale.

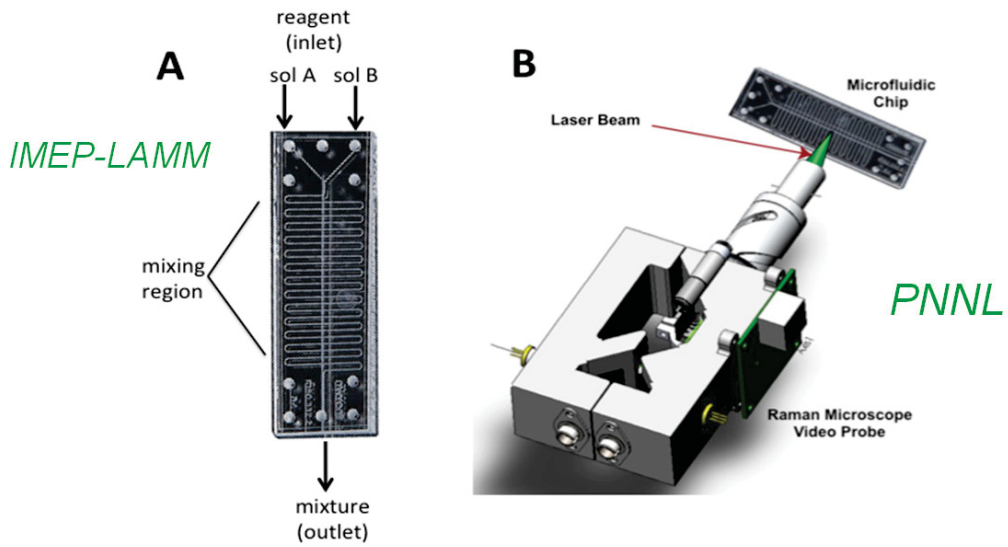

Figure 6. (A) Microfluidic chip for use in solvent extraction; (B) Schematic of the Raman Microscope-video probe adjacent to the microfluidic cell shown with the laser focus within the microchannels of the mixing chamber

Initial collaborative efforts between LAMM and PNNL involved PNNL scientists visiting the Institut de Microélectronique Electromagnétisme et Photonique in Grenoble, France and at LAMM in Marcuole, France to tour facilities/capabilities and outline the collaboration scope. A microRaman probe was obtained by PNNL from a Small Business Innovation Research (SBIR) funded collaboration for the purposes of integration with microfluidic cells. Work using the microRaman involved: assessed detection limits of $U$ and nitric acid for the microRaman probe with comparison to the current macroscale Raman probe, operability testing using a commercial microfluidic cell, showing real-time quantitative analysis of nitric acid with a $8 \mu \mathrm{L}$ cell, and development of a spectroscopic database/training set encompassing the expected range of concentrations for $U$ and nitric acid relevant to LAMM; compared results to the current macroscale Raman probe.

The second focus area for FY-15 involved the instrumenting and testing on-line spectroscopic process monitoring equipment to allow for the measurement of kinetic parameters of metal extraction/separation 
processes. The task was designed to develop spectroscopic instrumentation for use with solvent extraction mixer-settlers for the measurement of kinetic parameters of metal extraction/separation. This was achieved by the instrumentation of a Lewis Cell Designed for two-phase solvent extraction equipped with spectroscopic process monitoring probes designed for the accurate measurement of kinetic parameters for metal extraction from one phase to another within a solvent extraction system (Figure 7). The tests have focused on varying parameters within the Advanced TALSPEAK extraction system. This process monitoring system is designed to be easily transferred to any two-phase extraction system, including a bank of mixer-settlers, or centrifugal contactors.

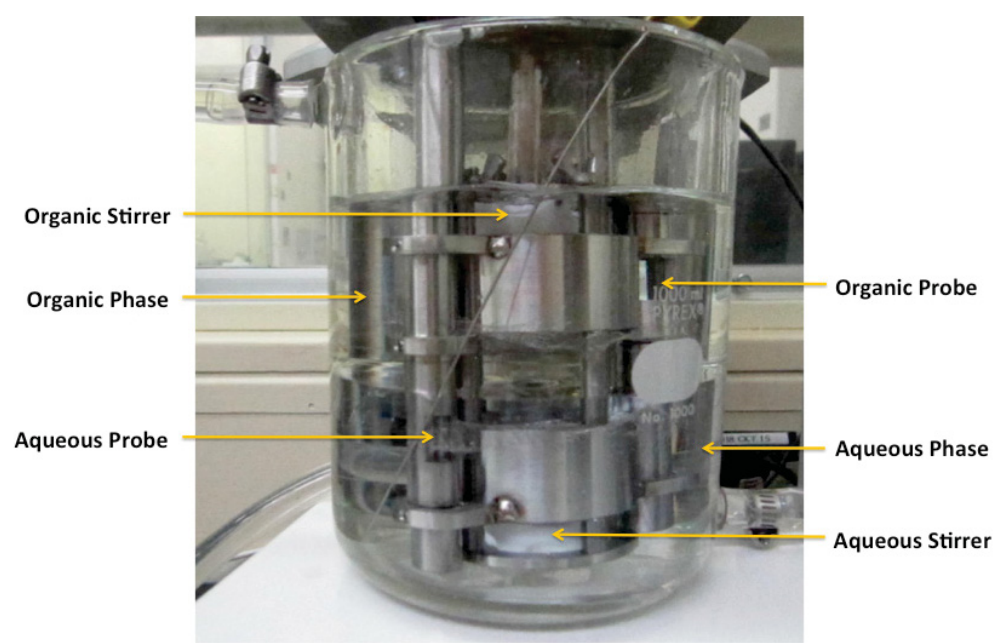

Figure 7. Lewis Cell instrumented with UV/vis/NIR probes for kinetic measurements during extraction/ separation processes

This second focus area also included adding communication between the data codes used in the chemometric modeling/analysis of on-line data and process equipment for active control by the model to maintain specified operational parameters, see Figure 8. An automated spectroscopic $\mathrm{pH}$ monitoring and control system designed to automatically control $\mathrm{pH}$ within a fuel reprocessing solution relevant to used nuclear fuel reprocessing was demonstrated. This automated monitoring and control system is based on custom Matlab and Labview code.

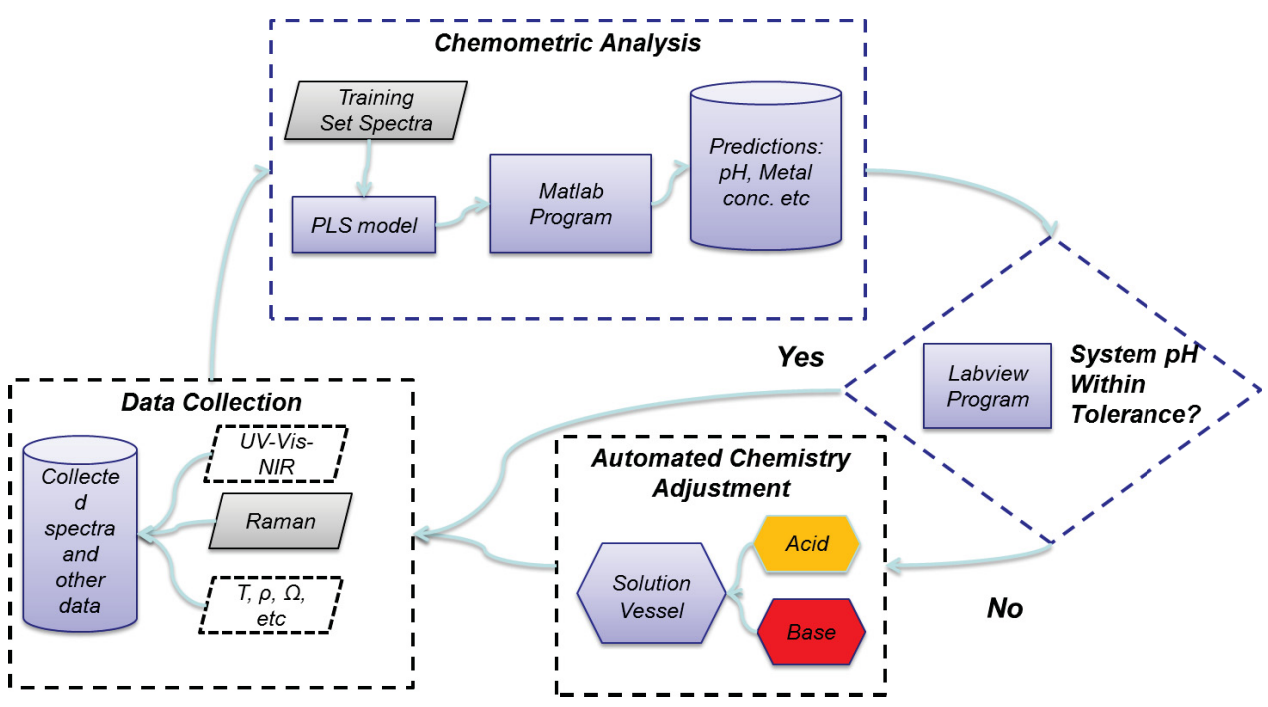

Figure 8. Detailed overview of process monitoring and control system 


\section{FY-15 Publications and Presentations}

\section{Journal Articles}

Casella, A. J., L. R. Hylden, E. L. Campbell, T. G. Levitskaia, J. M. Peterson, F. N. Smith, and S. A. Bryan, "Development of On-Line Spectroscopic pH Monitoring for Nuclear Fuel Reprocessing Plants: Weak Acid Schemes." Analytical Chemistry 87(10), 2015: 5139-5147. doi:10.1021/ac504578t.

Nee, K., S. Bryan, T. Levitskaia, J. Wei-Ju Kuo, M. Nilsson, 2015, "Combinations of NIR and Raman spectroscopy for Improved Monitoring of Material in Used Nuclear Fuel Separation Processes," submitted.

Schroll, C. A., A. M. Lines, W. R. Heineman, and S. A. Bryan, 2015, “Absorption Spectroscopy for Quantitative Prediction of Lanthanide Concentrations in $3 \mathrm{LiCl}-2 \mathrm{CsCl}$ Eutectic at $723 \mathrm{~K}$," submitted.

\section{Conference Proceedings}

Bryan, S. A., A. J. Casella, A. M. Lines, G. L. Nelson, and J. M. Bello, 2015, "Advances in On-Line Monitoring for Measurement within Nuclear Fuel Reprocessing Streams," Proceedings of GLOBAL 2015, 21 st International Conference \& Exhibition: Nuclear Fuel Cycle for a Low-Carbon Future, Paris, France, September 21-24, 2015, PNNL-SA-107043.

Bryan, S. A., A. J. Casella, and T. G. Levitskaia, 2014, "On-Line Monitoring for Process Control and Safeguarding of Radiochemical Streams at Spent Fuel Reprocessing Plants," Proceedings of the IAEA International Safeguards Symposium: Linking Strategy, Implementation and People, Vienna, Austria, October 20-24, 2014, PNNL-SA-105110.

\section{Presentations}

Bryan, S. A., A. J. Casella, L. R. Hylden, T. G. Levitskaia, and G. J. Lumetta, 2014, “Advances in OnLine Monitoring for Weak Acid Measurement within Nuclear Fuel Reprocessing Streams," 38th Actinide Separations Conference, Albuquerque, NM, May 19-22, 2014, PNNL-SA-102548.

Casella, A. J., L. R. Hylden, A. D. Crawford, F. D. Heller, N. H. Gunawardena, and S. A. Bryan, 2014, "On-Line Spectroscopic Monitoring of a Weak-Acid Based Separation Scheme: $\mathrm{pH}$ Variability and Accuracy." Abstract submitted to American Nuclear Society Winter Meeting, November 2014, Anaheim, CA.

Gunawardena, N. H., F. D. Heller, L. R. Hylden, A. J. Casella, and S. A. Bryan, 2015, "Laboratory scale on-line spectroscopic process monitoring and control for nuclear fuel reprocessing streams," Abstract submitted to INMM Annual Meeting 2015, Indian Wells, CA, PNNL-SA-107923.

Gunawardena, N. H., F. D. Heller, L. R. Hylden, A. J. Casella, and S. A. Bryan, 2015, “Application of Chemometrics within Laboratory Scale On-Line Spectroscopic Process Monitoring and Control in Nuclear Fuel Reprocessing Streams," Abstract submitted to American Chemical Society Northwest Regional Meeting, Pocatello, ID, PNNL-SA-109550.

Heller, F. D., S. A. Bryan, K. L. Nash, G. J. Lumetta, A. J. Casella, and S. I. Sinkov, 2015, "Phase Transfer Kinetics of Advanced-TALSPEAK Solvent Extraction Systems." Abstract submitted to American Chemical Society Northwest Regional Meeting, Pocatello, ID, PNNL-SA-109527. 


\subsection{Baseline H-Canyon Accountability (I)}

\section{B. Cipiti, SNL}

The purpose of the Baseline H-Canyon Accountability project was develop a generic methodology for integrating process monitoring and process modeling for both process control and safeguards. At nuclear processing facilities, the plant operator has a tremendous amount of process monitoring or process control data, but this data typically is not well integrated with safeguards. The nuclear material accounting system is limited by laboratory measurements with can be time-consuming and limit timeliness goals. This work examined how new on-line measurement technologies and more reliance on process monitoring could provide value, including improving timeliness for responding to off-normal conditions and potentially reducing the burden of laboratory analysis.

The SRNL H-Canyon facility was used to initially test the concept. They provided data on the process flow, tank inventories, and the baseline measurement system that is used currently. This data was used to generate a Matlab Simulink model of the H-Canyon facility with a focus on the safeguards system. The flow rates that were modeled were based on historical operations at full capacity. Figure 9 shows the model.

The model was used to examine the effectiveness of the new technologies being tested as part of the $\mathrm{H}$ Canyon Test Bed. This included UV-Vis spectrometry and the high-resolution X-ray technology (HiRX). While the test bed is providing valuable performance data on these technologies, the purpose of this work was to examine how they could improve overall safeguards effectiveness from a systems perspective.

The model was used to determine a baseline monthly inventory difference (ID) and overall error $\left(\sigma_{\text {ID }}\right)$, based on current measurements. Then various potential uses of the new measurement information were virtually tested to examine the effect on the safeguards metrics. The modeling found that the use of UVVis could potentially reduce the $\sigma_{\mathrm{ID}}$ for uranium by $40 \%$ if applied in one location in the plant. The use of HiRX to replace analytical measurements at multiple key sampling points could potentially reduce the $\sigma_{\text {ID }}$ for uranium by $60 \%$. It should be noted that these results are based on current assumptions for measurements at lower facility throughputs, so they may not be completely representative of how the instrumentation could help other reprocessing facilities. 


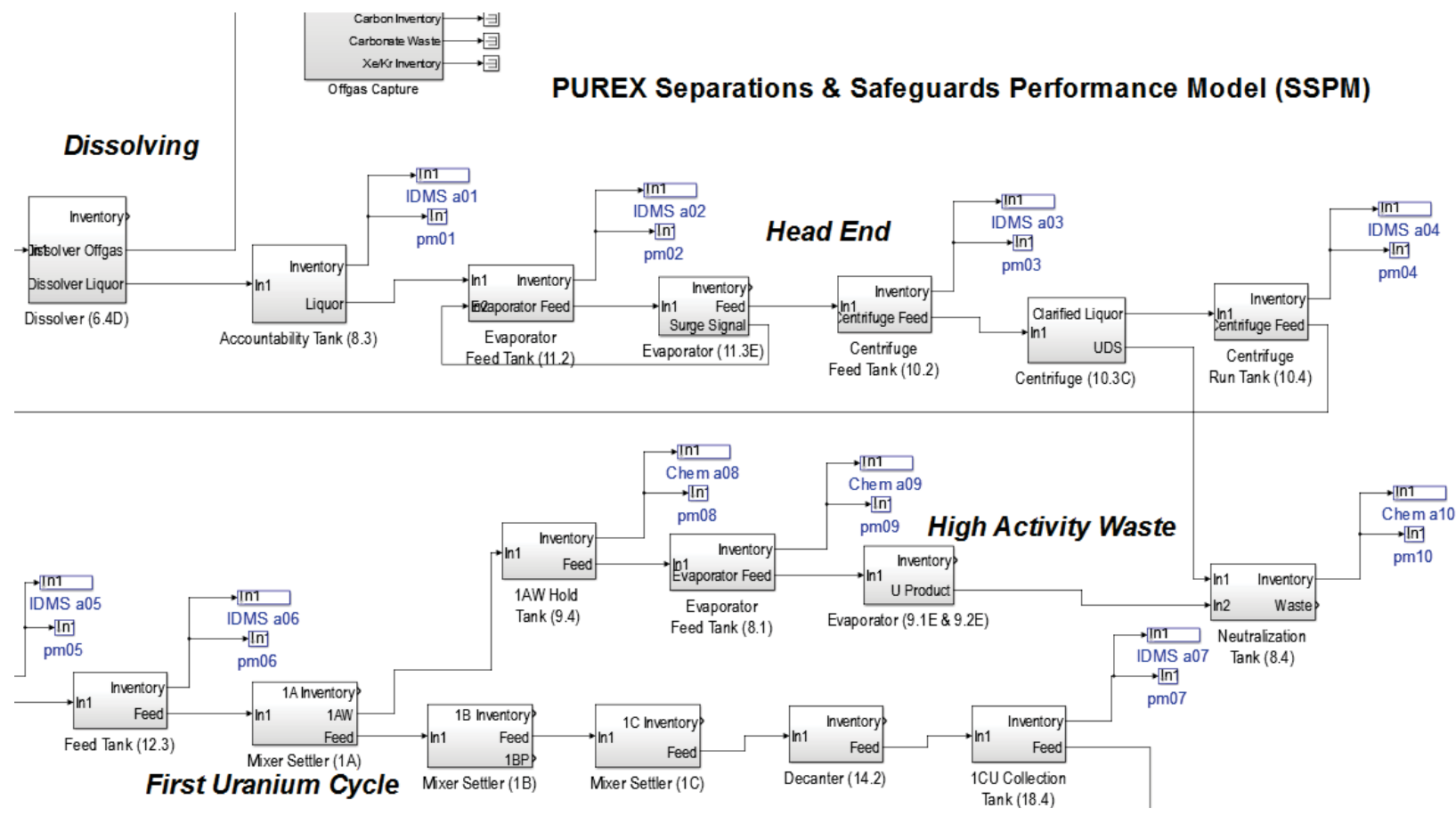

Figure 9. Portion of H-Canyon model in MatLab Simulink

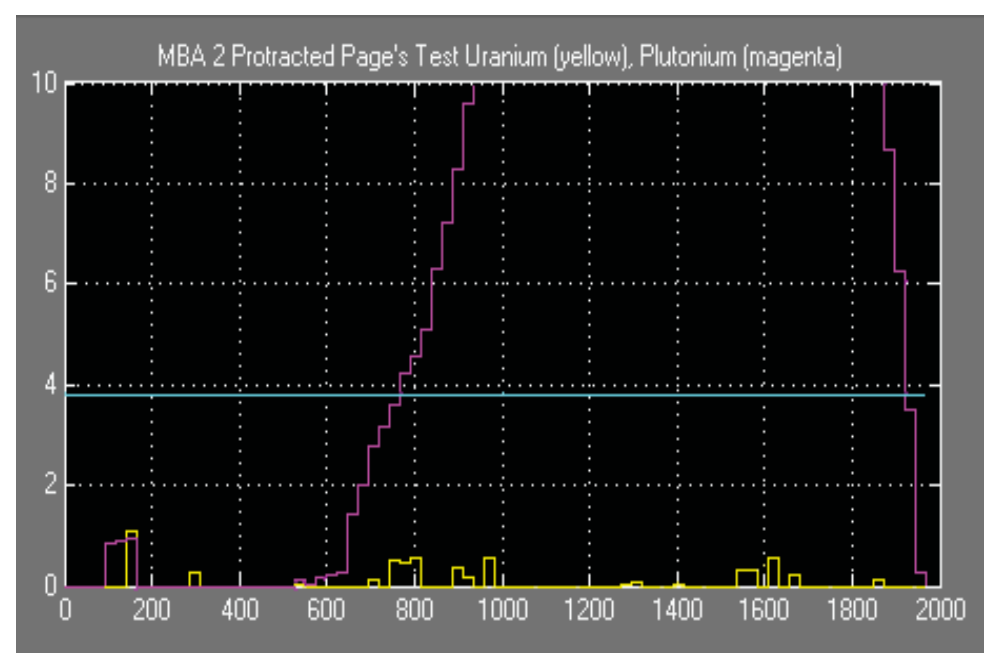

Figure 10. Example diversion result

These results were used to help inform a generic approach for integrating process monitoring data into safeguards and process control systems. ${ }^{1}$ The generic approach examined both qualitative and quantitative integration of process monitoring. The quantitative approach was found to be the preferred option since it directly integrates process monitoring data with the safeguards system. This approach used bulk mass balances coupled with UV-Vis spectroscopy to do near-real-time accountancy for a typical PUREX reprocessing plant. A daily material balance would be possible through the use of spectroscopy. Modeling, using a generic PUREX model, was used to examine the response of such a system to both direct and substitution diversion scenarios. Figure 10 shows an example of a protracted loss of $\mathrm{Pu}$ that was detected using the new system - the blue is a threshold condition and the magenta line surpassed that condition early in the material loss, indicated that detection would be highly probable. 
The system was found to be robust to both direct and substitution loss, and timeliness was much improved due to the daily balance. The bulk measurements provided early detection of direct loss (either from leaks or diversions). Spectroscopy can detect concentration shifts, so provided robust protection against substitution loss or other process upsets. These results can be directly applied to new fuel cycle facilities to continue to improve the effectiveness and efficiency of safeguards approaches. ${ }^{2}$

\section{References}

1. B. B. Cipiti and T. Severynse, "H-Canyon Measurement Uncertainty Quantification," Sandia National Laboratories, SAND2015-7744, September 2015.

2. B. B. Cipiti, T. Severynse, C. Pereira, and J. Bresee, "Generic Quantitative Process Monitoring and Accountability Methodology for Fuel Cycle Facilities," Proceedings of Global 2015, Paris, France, September 20-24, 2015.

\subsection{Baseline H-Canyon Accountability (II)}

T. Severynse, SRNL

\section{Introduction}

Special Nuclear Material (SNM) accountability in a fuel processing facility presents unique challenges due to the large quantities, various chemical and physical forms, and radiological properties of the materials. A typical separations plant can recover $10 \mathrm{~kg}$ of plutonium for every metric ton of uranium (MTU) processed, or 10 MT plutonium for a 1,000 MTU capacity plant. Such a plant must have a safeguards system that can detect the diversion of material. A robust accountability program is an important part of this safeguards system.

The H Canyon facility at the Savannah River Site is currently processing enriched uranium fuels from foreign and domestic research reactors to produce low-enriched uranium solution for use in commercial light water reactor fuel. A second mission processes plutonium materials to produce oxide suitable for the Mixed Oxide Fuel Fabrication facility. Both processes produce solutions of SNM of varying forms and concentrations, including a wide range of chemical composition and fission product content. SNM accountability is achieved by completion of a periodic physical inventory requiring facility shutdown, solution sampling, and destructive sample analysis at the remotely-located laboratory facility. A test bed program is in progress in $\mathrm{H}$ Canyon that allows installation and evaluation of monitoring technologies that can be useful for both process control and improved accountability.

\section{H Canyon Accountability Model}

A companion work page has incorporated engineering data (including key measurement points, associated process variables, measurement methods, and the sources and magnitude of uncertainty of each measurement) from H Canyon into the Separations and Safeguards Performance Model to assess accountability performance for enriched uranium processing. To achieve meaningful results, the model assumed historical throughput rates of 10-20 metric tons of uranium (HEU) per year. 
Application of the model with the $\mathrm{H}$ Canyon data has quantified the overall inventory uncertainty, and the results $^{\mathrm{a}}$ are in agreement with historical accountability performance for comparable throughput rates. The model also identified specific locations where the calculated inventory difference could be reduced by the application of process monitoring. The model has also quantified the reduction to overall inventory difference that could be realized from the universal deployment of each of two specific monitoring technologies (UV-Vis spectroscopy and absorbance-edge $\mathrm{x}$-ray fluorescence).

\section{Process Monitoring Opportunities}

The application of process monitoring technologies can supplement the material balance-based accountability process. Normal process operations rely on monitoring instrumentation for process control which, when combined with emerging technologies for surveillance and measurement of specific radionuclides, may approach near real-time accountability. Continuous measurement of SNM with the application of appropriate statistical testing can provide detection probabilities that satisfy international safeguards requirements.

The various technologies that are being developed or considered for process monitoring include spectroscopy (UV-Vis, Raman, x-ray fluorescence, gamma), neutron interrogation, and alpha monitoring. Evaluation of these technologies has determined that UV-Vis spectroscopy and absorbance-edge x-ray fluorescence provide improved real-time material accountability and are most easily and cost-effectively deployed within the H Canyon facility.

\section{Publications}

Severynse, T. F., 2015, "Evaluation of the H Canyon Accountability Model," FCRD-MRWFD-2015000523 (Draft), SRNL, September 2015.

Severynse, T. F., 2015, "Process Monitoring Opportunities for Improved Accountability," FCRDMRWFD-2015-000726 (Draft), SRNL, September 2015.

\subsection{Lab-scale Testing of Reference Processes (I)}

\section{Pereira, ANL}

\section{Lab-Scale Tests of the Codecontamination Flowsheet}

The reference $\mathrm{U} / \mathrm{Pu} / \mathrm{Np}$ recovery process, or Co-decontamination, is based on a co-extraction of $\mathrm{U}, \mathrm{Pu}$, and $\mathrm{Np}$ from dissolved spent fuel, followed by selective stripping to recover product streams containing $\mathrm{U} / \mathrm{Pu} / \mathrm{Np}$ and a second product stream containing the remaining $\mathrm{U}$. The Co-decontamination process is based on well-understood solvent extraction chemistry using tributyl phosphate (TBP). Consequently, the process requires predictable control of the behavior of the key species involved in the separations rather than on major new advances in chemistry or equipment. Multistage tests were run with a lab-scale $2-\mathrm{cm}$ contactor to validate the design criteria used to develop the flowsheet. Lab-scale flowsheet testing is divided into three components: (1) demonstrating that extraction of the key fission products, Ru, Mo and $\mathrm{Zr}$ is controlled as predicted by AMUSE, (2) characterizing the extraction of $\mathrm{Np}$ as a function of redox chemistry, and (3) demonstrating the partial stripping of $U$ in the second segment of the case study

a. Documented in a separate classified report. 
flowsheet. The first and third components require a full flowsheet, while the second component is being studied using microfluidics.

The flowsheet used for lab-scale tests is based on extraction of a feed containing natural uranium and cold $\mathrm{Mo}, \mathrm{Ru}$, and $\mathrm{Zr}$ at concentrations. Hydraulic issues with the $2-\mathrm{cm}$ contactor that were observed in the tests run in FY-14 necessitated deviations from the case study flowsheet to allow stable operation. Samples of the aqueous stage drains and effluents were collected and submitted for chemical analysis by ICP-MS. Samples were also analyzed by liquid scintillation counting (LSC) and energy dispersive X-ray fluorescence (XRF), which allowed the organic stage drains and effluent to be analyzed as well. Results obtained for uranium in the first Codecon segment indicated excellent performance with stage concentration profiles closely matching the AMUSE predictions. Although the $\mathrm{Mo}, \mathrm{Ru}$, and $\mathrm{Zr}$ profiles also approximated the expected behavior there was some deviation from the AMUSE predictions as the first scrub profiles were generally steeper while the second scrub showed flatter profiles. The XRF data showed good agreement with the ICP-MS data and suggest an effective method to examine the organic samples when the concentrations are relatively high.

The test of the second segment flowsheet also demonstrated some solvent back-up though operation was stable and the test was successfully completed. The uranium profiles measured by ICP-MS and LSC matched the profiles generated by AMUSE. Complexation of uranium by acetohydroxamic acid (AHA) in the absence of $\mathrm{Pu}$ or $\mathrm{Np}$ was indicated by a color change. However, there did not seem to be any impact on the expected behavior of uranium, but further study may be warranted. Mo, $\mathrm{Ru}$, and $\mathrm{Zr}$ were evident in the product and across the contactor stages at much higher concentrations than expected. Their presence can be attributed to imperfect scrubbing in the second scrub of the first segment, and does suggest that revisiting the behavior of fission product in the case study flowsheet is warranted.

\section{Lab-Scale Tests of the Codecontamination Flowsheet}

The tests of the reference Codecon flowsheet conducted to date suggest that the fission products behave in a manner consistent with the behavior predicted using the AMUSE code. However, Np was not included in those tests as its partitioning could not be easily proscribed due to its complex redox behavior in TBPalkane-nitric acid systems. After dissolution in nitric acid, neptunium is typically present in several valence states: $\mathrm{Np}(\mathrm{IV})$ and $\mathrm{Np}(\mathrm{VI})$ which extract, and $\mathrm{Np}(\mathrm{V})$ which does not. The valence state is in turn determined by a number of factors including the acidity, the treatment received by the feed, presence of nitrous acid and other redox agents, and radiolysis. In order to assure the desired behavior in the multistage tests, a number of small-scale tests using a microfluidic system were run to begin to bracket the stable operating regime for $\mathrm{Np}$ to define the conditions that will result in a successful flowsheet.

In order to provide a baseline for the extent of the extraction under different feed conditions, equilibrium contact tests were run for 24 hour contacts at 3, 4, and $5 \mathrm{M}$ nitric acid with $30 \%$ TBP in dodecane at an $\mathrm{O}$ :A ratio of 1 . In other tests, sodium metavanadate $(\mathrm{V}(\mathrm{V}))$ solution was added to the acid to ensure that $\mathrm{Np}$ was fully converted to $\mathrm{Np}(\mathrm{VI})$ as measured using D-values. Finally, a third set of tests were completed where sodium nitrite was added to the nitric acid solutions after equilibration with $\mathrm{V}(\mathrm{V})$ to simulate the radiolytic production of nitrous acid, which reduces $\mathrm{NpO}_{2}{ }^{2+-}$ to $\mathrm{NpO}^{2+}$ under the reference flowsheet conditions. Results showed D values well-below 1 for all three acids (without vanadate) upon initial production of the $\mathrm{Np}$ solution but a gradual increase over several hours to days to higher $\mathrm{D}$ values. Addition of vanadate raised the $\mathrm{D}$ values to 10 or higher, while addition of nitrite solution to a concentration of $1 \mathrm{mM}$ reduced the $\mathrm{D}$ values slightly. These results are consistent with results reported in the literature and established a baseline for comparison with the kinetics tests.

A series of extraction tests were run using a microfluidic system initially developed for actinidelanthanide separations development. The residence times for each set of feed compositions were controlled with a combination of variable speed syringe pumps and capillaries of three different lengths 
$(50,100$ and $200 \mathrm{~cm})$. The results were self-consistent for each capillary length based on the form of the $\mathrm{D}$-value and $\mathrm{ka}_{\mathrm{L}}$ (volumetric mass transfer coefficient) data. However, the $\mathrm{ka}_{\mathrm{L}}$ showed a dependence on the tubing length. The variability in the calculated $\mathrm{ka}_{\mathrm{L}}$ indicated a strong dependence on the droplet characteristics (i.e. droplet size, thin film thickness, and intra-phase mixing). One limitation with the systems was the need to prepare aqueous solutions prior to extraction in the capillary system. In-line mixing of aqueous feed component within the capillary system prior to introduction of solvent would more closely mimic the conditions within a contactor (annular, mixer-settler, or column) with the relatively minor addition of an injector junction and a syringe pump for the additional aqueous feeds. Because of the scale, applying microfluidics to kinetics analysis is cost effective and allows for the rapid evaluation of a number of cases. However, a consistent analysis method must be developed that will provide the desired mass transfer, and kinetics, data for the TBP/alkane-nitric acid system. 


\subsection{Lab-Scale Testing of Reference Processes (II)}

\section{R. Martin and C. Riddle, INL}

Experimental work to support the lab-scale testing of reference processes focused on simplified investigations to identify the behavior of $\mathrm{U}, \mathrm{Tc}, \mathrm{Zr}$, Mo and $\mathrm{Ru}$ in a Co-Decontamination type flowsheet. Simulants were prepared using representative metal concentrations (as in the FY-14 work) that were obtained from the recent case study flowsheet analysis performed for the MRWFD Campaign. ${ }^{1}$ Stable salts of fission products were used for the simulant, with the exception of a ${ }^{99} \mathrm{Tc}$ radioisotope and depleted $\mathrm{U}$ (DU). In the FY-15 studies the nitric acid concentration was kept constant at $2.83 \mathrm{M}$.

Distribution ratios for $U$ showed little to no change between the different tests. The experimentally determined distributions were consistent with the AMUSE predictions shown in Figure 11.
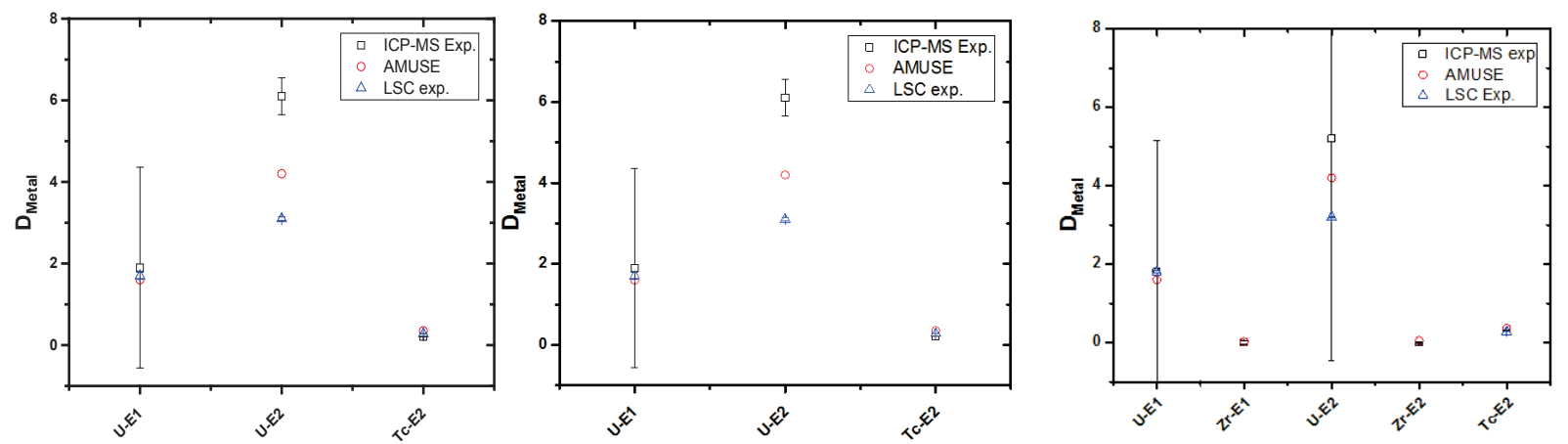

Figure 11. Distributions of $\mathrm{U}, \mathrm{Zr}$, and $\mathrm{Tc}$ in $2.83 \mathrm{M} \mathrm{HNO}_{3}$, separately and combined, (E1) contacted with organic phase of $30 \%$ TBP in dodecane. The organic phase (loaded $\mathrm{U}, \mathrm{Zr}$, or both in organic) is contacted with Tc in 2.83M $\mathrm{HNO}_{3}$ (E2).

However, $\mathrm{U}$ distributions when the loaded organic is contacted with Tc only solutions did vary slightly between the two analysis instruments and AMUSE predictions. Further investigation is needed to establish a more consistent baseline for the loaded $U$ contacts with in the two analysis regimes. Experiments incorporating the fluorine anion $\left(\mathrm{F}^{-}\right)$, in the form of $\mathrm{NaF}$, were performed in order to account for the hydrogen fluoride (HF) potentially present in Co-decontamination process feed and the impact it would have on metals present in the simulant. Tests incorporating $\mathrm{F}^{-}$were performed using $\mathrm{U}, \mathrm{Zr}, \mathrm{Tc}$, molybdenum $(\mathrm{Mo})$, and ruthenium $(\mathrm{Ru})$ in varied combinations and a test in incorporating all five metals is shown in Figure 12. 

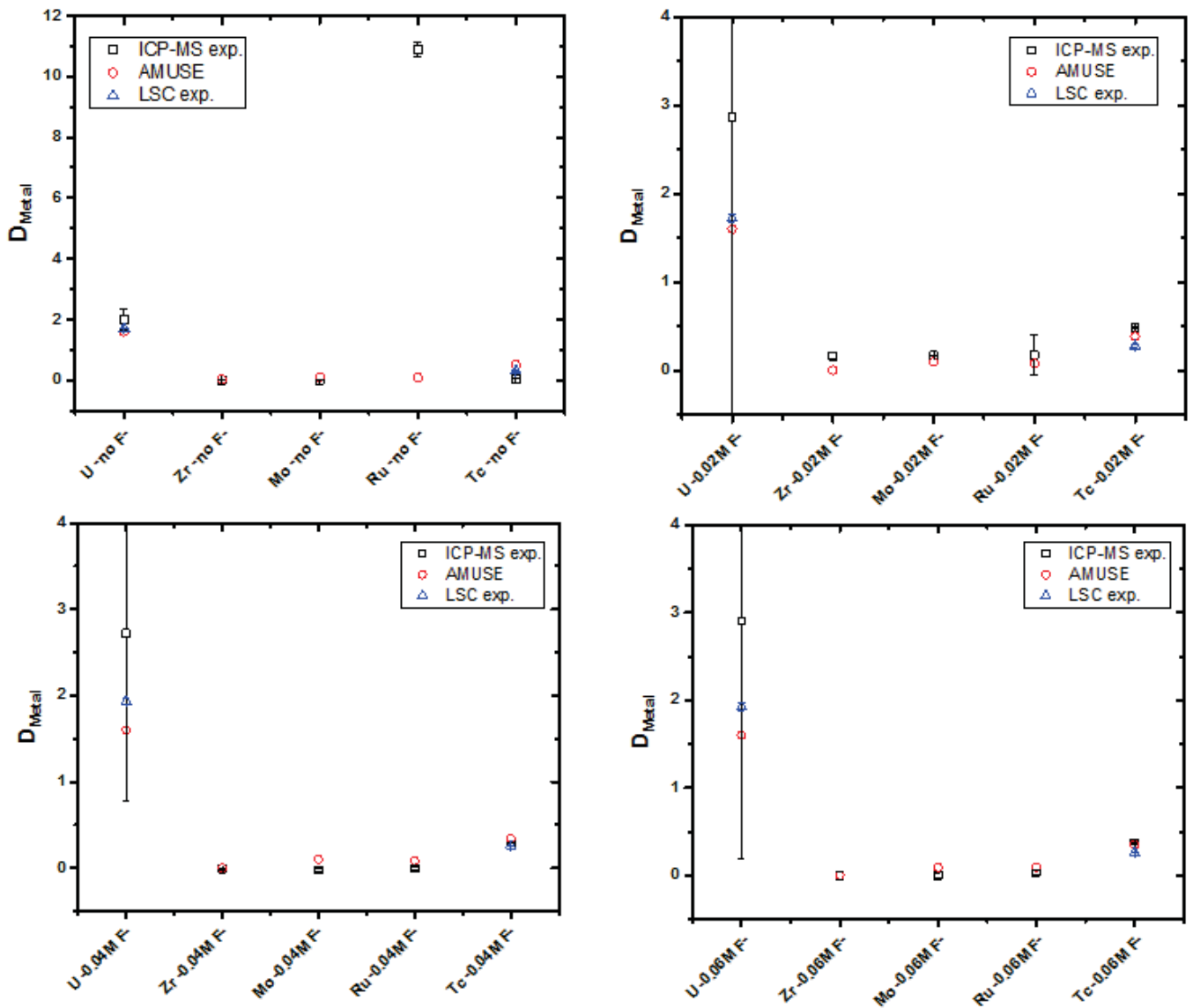

Figure 12. Distributions of $\mathrm{U}, \mathrm{Zr}, \mathrm{Mo}, \mathrm{Ru}$, and Tc with and without varied concentrations of fluoride present in the form of NaF.

The results for all $\mathrm{F}^{-}$tests showed little variance in distribution ratios for the metals and all aligned with the AMUSE predictions, with the exception of neat $\mathrm{Ru}$. The unusually high extraction of neat Ru may attributed to nitrosyl Ru complexes which have been shown to be very extractable at higher concentrations of nitric acid using TBP. Results for $\mathrm{Zr}$ and Tc only showed $\mathrm{Zr}$ has an enhancing effect on the extraction of Tc, however, Tc distribution ratios were still found to be lower than predicted by AMUSE. Figure 3 shows this trend in the experimental data with a $\mathrm{Zr} \mathrm{D}=0.63$, and Tc with a $\mathrm{D}=0.62$. Although the AMUSE predictions are lower for $\mathrm{Zr}$ and substantially higher for Tc, it has been shown in previous literature, ${ }^{2}$ that the experimental values in Figure 13 reflect enhanced distribution ratios for both $\mathrm{Zr}$ and Tc. The experimental results suggest the AMUSE model may need to be adjusted. Experimental data and computational values matched in many of the experiments performed and new experimental work will be designed based on these outcomes. Experiments that did not match well with the AMUSE code will need to be studied in order to layout a matrix that will reconcile experimental and AMUSE in areas of acid dependence data, $\mathrm{Zr}$ and $\mathrm{Tc}$ concentration, and $\mathrm{F}^{-}$for additional input into AMUSE results to update the code. For the experimental data that did match well, it may be more appropriate to consider a full simulant study at this point to ensure that the experimental data do not vary from the baseline with all dissolved fuel ions present. Future work will also require an expansion of the flowsheet tests to incorporate multiple extraction steps as this may lead to other differences observed between the AMUSE code and experimental results. 


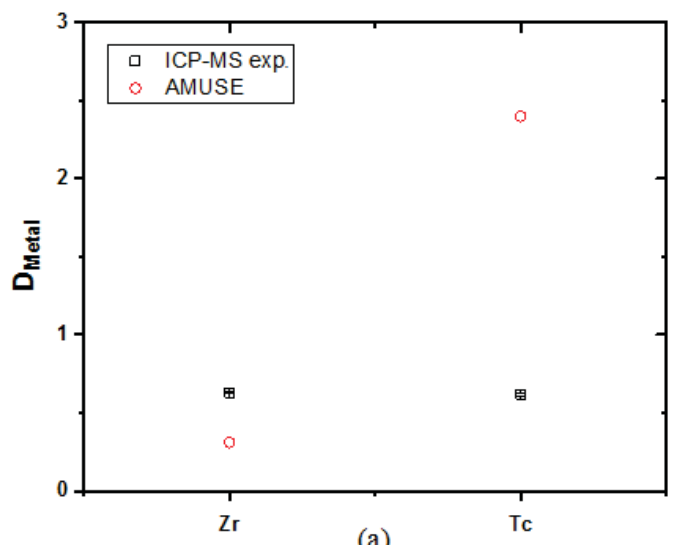

Figure 13. $\mathrm{Tc}$ and $\mathrm{Zr}$ in $2.83 \mathrm{M} \mathrm{HNO}_{3}$, where $\mathrm{Zr}$ is contacted with $30 \% \mathrm{TBP} /$ kerosene

\title{
References
}

1. J. Law, N. Soelberg, T. Todd, J. Tripp, C. Pereira, M. Williamson, W. Ebert, R. Jubin, B. Moyer, J. Vienna et al., 2013, "Separation and Waste Form Campaign Full Recycle Case Study," U.S. Department of Energy, FCRD-SWF-2013-000380, 2013: 24-32.

2. J. Garraway, 1984, "The Behavior of Technetium in a Nuclear Fuel Reprocessing Plant," The Institution of Chemical Engineers, ISBN 0-58295-182-5, 1984.

\subsection{Lab-Scale Testing of Reference Processes (III)}

\author{
R. T. Jubin, S. H. Bruffey, K. K. Patton, S. M. Robinson, M. R. Chattin and J. M. Giaquinto, ORNL
}

\section{lodine Capture Performance of Silver Nitrate Based Sorbents Exposed to High Levels of $\mathrm{NO}_{2}$}

One of the Reprocessing Case Studies included an advanced head-end unit operation that involved the use of high concentrations of $\mathrm{NO}_{2}$ and elevated temperatures to remove tritium from the UNF. Initial studies of this head-end process also showed that significant fractions of iodine may be volatilized during the treatment of the UNF. The treatment process also included a recycle loop for the $\mathrm{NO}_{2}$. If the iodine is released into the vapor phase, it would be desirable to remove the iodine from the circulating $\mathrm{NO}_{2}$ stream. Commonly utilized silver-based sorbents, such as silver mordenite, do not perform well in a high- $\mathrm{NO}_{2}$ environment. Scoping tests conducted in FY-15 investigated the use of silver-nitrate impregnated alumina (AgAlm) and a $\mathrm{AgNO}_{3}$ aqueous scrubber for iodine removal in the treatment process with the expectation that these methods may be more resistant to the deleterious effects of $\mathrm{NO}_{2}$.

Static aging of $\mathrm{AgAlm}$ was performed in a similar fashion to those reported on $\mathrm{Ag}^{0} \mathrm{Z}$ but at higher concentrations of $\mathrm{NO}_{2}$. A sample holder was loaded with $\sim 10 \mathrm{~g}$ of AgAlm. The holder was then evacuated, and charged with the desired $\mathrm{NO}_{2}$ environment. Next, the holder was pressurized slightly above atmospheric pressure and placed in an oven at $150{ }^{\circ} \mathrm{C}$ for up to 1 week

Unaged and aged materials were each loaded with iodine under conditions similar to those described in previous studies. The changes in weight obtained from the TGA data for 0 and 1 week $\mathrm{NO}_{2}$-aged $\mathrm{AgAlm}$ samples are shown in Figure 14. The time zero on this figure corresponds to the time at which the iodine stream was introduced to the sample. The data curves end after the 24-hour purging period. The unaged 
AgAlm showed a gain of approximately $100 \mathrm{mg} \mathrm{I} / \mathrm{g}$ sorbent. The sample aged 1 week under a high $\mathrm{NO}_{2}$ concentration lost 15\% iodine capture capacity, with a maximum loading of $85 \mathrm{mg} \mathrm{I} / \mathrm{g}$ sorbent.

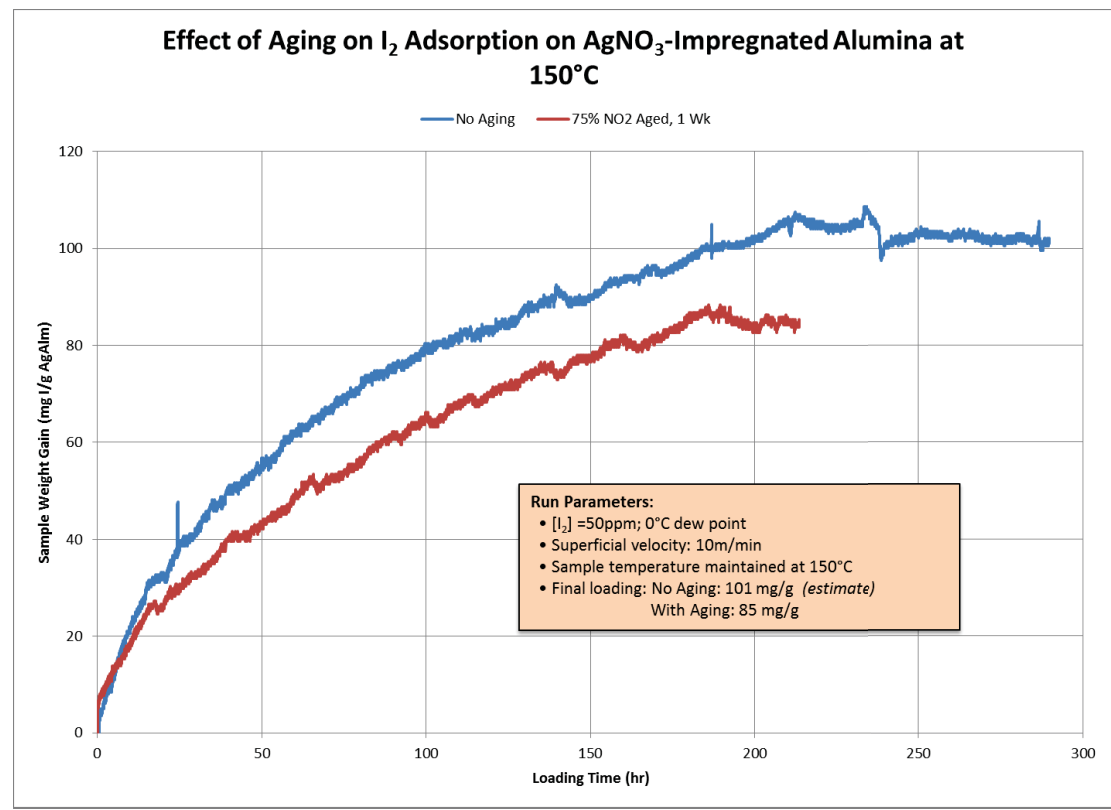

Figure 14. lodine loading behavior of $\mathrm{NO}_{2}$-aged $\mathrm{AgNO}_{3}$-impregnated alumina

In order to mimic the effects of high concentrations of $\mathrm{NO}_{2}$ on an $\mathrm{AgNO}_{3}$ aqueous scrubber, nitric acid solutions ranging from 1-3M were prepared and contained equal amounts of $\mathrm{AgNO}_{3}$ in each. The nitric acid in the silver nitrate solution was intended to simulate reactions between $\mathrm{NO}_{2}$ and an aqueous solution. An iodine stream was contacted with each solution, and the effluent from the scrubber was passed through a caustic trap intended to sequester any iodine that may pass through the AgNO3 scrubber. In the case of the aqueous bubbler, it was determined that the concentration of nitric acid within the bubbler system had little to no effect on iodine capture capacity.

Both the AgAlm and aqueous scrubber methods appear to be resistant to the effects of high concentrations of $\mathrm{NO}_{2}$ and hold promise for deployment as iodine getters in an advanced tritium pretreatment operation. To build upon these scoping tests, aging of AgAlm will be conducted for longer time periods and the $\mathrm{AgNO}_{3}$ scrubber will be utilized in the existing ORNL advanced tritium pretreatment loop

\section{Evaluation of Tritium Content and Release from Fuel Cladding}

Zircaloy cladding makes up roughly $25 \%$ by mass of UNF in the United States. Treatment options for Zircaloy cladding include recycling to recover the significant cost of the zirconium and eliminate costs associated with the disposal of transuranic-contaminated Zircaloy®. If LWR fuel is reprocessed and the fuel is dissolved without tritium pretreatment, the tritium in the cladding will remain bound to the cladding. If tritium pretreatment is included in the flowsheet, some portion of the tritium in the cladding may be released along with the tritium from the fuel matrix.

Reported estimates of the percentage of tritium in the fuel rod that is found in the cladding range from 0 $96 \%$. A single sample of cladding from fuel that had undergone the tritium pretreatment operation was analyzed as part of the Coupled End-To-End (CETE) project, and no tritium was detected in the cladding. This single data point was not a definitive test, but the results warranted additional investigation since it indicated that tritium pretreatment could potentially eliminate the presence of tritium in the zirconium recycle step. The present study was undertaken to understand how tritium pretreatment at standard air 
tritium pretreatment conditions $\left(480-600^{\circ} \mathrm{C}\right)$ and slightly higher affects the tritium content in the Zircaloy ${ }^{\circledR}$ cladding and the extent to which the tritium content could be reduced with modest increases in the tritium pretreatment temperature. Scoping tests are being performed to determine the tritium content of pre- and post-tritium pretreated cladding

For the characterization of tritium content in irradiated cladding, Carbolite Combustion tube furnace, Model MTT 12/38/850 was used. The furnace can operate at a maximum combustion zone temperature of $1200{ }^{\circ} \mathrm{C}$ and utilizes a copper metal catalyst in a separate heated zone for conversion of tritium gas to water for trapping. The sample carrier gas consisted of a 50:50 mixture of oxygen and nitrogen, and a $100 \%$ oxygen gas flow was used for the catalyst zone. Three bubblers containing $\sim 60 \mathrm{~mL}$ of deionized (DI) water each were connected in series to the outlet of the furnace. The first two bubblers were routinely sampled during the tests, and the third bubbler only sampled at the end of the test. The experimental system is shown schematically in Figure 15.

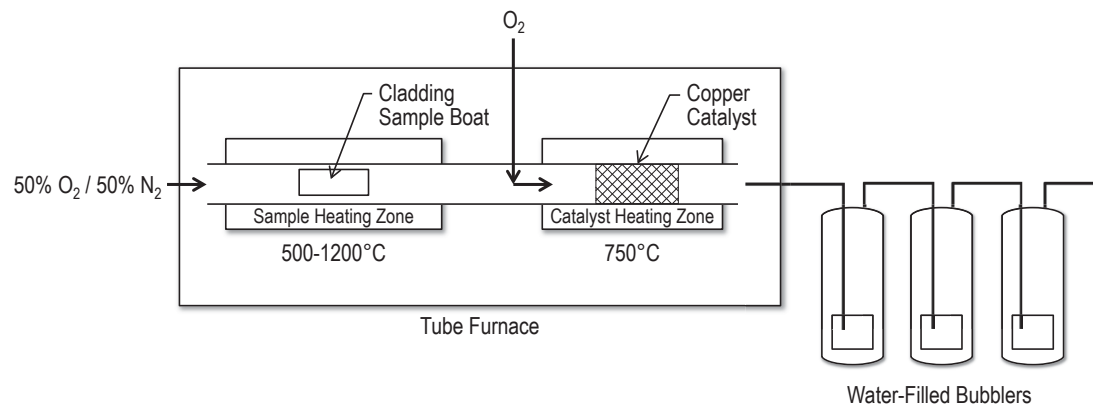

Figure 15. Schematic of experimental test system

Three rings of cladding were tested in this study: two Surry-2 rings and a ring of H.B Robinson cladding. One segment from each ring (approximately $1 / 3$ of the ring) of cladding received no simulated tritium pretreatment; it was heated to $1,100-1,200{ }^{\circ} \mathrm{C}$ to oxidize the zirconium and release all of the tritium in the cladding sample. The tritium content of the two Surry-2 cladding segments was measured to be 239 and $228 \mu \mathrm{Ci} / \mathrm{g}$ for an average of $234 \mu \mathrm{Ci} / \mathrm{g}$. The tritium content of the H.B. Robinson cladding segment was measured to be $500 \mu \mathrm{Ci} / \mathrm{g}$.

The results of tests to simulate tritium pretreatment are summarized in Table 2. The table shows the amount of tritium released during the simulated tritium pretreatment condition $\left(500-700{ }^{\circ} \mathrm{C}\right.$ for $\left.24-96 \mathrm{~h}\right)$, the amount of tritium released during the subsequent heating at $1,100-1,200{ }^{\circ} \mathrm{C}$ which oxidized the remaining tritium in the sample, the total amount of tritium, and the percentage of tritium released during the simulated pretreatment step. The tritium pretreatment conditions of 500 and $700^{\circ} \mathrm{C}$ for $24 \mathrm{~h}$ removed $\sim 0.2$ and $9 \%$ of the tritium in the Surry-2 cladding, respectively. Similarly, heating H.B. Robinson cladding at $700{ }^{\circ} \mathrm{C}$ for $24 \mathrm{~h}$ removed $\sim 11 \%$ of the tritium. Increasing the time the samples were exposed to heating at $700{ }^{\circ} \mathrm{C}$ from $24 \mathrm{~h}$ to $96 \mathrm{~h}$, significantly increased to amount of tritium removed during the pretreatment step: $99.4 \%$ and $99.0 \%$ for the Surry-2 and H.B. Robinson claddings, respectively. Only 3\% of the tritium was removed from a Surry-2 sample when it was heated to only $600{ }^{\circ} \mathrm{C}$ for $96 \mathrm{~h}$.

These data indicate that the amount of tritium released from tritium pretreatment systems will be dependent on both the operating temperature and length of time in the pretreatment system. Under certain conditions, a significant fraction of the tritium could remain bound in the cladding and would need to be considered in any subsequent processing of the cladding to recover/recycle the zirconium. 
Table 2. Results from the determination of tritium in reactor cladding test specimens

\begin{tabular}{|c|c|c|c|c|c|}
\hline $\begin{array}{c}\text { Cladding } \\
\text { sample }\end{array}$ & $\begin{array}{c}\text { Simulated tritium } \\
\text { pretreatment } \\
\text { condition } \\
\left({ }^{\circ} \mathrm{C}\right)\end{array}$ & $\begin{array}{c}\text { Tritium released } \\
\text { during simulated } \\
\text { tritium } \\
\text { pretreatment } \\
(\mu \mathrm{Ci} / \mathrm{g})\end{array}$ & $\begin{array}{c}\text { Tritium in cladding } \\
\text { sample during } \\
\text { oxidation }(\mu \mathrm{Ci} / \mathrm{g})\end{array}$ & $\begin{array}{c}\text { Total tritium } \\
\text { recovered from } \\
\text { cladding sample } \\
(\mu \mathrm{Ci} / \mathrm{g})\end{array}$ & $\begin{array}{c}\text { Tritium removed } \\
\text { during simulated } \\
\text { tritium } \\
\text { pretreatment } \\
(\%)\end{array}$ \\
\hline $\begin{array}{c}\text { Surry-2 } \\
\text { Ring } 1\end{array}$ & 500 for $24 \mathrm{~h}$ & 0.55 & 247.2 & 247.7 & 0.2 \\
\hline $\begin{array}{c}\text { Surry-2 } \\
\text { Ring } 1\end{array}$ & 700 for $24 \mathrm{~h}$ & 19.2 & 201.7 & 220.9 & 8.7 \\
\hline $\begin{array}{c}\text { H.B. } \\
\text { Robinson }\end{array}$ & 700 for $24 \mathrm{~h}$ & 59.9 & 478.0 & 537.9 & 11.1 \\
\hline $\begin{array}{c}\text { Surry-2 } \\
\text { Ring 2 }\end{array}$ & 600 for $96 \mathrm{~h}$ & 7.1 & 230.8 & 237.9 & 3.0 \\
\hline $\begin{array}{c}\text { Surry-2 } \\
\text { Ring 2 }\end{array}$ & 700 for $96 \mathrm{~h}$ & 193.3 & 1.2 & 64.5 & 99.4 \\
\hline $\begin{array}{c}\text { H.B. } \\
\text { Robinson }\end{array}$ & 700 for $96 \mathrm{~h}$ & 631.8 & 6.7 & 638.5 & 99.0 \\
\hline
\end{tabular}

a. Oxidation of cladding at $1,100-1,200{ }^{\circ} \mathrm{C}$ to release residual tritium.

\title{
Publications
}

Robinson, Sharon M., Marc R. Chattin, Joseph M. Giaquinto, and Robert T. Jubin. 2015, "Evaluation of Tritium Content and Release from Pressurized Water Reactor Fuel Cladding," FCRD-MRWFD-2015000617, ORNL/SPR-2015/42.

\subsection{Lab-Scale Testing of Reference Processes (IV)}

\author{
G. J. Lumetta, A. J. Casella, and L. Lin, PNNL
}

\section{Introduction}

Separating the lanthanide fission product elements from the minor actinide elements (Am and $\mathrm{Cm}$ ) at an industrial scale is one of the most daunting challenges to fully closing the nuclear fuel cycle. ${ }^{1,2}$ Achieving this separation is necessary if the minor actinide elements are to be converted to short-lived or stable isotopes in fast reactors because of the relatively large neutron cross sections of the light lanthanide elements. Nearly all methods under investigation for separating the minor actinides from the lanthanides exploit the apparent slightly softer character of the trivalent actinide ions compared to the trivalent lanthanide ions. Thus ligands containing nitrogen or sulfur donors have received considerable attention. ${ }^{1,3,4,5}$ The ligands can be deployed in either the organic phase (as extractant) or in the aqueous phase (as an actinide-holdback reagent) in liquid-liquid extraction systems.

The Full Recycle Case Study that was performed in FY-13, and updated in FY-14 and FY-15, identified the Trivalent Actinide-Lanthanide Separations by Phosphorus-reagent Extraction from Aqueous Complexes (TALSPEAK) process ${ }^{6,7}$ as the reference process for separating the lanthanides from the minor actinides. The TALSPEAK process has previously been demonstrated at a laboratory scale to separate the minor actinides from the lanthanides. ${ }^{8}$ However, the Case Study also identified a variation of the TALSPEAK process for potential near-term insertion into the fuel recycle flowsheet. In this variant of TALSPEAK, the traditionally used extractant, di-(2-ethylhexyl)phosphoric acid (HDEHP; Figure 16), is replaced with 2-ethylhexylphosphonic acid mono-2-ethylhexyl ester (HEH[EHP]; Figure 16). ${ }^{9}$ This 
variant of the TALSPEAK process is now referred to as Advanced TALSPEAK. Batch distribution measurements conducted at PNNL in FY-13 showed that Advanced TALSPEAK should be much more robust than conventional TALSPEAK with respect to variations in the aqueous phase $\mathrm{pH}$. However, single-stage 2-cm contactor tests indicated the extraction of the lanthanide elements $\mathrm{Sm}, \mathrm{Eu}$, and $\mathrm{Gd}$ was slow in the Advanced TALSPEAK system. The slow extraction of these elements led to ineffective separation from the trivalent actinide elements. ${ }^{10}$ For this reason, work in FY-15 focused on exploring modifications to the Advanced TALSPEAK chemistry to increase the extraction rates for Sm, Eu, and Gd.

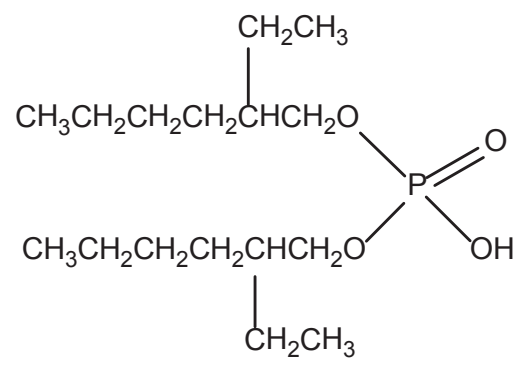

HDEHP

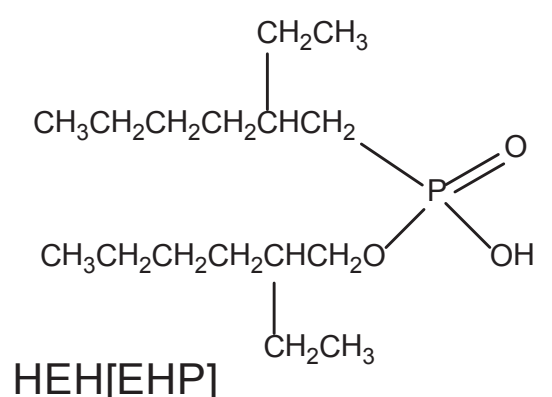

$\mathrm{HEH}[\mathrm{EHP}]$

Figure 16. Chemical structures of the TALSPEAK (HDEHP) and Advanced TALSPEAK (HEH[EHP]) extractants.

\section{Process Concept}

The Advanced TALSPEAK system operates by extracting the lanthanide ions into an aliphatic hydrocarbon phase containing HEH[EHP]. A polyaminocarboxylate ligand is added to the aqueous phase to suppress the extraction of Am and $\mathrm{Cm}$ relative to the lanthanides. In this case, the soft amine donor groups in the polyaminocarboxylate ligand preferentially bind the softer actinide ions, keeping them in the aqueous phase. Batch distribution measurements conducted in FY-13 led to the choice of N-(2hydroxyethyl)ethylenediamine-N,N',N'-triacetic acid (HEDTA; Figure 17) as the preferred polyaminocarboxylate ligand to use as the actinide-holdback reagent in the Advanced TALSPEAK system. Citric acid is also added to the aqueous phase to control the solution $\mathrm{pH}$ (Figure 17). However, a major focus of the FY-15 research was devoted to exploring other aqueous phase compositions, including changing the aminocarboxylate actinide holdback ligand, and the buffer.
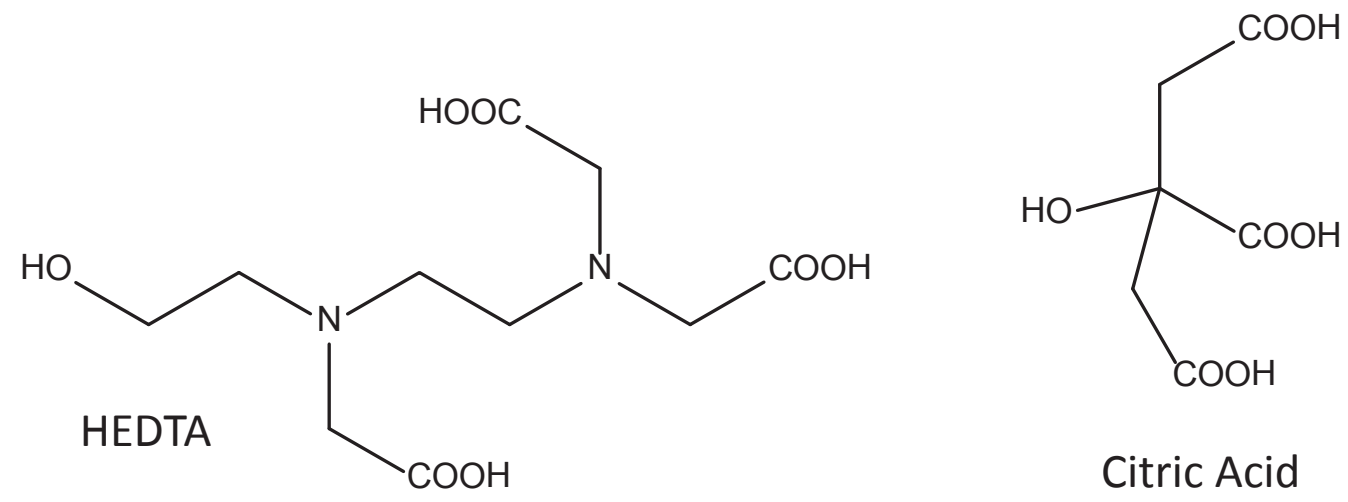

\section{Citric Acid}

Figure 17. Chemical structures of the aqueous-phase complexant and buffers used in the Advanced TALSPEAK system.

\section{Objectives}

The objective of this work is to generate the data required for designing and testing the Advanced TALSPEAK flowsheet. Batch distribution measurements indicated the feasibility of the concept from a 
thermodynamic point of view, but single-stage flow experiments using a 2-cm centrifugal contactor indicated inefficient separation of $\mathrm{Sm}, \mathrm{Eu}$, and $\mathrm{Gd}$ from $\mathrm{Am}$. The objective of the FY-15 was to overcome the slow extraction rates for $\mathrm{Sm}, \mathrm{Eu}$, and $\mathrm{Gd}$ so that an effective separation of the lanthanides from the trivalent actinides can be achieved under dynamic flow conditions.

\section{Accomplishments}

A number of approaches to modifying the Advanced TALSPEAK aqueous phase were investigated in an attempt to improve the Sm, Eu, and Gd extraction rates. These included (1) modifying the citrate concentration and $\mathrm{pH},(2)$ using a malonate buffer, (3) using a more lipophilic homolog of lactic acid as buffer, and (4) changing the actinide holdback complexant. Of these approaches, the most promising were modifying the citrate buffer and using nitrilotriacetic acid (NTA) as the actinide holdback complexant.

The influence of the citrate concentration on the $\mathrm{Eu}(\mathrm{III})$ extraction rate was investigated by determining the Eu distribution ratio $(\mathrm{DEu}=$ concentration of $\mathrm{Eu}$ in the organic phase divided by the concentration in the aqueous phase) as a function of time for extraction into $1.0 \mathrm{~mol} / \mathrm{L} \mathrm{HEH}[\mathrm{EHP}]$ from aqueous solutions containing $0.125 \mathrm{~mol} / \mathrm{L}$ HEDTA and varied citrate concentration at $\mathrm{pH}=3.1$. Generally, the DEu values decrease with increasing citrate concentration, as might be expected simply based on increased complexation of $\mathrm{Eu}$ (III) ions by citrate in the aqueous phase. This is especially evident under the equilibrium conditions achieved after $5 \mathrm{~min}$ of mixing. The data suggest that in the 0.4 to $0.6 \mathrm{~mol} / \mathrm{L}$ citrate range, the DEu values are near or slightly above 1 at $21 \mathrm{sec}$ of mixing. For this reason, the 0.6 $\mathrm{mol} / \mathrm{L}$ citrate condition was explored further.

The extraction of Eu(III) from $0.6 \mathrm{~mol} / \mathrm{L}$ citrate $+0.125 \mathrm{~mol} / \mathrm{L}$ HEDTA into $1.0 \mathrm{~mol} / \mathrm{L}$ HEH[EHP] was investigated at several different $\mathrm{pH}$ conditions. The extraction rates tended to decrease as the $\mathrm{pH}$ was increased. Again, this was likely because of increased binding of Eu(III) by HEDTA and citrate as the carboxylate groups on these ligands become increasingly deprotonated with increasing $\mathrm{pH}$. The data suggested the effective $D_{E u}$ value that would be expected in a 2-cm centrifugal contactor would be approximately 4.9 for the $\mathrm{pH} 2.6$ condition. Based on this promising result, another test was performed under these conditions with additional lanthanides present.

Figure 18a presents the extraction kinetic data for extraction of $\mathrm{La}, \mathrm{Ce}, \mathrm{Pr}, \mathrm{Nd}, \mathrm{Sm}, \mathrm{Eu}$, and Gd from an aqueous solution consisting of $0.125 \mathrm{~mol} / \mathrm{L}$ HEDTA in a $0.6 \mathrm{~mol} / \mathrm{L}$ citrate buffer at $\mathrm{pH} 2.6$. Figure $18 \mathrm{~b}$ compares the same data for $\mathrm{Sm}, \mathrm{Eu}$, and $\mathrm{Gd}$ to the analogous data obtained when the aqueous phase was $0.125 \mathrm{~mol} / \mathrm{L}$ HEDTA in a $0.2 \mathrm{~mol} / \mathrm{L}$ citrate buffer at $\mathrm{pH} 3.1 .^{[10]}$ The lanthanide extraction rates are much improved in the $0.6 \mathrm{~mol} / \mathrm{L}$ citrate system compared to the $0.2 \mathrm{~mol} / \mathrm{L}$ citrate $/ \mathrm{pH} 3.1$ system, although the equilibrium $D$ values for the lighter lanthanides are somewhat lower at the higher citrate concentration. Despite the lower $D$ values, it should be possible to operate the Advanced TALSPEAK system in centrifugal contactors with an aqueous phase consisting of $0.125 \mathrm{~mol} / \mathrm{L}$ HEDTA $+0.6 \mathrm{~mol} / \mathrm{L}$ citrate buffer at $\mathrm{pH} 2.6$, since the $\operatorname{Ln} D$ values are all projected to be $>2$ in the contactor system (based on the 20$\mathrm{sec}$ vortex mixing data points). Centrifugal contactor tests are needed to verify this conclusion. 

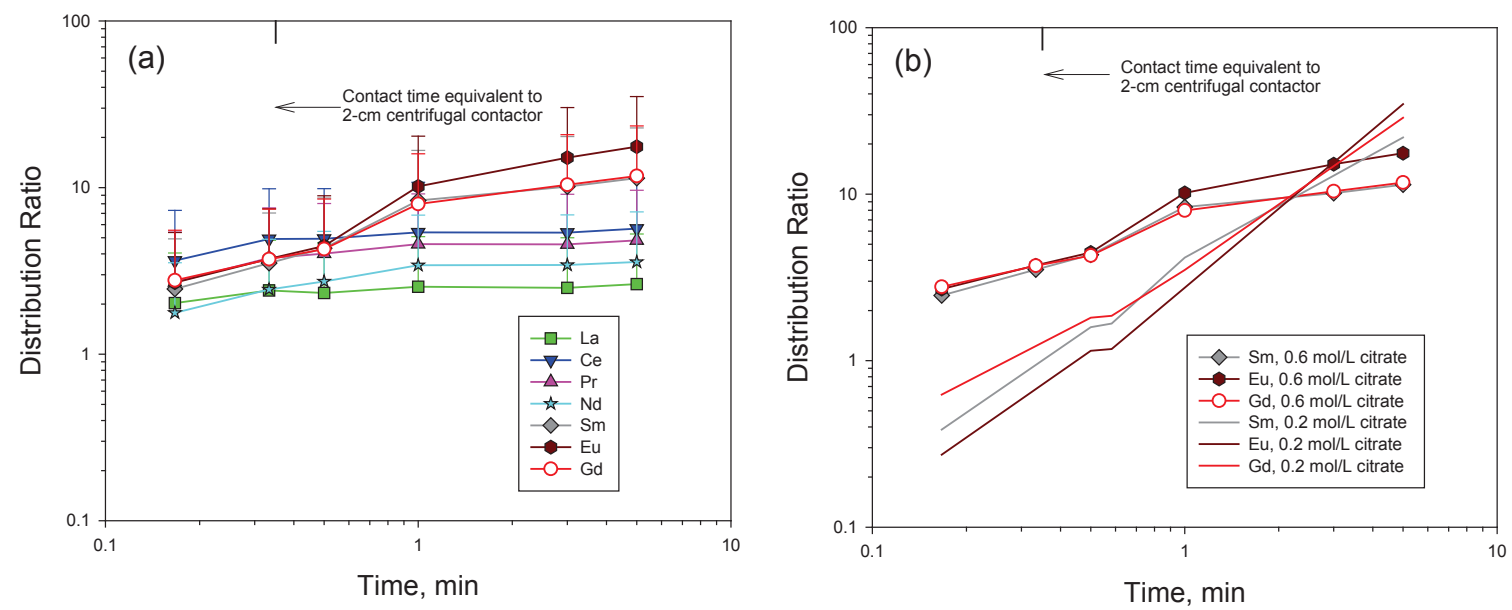

Figure 18. a) Extraction of $\operatorname{Ln}(\mathrm{III})$ from $0.6 \mathrm{~mol} / \mathrm{L}$ citrate $+0.125 \mathrm{~mol} / \mathrm{L}$ HEDTA at $\mathrm{pH}=2.6$ into $1.0 \mathrm{~mol} / \mathrm{L} \mathrm{HEH}[\mathrm{EHP}] / n$ dodecane. b) Comparison of the $\mathrm{Sm}$, Eu, and Gd extraction data for the $0.6 \mathrm{~mol} / \mathrm{L}$ citrate $+0.125 \mathrm{~mol} / \mathrm{L}$ HEDTA at pH $=2.6$ system to those for the $0.2 \mathrm{~mol} / \mathrm{L}$ citrate $+0.125 \mathrm{~mol} / \mathrm{L}$ HEDTA at $\mathrm{pH}=3.1$ system.

An alternative approach to improving the lanthanide extraction rates is to consider different aminocarboxylate ligands as the actinide holdback reagent. The slow rate of extraction of $\mathrm{Sm}, \mathrm{Eu}$, and $\mathrm{Gd}$ in the Advanced TALSPEAK system is presumably due to relatively strong complexation of the trivalent ions of these elements by HEDTA in the aqueous phase. Decomplexation of the metal ion from HEDTA must occur before it can be transferred to the organic phase through complexation by HEH[EHP]. Therefore, it was hypothesized that the problem of slow extraction rates can be alleviated by using a weaker complexant as the actinide holdback reagent in the aqueous phase.

Four alternative complexants were considered: (1) $N$-(2-hydroxyethyl)iminodiacetic acid (HIDA), (2) nitrilotriacetic acid (NTA), (3) 1,3-diaminopropane-N,N,N',N'-tetraacetic acid (DPTA), and (4) 1,3diamino-2-hydroxypropane-N,N,N',N'-tetraacetic acid (HDPTA). Aqueous solutions were prepared containing $0.125 \mathrm{~mol} / \mathrm{L}$ of the candidate actinide complexant, $0.2 \mathrm{~mol} / \mathrm{L}$ citrate, and $16 \mathrm{mmol} / \mathrm{L} \mathrm{Eu}(\mathrm{III})$; the $\mathrm{pH}$ of these solutions was adjusted to $\sim 3.1$. These solutions were contacted with $1.0 \mathrm{~mol} / \mathrm{L} \mathrm{HEH}[\mathrm{EHP}]$ and the $\mathrm{Eu}(\mathrm{III})$ distribution ratio was measured at designated time points. As expected based on the relatively low complexing strength of HIDA, $\mathrm{Eu}(\mathrm{III})$ was rapidly extracted from the solution containing that ligand. NTA, with binding strength between those of HIDA and HEDTA led to Eu(III) extraction behavior that was intermediate between those of HIDA and HEDTA. The Eu(III) extraction behavior in the presence of DPTA or HDPTA was similar to that with HIDA present; that is, Eu(III) was rapidly extracted. Although this result was initially surprising based on published metal ion binding constants, it was easily explained when the ligand protonation constants were taken into account.

Using NTA as the actinide holdback reagent in the Advanced TALSPEAK system was investigated further. An experiment was performed in which a suite of lanthanide elements ( $\mathrm{La}, \mathrm{Ce}, \mathrm{Pr}, \mathrm{Nd}, \mathrm{Sm}, \mathrm{Eu}$, and $\mathrm{Gd}$ ) was added to an aqueous solution consisting of $0.25 \mathrm{~mol} / \mathrm{L} \mathrm{NTA}+0.2 \mathrm{~mol} / \mathrm{L}$ citric acid at $\mathrm{pH}$ 3.11. This aqueous solution was then contacted with $1.0 \mathrm{~mol} / \mathrm{L} \mathrm{HEH}[\mathrm{EHP}] / n$-dodecane and the metal ion distribution ratios were determined as a function of time (Figure 19). Very rapid extraction of the lanthanides was achieved, with equilibrium being reached in $10 \mathrm{sec}$ of vortex mixing (with the possible exception of Gd). For the first minute of contact, the $D_{A m}$ values were $\sim 0.4$. Although increased Am extraction was observed at 5 and 30 min of vortex mixing, the $D_{A m}$ values still remained below 1 . Using the 20 -sec vortex mixing time to project the expected single-stage 2 -cm contactor performance, ${ }^{[10]} \mathrm{a}$ minimum separation factor $\left(\mathrm{SF}=D_{N d} / D_{A m}\right.$ ) of 20 would be expected under these conditions. Thus $0.25 \mathrm{~mol} / \mathrm{L} \mathrm{NTA}, 0.2 \mathrm{~mol} / \mathrm{L}$ citrate, and $\mathrm{pH} 3.1$ appeared to be a promising option as the aqueous phase composition in the Advanced TALSPEAK system. 
A 2-cm centrifugal contactor experiment was performed to determine the effective lanthanide and Am $D$ values achieved in a single stage, with the aqueous phase formulated as $0.25 \mathrm{~mol} / \mathrm{L} \mathrm{NTA}$ in a $0.2 \mathrm{~mol} / \mathrm{L}$ citrate buffer at $\mathrm{pH}$ 3.1. In contrast to what was observed in the previous Advanced TALSPEAK system (i.e., $0.125 \mathrm{~mol} / \mathrm{L}$ HEDTA $+0.2 \mathrm{~mol} / \mathrm{L}$ citrate at $\mathrm{pH} 3.1$ ), the lanthanide $D$ values were all $>1$ for the 0.25 $\mathrm{mol} / \mathrm{L}$ NTA in a $0.2 \mathrm{~mol} / \mathrm{L}$ citrate buffer system. Furthermore, the Am $D$ value was $<1(0.55)$. Thus in principle, the NTA system should be suitable for separating trivalent actinides from the lanthanides. However, the minimum separation factor achieved was less than expected based on the data in Figure 19. The batch data in Figure 19 suggest the minimum separation factor should be approximately 20 and defined by the $\mathrm{Nd} / \mathrm{Am}$ couple, whereas the results of the contactor test indicated the minimum separation factor to be 7, defined by the Gd/Am couple. The result of the NTA experiment is promising, but further optimization of the system is warranted.

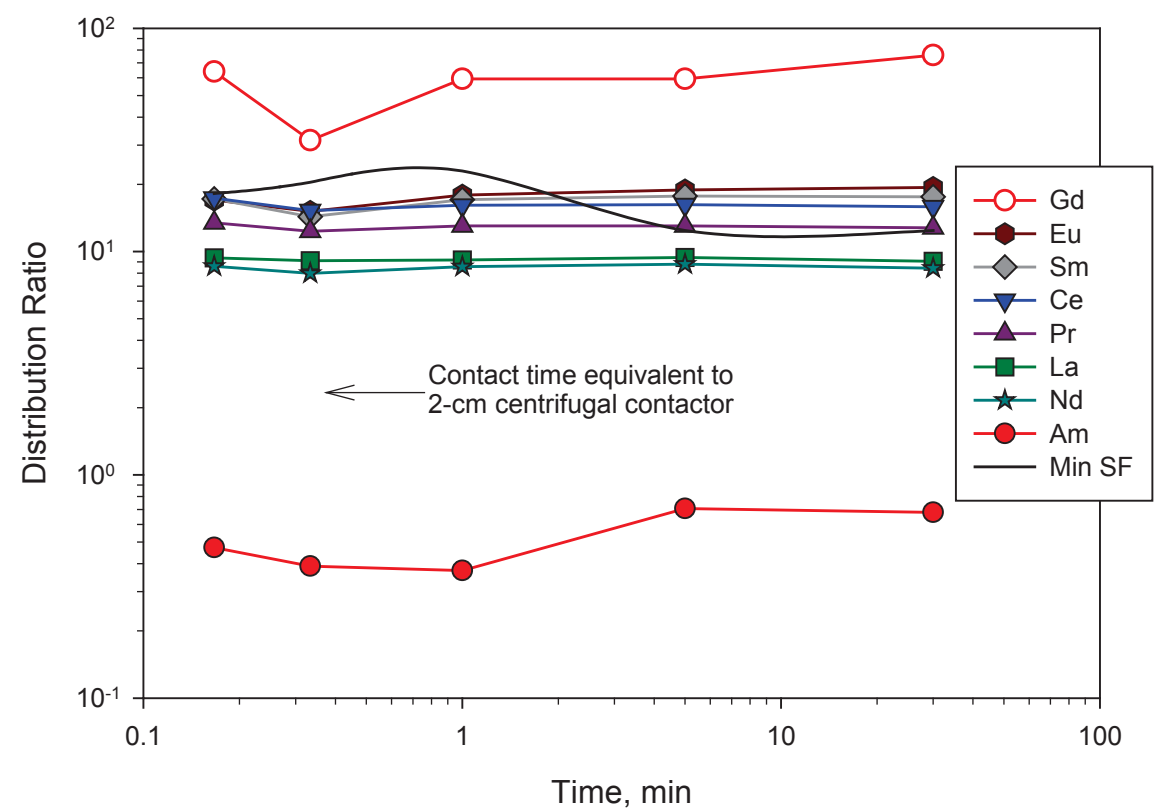

Figure 19. Time dependence of $\mathrm{Am}$ (III) and $\mathrm{Ln}$ (III) extraction from aqueous solution containing $0.25 \mathrm{~mol} / \mathrm{L} \mathrm{NTA}$ and $0.2 \mathrm{~mol} / \mathrm{L}$ citrate into $1 \mathrm{~mol} / \mathrm{L} \mathrm{HEH}[\mathrm{EHP}]$ in $\mathrm{n}$-dodecane. The initial $\mathrm{pH}$ of the aqueous phase was 3.11.

\section{Conclusions}

In this work, we studied the process chemistry related to the Advanced TALSPEAK system with a focus on modifying the aqueous phase chemistry to improve the rate of extraction of the lanthanide elements, especially $\mathrm{Sm}, \mathrm{Eu}$, and $\mathrm{Gd}$. Under the conditions studied here, switching from a citrate to a malonate buffer did not appear to offer significant improvement in the extraction kinetics. Likewise, no improvement was seen with higher homologs of lactic acid as the buffering medium. Increasing the citrate concentration in the buffer from 0.2 to $0.6 \mathrm{~mol} / \mathrm{L}$ and lowering the $\mathrm{pH}$ to 2.6 (still using HEDTA as the minor actinide stripping complexant) resulted in improved extraction rates, as did switching the actinide holdback reagent to $0.25 \mathrm{~mol} / \mathrm{L}$ NTA in a $\mathrm{pH} 3.1$ citrate buffer. The latter system was tested in a singlestage centrifugal contactor, with promising results; however, some optimization of the NTA system is still needed.

\section{References}

1. M. J. Hudson, L. M. Harwood, D. M. Laventine, and F. W. Lewis, "Use of Soft Heterocyclic NDonor Ligands to Separate Actinides and Lanthanides," Inorganic Chemistry 52, 2013: 3414-3428.

2. T. A. Todd, "Separations Research for Advanced Nuclear Fuel Cycles," Nuclear Energy and the 
Environment; C. M. Wai, B. J. Mincher, Eds; American Chemical Society, 2010, 13-18.

3. C. Ekberg, A. Fermvik, T. Retegan, G. Skarnemark, M. R. S. Foreman, M. J. Hudson, S. Englund, Nilsson, M., "An overview and historical look back at the solvent extraction using nitrogen donor ligands to extract and separate An(III) from Ln(III)," Radiochimica Acta 96, 2008: 225-233.

4. X. Wang, Y. Zhu, R. Jiao, 2001, "Separation of Am from Macro Amount of Lanthanides by a Countercurrent Multistage Extraction with Purified Cyanex 301 and TBP," Solvent Extraction and Ion Exchange 19, 2001: 1007-1015.

5. J. D. Law, D. R. Peterman, T. A. Todd, R. D. Tillotson, 2006, "Separation of trivalent actinides from lanthanides in an acetate buffer solution using Cyanex 301," Radiochimica Acta 94, 2006: 261-266.

6. B. Weaver and F. A. Kappelmann, 1968, "Preferential Extraction of Lanthanides Over Trivalent Actinides by Monoacidic Organophosphates from Carboxylic Acids and from Mixtures of Carboxylic Acids and Aminopolyacetic Acids," Journal of Inorganic and Nuclear Chemistry 30, 1968: 263-272.

7. M. Nilsson and K. L. Nash, "A Review of the Development and Operational Characteristics of the TALSPEAK Process," Solvent Extraction and Ion Exchange 25, 2007: 665-701.

8. M. C. Regalbuto, 2011, "Alternative separation and extraction: UREX+ processes for actinide and targeted fission product recovery," Advanced Separation Techniques for Nuclear Fuel Reprocessing and Radioactive Waste Treatment, K. L. Nash, G. J. Lumetta, Eds; Woodhead Publishing: Oxford, 2011, 176-200.

9. J. C. Braley, T. S. Grimes, K. L. Nash, “Alternatives to HDEHP and DTPA for Simplified TALSPEAK Separations," Industrial \& Engineering Chemistry Research 51, 2012: 629-638.

10. G. J. Lumetta, A. J. Casella, B. M. Rapko, T. G. Levitskaia, N. K. Pence, J. C. Carter, C. M. Niver, M. R. Smoot, "An Advanced TALSPEAK Concept using 2-Ethylhexylphosphonic Acid Mono-2Ethylhexyl Ester as the Extractant," Solvent Extraction and Ion Exchange 33, 2015: 211-223. 
This page intentionally left blank. 


\section{Sigma Team for Advanced Actinide Recycle}


This page intentionally left blank. 


\section{SIGMA TEAM FOR ADVANCED ACTINIDE RECYCLE}

\subsection{Electrochemical Oxidation of Americium}

\section{Dares and T. J. Meyer, UNC-CH; B. J. Mincher, INL}

The initial results on the electrochemical oxidation of americium reported in FY-14 ${ }^{1}$ and have been confirmed for this first ever oxidation of Am(III) at an electrode in a noncomplexing acidic aqueous medium. ${ }^{2}$ If an electrochemical approach to generating the higher oxidation states of Am in nitric acid media can be made practical, it would enable subsequent americium separations while avoiding the addition of chemical oxidants and corresponding increase in HLW mass. Challenges include understanding and controlling the molecular redox processes that occur at the electrode surface and stabilizing the resulting $\mathrm{Am}(\mathrm{V})$ and $\mathrm{Am}(\mathrm{VI})$ oxidation products to the thermodynamically favorable parasitic oxidation of water.

The electrolysis makes use of a high surface-area, fluoride-doped tin oxide electrode coated with nanoparticles of tin-doped indium oxide ( $n$ ITO). Experiments were designed to test the hypothesis that binding of Am(III) at the electrode surface facilitates electron transfer to the electrode. Figure 20 illustrates the attachment of an americium-selective terpyridine ligand to the $n$ ITO surface. At an anodic potential of $2.25 \mathrm{~V}$ vs $\mathrm{Ag} / \mathrm{AgCl}, \mathrm{Am}(\mathrm{III})$ at $84 \mu \mathrm{M}$ in $0.1 \mathrm{M}$ nitric acid and $0.95 \mathrm{M}$ sodium nitrate oxidizes over $13 \mathrm{~h}$ to $36 \% \mathrm{Am}(\mathrm{VI})$ and $54 \% \mathrm{Am}(\mathrm{V})$ as observed by electronic spectroscopy (Figure 21). The yield of Am(VI) improves to 53\% with $40 \% \mathrm{Am}(\mathrm{V})$ at $2.7 \mathrm{~V}$ and $1.84 \mathrm{mM} \mathrm{Am}(\mathrm{III})$ after $7 \mathrm{~h}$, the highest yield observed to date. Control electrolysis at 1.8-2.7 V for $n$ ITO without attached ligands gives no oxidation of Am(III); interestingly, the underivatized $n$ ITO degrades after an hour of oxidizing conditions, while the derivatized $n$ ITO is more robust. In view of the control results, the observed twoelectron oxidation of Am(III) is thought to support the hypothesis of facilitated electron transfer by coordination of Am(III) to the surface-bound terpyridine ligand. Systematic investigations will be carried out in the future to understand conditions that lead to electrochemical oxidation of Am(III) to Am(V) or $\mathrm{Am}(\mathrm{VI})$ with subsequent separation from a relevant waste composition.

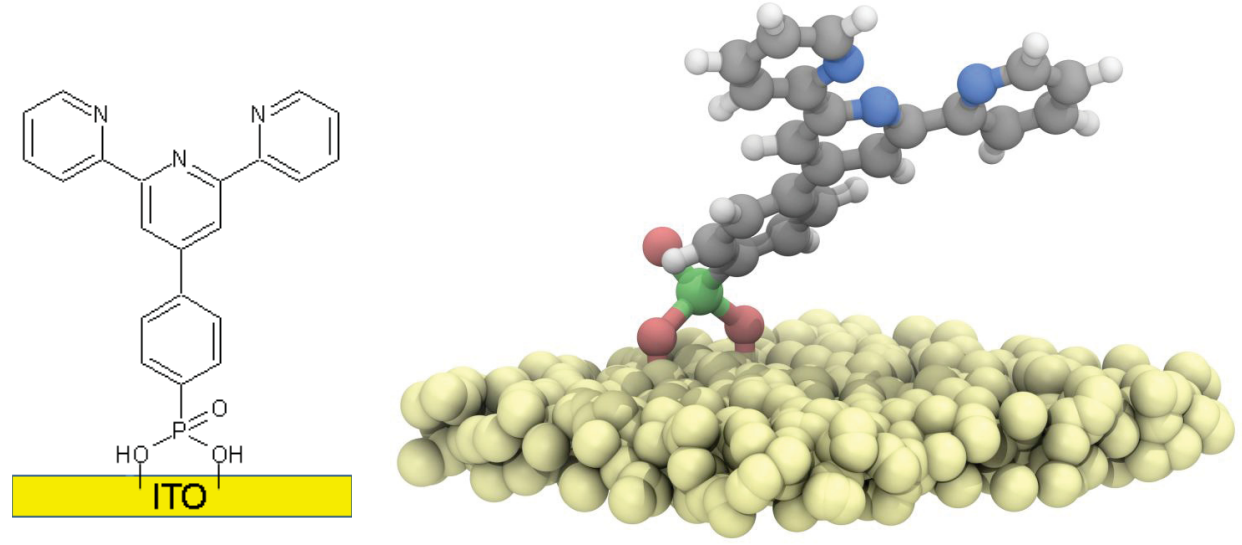

Figure 20. A terpyridine ligand bound to an indium tin oxide particle on an electrode surface via a phosphonic acid linker. 

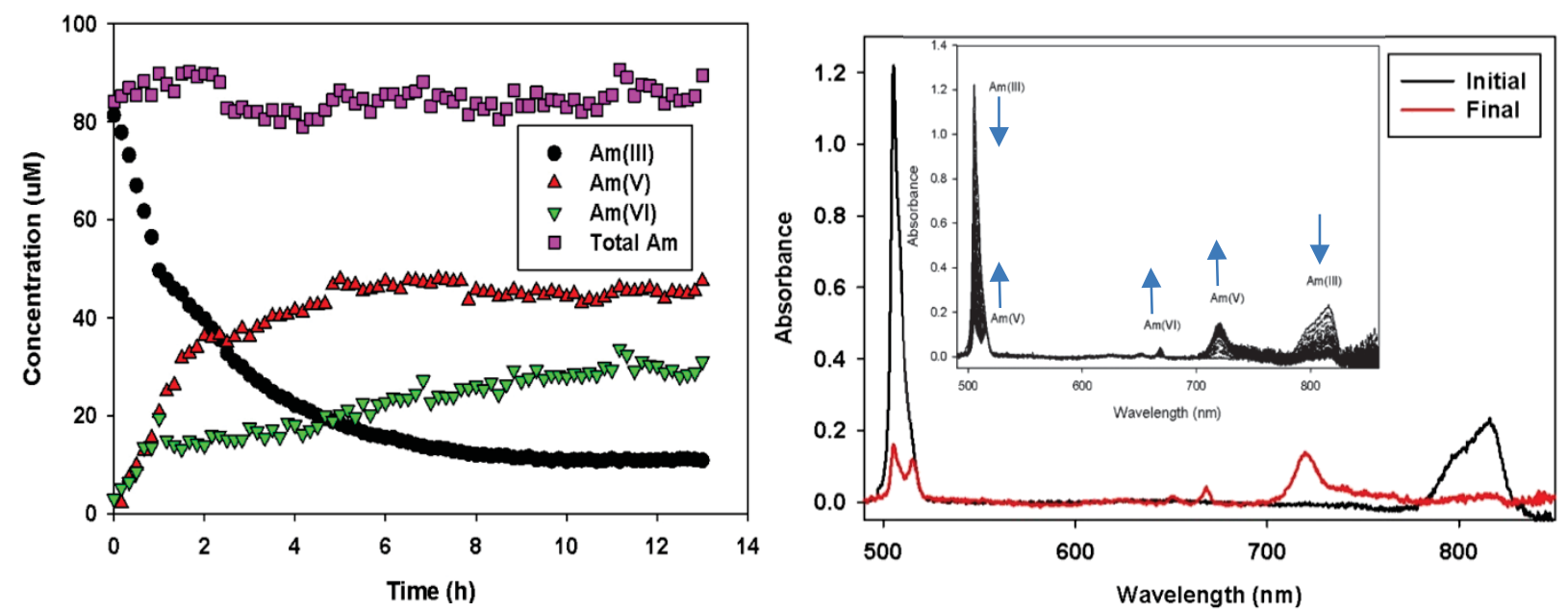

Figure 21. Concentration of Am species in solution (left) as measured by visible spectroscopy in a $50 \mathrm{~cm}$ waveguide (right) over time during a controlled-potential electrolysis of initially $84 \mu \mathrm{M} \mathrm{Am}$ (III) at $2.25 \mathrm{~V} \mathrm{vs} \mathrm{Ag/AgCl}$. The working electrode was a ligand-modified high-surface-area $n$ ITO, with a Pt foil counter electrode and a $\mathrm{Ag} / \mathrm{AgCl}$ wire reference electrode. The aqueous electrolyte was $0.1 \mathrm{M}$ nitric acid and $0.95 \mathrm{M}$ sodium nitrate. (Right) Initial and final electronic spectra measured in a $1 \mathrm{~cm}$ path-length cuvette and modeled with Gaussian functions.

\section{References}

1. C. J. Dares and T. J. Meyer, 2014, "Strategic Plan for Am Oxidation,” FCRD-SWF-2014-000422, Idaho National Laboratory, August 25, 2014.

2. C. J. Dares, A. M. Lapides, B. J. Mincher, and T. J. Meyer, 2015, "Electrochemical Oxidation of ${ }^{243} \mathrm{Am}(\mathrm{III})$ in Nitric acid by a Terpyridyl-Derivatized Electrode," Science, October 2015.

\subsection{Co-crystallization of Actinyl Nitrates}

\section{J. D. Burns and B. A. Moyer, ORNL}

The first ever co-crystallization of $\mathrm{Am}(\mathrm{VI})$ with $\mathrm{UO}_{2}\left(\mathrm{NO}_{3}\right)_{2} \cdot 6 \mathrm{H}_{2} \mathrm{O}$ has been achieved. The result opens the door to a new approach of used nuclear fuel recycling where the bulk of the $\mathrm{U}, \mathrm{Np}, \mathrm{Pu}$, and Am can all be removed from the waste stream together using a single technique without use of organic solvents. The hexavalent dioxo cations of $\mathrm{Np}, \mathrm{Pu}$, and $\mathrm{Am}$ have all been co-crystallized with $\mathrm{UO}_{2}\left(\mathrm{NO}_{3}\right)_{2} \cdot 6 \mathrm{H}_{2} \mathrm{O}$ in near proportion by a simple reduction in temperature, while the tri- and tetravalent states are only slightly removed from solution. In the co-crystallized form, the $\mathrm{Am}(\mathrm{VI})$ shows a much greater stability, with no reduction observed after 13 days, while in solution over $50 \%$ is reduced after only 10 days.

Americium(VI) proves to be stable in the presence of uranyl nitrate. A sample of Am(VI) was prepared with $\mathrm{NaBiO}_{3}$, and the spectrum was observed for 10 days (see Figure 22). For the first 66 h, no change was observed in the Am(VI) absorption band at $1000 \mathrm{~nm}$. After 10 days, roughly 53\% of the Am(VI) had become reduced to Am(III). Thus, under simple conditions using bismuthate as oxidant, Am(VI) is expected to persist long enough for subsequent co-crystallization steps. 


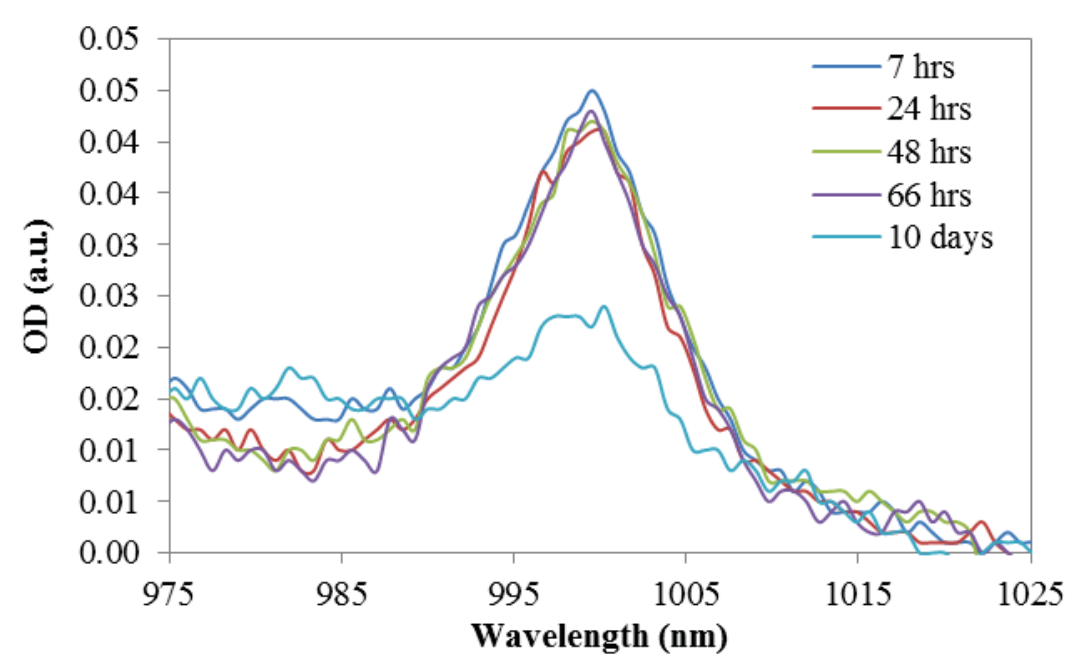

Figure 22. Spectra show Am(VI) stability in uranyl nitrate.

Co-crystallization was demonstrated with a freshly prepared $\mathrm{Am}(\mathrm{VI})$ sample consisting of $\left.0.84 \mathrm{M}^{\mathrm{U}} \mathrm{UO}_{2}{ }^{2+}\right]$ and $0.31 \mathrm{mM}[\mathrm{Am}(\mathrm{VI})]$. Once cooled to $3-4{ }^{\circ} \mathrm{C}$, the mother liquor was separated from the crystals by decantation rather than filtration to avoid any reduction due to the filters; however, it should be noted that decantation does not allow for a separation that is as complete as filtration. The electronic spectrum showed $32.0 \%$ of $\mathrm{UO}_{2}{ }^{2+}$ and $31.0 \%$ of the $\mathrm{Am}(\mathrm{VI})$ had been removed from solution. Gamma spectroscopy showed a similar amount of $34.9 \%$ of the ${ }^{243} \mathrm{Am}$ activity to be in the crystals.

Americium(VI) is stable in the crystals. Upon redissolution of the crystals after $13 \mathrm{~d}$, the spectra revealed $87 \%$ Am(VI) with $\sim 13 \%$ Am(III), consistent with the known incomplete separation of the crystals from the initial mother liquor. Whereas Am(VI) gradually reduces to $\mathrm{Am}(\mathrm{III})$ in the presence of $\mathrm{UO}_{2}\left(\mathrm{NO}_{3}\right)_{2}$, little or no reduction of the $\mathrm{Am}(\mathrm{VI})$ occurs in the crystals before dissolution. Crystals from $\mathrm{Np}(\mathrm{VI})$ and $\mathrm{Pu}(\mathrm{VI})$ co-crystallization experiments were also dissolved and showed similar results as the Am(VI).

Table 3 summarizes the results from separate co-crystallization experiments of U(VI) with Am(III), $\mathrm{Pu}(\mathrm{VI}), \mathrm{Np}(\mathrm{VI}), \mathrm{Pu}(\mathrm{VI})$, and $\mathrm{Am}(\mathrm{VI})$. For the lower valence ions $\mathrm{Am}(\mathrm{III})$ and $\mathrm{Pu}(\mathrm{VI})$, the relative amount removed from solution was roughly an order of magnitude lower than that of U(VI), while the An(VI) ions were removed in near proportion to the U(VI). These ratios indicate that the process of removing $\mathrm{An}(\mathrm{VI})$ ions from solution is a co-crystallization mechanism rather than just a co-precipitation mechanism, with a strong indication of the $\mathrm{An}(\mathrm{VI})$ dioxo cation replacing itself for a $\mathrm{UO}_{2}{ }^{2+}$ in the lattice structure of $\mathrm{UO}_{2}\left(\mathrm{NO}_{3}\right)_{2} \cdot 6 \mathrm{H}_{2} \mathrm{O}$.

\begin{tabular}{cccc}
\multicolumn{3}{c}{ Table 3. Ratios of the percent precipitation of different TRU species with respect to $\mathrm{UO}_{2}{ }^{2+}$} \\
\hline \multirow{2}{*}{ TRU Species } & \multicolumn{2}{c}{ \% Precipitation } & Ratio \\
& $\mathrm{U}$ & TRU & U:TRU \\
\hline $\mathrm{Am}(\mathrm{III})$ & 71.5 & 6.4 & 11.2 \\
$\mathrm{Pu}(\mathrm{IV})$ & 41.2 & 4.1 & 10.0 \\
$\mathrm{~Np}(\mathrm{VI})$ & 70.5 & 73.6 & 0.96 \\
& 82.9 & 82.0 & 1.01 \\
$\mathrm{Pu}(\mathrm{VI})$ & 29.9 & 28.0 & 1.07 \\
& 79.8 & 73.4 & 1.09 \\
$\mathrm{Am}(\mathrm{VI})$ & 32.0 & 31.0 & 1.03 \\
\hline
\end{tabular}




\subsection{ALSEP Process Development for An/Ln Separation}

\section{General Process Description}

\section{G. J. Lumetta, PNNL; A. V. Gelis, ANL}

The Actinide-Lanthanide SEParation (ALSEP) process concept ${ }^{1,2}$ has matured toward a bench-scale test in engineering equipment targeted for FY-17. ALSEP combines an acidic extractant with a neutral chelating extractant to yield a single hybrid process for recovering the trivalent MA elements Am and Cm from acidic HLW raffinate. The raffinate is assumed to be generated by an initial co-decontamination step that removes the bulk of the $\mathrm{U}, \mathrm{Pu}$, and $\mathrm{Np}$, as defined in a recent case study. ${ }^{3}$ This single process has the potential to replace two separate processes previously required to achieve this separation, thus significantly simplifying a closed fuel-cycle. The ALSEP approach involves (1) co-extracting the trivalent actinides (An) and lanthanides ( $\mathrm{Ln}),(2)$ selectively stripping the actinides from the loaded organic solvent, and (3) stripping the lanthanides and other fission products from the solvent. The neutral extractant serves to co-extract the trivalent An and Ln from nitric acid solutions, while the acidic extractant serves to hold the trivalent $\mathrm{Ln}$ in the organic phase while the An are selectively stripped into a carboxylate-buffered solution containing a polyaminocarboxylate complexant (Figure 23). Research has compared the effectiveness of combinations of various candidate extractants, complexants, and buffers. $^{1-2,4-7}$ Efforts in FY-15 dealt with overcoming the unwanted extraction of certain fission products and with improving the kinetics of stripping in the ALSEP process.
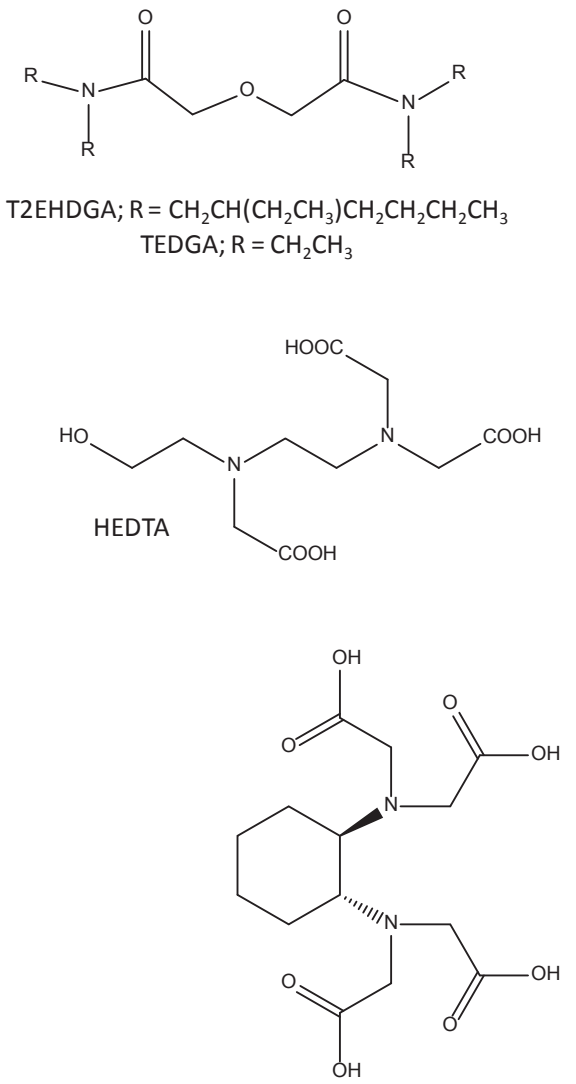
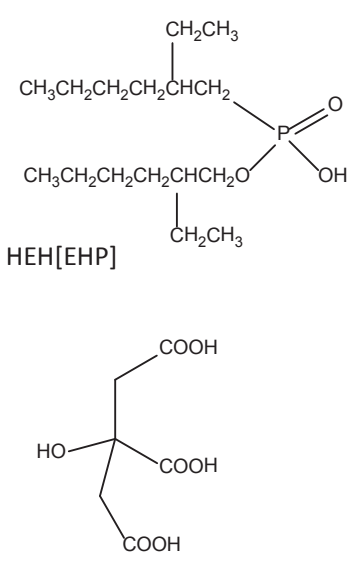

Citric Acid

CDTA

Figure 23. Component extractants and aqueous components used in the ALSEP process. 


\section{References}

1. A. V. Gelis and G. J. Lumetta, “Actinide Lanthanide Separation Process - ALSEP," Industrial \& Engineering Chemistry Research, 53, 2014: 1624-1631.

2. Lumetta, G. J., A. V. Gelis, J. C. Carter, C. M. Niver, and M. R. Smoot, "The Actinide-Lanthanide Separation Process," Solvent Extraction and Ion Exchange, 32(4), 2014: 333-347.

3. J. Law, N. Soelberg, T. A. Todd, J. Tripp, C. Pereira, M. Williamson, W. Ebert, R. T. Jubin, B. A. Moyer, J. Vienna, G. J. Lumetta, J. V. Crum, T. Rudisill, J. Bresee, C. Phillips, B. Willis, P. Murray, and S. Bader, 2013, "Separation and Waste Form Campaign Full Recycle Case Study," FCRD-SWF2013-000380 (Limited Distribution), INL.

4. G. J. Lumetta, D. Neiner, S. I. Sinkov, J. C. Carter, J. C. Braley, S. L. Latesky, A. V. Gelis, P. Tkac, G. F. Vandegrift, 2011, "Combining Neutral and Acidic Extractants for Recovering Transuranic Elements from Nuclear Fuel," Proceedings of the $19^{\text {th }}$ International Solvent Extraction Conference, L. F. Valenzuela, B. A. Moyer, Eds., Gecamin Ltd: Santiago, Chile; Paper No. 68.

5. G. J. Lumetta, A. V. Gelis, J. C. Braley, J. C. Carter, J. W. Pittman, M. G. Warner, G. F Vandegrift, "The TRUSPEAK Concept: Combining CMPO and HDEHP for Separating Trivalent Lanthanides from the Transuranic Elements," Solvent Extraction and Ion Exchange 31(3), 2013: 223-236.

6. J. C. Braley, G. J. Lumetta, J. C. Carter, "Combining CMPO and HEH[EHP] for Separating Trivalent Lanthanides from the Transuranic Elements," Solvent Extraction and Ion Exchange 31(6), 2013: $567-$ 577.

7. P. Tkac, G. F. Vandegrift, G. J. Lumetta, and A. V Gelis, "Study of the Interaction between HDEHP and CMPO and its Effect on the Extraction of Selected Lanthanides," Industrial \& Engineering Chemistry Research 51(31), 2012: 10433-10444.

\section{Progress in ALSEP Chemical Development}

\section{G. J. Lumetta, E. L. Campbell, A. J. Casella, G. Hall, T. G. Levitskaia, F. N. Smith, and G. Carter, PNNL}

Technical risks and uncertainties have been addressed in FY-15, including: (1) management of zirconium, (2) management of molybdenum, (3) unknown behavior of ruthenium, (4) unknown behavior of iron, and

(5) slow stripping of americium from the loaded ALSEP solvent. Efforts have focused on a solvent combination consisting of $0.05 \mathrm{M} N, N, N^{\prime}, N^{\prime}$-tetra(2-ethylhexyl)diglycolamide (T2EHDGA) combined with 0.75 M 2-ethylhexylphosphonic acid mono-2-ethylhexyl ester (HEH[EHP]) dissolved in $n$-dodecane.

Problems from three potentially problematic metals can likely be avoided. Zirconium is strongly extracted from nitric acid solutions into the ALSEP solvent. Addition of the complexing agent trans-1,2diaminocyclohexane- $N, N, N^{\prime}, N^{\prime}$-tetraacetic acid (CDTA) into the aqueous feed solution completely suppresses the $\mathrm{Zr}$ extraction, which can greatly simplify the downstream portions of the ALSEP flowsheet. For this reason, it is recommended that CDTA be added to the ALSEP feed. Ruthenium(III) is not appreciably extracted into the ALSEP solvent, so it is anticipated that Ru will easily be routed to the HLW raffinate from the ALSEP process. However, iron(III) is appreciably extracted from nitric acid solutions into the ALSEP solvent. Addition of CDTA reduces the Fe extraction somewhat, but the equilibrium Fe distribution ratios $(D)$ are well above 1 at nitric acid concentrations in the extraction operating range for ALSEP $\left(\geq 2 \mathrm{M} \mathrm{HNO}_{3}\right)$. Fortunately, the Fe extraction is slow. It therefore seems likely that little Fe extraction would occur during the short contact time experienced in a centrifugal contactor. If this proves to be the case, then Fe extraction will not pose a significant problem in implementing ALSEP. 
A mixer-settler and a 2-cm centrifugal contactor were directly compared for the Am stripping operation in the ALSEP system. This experiment suggested that, under the conditions examined, there is no advantage to using the mixer-settler rather than the centrifugal contactor. Other solutions to the slow Am stripping are required before an ALSEP demonstration can be achieved.

Certain fundamental aspects of the ALSEP chemistry are being explored. This includes investigating the extraction mechanism through systematic examination of Eu(III) extraction by T2EHDGA, and theoretical calculation of relevant Nd(III) absorption spectra. Measurement of the $\mathrm{Eu}(\mathrm{III})$ distribution ratio for extraction from $\mathrm{HNO}_{3}$ solution as a function of the organic-phase T2EHDGA concentration suggests that three T2EHDGA ligands coordinate to $\mathrm{Eu}(\mathrm{III})$ in the extracted species. However, the dependence of the $\mathrm{Eu}(\mathrm{III})$ distribution ratio on the $\mathrm{HNO}_{3}$ concentration is complex and requires further study. Progress is being made in applying time-dependent density functional theory calculations to interpretation of $\mathrm{Nd}$ absorption spectra. Near term, the methodology is being worked out to simulate the electronic absorption spectrum of $\mathrm{Nd}^{3+}$ ion in aqueous solution. Once perfected, the method will be extended to calculate the spectra of proposed organic-phase Nd complexes relevant to the ALSEP system.

\section{Improving the Stripping Efficiency of ALSEP}

\section{A. V. Gelis and M. A. Brown, ANL}

Experiments on the partitioning of the fission products, lanthanides, and americium using a 2-cm ANL centrifugal contactor and a mixer-settler provided valuable information on process dynamics. It has been found that the kinetics of co-extraction of Am and Ln from a PUREX-type simulated raffinate are fast. The Am partitioning compares with batch tests, and no issues with fission products and Ln partitioning have been observed. Molybdenum can be scrubbed from the solvent without any issues.

In contrast, the selective stripping of Am from Ln in the loaded solvent is slow using a buffered solution in a $\mathrm{pH}$ range between 2.5 and 3.5 containing either diethylenetriaminepentaacetic acid (DTPA) or hydroxyethylenediaminetriacetic acid (HEDTA) complexing agents. The kinetic behavior results in a loss of stripping selectivity, which improves as the flow rate decreases or temperature increases. HEDTA promotes a faster Am back extraction rate than does DTPA. Stripping efficiency improves further when the extraction is conducted at longer contact time in a modified 2-cm centrifugal contactor with an extended mixing zone. For this work, a newly designed housing was 3D-printed in stainless steel, while the standard 2-cm rotor/motor assembly was used. A minimum separation factor (SF) of 10 for $\mathrm{Nd} / \mathrm{Am}$ and $\mathrm{Pm} / \mathrm{Am}$ pairs has been demonstrated numerous times under different chemical conditions at both ambient and elevated temperatures (Figure 24). The SFs for the remaining lanthanides are in the 12 to 90 range. The latest modifications of the contactor housing provided even higher SFs due to the increased residence time in the mixing zone. If HEDTA/citrate buffered solution is used, a SF (Nd/Am) of 16 is achieved. Comparison tests of a mixer-settler and standard 2-cm centrifugal contactors, conducted at PNNL, indicate that due to various reasons none of devices provides sufficient interfacial mass-transfer stage efficiency to accomplish satisfactory $\mathrm{Ln} / \mathrm{Am}$ separation step. 


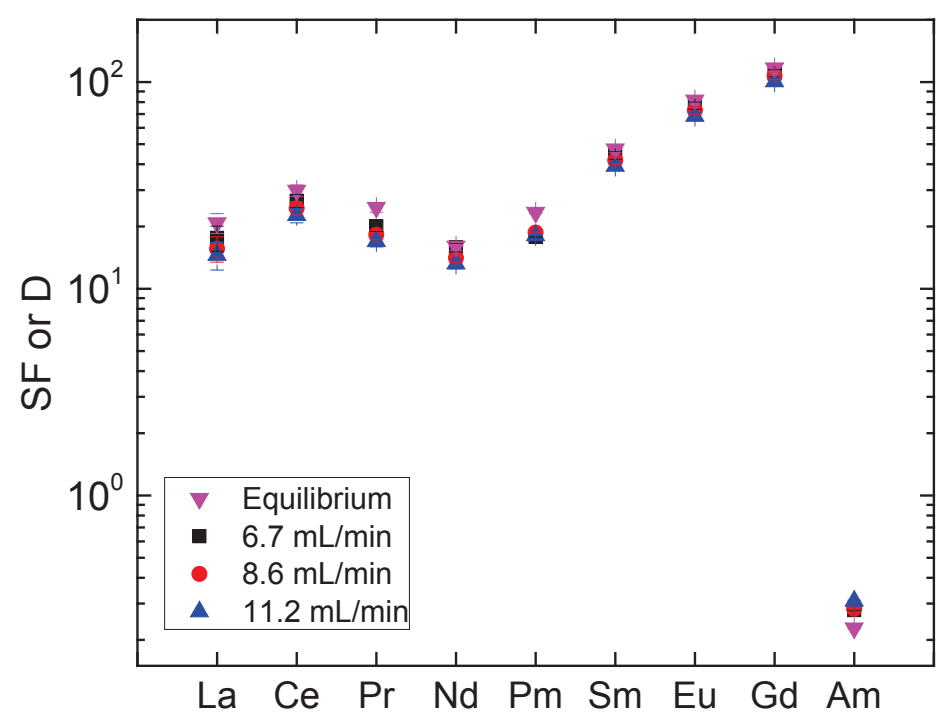

Figure 24. Separation factors for $\operatorname{Ln}(\mathrm{III}) / \mathrm{Am}$ (III) and distribution ratios of Am(III) at the Am-strip step using a modified centrifugal contactor with increased mixing residence time. Organic phase: 0.045 M T2EHDGA/0.6 M HEH[EHP]. Aqueous phase: $0.125 \mathrm{M}$ HEDTA/0.2 $\mathrm{M}$ citrate, $\mathrm{pH} 2.81 . T=21 \pm 2^{\circ} \mathrm{C}$.

\subsection{Fundamental Chemistry of TALSPEAK-Based Systems}

\section{K. L. Nash, WSU}

In a 1974 review of trivalent Ln-An separations, Boyd Weaver (developer of the TALSPEAK process) articulated the philosophy of his approach to accomplishing this challenging separation with the observation that (after years of seeking actinide-selective extractants) “...the separation was only accomplished by drastically altering the aqueous phase..." Broadly considered, most An(III)/Ln(III) solvent extraction/ion exchange based separations under investigation globally (e.g., GANEX, DIAMEXSANEX, TRUSPEAK, ALSEP) are based on this approach and the application of pH-buffered actinideselective $\mathrm{N}$-donor stripping agents. This investigation has focused from the beginning on advancing the fundamental science that underpins TALSPEAK-like separations of the MAs from fission-product lanthanides. The increased understanding that has been gained regarding TALSPEAK-based separations ${ }^{1}$ has effectively enabled the development of Advanced TALSPEAK and ALSEP systems.

TALSPEAK-like separations are those systems based on the use of actinide-selective aqueous polyaminopolycarboxylate complexants like DTPA. As recently reviewed, ${ }^{1}$ it has been demonstrated that conventional TALSPEAK (based on lactate buffers, HDEHP/diisopropylbenzene, and DTPA) is characterized by complex interactions that reduce predictability of system performance. These interactions give rise to the impractical steep $\mathrm{pH}$ dependence that defines conventional TALSPEAK separations. Insights developed in the WSU investigations have led to the Advanced TALSPEAK system based on the phosphonate (HEH[EHP]) analog to the TALSPEAK extractant HDEHP matched to a weaker holdback reagent and potentially a different buffer. The combination dramatically reduces the need for a concentrated buffer, improves predictability of TALSPEAK separations, and almost completely eliminates the $\mathrm{pH}$ dependence. The Advanced TALSPEAK concept and the introduction of $\mathrm{HEH}[\mathrm{EHP}]$ led to the ALSEP combined process concept (see above).

Current research has focused on (1) alternative buffers (specifically malonate) for Advanced TALSPEAK, (2) dipicolinate derivatives as alternatives to conventional polyaminopolycarboxylate 
holdback reagents, and (3) a mixed-extractant system based on equimolar mixtures of the commercially available extractants Cyanex 923 and HEH[EHP] (commercially available as PC-88A, Ionquest 801) combined with a glycine buffer and various actinide selective holdback reagents. The latter system, TALSPEAK-MME (Mixed Monofunctional Extractants), enables efficient and rapid extraction of $\mathrm{Ln}\left(\mathrm{NO}_{3}\right)_{3} / \mathrm{An}\left(\mathrm{NO}_{3}\right)_{3}$ from $1 \mathrm{M} \mathrm{HNO}_{3}$ media, conditioning to $\mathrm{pH} 2.5$ using a glycine buffer, and selective removal of $\mathrm{Am}^{3+}$ with a glycine-buffered HEDTA or triethylenetetraminehexacetic acid solution with a (not fully optimized) group SF of 10. An example of a new dipicolinate derivative applied as an actinideselective stripping agent in the TALSPEAK-MME system is shown in Figure 25.

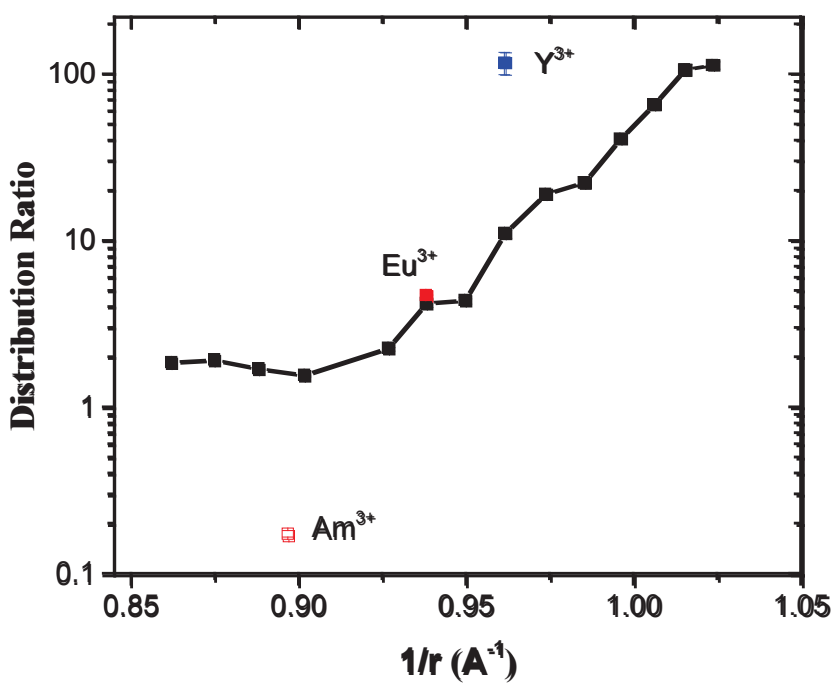

Figure 25. Application of actinide stripping agent in TALSPEAK-MME Ln/Am separation system. Aqueous phase: $7.01 \mathrm{mM} N$ methylpiperidine dipicolinic acid, $0.1 \mathrm{M}$ glycine, pH 2.55. Organic phase: $0.4 \mathrm{M}$ (HEH)EHP and $0.4 \mathrm{M}$ Cyanex 923 in $n$ dodecane.

A recent advance was the demonstration that an alternative buffer, malonate, was applicable in TALSPEAK-like systems. An investigation of the basic extraction chemistry of the malonate/HEDTA/HEH[EHP]-dodecane system has established the potential to produce acceptable $\mathrm{Ln} / \mathrm{Am} \mathrm{SFs}$ at $\mathrm{pH} 2.5$ with rapid extraction kinetics and a flat separation vs. $\mathrm{pH}$ profile. Toward a more thermodynamic understanding, spectrophotometric investigations conducted at PNNL (Figure 26) revealed the formation of mixed Ln(Mal)(HEDTA) complexes in the aqueous phase of a malonate-based Advanced TALSPEAK system. The principal issue with this system is that $\mathrm{La}^{3+}$ is relatively poorly extracted, possibly resulting in some La contamination of the Am product (also observed in ALSEP separations). Separation of Am from strongly neutron absorbing $\mathrm{Nd}, \mathrm{Sm}, \mathrm{Eu}$, and $\mathrm{Gd}$ is significantly better. 

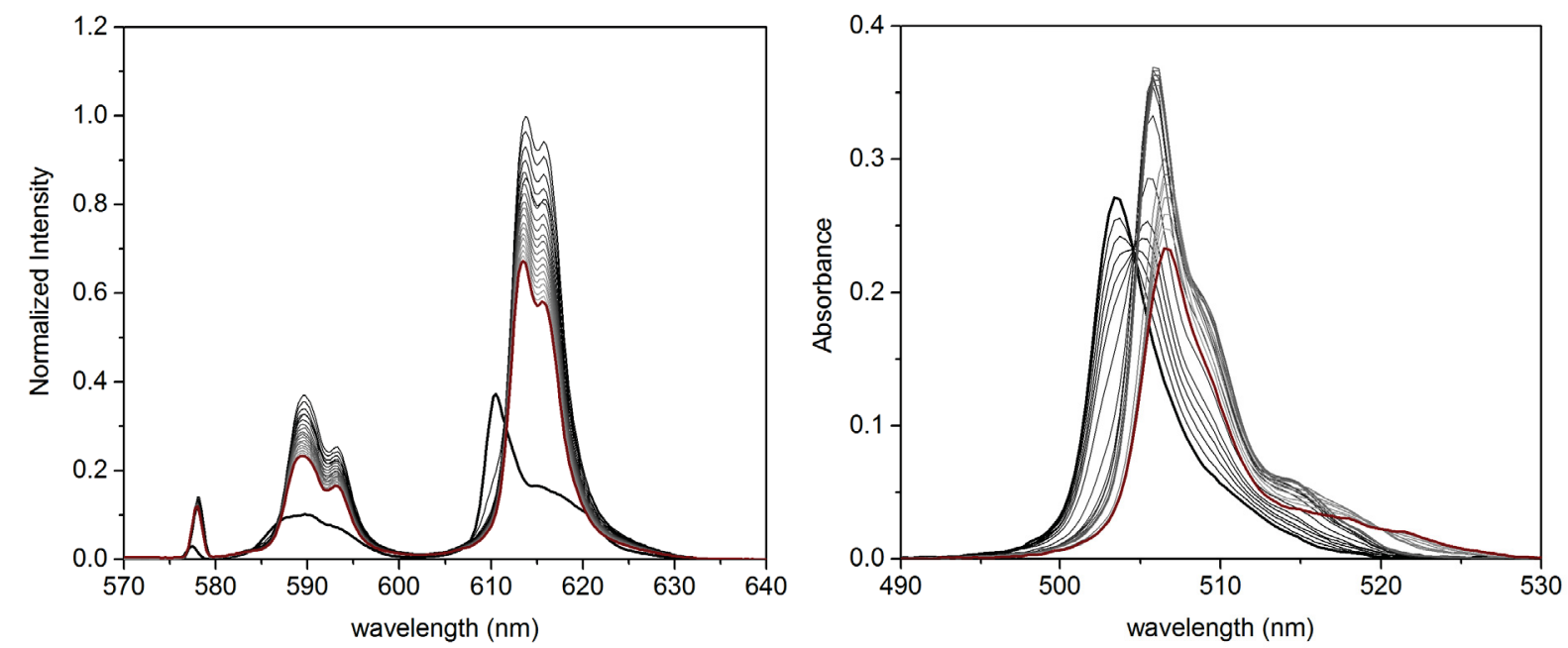

Figure 26. Luminescence $\left(\mathrm{Eu}^{3+}\right)$ and absorption $\left(\mathrm{Am}^{3+}\right)$ spectroscopy determination of thermodynamic parameters confirming the existence of mixed M(Mal)(HEDTA) ${ }^{2-}$ complexes in malonate buffered Advanced TALSPEAK. Left: 99.8 mM HEDTA titrated into $1.98 \mathrm{mM} \mathrm{Eu}^{3+}, 0.500 \mathrm{M}$ malonate. Right: $25.0 \mathrm{mM}$ HEDTA titrated into $0.818 \mathrm{mM} \mathrm{Am}^{3+}, 0.600 \mathrm{M}$ malonate.

\section{References}

1. K. L. Nash, "The Chemistry of TALSPEAK: A Review of the Science," Solvent Extraction and Ion Exchange 33(1), 2015: 1-57. DOI 10.1080/07366299.2014.985912

\subsection{Mixed-Donor Extractants}

\section{S. Jansone-Popova, V. Bryantsev, F. V. Sloop, Jr., R. Custelcean, and B. A. Moyer, ORNL}

Two new classes of mixed N,O-donor ligands have been identified for effective An(III)/Ln(III) separation (Figure 27, A). Bidentate ligand 6 and tetradentate ligand 7 possess N-heterocycle (triazole, phenanthroline) linked with $\delta$-lactam unit(s). Both ligands are highly preorganized (rigid cyclic amide vs acyclic amide), leading to stronger binding of trivalent Ln and An ions.

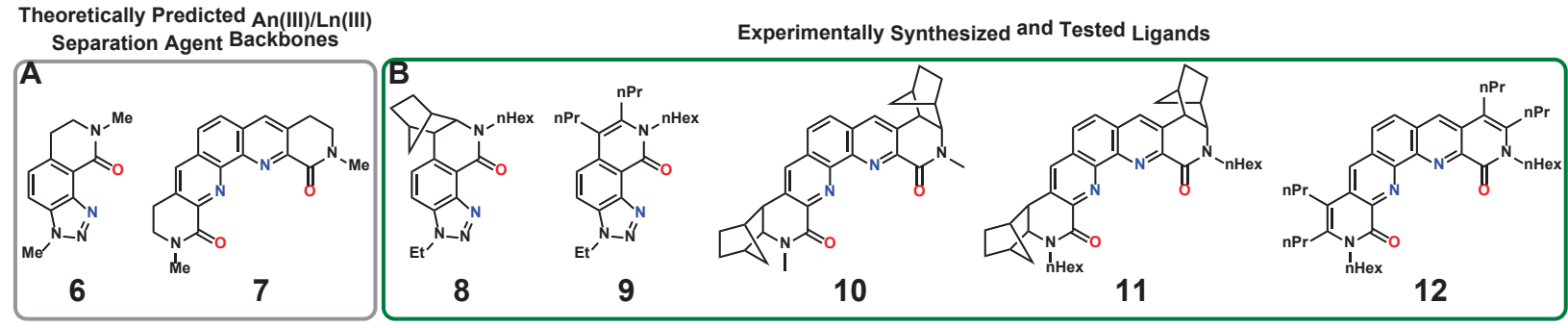

Figure 27. New bidentate and tetradentate mixed N,O-donor ligands.

Judicious selection of synthetic manipulations allows for introduction of long aliphatic substituents around the backbones in $\mathbf{6}$ and $\mathbf{7}$ that improve the solubility of the ligands in nonpolar solvents. Multi-step syntheses were used to prepare ligands 8 through 12 with good overall yields (Figure 27, B). We have established through experiment that the unsaturated ligands $\mathbf{9}$ and $\mathbf{1 2}$ are more soluble in nonpolar solvents ( $n$-dodecane) than their corresponding saturated counterparts $(\mathbf{8}, \mathbf{1 0}$, and 11). Additionally, tests employing $3 \mathrm{M} \mathrm{HNO}_{3}$ revealed much higher stability of saturated series (ligands $\mathbf{8}, \mathbf{1 0}$, and $\mathbf{1 1}$ proved to 
be quite robust) compared to the unsaturated ones; this is mainly attributed to the absence of easily oxidizable benzylic $\mathrm{C}-\mathrm{H}$ bonds in former case.

Next, all new ligands were tested as extracting agents for the selective separation of An(III) from Ln(III) ions. The small quantities of the compounds available limited the experiments to a single set of conditions, and thus, the influence of kinetics, nitric acid concentration, etc. cannot be fully appreciated at this early stage. Nevertheless, the initial results are encouraging overall. Representative preliminary extraction results are combined in Table 4. Bidentate ligands $\mathbf{8}$ and $\mathbf{9}$ were found to be very poor extractants in 1,2-dichloroethane and nitrobenzene under both high-acidity and low-acidity/high-ionic strength conditions. Conversely, saturated tetradentate phenanthroline-based ligands $\mathbf{1 0}$ and $\mathbf{1 1}$ proved to be very strong extractants of both $\mathrm{Am}$ (III) and $\mathrm{Eu}$ (III) ions when tested at $1 \mathrm{mM}$ concentrations under both high-acidity and low-acidity/high-ionic strength conditions using 1,2-dichloroethane and nitrobenzene as the solvent. However, the SFs were quite low. Relatively high solubility of the unsaturated tetradentate phenanthroline-based ligand 12 permitted use of $n$-dodecane as an organic solvent. Ligand 12 exhibited excellent SFs in all solvents under high-acidity/low-ionic strength conditions with the highest SF of An(III) over Ln(III) of 65.

Table 4. Preliminary distribution ratios and SFs of Am(III)/Eu(III) using ligands 10, 11, and 12.

\begin{tabular}{|l|l|l|l|l|l|}
\hline $\begin{array}{l}\text { Ligand, } \\
(\mathbf{1} \mathbf{m M})\end{array}$ & \multicolumn{1}{|c|}{ Solvent } & \multicolumn{1}{|c|}{ Aqueous Phase } & \multicolumn{1}{c|}{$\boldsymbol{D}_{\mathbf{A m}}$} & \multicolumn{1}{c|}{$\boldsymbol{D}_{\mathbf{E u}}$} & \multicolumn{1}{c|}{$\mathbf{S F}$} \\
\hline $\mathbf{1 0}$ & Nitrobenzene & $1 \mathrm{M} \mathrm{HNO}_{3}$ & 9333 & 2909 & 3.2 \\
\hline $\mathbf{1 1}$ & Nitrobenzene & $0.1 \mathrm{mM} \mathrm{HNO}_{3}+7 \mathrm{M} \mathrm{LiNO}_{3}$ & 581 & 479 & 1.2 \\
\hline \multirow{3}{*}{$\mathbf{1 2}$} & 1,2 -Dichloroethane & $1 \mathrm{M} \mathrm{HNO}_{3}$ & 2.5 & 0.06 & 42 \\
\cline { 2 - 7 } & Nitrobenzene & $1 \mathrm{M} \mathrm{HNO}_{3}$ & 0.83 & 0.01 & 59 \\
\cline { 2 - 7 } & $n$-Dodecane & $1 \mathrm{M} \mathrm{HNO}_{3}$ & 0.05 & $<0.01$ & 65 \\
\hline
\end{tabular}

In addition, the crystal structure of 11 complexed with $\mathrm{Eu}(\mathrm{NO} 3) 3$ was obtained (Figure 28). The ligand binds $\mathrm{Eu} 3+$ ion via two phenanthroline $\mathrm{N}$-atoms and two amide $\mathrm{O}$-atoms, and three bidentate nitrate anions complete the coordination sphere, yielding a charge-neutral complex [Eu(11)(NO3)3)]. Moreover, UV-vis titration experiments performed in methanol confirmed the formation of persistent complex between ligand 11 and $\mathrm{Eu}(\mathrm{NO} 3) 3$ with 1:1 stoichiometry.
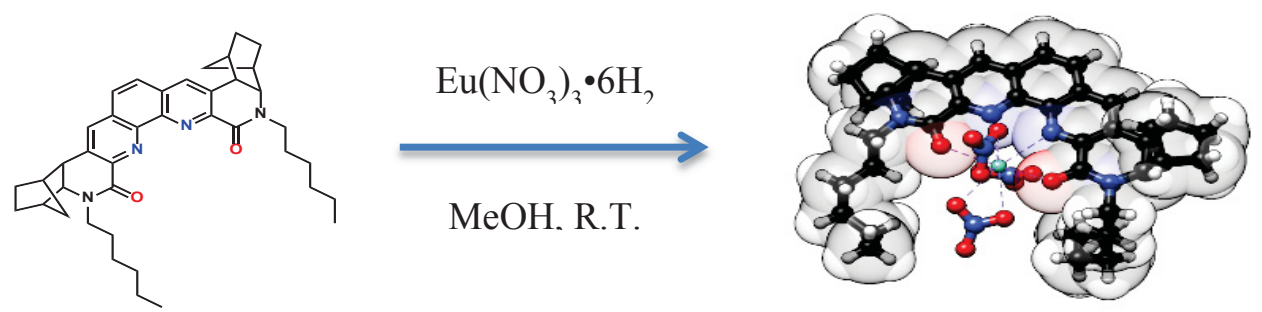

Figure 28. Crystal structure of extractant 11 with $\mathrm{Eu}\left(\mathrm{NO}_{3}\right)_{3}$. 


\subsection{Theoretical Prediction of Am(III)/Eu(III) Selectivity}

\section{S. Bryantsev and B. P. Hay, ORNL}

Establishing a reliable computational protocol for predicting the thermodynamics of binding trivalent actinides and lanthanides can provide valuable insights into their solution chemistry and open up new opportunities for the use of theory in guiding the design of novel ligands for An(III)/Ln(III) separation. To address this question, we examined the ability of several density functional theory (DFT) methods to predict Am(III)/Eu(III) selectivity with six oxygen, mixed oxygen-nitrogen, and sulfur donor ligands, as observed in liquid-liquid extraction and aqueous-phase selective complexation studies. Am(III)/Eu(III) selectivities were calculated as the differences in complexation energies between the extractants and metal ions:

$$
\begin{aligned}
& \mathrm{Am}\left[\left(\mathrm{H}_{2} \mathrm{O}\right)_{9}\right]^{3+}{ }_{(\mathrm{aq})}+\mathrm{Eu}(\mathrm{L})_{n}\left(\mathrm{NO}_{3}\right)_{3(\mathrm{org})} \rightleftharpoons \mathrm{Am}(\mathrm{L})_{n}\left(\mathrm{NO}_{3}\right)_{3(\mathrm{org})}+\mathrm{Eu}\left[\left(\mathrm{H}_{2} \mathrm{O}\right)\right]_{9}{ }^{3+}{ }_{(\mathrm{aq})}, \Delta \Delta G_{\text {ext }}(\mathrm{Am} / \mathrm{Eu}) \\
& \Delta \Delta G_{\text {ext }}(\mathrm{Am} / \mathrm{Eu})=\Delta G_{\text {ext }}(\mathrm{Am})-\Delta G_{\text {ext }}(\mathrm{Eu})
\end{aligned}
$$

The results established that certain diffuse density functionals are capable of correctly predicting the selectivity differences among several ligands. The composition of the extracted species used in the calculations is consistent with the proposed stoichiometry of the organic-phase complexes. Selectivities estimated as $\Delta \Delta G_{\text {ext }}(\mathrm{Am} / \mathrm{Eu})$ values were obtained by combining our best estimates of the gas-phase free energies with implicit solvent corrections for both the aqueous and organic phase included. Table 5 shows that our computational protocol is able to reproduce higher affinity of the mixed N,O-donor and S-donor ligands for Am(III) over Eu(III) and rank-order their separation ability.

Table 5. Calculated and measured selectivities in the solvent extraction of $\mathrm{Am}^{3+}$ and $\mathrm{Eu}^{3+}$ (kcal/mol). Computed selectivities are obtained as the changes in the free energies for reaction 1a $\left(\Delta \Delta G_{\text {ext }}(A m / E u)\right){ }^{a}$

\begin{tabular}{lcl}
\hline Complex & Calc & Expt \\
\hline $\mathrm{M}\left(\mathrm{H}_{2} \mathrm{O}\right)_{4}\left(\mathrm{NO}_{3}\right)_{3}$ & 0.861 & $\sim 0$ \\
$\mathrm{M}(\mathbf{1})_{2}\left(\mathrm{NO}_{3}\right)_{3}$ & -2.23 & -1.53 \\
$\mathrm{M}(2)_{3}$ & -3.97 & -6.82
\end{tabular}

a. $\mathbf{1}$ is 7-methyl-8-hydroxyquinolinol, and $\mathbf{2}$ is bis(o-trifluoromethylphenyl)dithiophosphinic acid.

Further validation of our theoretical model was carried out by comparison of the predicted and measured relative complexation energies of $\mathrm{Am}^{3+}$ and $\mathrm{Eu}^{3+}$ in the aqueous phase. Ligands with $\mathrm{O}$ - (oxalate), mixed N,O- (dipicolinate), and N-donor (ADPTZ) atoms were included (Figure 29). A competitive complexation of $\mathrm{Am}^{3+}$ and $\mathrm{Eu}^{3+}$ ions with these ligands was modeled according to reaction (2):

$$
\begin{aligned}
& {\left[\mathrm{Am}\left(\mathrm{H}_{2} \mathrm{O}\right)_{9}\right]^{3+}+\left[\mathrm{Eu}(\text { ligand })\left(\mathrm{H}_{2} \mathrm{O}\right)_{n}\right]^{m+}=\left[\mathrm{Am}(\text { ligand })\left(\mathrm{H}_{2} \mathrm{O}\right)_{n}\right]^{m+}+\left[\mathrm{Eu}\left(\mathrm{H}_{2} \mathrm{O}\right)_{9}\right]^{3+}} \\
& \Delta \Delta G_{\text {compl }}(\mathrm{Am} / \mathrm{Eu})=\Delta G_{\text {compl }}(\mathrm{Am})-\Delta G_{\text {compl }}(\mathrm{Eu})
\end{aligned}
$$

Several initial geometries were built by substituting two and three water molecules in $\left[\mathrm{M}\left(\mathrm{H}_{2} \mathrm{O}\right)_{9}\right]^{3+}$ by the corresponding bidentate and tridentate ligands, respectively. Adding two additional water molecules to solvate dianionic ligands was deemed necessary to stabilize each cluster in the nine-coordinate geometry. With these considerations, the results, Table 6 , demonstrate that our theoretical prediction of aqueous 
complexation agrees closely with experimental measurements, reproducing the selectivity of 'hard' Odonor ligands for $\mathrm{Eu}^{3+}$ and 'softer' polyazine ligands for $\mathrm{Am}^{3+}$.

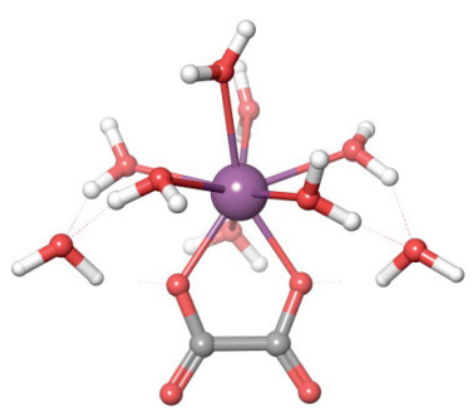

$\left[\text { Am(oxalate) }\left(\mathrm{H}_{2} \mathrm{O}\right)_{9}\right]^{+}$

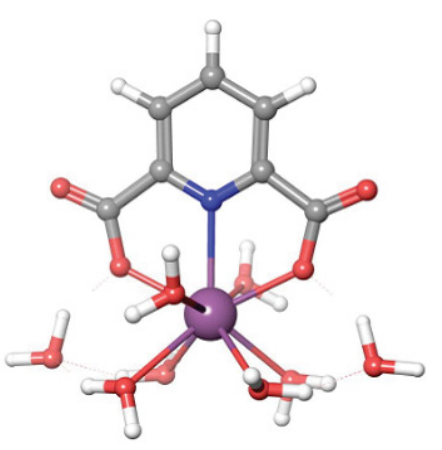

$\left[\text { Am(dipicolinate) }\left(\mathrm{H}_{2} \mathrm{O}\right)_{8}\right]^{+}$

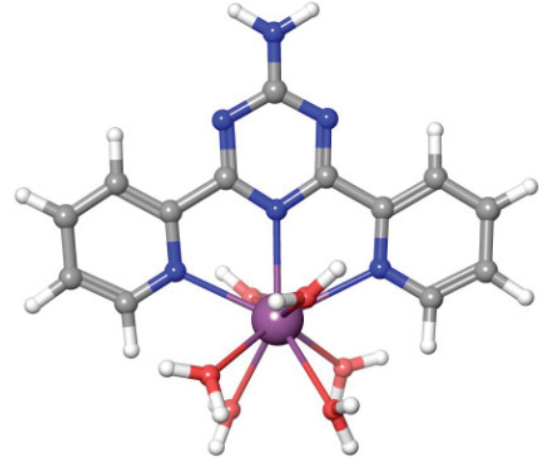

$\left[\mathrm{Am}(\mathrm{ADPTZ})\left(\mathrm{H}_{2} \mathrm{O}\right)_{5}\right]^{+}$

Figure 29. Optimized structures for aqueous 1:1 metal ion-ligand complexes stabilized in the nine-coordinate geometry

Table 6. Predicted and experimental differences in complexation free energies of O- and $\mathrm{N}$-donor ligands with $\mathrm{Am}^{3+}$ and $\mathrm{Eu}^{3+}$ ions in aqueous solution ( $\mathrm{kcal} / \mathrm{mol})$. Computed selectivities are obtained as the changes in the free energies for reaction $2 \mathrm{a}$ $\left(\Delta \Delta G_{\text {compl }}(\mathrm{Am} / \mathrm{Eu})\right.$

\begin{tabular}{lll}
\hline Complex & Calc & Expt \\
\hline Oxalate & 1.60 & 0.20 \\
Dipicolinate & 0.89 & 0.0 \\
ADPTZ & -1.91 & -1.72 \\
\hline
\end{tabular}

Building upon the results obtained in FY-15, in the next research cycle we will further examine several types of models for their ability to reproduce $\mathrm{An}(\mathrm{III}) / \mathrm{Ln}$ (III) selectivities for a larger set of ligands, including heterocyclic N-donor and mixed N,O-donor ligand. The most accurate computational scheme will be applied to estimate the selectivity of novel mixed oxygen-nitrogen donor ligands formed by covalently linking a heterocycle with an amide group (see above).

\section{Publications}

Braley, J. C.; G. J. Lumetta, J. C. Carter, “Combining CMPO and HEH[EHP] for Separating Trivalent Lanthanides from the Transuranic Elements," Solvent Extraction and Ion Exchange 31(6), 2013: 567577.

Gelis, A. V. and G. J. Lumetta, “Actinide Lanthanide Separation Process-ALSEP,” Industrial \& Engineering Chemistry Research 53, 2014: 1624-1631.

Jensen, M. P.; Chiarizia, R.; Shkrob, I. A.; Ulicki, J. S.; Spindler, B. D.; Murphy, D. J.; Hossain, M.; Roca-Sabio, A.; Platas-Iglesias, C.; de Blas, A.; Rodríguez-Blas, T., "Aqueous Complexes for Efficient Size-based Separation of Americium from Curium," Inorganic Chemistry 53, 2014, 60036012 .

Jensen, M. P.; Chiarizia, R.; Ulicki, J. S.; Spindler, B. D.; Murphy, D. J.; Hossain, M. M.; Roca-Sabio, A.; de Blas, A.; Rodríguez-Blas, T. Solvent Extraction Separation of Trivalent Americium from Curium and the Lanthanides. Solvent Extraction and Ion Exchange 33(4), 2015: 329-345.

Law, J., N. Soelberg, T. A. Todd, J. Tripp, C. Pereira, M. Williamson, W. Ebert, R. T. Jubin, B. A. Moyer, J. Vienna, G. J. Lumetta, J. V. Crum, T. Rudisill, J. Bresee, C. Phillips, B. Willis, P. Murray, 
and S. Bader, 2013, "Separation and Waste Form Campaign Full Recycle Case Study," FCRD-SWF2013-000380 (Limited Distribution), Idaho National Laboratory.

Lumetta G. J., D. Neiner, S. I. Sinkov, J. C. Carter, J. C. Braley, S. L. Latesky, A. V. Gelis, P. Tkac, G. F. Vandegrift, 2011, "Combining Neutral and Acidic Extractants for Recovering Transuranic Elements from Nuclear Fuel," Proceedings of the $19^{\text {th }}$ International Solvent Extraction Conference, L. F. Valenzuela, B. A. Moyer, Eds., Gecamin Ltd: Santiago, Chile; Paper No. 68.

Lumetta, G. J., A. V. Gelis, J. C. Braley, J. C. Carter, J. W. Pittman, M. G. Warner, G. F Vandegrift, “The TRUSPEAK Concept: Combining CMPO and HDEHP for Separating Trivalent Lanthanides from the Transuranic Elements," Solvent Extraction and Ion Exchange 31(3), 2013: 223-236.

Lumetta, G. J., A. V. Gelis, J. C. Carter, C. M. Niver, and M. R. Smoot, "The Actinide-Lanthanide Separation Process," Solvent Extraction and Ion Exchange 32(4), 2014: 333-347.

Nash, K. L., "The Chemistry of TALSPEAK: A Review of the Science," Solvent Extraction and Ion Exchange 2015, 33(1) 1-57. DOI 10.1080/07366299.2014.985912

Pillon, S.; Somers, J.; Grandjean, S.; Lacquement, J. "Aspects of fabrication of curium-based fuels and targets," Journal of Nuclear Materials 320, 2003: 36-43.

Tkac, P., G. F. Vandegrift, G. J. Lumetta, and A. V Gelis, "Study of the Interaction between HDEHP and CMPO and its Effect on the Extraction of Selected Lanthanides," Industrial \& Engineering Chemistry Research 51(31), 2012: 10433-10444.

\section{Patents}

Dares, C. J. A. M. Lapides, B. J. Mincher, T. J. Meyer, "Electrochemical Treatment of Nuclear Waste Streams," Patent pending.

Gelis, A. V. and M. A. Brown, "Transition metal recovery from nitric acid," Patent application submitted.

Goff, G. S., L. S. Seaman, W. Runde, G. D, Jarvinen, “Oxidation of Americium in Acidic Solution,” Patent Pending.

\section{Sigma Team Publications}

Bryantsev, V. S. and B. P. Hay, "Theoretical prediction of Am(III)/Eu(III) Selectivity to Aid the Design of Actinide-Lanthanide Separation Agents," Dalton Trans. 44, 2015: 7935-7942.

Dares, C. J., A. M. Lapides, B. J. Mincher, T. J. Meyer, "Electrochemical Oxidation of 243Am(III) in Nitric acid by a Terpyridyl-Derivatized Electrode," Science, October 2015.

Hay, B. P., A. M. Panagopoulos, L. H. Delmau, R. Custelcean, B. A. Moyer, L. A. Watson, “Ligand Preorganization Leads to 108-fold Increase in Extraction Efficiency of Trivalent f-block Metal Ions by Lipophilic Picolinamides," submitted to Inorganic Chemistry, Sept. 2015.

Jensen, M. P., R. Chiarizia, J. S. Ulicki, B. D. Spindler, D. J. Murphy, M. M. Hossain, A. Roca-Sabio, A. de Blas, T. Rodríguez-Blas, "Solvent Extraction Separation of Trivalent Americium from Curium and the Lanthanides," Solvent Extraction and Ion Exchange, 33(4), 2015: 329-345.

Johnson, A. T. and K. L. Nash, "Mixed Monofunctional Extractants for Trivalent Actinide/Lanthanide Separations: TALSPEAK MME," Solvent Extraction and Ion Exchange 2015, 33, in press; DOI 10.1080/07366299.2015.1085225

Krahn, E. O. and K. L. Nash, "Insights in Lanthanide-HEH[EHP] Exchange Dynamics in Advanced TALSPEAK Systems," Proceedings of Global 2015, Paris, France, September 20-24, 2015, Paper 5360 . 
Lapka, J. L. and K. L. Nash, "Advanced TALSPEAK Separations Using a Malonate Buffer System," Solvent Extraction and Ion Exchange 33, 2015, in press; DOI 10.1080/07366299.2015.1012878

Lumetta, G. J., A. J. Casella, B. M. Rapko, T. G. Levitskaia, N. K. Pence, J. C. Carter, C. M. Niver, and M. R. Smoot, "An Advanced TALSPEAK Concept Using 2-Ethylhexylphosphonic Acid Mono-2ethylhexyl Ester as the Extractant," Solvent Extraction and Ion Exchange 33, 2015: 211-223.

Mincher, B. J., N. C. Schmitt, and T. S Grimes, "The Persistence of Am(VI) in Nitric Acid Solution," Submitted to Solvent Extraction and Ion Exchange.

Mincher, B. J., N. C. Schmitt, B. K. Schuetz T. C. Shehee, D. T. Hobbs, "Recent Advances in f-Element Separations Based on a New Method for the Production of Pentavalent Americium in Acidic Solution," RSC Advances 5, 2015: 27205-27210.

Mincher, B. J., R. D. Tillotson, J. D. Law, T. Garn, V. Rutledge, N. C. Schmitt, 2015, "The Solvent Extraction of Am(VI) Using Centrifugal Contactors," Submitted to Journal of Radioanalytical Nuclear Chemistry, June 2015.

Moyer, B. A., G. L. Lumetta, B. J. Mincher, "Minor Actinide Separation in the Reprocessing of Spent Nuclear Fuels: Recent Advances in the United States," Reprocessing and Recycling of Spent Nuclear Fuels, Waltham, MA: Woodhead Publishing, 2015; Chap. 11, pp 289-312.

Nash, K. L. "The Chemistry of TALSPEAK: A Review of the Science," Solvent Extraction and Ion Exchange 33(1), 2015: 1-57. DOI 10.1080/07366299.2014.985912

Nash, K. L., J. L. Lapka, S. Wahu, G. Ferru, C. R. Heathman, A. T. Johnson, "Improving TALSPEAK Separations: New Knowledge Leading to Alternate Extractants, Holdback Reagents, and Buffers," Proceedings of Global 2015, September 20-24, 2015, Paris, France; Paper 5128.

Shehee, T. C.; Hobbs, D. T., "Oxidation of Metal Ions by Peroxydisulfate in Dilute Nitric Acid," Sumbbited to Radiochimica Acta.

Sinkov S. I. and G. J. Lumetta, “Americium(III) Oxidation by Copper(III) Periodate in Nitric Acid Solution as Compared with the Action of $\mathrm{Bi}(\mathrm{V})$ Compounds of Sodium, Lithium, and Potassium," Radiochimica Acta, in press.

Tai, S., S. V. Marchi, and J. D. Carrick, "Efficient Preparation of Pyridinyl-1,2,4-triazines via Telescoped Condensation with Diversely Functionalized 1,2-Dicarbonyls," Journal of Heterocyclic Chemistry, 2015, DOI: 10.1002/jhet.2374.

Tai, S., S. V. Marchi, E. J. Dover, and J. D. Carrick, "Pd-Catalyzed Diamination of Dibromo-1,2,4triazinyl Complexant Scaffolds," Journal of Organic Chemistry, 2015, DOI: 10.2021/acs.joc.5b00710.

Tai, S., N. J. Williams, J. D. Carrick, "Synthesis of bis-1,2,4-triazines via Telescoped Condensation of [1,10]-Phenanthroline-2,9-dicarbonitrile with Aromatic 1,2-Dicarbonyls " Journal of Heterocyclic Chemistry, 2015, DOI: 10.1002/jhet.2295.

Tevepaugh, K. N.; Carrick, J. D.; Tai, S.; Coonce, J. G.; Delmau, L. H.; Ensor, D. D., "Separation of Americium from Europium using Camphor-BisTriazinyl Pyridine, A Fundamental Study," Solvent Extraction and Ion Exchange (accepted).

Todd, T. A., B. A. Moyer, B. J. Mincher, J. Law, G. Goff, S. Sinkov, G. J. Lumetta, "Oxidation and Extraction of Americiium(VI) from Lanthanides," Nuclear Fuel Cycle for a Low-Carbon Future, Global 2015, Paris, France, September 20-24, 2015.

Zalupski, P. R., J. R. Klaehn, and D. R. Peterman, "Complete Recovery of Actinides from UREX-like Raffinates using a Combination of Hard and Soft Donor Ligands. II. Soft Donor Structure Variation," Solvent Extraction and Ion Exchange," 2015, DOI 10.1080/07366299.2015.1064296. 


\title{
3.7 Define \& Document Reference Flowsheet
}

\author{
J. Law, INL; J. Vienna, PNNL
}

\section{Full Recycle Case Study}

A team of experts from ANL, INL, ORNL, PNNL, SRNL, the DOE-NE, AREVA and Energy Solutions was assembled in FY-13 to perform a case study evaluation of full recycle technologies for both the processing of light-water reactor (LWR) UNF as well as fast reactor (FR) UNF in the full recycle option. This effort focused on the identification of the case study processes and the initial preparation of material balance flowsheets for the identified technologies. In identifying the case study flowsheets, it was decided that two cases would be developed: one which identifies the flowsheet as currently developed and another near-term target flowsheet which identifies the flowsheet as envisioned within a few years, pending the results of ongoing research. In FY-14 the team revisited this effort and updated this document based upon results of research which occurred in FY-14 (FCRD-SWF-2013-000380). ${ }^{1}$ This effort was again revisited in FY-15 and this document revised based upon results of research and studies which occurred in FY-15. Changes to the case study or near-term target case flowsheets are detailed in Report FCRDMRWFD-2015-000241. ${ }^{2}$ Specifically, the following revisions were made: (1) Oxidation with $\mathrm{NO}_{2}$ was chosen as the sole near-term target tritium pretreatment (TPT) technology in FY-14 as compared to FY13 which included both $\mathrm{NO}_{2}$ and $\mathrm{O}_{2}$. The $\mathrm{NO}_{2}$ TPT portion of the report was updated with the latest information and the $\mathrm{O}_{2}$ portion was deleted in this year's version, (2) the waste treatment and disposal sections for aqueous and electrochemical separations were modified significantly based upon the final version of the Closed Fuel Cycle Waste Treatment Strategy report (FCRD-MRWFD-2015-000674), ${ }^{3}$ (3) mass balance assumptions were updated in all areas based upon the results of recent research, and (4) research needs were updated based upon the FY-15 Prioritized List of Research Needs (FCRD-MRWFD2015-000571). ${ }^{4}$

The case study focus is homogeneous recycle of the U/TRU resulting from the aqueous processing of LWR UNF as feed for metal fuel fabrication. The metal fuel is utilized in a sodium cooled fast reactor (SFR) and the used fast reactor fuel processed using electrochemical separations. The recovered U/TRU from electrochemical separations is recycled to fuel fabrication and the FR. Waste streams from the aqueous and electrochemical processing are treated and prepared for disposition. Off-gas from the separations and waste processing are also treated. The document presents, in detail, the technologies chosen by the team for the case study flowsheet and near-term target case flowsheet. The technologies are described and assumptions as to the behavior of actinides, fission products and other elements of interest are documented to support development of the mass balance. In addition, unknowns, areas for development and current research status are detailed.

In conjunction with documentation of the flowsheet technologies, mass balances have been created. Mass balances were updated in FY-15 to match changes to the document.

Development of the case study flowsheet will allow for objective comparison of technologies currently being developed by the MRWFD Campaign as well as future technology developments, to assess their benefits and potential improvements relative to this full recycle flowsheet. Ultimately, this effort will provide benefits in terms of understanding the interfaces between specific processes both upstream and downstream, will aid in identifying knowledge gaps and areas for process improvements, will serve as a tool for comparison of new technologies, and will identify potential regulatory issues for UNF recycling.

\section{Closed Fuel Cycle Waste Management Strategy}

The existing waste management approaches for nuclear fuel cycle facilities were evaluated assuming the flowsheets developed in report FRCD-MRWFD-2015-000571. ${ }^{4}$ Waste forms and processes were 
compared to comparison to the objectives of implementing an advanced fuel cycle in the U.S. under current legal, regulatory, and logistical constructs. The study began with the Global Nuclear Energy Partnership (GNEP) Integrated Waste Management Strategy (IWMS) ${ }^{5}$ as a general strategy and associated Waste Treatment Baseline Study (WTBS) . ${ }^{6}$ The bases of the IWMS are equally valid to the current waste management study. However, the flowsheet details have changed significantly from those considered under GNEP. In addition, significant additional waste management technology development has occurred since the GNEP waste management studies were performed. This study updated the information found in the WTBS, summarized the results of more recent technology development efforts, and described waste management approaches as they apply to the full recycle reprocessing flowsheets described above. Many of the waste management technologies discussed also apply to other potential flowsheets that involve reprocessing. These applications were occasionally discussed where the data were more readily available.

The report summarized the waste arising from aqueous reprocessing of a typical light-water reactor (LWR) fuel to separate actinides for use in fabricating metal sodium fast reactor (SFR) fuel and from electrochemical reprocessing of the metal SFR fuel to separate actinides for recycle back into the SFR in the form of metal fuel. The primary streams considered and the recommended waste forms include:

- Tritium separated from either a low-volume gas stream or a high-volume water stream. The recommended waste form is low-water cement in high-integrity containers.

- Iodine-129 separated from off-gas streams in aqueous processing. There are a range of potentially suitable waste forms. As a reference case, a glass composite material (GCM) formed by the encapsulation of the silver Mordenite (AgZ) getter material in a low-temperature glass is assumed. A number of alternatives with distinct advantages are also considered including a fused silica waste form with encapsulated nano-sized AgI crystals.

- Carbon-14 separated from LWR fuel treatment off-gases and immobilized as a $\mathrm{CaCO}_{3}$ in a cement waste form.

- Krypton-85 separated from LWR and SFR fuel treatment off-gases and stored as a compressed gas.

- An aqueous reprocessing HLW raffinate waste which is immobilized by the vitrification process in one of three forms: a single-phase borosilicate glass, a borosilicate based glass ceramic, or a multiphased titanate ceramic [e.g., synthetic rock (Synroc)].

- An undissolved solids (UDS) fraction from aqueous reprocessing of LWR fuel that is either included in the borosilicate HLW glass or is immobilized in the form of a metal alloy in the case of glass ceramics or titanate ceramics.

- Zirconium-based LWR fuel cladding hulls and stainless steel (SS) fuel assembly hardware that are washed and super-compacted for disposal or as an alternative with high promise for the purification and reuse (or disposal as low-level waste, LLW) of Zr by reactive gas separations.

- Electrochemical process salt HLW which is incorporated into a glass bonded Sodalite waste form known as the ceramic waste form $(\mathrm{CWF})$.

- Electrochemical process UDS and SS cladding hulls which are melted into an iron based alloy waste form.

Mass and volume estimates for each of the recommended waste forms based on the source terms from a representative flowsheet were reported. In addition to the above listed primary waste streams, a range of secondary process wastes are generated by aqueous reprocessing of LWR fuel, metal SFR fuel fabrication, and electrochemical reprocessing of SFR fuel. These secondary wastes were summarized and volumes estimated by type and classification. The important waste management data gaps and research needs have been summarized for each primary waste stream and selected waste process. 


\section{References}

1. J. D. Law, N. R. Soelberg, T. A. Todd, J. Tripp, C. Pereira, M. A. Williamson, W. L. Ebert, R. T. Jubin, B. A. Moyer, J. D. Vienna, G. J. Lumetta, J. V. Crum, T. S. Rudisill, J. Bresee, C. Phillips, B. Willis, P. Murray, and S. Bader, 2014, "Separation and Waste Form Campaign Full Recycle Case Study," FCRD-SWF-2013-000380, Rev. 1, INL.

2. J. D. Law, N. R. Soelberg, T. A. Todd, J. Tripp, C. Pereira, M. A. Williamson, W. L. Ebert, R. T. Jubin, B. A. Moyer, J. D. Vienna, G. J. Lumetta, J. V. Crum, T. S. Rudisill, J. Bresee, C. Phillips, B. Willis, P. Murray, and S. Bader, 2015, "Material Recovery and Waste Forms Development Campaign Full Recycle Case Study," FCRD-MRWFD-2015-000241, INL.

3. J. D. Vienna, E. D. Collins, J. V. Crum, W. L. Ebert, S. M. Frank, T. G. Garn, D. Gombert, R. Jones, R. T. Jubin, V. C. Maio, J. C. Marra, J. Matyas, T. M. Nenoff, B. J. Riley, G. J. Sevigny, N. R. Soelberg, D. M. Strachan, P. K. Thallapally, and J. H. Westsik. 2015, "Closed Fuel Cycle Waste Treatment Strategy,” FCRD-MRWFD-2015-000674, PNNL-24114, PNNL.

4. J. D. Law, Todd, T. A., Soelberg, N. R., Pereira, C., Williamson, M. A., Ebert, W. L., Willit, J, Jubin, R. T., Vienna, J. D., Lumetta, G. J., Rudisill, T. S. 2015, "Prioritized List of Research Needs to support MRWFD Case Study Flowsheet Advancement," FCRD-MRWFD-2015-000571, INL.

5. D. Gombert, J. Carter, A. Cozzi, R. Jones, G. Matthern, M. Nutt, S. Priebe, and K. B. Sorenson, 2008, "Global Nuclear Energy Partnership Integrated Waste Management Strategy," GNEP-WAST-WASTAI-RT-2008-000214, INL.

6. D. Gombert, R. Counce, A. Cozzi, J. V. Crum, W. L. Ebert, C. M. Jantzen, J. Jerden, R. Jubin, M. D. Kaminski, V. Maio, J. C. Marra, T. M. Nenoff, R. D. Scheele, H. D. Smith, B. Spencer, D. M. Strachan, and J. D. Vienna, 2007, "Global Nuclear Energy Partnership Integrated Waste Management Strategy Waste Treatment Baseline Study,” GNEP-WAST-AI-RT-2007-000324, INL. 
This page intentionally left blank. 


\section{Sigma Team for Off-Gas Capture and Immobilization}


This page intentionally left blank. 


\section{SIGMA TEAM FOR OFF-GAS CAPTURE AND IMMOBILIZATION}

\subsection{Introduction}

The Sigma Team for Off-Gas Capture and Immobilization was formed in FY-10 to bring together multidisciplinary teams from across the DOE complex and academia that would work collaboratively to solve the technical challenges and to develop the scientific basis for the capture and immobilization of airborne effluents from used fuel treatment processes so that regulatory requirements could be met. The overarching goal of the team is to develop effective methods to capture and immobilize iodine-129, carbon-14, krypton-85, and tritium released from fuel treatment processes to enable a range of advanced fuel cycle options in the U.S. General Sigma Team objectives include:

1. Development of materials and processes for capture of iodine, tritium, krypton, and carbon for effective implementation across likely used fuel treatment processes.

2. Development of fundamental understanding of the generation, capture, and immobilization radionuclides from used fuel treatment process off-gas to gain confidence in their performance and allow for new solutions to be developed as fuel treatment processes are better defined.

3. Develop waste forms and processes to manage off-gas waste streams in an effective manner.

4. Design and demonstrate the effectiveness of integrated off-gas treatment systems for likely fuel treatment processes.

Five major thrust areas were included in the activities for FY-15: (1) iodine capture, (2) iodine immobilization, (3) tritium separations from head-end off-gas deploying a tritium pretreatment process, (4) krypton separations and storage, and (5) integrated off-gas treatment system development. Highlights from these activities are summarized below and described in detail in the associated technical reports generated for each task at each contributing laboratory.

\subsection{Preliminary Evaluation of Exchange of Hydrogen Isotopes in the Structure of a Mordenite-Based Sorbent}

\section{B. B. Spencer, S. H. Bruffey, J. F. Walker, Jr. and R. T. Jubin, ORNL}

Silver-exchanged sodium mordenite (AgZ) is being evaluated as a sorbent to remove iodine from gaseous process effluent streams of used nuclear fuel (UNF) treatment plants. Although it removes iodine, previous studies have shown that $\mathrm{AgZ}$ also adsorbs significant quantities of water from a humid gas phase. In UNF processing plants, the water contains radiologically significant fractions of tritiated water. Methods to reduce or prevent the accumulation of water with the iodine have been devised and demonstrated; nonetheless, a concern arises that contact with tritiated water will permit an exchange of some of the stable hydrogen in the mordenite structure for tritium. Such tritium could remain in the mordenite even after thermal treatment to remove the physisorbed surface water. Subsequent processes that might destroy the structure (e.g., waste form fabrication) have the potential to release the tritiated water, enabling a potential pathway for release of tritium to the environment. The purpose of the present study was to evaluate the exchange of hydrogen isotopes in the mordenite structure with hydrogen isotopes associated with fluids in contact with the mordenite.

Samples of sodium mordenite (NaZ) and hydrogen-reduced silver mordenite $\left(\mathrm{Ag}^{0} \mathrm{Z}\right)$ were hydrated at $\sim 22^{\circ} \mathrm{C}$ with humid air containing either natural water or deuterium oxide $\left(\mathrm{D}_{2} \mathrm{O}\right)$ at $100 \%$ relative humidity. Sample weight-gain ranged up to $18.9 \%$ for $\mathrm{NaZ}$ and $15.7 \%$ for $\mathrm{Ag}^{0} \mathrm{Z}$. Some samples remained at room temperature while others were placed in stainless steel capsules, which were then sealed and 
heated to an elevated temperature $\left(150{ }^{\circ} \mathrm{C}\right.$ ) for varying lengths of time (up to $192 \mathrm{~h}$ ). Under these conditions the concentration of deuterium would be over three orders of magnitude greater than the tritium found in typical off-gas streams. All samples were then dried at $215^{\circ} \mathrm{C}$.

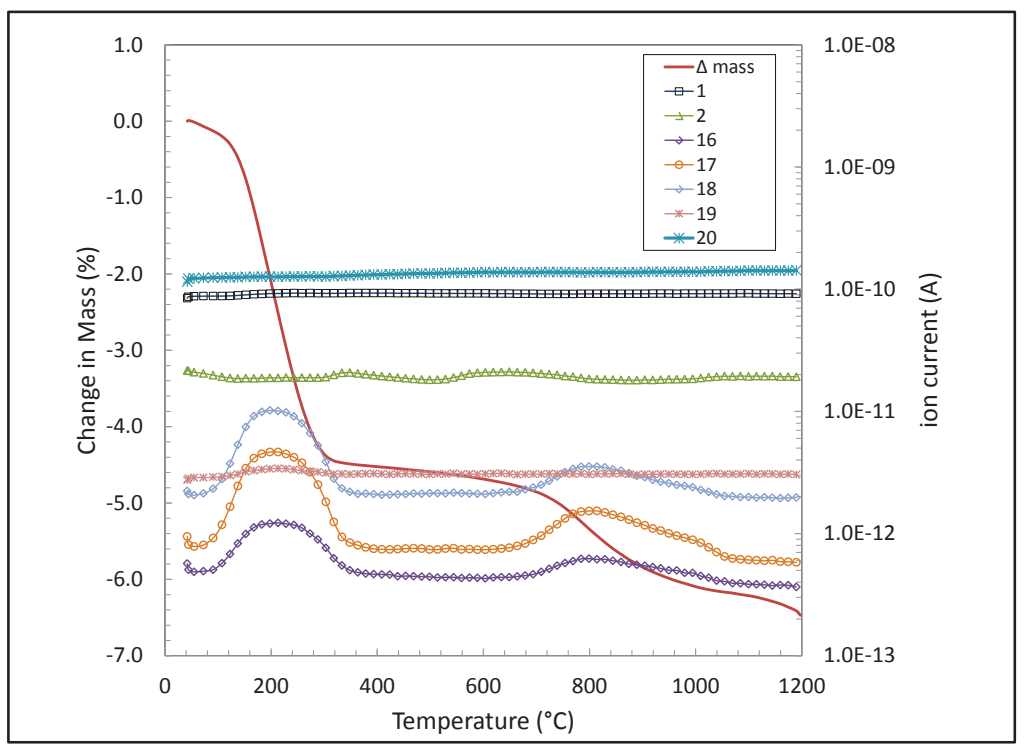

Figure 30. TGA-MS for $\mathrm{Ag}^{0} \mathrm{Z}-006$, contacted with deuterated water for $192 \mathrm{~h}$ at $150^{\circ} \mathrm{C}$.

Thermogravimetric-mass spectrometry (TGA-MS) indicated the removal of water from NaZ at temperatures below $500^{\circ} \mathrm{C}$, indicating water and deuterated water $(17,18$, and $19 \mathrm{~m} / \mathrm{Z})$ loss from the surface. The $\mathrm{AgZ}$ test specimen exhibited peaks at two temperature indicating water removal; the first below $500^{\circ} \mathrm{C}$, similar to the $\mathrm{NaZ}$ samples, and the second around $800^{\circ} \mathrm{C}$ (Figure 30). It is speculated that the presence of the silver enables a substantial structural change that is accompanied by the release of water at the higher temperature. In no case did the water released at the higher temperature include measureable amounts of deuterated water.

The samples were also analyzed with NMR to detect and measure deuterium in the solid at room temperature. Sample preparation showed complete deuterium removal under vacuum at $100^{\circ} \mathrm{C}$ within $2 \mathrm{~h}$, indicating that this easily removed water was sorbed on the surface or embedded in pores. The detection limits were equivalent to an isotopic exchange of $\leq 0.091 \%$. Calculations at this level of exchange indicate very little effect on the plant DF, should the structural tritium-containing water somehow be released.

\section{Publications}

Spencer, B. B., S. H. Bruffey, E. W. Hagaman, R. D. Hunt, and J. W. McMurray, 2015, "Preliminary Evaluation of Exchange of Hydrogen Isotopes in the Structure of a Mordenite-Based Sorbent," FCRD-MRWFD-2015-000422, ORNL/SPR-2015/392. 


\title{
4.3 lodine Capture System for ATALANTE
}

\author{
J. F. Walker, Jr., J. Jordan, and R. T. Jubin, ORNL
}

A sorbent-based capture system designed for integration into the existing dissolver off-gas (DOG) treatment system at the ATelier Alpha et Laboratoires pour ANalyses, Transuraniens et Etudes de retraitement (ATALANTE) facility has been successfully designed and fabricated and has undergone shakeout testing at ORNL. A schematic diagram of the simplified system which resulted from this testing is presented in Figure 31.

The off-gas from the dissolver and condenser currently located in the ATALANTE facility, which is expected to be $\sim 100 \mathrm{~L} / \mathrm{h}$, will be transported to the sorbent column through a $1 / 4$-in. line which is heat traced. The column, which is fabricated from stainless steel, has an outside diameter of 1-in., a wall thickness of 0.065 -in., and an overall height of 11.75-in. The DOG will enter and exit the column through 1/4-in. diameter stainless tubing that has been fitted with stainless steel size $12 / 5$ ball or socket joints. Swagelok ${ }^{\circledR}$ fittings are located at both the top and the bottom of the column for the insertion of $1 / 8$ in. diameter thermocouples. Four removable inner sections, each with a stainless steel screen welded to the bottom, will contain the capture sorbent. The Swagelok ${ }^{\circledR}$ fitting (SS-16-UT-6) located at the top of the column is removable so that the inner sections holding the sorbent can be added to or taken from the column.

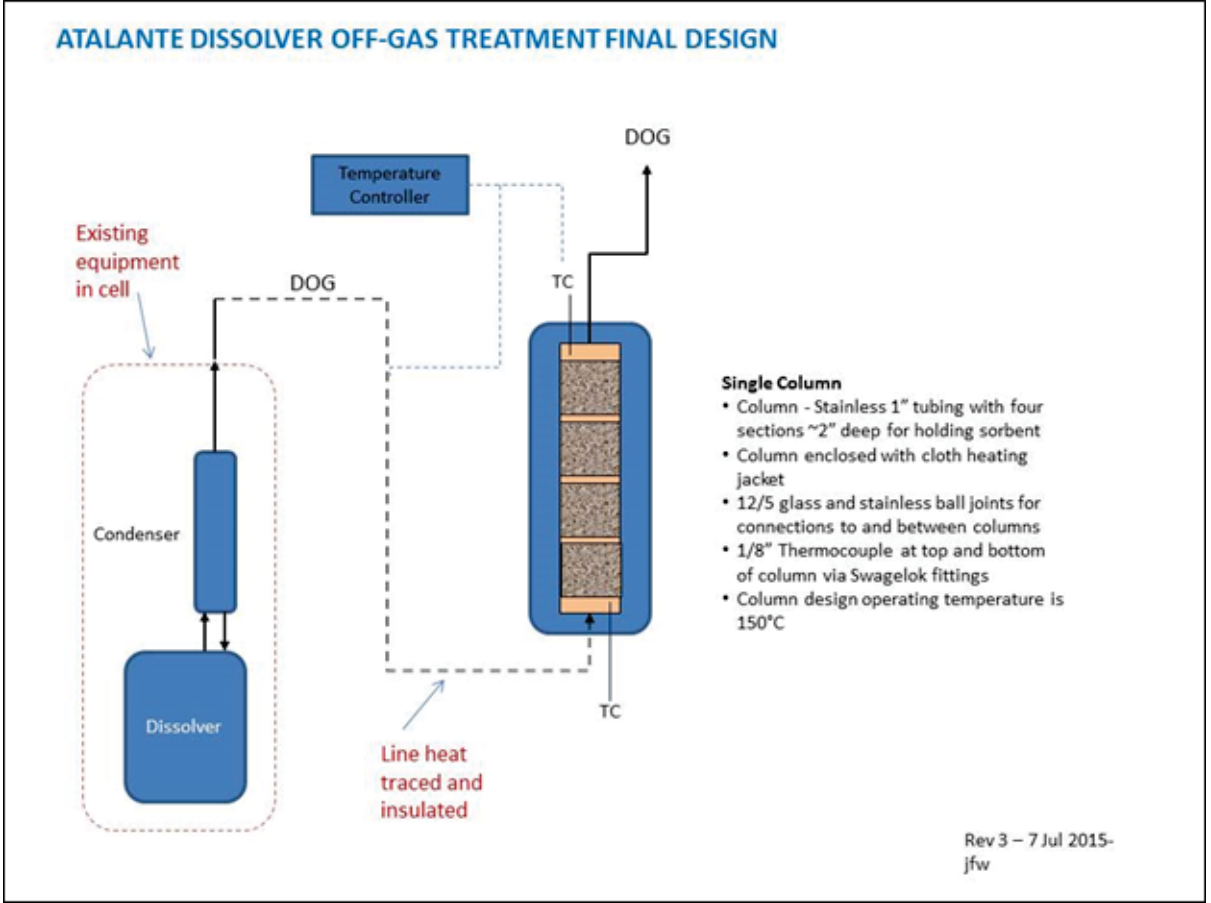

Figure 31. Schematic of ATALANTE iodine capture system

The column is completely covered by a heating jacket provided by HTS/Amptek ${ }^{\circledR}$, which is designed to heat and maintain the process gas and sorbent at $150^{\circ} \mathrm{C}$. To meet ATALANTE requirements, the jacket is designed to maintain a temperature $<50^{\circ} \mathrm{C}$ on all outer surfaces. Openings are provided at the top and bottom to accommodate thermocouples for measuring sorbent and gas temperatures as well as for accommodating the 1/4-in. lines for DOG entering and exiting the column. Power for the jacket is singlephase, 220-240 volts, and 65 watts. It is provided with a type $\mathrm{K}$ thermocouple, for temperature feedback 
to the temperature controller, and a NEMA-5-15P plug for electrical power. Both the thermocouple and the power cord are 48 -in. long.

The temperature controller for both the heat tape and the heating jacket was procured from TEMPCO. It is a Model TPC 30013 three zone controller which has a self-powered direct current of 2.7 A. Heating tapes rated at $240 \mathrm{~V}$ have been provided by HTS/Amptek should additional heating be required at the ATALANTE facility.

A photograph of the individual components used in the iodine capture system is presented in Figure 32. This system should be easily installed into the existing facility and should be straightforward to operate during future experimental testing. All parts were selected to be compatible with ATALANTE power supplies, space requirements, and the existing DOG treatment system. Additionally, the system was demonstrated to meet all of four design requirements for the ATALANE facility. These include (1) a dissolver off-gas flow rate of $\leq 100 \mathrm{~L} / \mathrm{h}(1.67 \mathrm{~L} / \mathrm{min})$, (2) an external temperature of $\leq 50^{\circ} \mathrm{C}$ for all system components placed in the hot cell, (3) a sorbent bed temperature of $\sim 150^{\circ} \mathrm{C}$, and (4) a gas temperature of $\sim 150^{\circ} \mathrm{C}$ upon entry into the sorbent bed. The system will be ready for shipment and installation in the existing DOG treatment system at ATALANTE in FY-16.

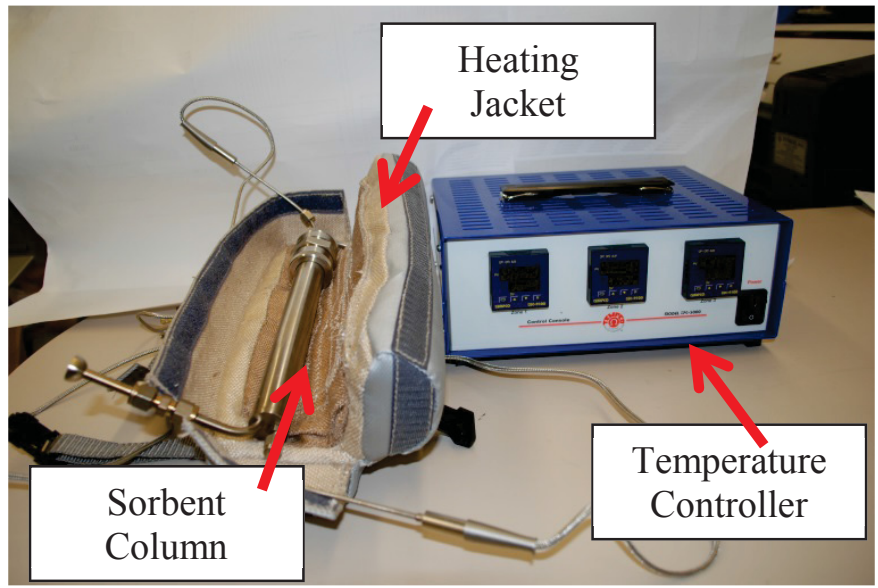

Figure 32. Photograph of the individual components of the iodine capture system.

\section{References}

Bruffey, S. H., K. K. Anderson, J. F. Walker Jr., and R. T. Jubin, 2013, "Humid Aging and Iodine Loading of Silver-Functionalized Aerogels,” FCRD-SWF-2013-000258, August 30, 2015.

Bruffey, S. H., K. K. Anderson, R. T. Jubin, and J. F. Walker Jr., 2012, "Aging and Iodine Loading of Silver-Functionalized Aerogels,” FCRD-SWF-2012-000256. August 31, 2015.

Bruffey, S. H., R. T. Jubin, K. K. Anderson, and J. F. Walker, Jr., 2013, "Aging and Iodine Loading of Ag0Z in a static 2\% NO2 Environment," ORNL/LTR-2013/351, U.S. Department of Energy

Separations and Waste Forms Campaign, August 2013.

Jubin, R. T., S. H. Bruffey, K. K. Patton, 2014, "Humid Aging and Iodine Loading of SilverFunctionalized Aerogels,” FCRD-SWF-2014-000594, September 2015. 


\subsection{Methyl lodide and lodine Adsorption in Deep Beds}

N. Soelberg, INL

Significant accomplishments for deep-bed iodine testing at the INL during FY-15 include (a) continued testing of $\mathrm{Ag}$ zeolite $(\mathrm{AgZ})$ for capturing organic iodides with methyl iodide $\left(\mathrm{CH}_{3} \mathrm{I}\right)$ as a surrogate, and (b) design, procurement, and testing of $\mathrm{HNO}_{3}$ and $\mathrm{NO}_{2}$ generators that expand the range of testing capability to simulate a wider range of dissolver off-gas (DOG) concentrations.

A long-term $\mathrm{CH}_{3} \mathrm{I}$ adsorption test was completed in August 2015. This test had higher $\mathrm{NO}$ and $\mathrm{NO}_{2}$ concentrations (1,000 ppm each compared to about $800 \mathrm{ppm}$ each) and a higher adsorbent temperature $\left(165^{\circ} \mathrm{C}\right.$ compared to $\left.150^{\circ} \mathrm{C}\right)$ than prior tests. Figure 33 shows the posttest iodine adsorption profile for the $8 \mathrm{in}$. deep bed of AgZ sorbent. The maximum iodine loading was about $6.1 \mathrm{wt} \%$. If the first $\sim 2 \mathrm{in}$. of bed depth reached a practical iodine capacity during this long-duration test, the maximum Ag utilization was only about $50 \%$, and the last $4-8$ in. of the bed depth only reached about $80 \%$ of the practical capacity. Additional sample and data analyses are in progress to determine iodine adsorption efficiencies and estimate the mass transfer zone. When compared to previous testing, both the capacity and Ag utilization for $\mathrm{CH}_{3} \mathrm{I}$ adsorption were about one-half to two-thirds of the respective values for $\mathrm{I}_{2}$ adsorption from simulated aqueous DOG streams.

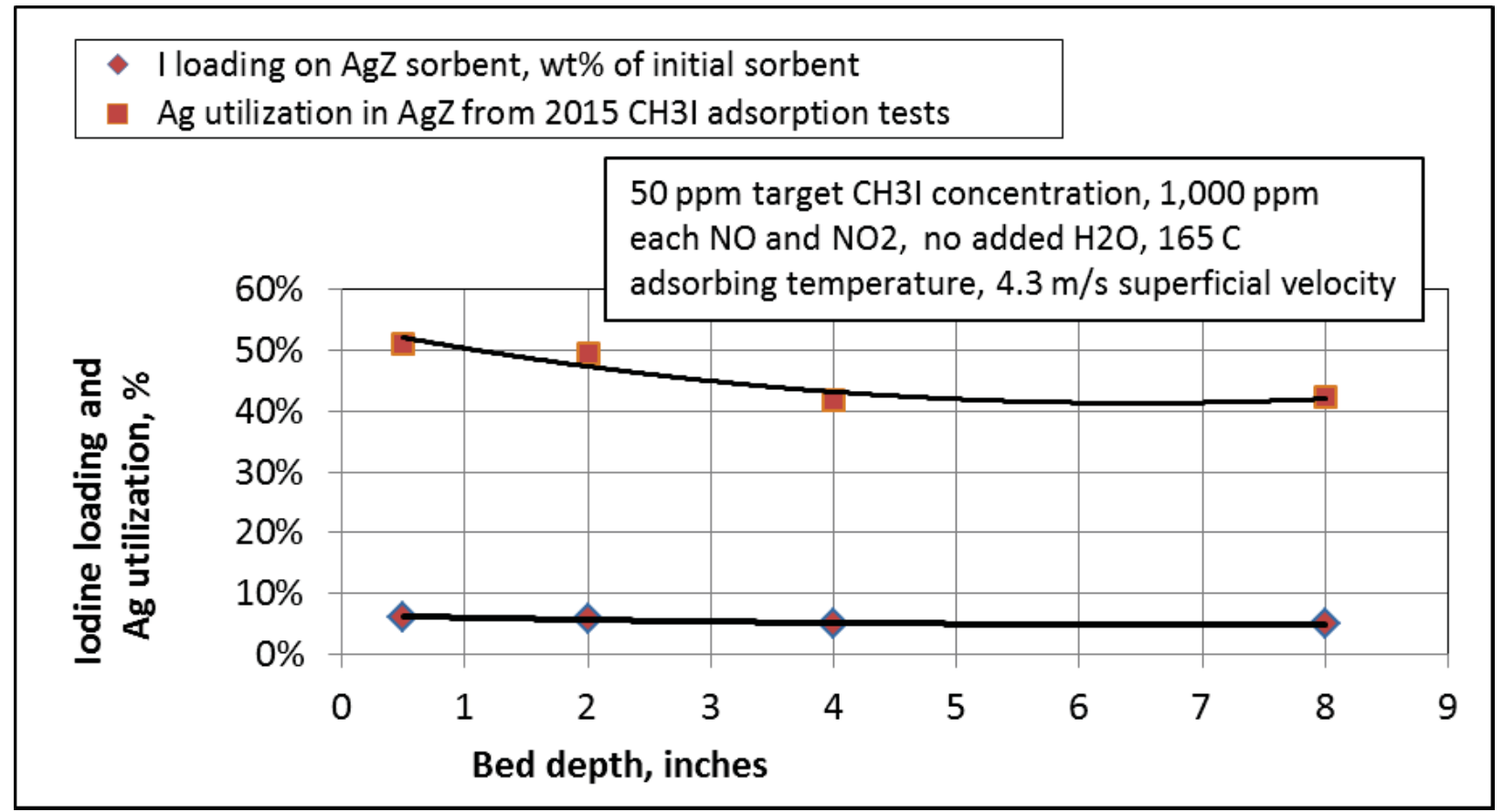

Figure 33. Practical iodine capacity and $\mathrm{Ag}$ utilization of $\mathrm{AgZ}$ sorbent for $\mathrm{CH}_{3} \mathrm{I}$ adsorption from simulated DOG streams.

For the recent Case Study ${ }^{1}$ and based on results of dissolver off-gas testing by Birdwell ${ }^{2}$, benchmark total $\mathrm{NO}_{\mathrm{x}}$ levels in the DOG stream downstream of a recycling condenser have been estimated at 1 volume \%, of which $\mathrm{NO}$ is $30 \%$ of the total $\mathrm{NO}_{\mathrm{x}}$. Higher $\mathrm{NO}_{2}$ concentrations in the INL deep-bed tests have been limited to $1,000 \mathrm{ppmv}$ due to the practicality and cost of using compressed gases for providing higher $\mathrm{NO}_{2}$ flowrates. In addition, testing to date has not yet included evaporated $\mathrm{HNO}_{3}$.

During FY-15, a gaseous $\mathrm{NO}_{2}$ generator and a gaseous $\mathrm{HNO}_{3}$ generator were designed, procured, and successfully tested to enable both higher concentrations of $\mathrm{NO}_{2}$ for the deep-bed iodine adsorption tests and also to provide for adding $\mathrm{HNO}_{3}$ vapor. The $\mathrm{NO}_{2}$ generator evaporates liquid $\mathrm{NO}_{2}$. The $\mathrm{HNO}_{3}$ 
generator evaporates $68 \mathrm{wt} \% \mathrm{HNO}_{3}$ in azeotropic solution with water. Both these generator systems required design and operation to mitigate hazards and approval from INL safety and fire subject matter experts for updating work control documentation.

\section{References}

1. J. D. Law, N. R. Soelberg, T. A. Todd, J. Tripp, C. Pereira, M. A. Williamson, W. L. Ebert, R. T. Jubin, B. A. Moyer, J. D. Vienna, G. J. Lumetta, J. V. Crum, T. S. Rudisill, J. Bresee, C. Phillips, B. Willis, P. Murray, and S. Bader, 2014, "Separation and Waste Form Campaign Full Recycle Case Study," FCRD-SWF-2013-000380, Rev. 1, INL.

2. J. F. Birdwell, 1991, "Iodine and $\mathrm{NO}_{\mathrm{x}}$ Behavior in the Dissolver Off-gas and IODCX Systems in the Oak Ridge National Laboratory Integrated Equipment Test Facility," NUREG/CP-011-Vol.1, Proceedings of the 21st DOE/NRC Nuclear Air Cleaning Conference, San Diego, CA, 1991, 271-298.

\subsection{Silver-Functionalized Silica-Aerogels: Progress Towards a Mechanically Robust Form, Performance and Consolidation}

\section{J. Matyáš, S. E. Sannoh, N. Canfield, PNNL; S. H. Bruffey, R. T. Jubin, ORNL}

Silver-functionalized silica aerogel ( $\mathrm{Ag}^{0}$-aerogel) is being developed for the removal and sequestration of iodine compounds from the off-gas of a nuclear fuel reprocessing plant. A three-step process ${ }^{1}$ is used to synthesize $\mathrm{Ag}^{0}$-aerogel in the form of granules larger than $0.85 \mathrm{~mm}$ with a surface area of $\sim 150 \mathrm{~m}^{2} / \mathrm{g}$, pore volume $\sim 0.5 \mathrm{~mL} / \mathrm{g}$, and bulk density $\sim 500 \mathrm{~kg} / \mathrm{m}^{3}$. Significant accomplishments in 2015 include: (1) production of aerogel with improved mechanical stability, (2) evaluation of the effects of aging in $1 \%$ $\mathrm{NO}$, and (3) direct consolidation of iodine-loaded $\mathrm{Ag}^{0}$-aerogel into a stable waste form.

While the mechanical disturbance of the sorbent inside the columns during sorption in the plant is expected to be minimal, it would still be beneficial to improve the mechanical properties of $\mathrm{Ag}^{0}$-aerogel for handling purposes. In FY-15 efforts were made to increase the strength of the aerogel porous structure. A high-temperature strengthening of silica aerogel produced a backbone for $\mathrm{Ag}^{0}$-aerogel with improved mechanical properties while retaining unique features of aerogel: high surface area $(1,105-$ $\left.1,170 \mathrm{~m}^{2} / \mathrm{g}\right)$, large pore volume $(8.1-8.9 \mathrm{~mL} / \mathrm{g})$, and mesoporous pore size distribution. The granules, with a hardness of $2.3 \mathrm{MPa}(\sim 7$ times higher than that of the as-received silica aerogel) and an elastic modulus of $14.6 \mathrm{MPa}(\sim 9$ times higher than that of the as-received silica aerogel), were produced by heating at $5^{\circ} \mathrm{C} / \mathrm{min}$ to $900^{\circ} \mathrm{C}$. $^{2}$

In off-gas treatment systems within a nuclear fuel reprocessing plant, sorbents will be exposed to gas streams containing $\mathrm{H}_{2} \mathrm{O}$ and $\mathrm{NO}_{\mathrm{x}}$ at elevated temperature for extended periods during their lifetime. It is therefore important to investigate the effects of this long-term exposure (denoted as "aging") on sorption performance. Previous studies showed that $\mathrm{Ag}^{0}$-aerogel retained high selectivity and sorption capacity for iodine even after a long-term exposure to dry/humid air and dry air containing $2 \% \mathrm{NO}_{2}$. A study conducted this year demonstrated that exposure of $\mathrm{Ag}^{0}$-aerogel to $1 \% \mathrm{NO}$ at $150^{\circ} \mathrm{C}$ for two months decreased sorption capacity by 43 relative percent, still an order of magnitude higher capacity than AgZ tested under the same conditions. ${ }^{3}$

To convert the iodine-loaded $\mathrm{Ag}^{0}$-silica aerogel into a waste form, rapid consolidation with hot uniaxial pressing (HUP), hot isostatic pressing (HIP), and spark plasma sintering (SPS) at moderate temperatures and pressures yielded a final waste form consisting of AgI particles encapsulated in fused silica. HUP processing at $1200^{\circ} \mathrm{C}$ for 30 min under $29 \mathrm{MPa}$ pressure of $\mathrm{Ag}^{0}$-aerogel loaded with 20.2 mass $\%$ of iodine 
provided a product with a residual open porosity of $16.9 \%$. The sintered material retained $\sim 93 \%$ of the sorbed iodine. Densification with HIP at $1200^{\circ} \mathrm{C}$ for 30 min under $207 \mathrm{MPa}$ pressure resulted in a fully dense waste form of $3.3 \times 10^{3} \mathrm{~kg} / \mathrm{m}^{3}$ bulk density containing $\sim 22$ mass $\%$ of iodine. ${ }^{4}$ A second fully dense waste form containing $\sim 38$ mass $\%$ of iodine in the form of uniformly dispersed nano- and microinclusions of $\mathrm{AgI}$ was also produced from highly iodine-loaded $\mathrm{Ag}^{0}$-aerogel using HIP.

Additives were not needed to enhance the sintering process, as evidenced by the lack of open porosity and $100 \%$ retention of iodine in the consolidated product. Figure 34 details the HIP-consolidated product; white and light gray areas represent AgI inclusions dispersed in the silica matrix (dark areas). Processing of samples with SPS with or without iodine revealed a benefit of additive-enhanced sintering. The samples with additives such as raw silica aerogel, colloidal silica, and $\mathrm{Ag}^{0}$-aerogel consolidated faster and at lower temperatures $\left(<900^{\circ} \mathrm{C}\right)$. In addition, additives significantly improved the distribution of silver compounds in the fully densified products, thereby considerably decreasing the number of micrometersized inclusions of $\mathrm{AgI}, \mathrm{Ag}$, and $\mathrm{Ag}_{2} \mathrm{~S}$ at the grain boundaries.
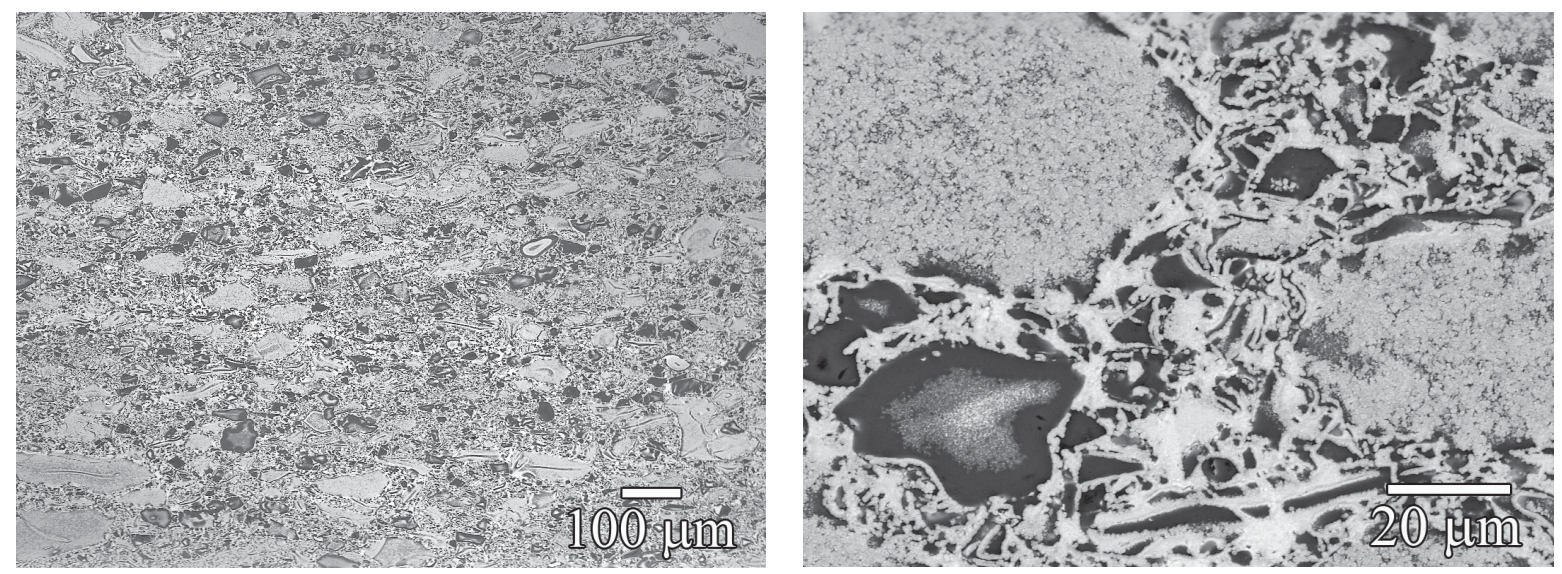

Figure 34. HIP-consolidated iodine-loaded silver-functionalized silica aerogel. White and light gray areas represent AgI inclusions dispersed in the silica matrix (dark areas).

\section{References}

1. J. Matyáš, G. E. Fryxell, B. J. Busche, K. Wallace, and L. S. Fifield, "Functionalized Silica Aerogels: Advanced Materials to Capture and Immobilize Radioactive Iodine," in Ceramic Materials for Energy Applications (Eds. H. Lin, Y. Katoh, K. M. Fox, I. Belharouak, S. Widjaja, and D. Singh), Hoboken, New Jersey: John Wiley \& Sons, doi: 10.1002/9781118095386.ch3, Ceramic Engineering and Science, 32(9): 23-33, 2011.

2. J. Matyáš and S. E. Sannoh, 2015, "Development of a Mechanically Robust Form of AgFunctionalized Silica Aerogel, FCRD-MRWFD-2015-000481, PNNL.

3. S. H. Bruffey, K. K. Patton, R. T. Jubin, 2015, "Complete Iodine Loading of NO-aged $\mathrm{Ag}^{0}$ Functionalized Silica Aerogel," FCRD-MRWFD-2015-000419, ORNL.

4. J. Matyáš and A. V. Walters, 2015, "Consolidation of Iodine-Loaded Ag ${ }^{0}$-Functionalized Silica Aerogel with HUP, HIP, and SPS,” FCRD-MRWFD-2015-000480, PNNL. 


\title{
4.6 Results of $\mathrm{Kr} / \mathrm{Xe}$ Multi-Column Adsorption tests
}

\author{
T. G. Garn, M. Greenhalgh, K. L. Lyon, A. K. Welty, T. L. Watson, C. Rae, INL
}

Off-gas research activities performed at INL have demonstrated that a hydrogen mordenitepolyacrylonitrile (HZ-PAN) engineered form sorbent can be used to effectively capture $\mathrm{Kr}$ at reduced temperatures $(\sim 190 \mathrm{~K})$ and that silver converted mordenite-polyacrylonitrile (AgZ-PAN) engineered form sorbent shows a high selectivity for Xe over $\mathrm{Kr}$ at or near room temperature (295 to $220 \mathrm{~K}$ ). ${ }^{1}$ Building upon this information, a second cooler and column were added to existing test setups to create a multi-column test bed that would be used to demonstrate the effective separation of $\mathrm{Xe}$ and $\mathrm{Kr}$ from a mixed gas feed stream. A schematic of the new multi-column system can be seen in Figure 35.

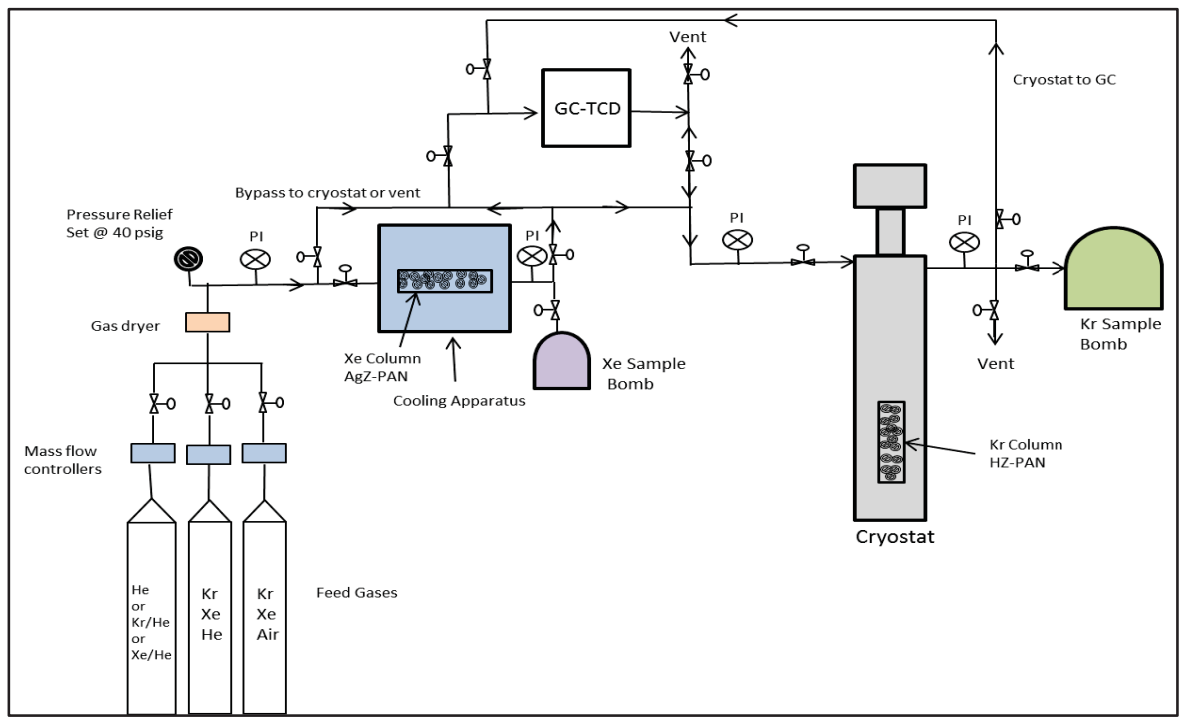

Figure 35. Multi-column experimental test bed.

The AgZ-PAN sorbent, due to its Xe selectivity, was loaded in the first column to capture Xe while allowing $\mathrm{Kr}$ to flow through and be routed to a second column containing HZ-PAN for capture and subsequent analysis. Two separation tests were performed utilizing a feed gas consisting of 1,000 ppmv $\mathrm{Xe}$ and $150 \mathrm{ppmv} \mathrm{Kr}$ (balanced with air). The AgZ-PAN column temperature was held at either 295 or $253 \mathrm{~K}$ while the HZ-PAN column was held at $191 \mathrm{~K}$ for both tests. The gases captured on both columns were sampled with evacuated sample bombs and subsequently analyzed with GC-MS for both $\mathrm{Kr}$ and Xe. $\mathrm{The} \mathrm{Kr}$ and $\mathrm{Xe}$ gas concentrations analyzed from the sample bombs found in Table 7 indicate that an excellent separation of $\mathrm{Xe}$ from $\mathrm{Kr}$ could be attained with the newly installed multi-column system. Results demonstrated that the choice of operational parameters will affect the purity of the Kr product.

Table 7. Xe/Kr concentrations from sample bombs

\begin{tabular}{llll}
\hline Temperature $(\mathrm{K})$ & Column Sample & Average Xe $(\mathrm{ppm})$ & Average Kr $(\mathrm{ppm})$ \\
\hline 295 & Xe Column & 52 & 70 \\
295 & Kr Column & 1 & 50 \\
253 & Xe Column & BDL & 91 \\
253 & Kr Column & BDL & 273 \\
\hline
\end{tabular}

The sample bomb gas collection and analysis procedure provided inconsistent results, although it does indicate that effective $\mathrm{Xe}$ and $\mathrm{Kr}$ desorption from the sorbents requires not only temperature or pressureswing operation but also a flow of purge gas, which is to be expected based on adsorption isotherm 
theory. The sample bomb procedure should be refined and made consistent from sample to sample if it is to be used in future tests.

The results of these initial tests can be used to develop the scope of future testing and analysis using this test bed for demonstrating the capture and separation of $\mathrm{Xe}$ and $\mathrm{Kr}$ using sorbents, for demonstrating desorption and regeneration of the sorbents, and for determining compositions of the desorbed gases.

\section{References}

1. T. G. Garn, M. R. Greenhalgh, and T. Watson, 2015, "Xe/Kr Selectivity Measurements Using AgZPAN at Various Temperatures," FCRD-MRWFD-2015-000586.

\section{Publications}

Garn, T. G., M. R. Greenhalgh, and J. D. Law, 2015, "Development and Evaluation of a Silver Mordenite Composite Sorbent for the Partitioning of Xenon from Krypton in Gas Compositions," Journal of Nuclear Science and Technology, submitted July 28, 2015.

Garn, T. G., M. R. Greenhalgh, T. Watson, 2014, "Development and Design of a Multi-column Experimental Setup for Kr/Xe Separation,” FCRD-MRWFD-2015-000589, Dec. 24, 2014.

Garn, T. G., M. Greenhalgh, K. L. Lyon, and J. D. Law, 2015, "Multi-Component Testing Using HZPAN and AgZ-PAN Sorbents for OSPREY Model Validation," FCRD-MRWFD-2015-000269, April 24, 2015.

Garn, T. G., 2015, “Complete Setup of Multi-column Experimental Test Bed,” FCRD-MRWFD-2015000585, June 24, 2015.

Greenhalgh, M., T. G. Garn, A. Welty, K. Lyon, and T. Watson, 2015, "Multi-Column Experimental Test Bed for Xe/Kr Separation,” FCRD-MRWFD-2015-000047, August 31, 2015. 


\subsection{Effects of Functionalization of MOFs on $\mathrm{Kr} / \mathrm{Xe}$ Capture, Separation, and Stability}

\section{P. K. Thallapally, PNNL}

In an effort to develop advanced materials with improved Xenon (Xe) and Krypton (Kr) adsorption capacity and selectivity, we recently synthesized from inexpensive starting material a new metal organic framework (MOF) that forms a one dimensional channel with average cross section of $5.9 \AA \times 5.8 \AA$ (Figure 36). The material shows high thermal stability $\left(\sim 500^{\circ} \mathrm{C}\right)$, higher than most of the MOFs reported in the literature. ${ }^{1}$ The pure-component Xe adsorption isotherms at room temperature indicate the MOF saturates quickly (at $20 \mathrm{kPa}$ ), indicative of a strong framework-Xe interaction. The MOF shows high Xe uptake of $0.075 \mathrm{mmol} / \mathrm{g}$ at $3 \mathrm{kPa}$, which is considerably higher than the current benchmark materials NiMOF-74 and CC3 under similar experimental conditions. In contrast, the $\mathrm{Kr}$ adsorption isotherm exhibits a smaller uptake and does not saturate even at $100 \mathrm{kPa}$, indicative of a much weaker framework$\mathrm{Kr}$ interaction. This indicates that this new MOF is highly discriminatory for Xe over $\mathrm{Kr}$. At $100 \mathrm{kPa}$, the MOF adsorbs $1.3 \mathrm{mmol} / \mathrm{g}$ of Xenon at room temperature; however, under the same condition $\mathrm{Kr}$ adsorption is $0.8 \mathrm{mmol} / \mathrm{g}$. The $\mathrm{Kr}$ loading can be significantly improved by lowering the temperature (1.3 $\left.\mathrm{mmol} / \mathrm{g} ; 5^{\circ} \mathrm{C}\right)$.
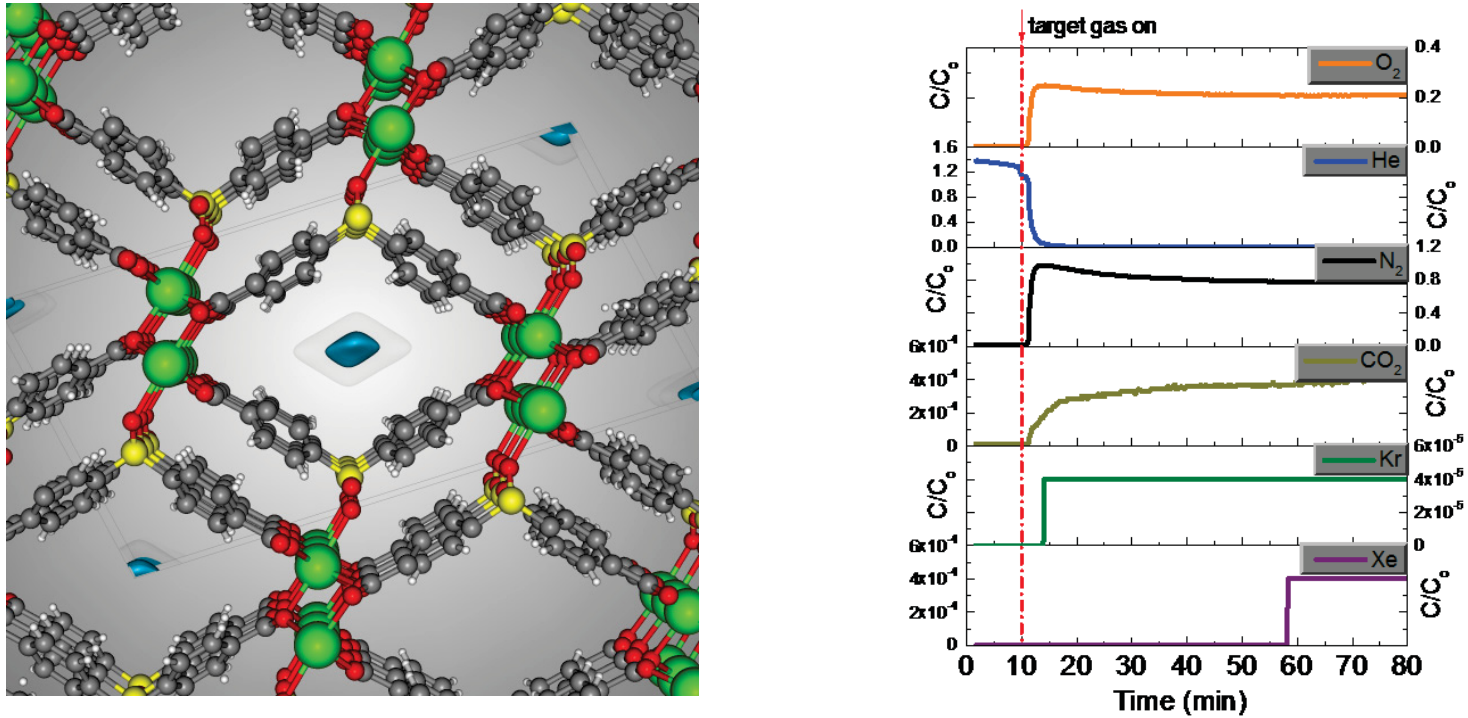

Figure 36. Solid-state packing of a new MOF with active site is shown in blue (left). The single-column breakthrough experiments using a gas mixture with $400 \mathrm{ppm} \mathrm{Xe,} 40 \mathrm{ppm} \mathrm{Kr}, 78 \% \mathrm{~N}_{2}, 21 \% \mathrm{O}_{2}, 0.9 \% \mathrm{Ar}, 0.03 \% \mathrm{CO}_{2}$ in $40 \%$ relative humidity.

Single-column breakthrough experiments on the new MOF were conducted using a gas mixture containing $400 \mathrm{ppm} \mathrm{Xe}, 40 \mathrm{ppm} \mathrm{Kr}, 78 \% \mathrm{~N}_{2}, 21 \% \mathrm{O}_{2}, 0.9 \% \mathrm{Ar}, 0.03 \% \mathrm{CO}_{2}$ at room temperature (Figure $36)$. The material shows a very high Xe adsorption capacity under these conditions $(14 \mathrm{mmol} / \mathrm{kg})$. The $\mathrm{Xe} / \mathrm{Kr}$ selectivity under breakthrough measurements was found to be 14, twice the value observed for NiMOF-74. Remarkably, the MOF retains its Xe uptake capacity even in the presence of water vapor ( $40 \%$ relative humidity) whereas water competes for the same adsorption sites as $\mathrm{Xe} / \mathrm{Kr}$ in NiMOF-74 and CC 3 under similar conditions. The outstanding Xe capacity under simulated conditions with and without water vapor makes this new MOF a leading candidate for separating the $\mathrm{Xe} / \mathrm{Kr}$ from nuclear reprocessing applications. 


\section{References}

1. E. A. Chen, P. S. Riess, S. Y. Chong, D. Holden, K. E. Jelfs, T. Hasell, M. A. Little, A. Kewley, M. E. Briggs, A. Stephenson, M. Thomas, J. A. Armstong, J. Bell. J. Busto, R. Noel, J. Liu, D. M. Strachan, P. K. Thallapally, A. I. Cooper, 2014, "Separation of Rare Gases and Chiral Molecules by Selective Binding in Porous Organic Cages," Nature Materials: 1-7.

\section{Publications}

Liu, J., C. A. Fernandez, P. F. Martin, P. K. Thallapally and D. M. Strachan, “A Two-Column Method for the Separation of $\mathrm{Kr}$ and Xe from Process Off-Gases," Industrial \& Engineering Chemistry Research 53(32), 2014: 12893-12899.

Liu, J., D. M. Strachan and P. K. Thallapally, "Enhanced noble gas adsorption in Ag@MOF-74Ni." Chemical Communications 50(4), 2014: 466-468.

\subsection{Analysis of Penetrating Forms of lodine}

S. H. Bruffey, R. T. Jubin, B. B. Spencer, ORNL; D. M. Strachan, Strata-G, LLC; N. R. Soelberg, INL; B. J. Riley, PNNL

The study of inorganic iodide in off-gas systems has been almost exclusively limited to $\mathrm{I}_{2}$, and the focus of organic iodide studies has been $\mathrm{CH}_{3} \mathrm{I}$. In FY-15, an examination of publicly available literature that is relevant to the presence and sources of both inorganic and organic iodine-bearing species in reprocessing plants was conducted. This review focused especially on iodine forms that have the potential to be poorly sequestered with traditional capture methodologies. These forms have historically been known as penetrating iodine-bearing species. Motivation for this study is was based upon the restriction of iodine release by U.S. Environmental Protection Agency regulation governing nuclear facilities (40 CFR 190), which states that the total quantity of radioactive materials entering the general environment from the entire uranium fuel cycle, per gigawatt-year of electrical energy produced by the fuel cycle, must contain less than $5 \mathrm{mCi}$ of ${ }^{129} \mathrm{I}$. The practical impact of this regulation is that very high decontamination factors for iodine must be achieved in off-gas streams to meet the EPA regulation.

To understand the importance of capturing penetrating forms of iodine, a calculation of the overall plant decontamination factor (DF) was carried out by estimating the iodine splits, speciation and individual DFs for each off-gas stream within the UNF reprocessing plant. This analysis led to several key observations. First, in spite of high decontamination factors (DFs) for treatment of the dissolver off-gas (DOG), the losses to the head-end cell control the overall plant DF. Second, the vessel off-gas (VOG) DF may be limiting to the overall plant DF as it is the stream where penetrating, or difficult to remove, iodine species are most likely. Additionally, iodine is present in very dilute concentration in the VOG which can negatively affect its abatement. This concentration effect may complicate the efficient abatement of iodine in both the VOG and cell-off gas (COG) streams. Third, the contributions from penetrating forms of iodine to the plant DF are largely unknown; the overall plant DF depends strongly on the possible DF value that can be achieved for these penetrating forms at each off-gas stream.

Based on the results of the literature survey and some limited thermodynamic modeling, the inorganic iodine species $\mathrm{HOI}$ and $\mathrm{ICl}$ were identified as penetrating iodine species that could present in off-gas systems. Organic species of interest included both short chain alkyl iodides such as methyl iodide $\left(\mathrm{CH}_{3} \mathrm{I}\right)$ and longer alkyl iodides such as iodododecane $\left(\mathrm{C}_{12} \mathrm{H}_{25} \mathrm{I}\right)$. Both inorganic and organic iodine-bearing 
species will be released into the off-gas by various processes throughout the plant, creating a potentially complicated abatement problem.

Specifically, fuel dissolution may provide conditions conducive to HOI formation and has been proven to generate long-chain alkyl iodides although these may not volatilize until later in the reprocessing sequence. Solvent extraction processes are expected to be significant sources of various organic iodinebearing species; formation of these is facilitated by the presence of radiolytic decomposition products resulting from radiolysis of tri- $n$-butyl phosphate and dodecane. Primarily inorganic iodine compounds are expected from waste management processes, including chlorinated species such as ICl.

Critical knowledge gaps that must still be addressed include confirmation of the existence and, if possible, quantification of low-sorbing species in the off-gas of reprocessing facilities. In many cases, confirmation of their presence is a difficult analytical problem as iodine-bearing species are a function of process environment and may evolve over time and distance from point of origin in plant before reaching the iodine traps due to gas phase reactions with other volatile compounds. Beyond confirmation, quantification of these species may also be desired. Closure of these knowledge gaps would allow for better analysis of the contribution that penetrating forms of iodine may have on achieving the desired overall plant target DF. Upon confirmation of the species present in an off-gas system, characterization of their behavior throughout the iodine abatement system should be performed.

This review indicates that penetrating iodine-bearing species may respond differently than elemental iodine to current capture technology. These species are likely to be more difficult to remove, and it is likely that their sequestration could be improved through the use of different sorbents, through design modifications of the off-gas capture system, or through chemical conversion prior to iodine abatement that would produce more easily captured forms. This type of research will be valuable in determining the impact that potentially penetrating iodine species have on the DF of a reprocessing facility and will allow design of a facility that can provide the highest quality of iodine abatement.

\section{Publications}

Bruffey, S.H., B.B. Spencer, D. M. Strachan, R. T. Jubin, N Soelberg, and B. J. Riley, 2015, “A Literature Survey to Identify Potentially Problematic Volatile Iodine- Bearing Species Present in Offgas Streams,” FCRD-MRWFD-2015-000421, ORNL-SPR-2015/290, INL/EXT-15-35609.

Jubin, R., N. Soelberg, D. Strachan, and G. Ilas, 2011, “Assessments and Options for Removal and Immobilization of Volatile Radionuclides from the Processing of Used Nuclear Fuel," FCRD-SWF2011-000305, ORNL.

Jubin, R., N. Soelberg, D. Strachan, and G. Ilas, 2012, "Fuel Age Impacts on Gaseous Fission Product Capture During Separations,” FCRD-SWF-2012-000089, PNNL-22550, ORNL. 


\title{
4.9 Scale-Up of GCM Materials for lodine Waste Forms
}

\author{
T. M. Nenoff, P. V. Brady, C. Mowry, T. J. Garino, K. Croes, M. A. Rodriguez, SNL
}

Development of iodine waste forms has focused on silver loaded zeolite waste forms, evaluation of iodine loaded getter materials (e.g., mordenite zeolite), and the development of low-temperature glass waste forms that successfully incorporate iodine loaded getter materials from $\mathrm{I}_{2}$, organic iodide, etc. containing off-gas streams.

This year the fabrication of two scaled-up Glass Composite Material (GCM) waste forms containing AgImordenite was completed. The first contained methyl iodide-loaded AgI-mordenite that was received from INL and the second contained iodine vapor loaded AgI- mordenite that was received from ORNL. These waste forms are shown in Figure 37.

The composition for each GCM was $20 \mathrm{wt} \%$ AgI-mordenite and $80 \mathrm{wt} \%$ Ferro EG2922 low-sinteringtemperature glass along with enough added silver flake to limit $\mathrm{I}_{2}$ loss during the firing process. Those silver amounts were $1.2 \mathrm{wt} \%$ for the GCM with the INL AgI-mordenite and $3 \mathrm{wt} \%$ for the GCM contained the ORNL AgI-moredenite. The GCMs, nominally $100 \mathrm{~g}$, were first uniaxially pressed to 6.35$\mathrm{cm}$ (2.5-in.) diameter disks then cold isostatically pressed before firing in air to $550{ }^{\circ} \mathrm{C}$ for $1 \mathrm{hr}$. They were cooled slowly $\left(1^{\circ} \mathrm{C} / \mathrm{min}\right)$ from the firing temperature to limit cracking due to temperature gradients.

The final GCMs were $\sim 5 \mathrm{~cm}$ in diameter and were non-porous with densities of $\sim 4.2 \mathrm{~g} / \mathrm{cm}^{3}$. X-ray diffraction indicated that they consisted of the amorphous glass phase with mordenite and AgI, whose presence was confirmed also by x-ray fluorescence. Next steps could include further scale up of the GCM to industrial sizes, durability studies on the GCM, optimization of composition and sintering conditions based on variables such as $\mathrm{N}_{2}$ or $\mathrm{He}$ versus air sintering atmosphere (in $\mathrm{N}_{2}$ or $\mathrm{He}$ environments, additional $\mathrm{Ag}$ flake is not as necessary as sintering in air).

It is anticipated that these scaled-up GCMs will exhibit the same durability characteristics as have been reported for smaller versions in years past. This hypothesis is based upon (1) the consistency of the procedure in scaling up from small scale to the $\sim 2$-in.-diameter size GCM, (2) the replication of appearance of the GCMs in larger size, and (3) the complimentary materials characterization results (XRD, XRF and water-drop porosity test) when comparing small- and large-scale GCMs. Data collected for small scale GCMs showed that the durability of the small scale GCM and release rates approximated those of established nuclear waste glasses, or analogues such as basaltic glass. This suggests that the $\mathrm{Bi}-$ $\mathrm{Si}-\mathrm{Zn} \mathrm{GCM}$ of either size is a viable candidate as a repository iodine waste form. 


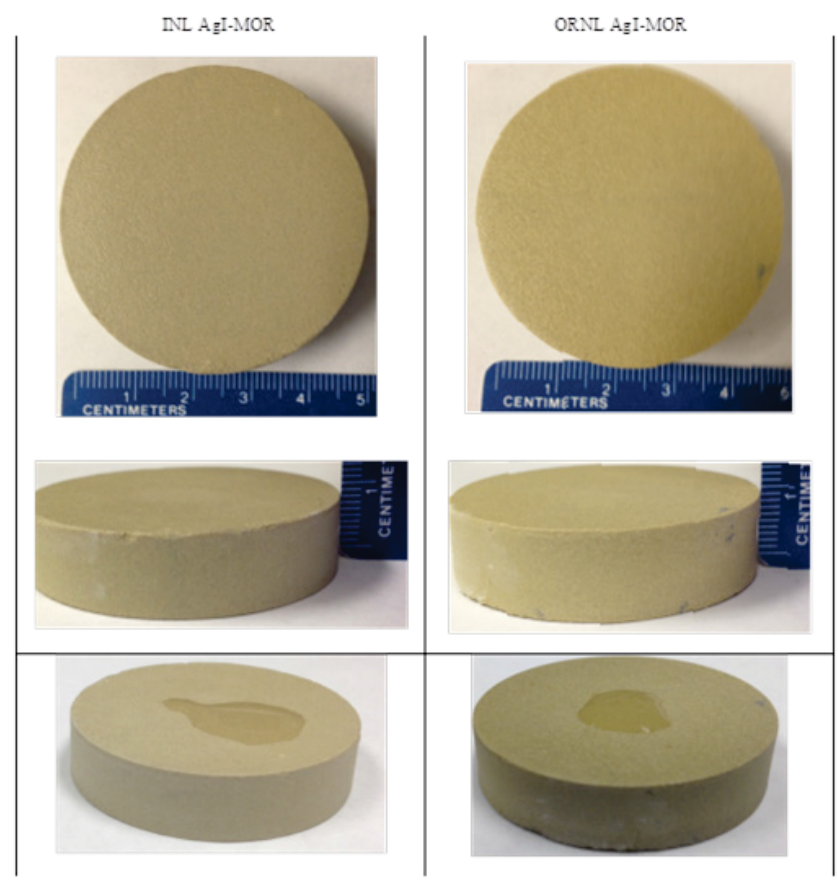

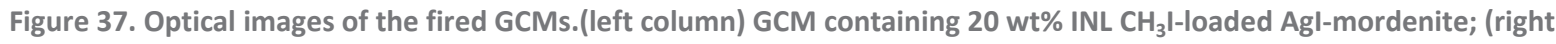
column) GCM containing 20 wt\% ORNL I -loaded Agl-moredenite.

\section{Publications}

Garino, T. J., Tina M. Nenoff, Mark A. Rodriguez, and Kenneth Croes, July 2015, "Demonstrate Scale-up Procedure for Glass Composite Material (GCM) for Incorporation of Iodine Loaded AgZ," FCRDMRWFD-2015-000120, SNL.

\subsection{Vessel Off-Gas Testing of Silver Exchanged Mordenite}

\section{S. H. Bruffey and R. T. Jubin, ORNL}

An important focus of FY-15 iodine capture testing has been the investigation of iodine abatement from the vessel off-gas (VOG) stream. This stream may contain 1-3\% of the total iodine entering the plant in a large volume of air, resulting in iodine concentrations at parts-per-billion (ppb) levels. It is also likely that this stream will contain a large proportion of organic iodine species, such as methyl iodide $\left(\mathrm{CH}_{3} \mathrm{I}\right)$. In addition to low concentrations of iodine and organic iodine species, the sorbent will also be exposed to moist air as a component. Testing was designed to explore the performance of silver-exchanged mordenite (AgZ) as iodine sorbent under these challenging conditions.

Two tests of extended duration ( $\sim 4$ months) were conducted in FY-15. In the first, AgZ was exposed to a feed stream containing $20 \mathrm{ppb} \mathrm{I}_{2}$; the second feed stream contained $40 \mathrm{ppb} \mathrm{CH}_{3} \mathrm{I}$. In both cases, the sorbent and gas were held at $150^{\circ} \mathrm{C}$ and the feed stream contained moist air with an inlet dew point of $0^{\circ} \mathrm{C}$. The sorbent material was contained in three glass columns with an internal diameter of roughly $1 \mathrm{in}$. The first column contained a very thin bed of $\mathrm{AgZ}$ that was subdivided into quadrants. Quadrants were periodically removed from this bed during testing to allow determination of the loading rate of the material. The second column was a deep bed that remained online for the full test duration. It was removed in segments to enable resolution of the iodine adsorption through the bed. The third column 
contained a thin bed that was periodically removed and replaced to analyze for iodine breakthrough. The loaded sorbent was analyzed by neutron activation analysis for iodine concentration.

A process upset was experienced during the first test, conducted with $\mathrm{I}_{2}$. This resulted in a spike in $\mathrm{I}_{2}$ concentration during the first week of the test. Despite this upset, no iodine was observed to break through the last column. Without breakthrough (which is unlikely at such low concentrations), exact calculation of DF is not possible, but based on analytical detection limits, the minimum DF is $>23$. In practical application, it is likely much higher. Penetration of iodine into the deep bed was limited to 3.5 in.

The second test, conducted with $\mathrm{CH}_{3} \mathrm{I}$, resulted in the adsorption profile shown in Figure 38. It is observed that $\mathrm{CH}_{3} \mathrm{I}$ penetrated approximately 4.5 in into the deep bed, confirming that it is a more challenging species to capture than $\mathrm{I}_{2}$. This is especially true in light of the feed concentration spike observed in $\mathrm{I}_{2}$ testing, which resulted in a substantially larger total amount of iodine abated by the sorbent beds. Analytical detection limits for the second test allowed the determination of 173 as the minimum possible DF for the tested conditions.

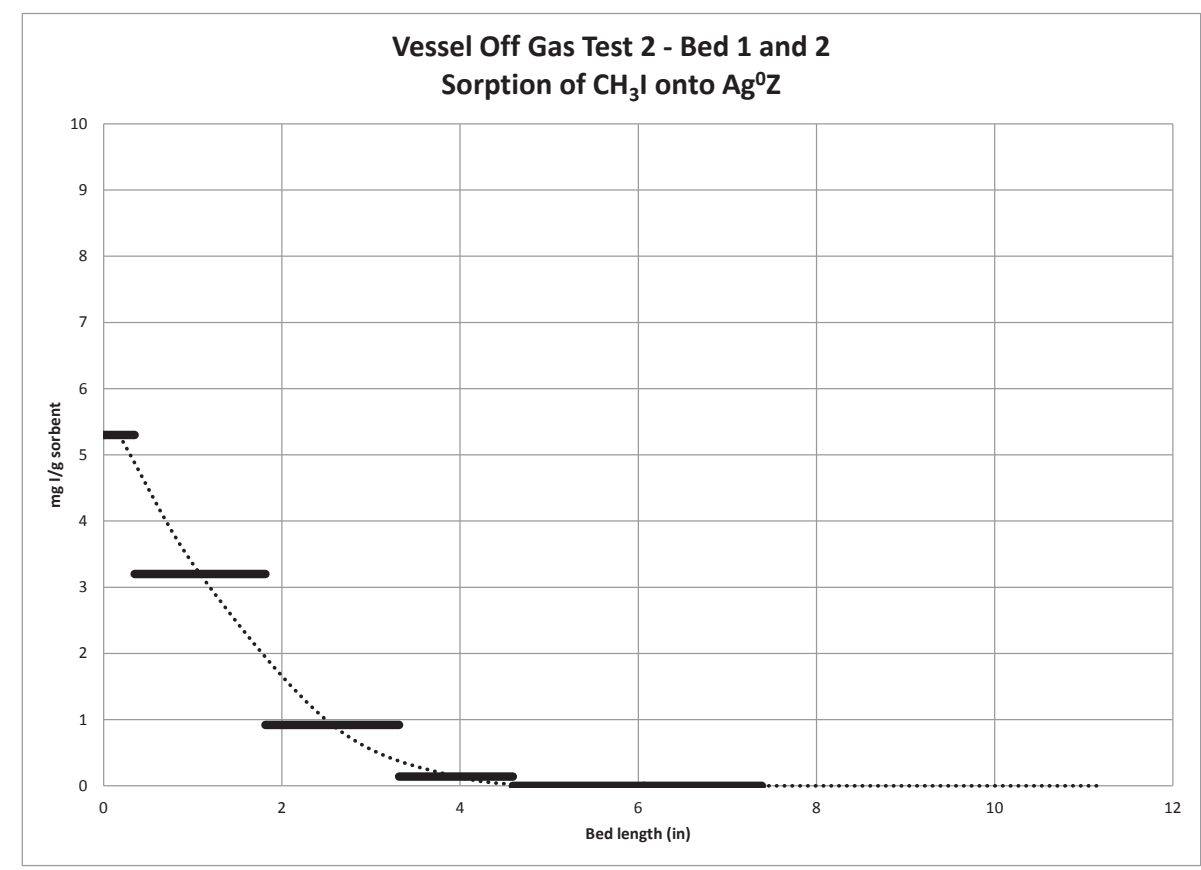

Figure 38. Sorption of $\mathrm{CH}_{3}$ I onto $\mathrm{Ag}^{0} \mathrm{Z}$ under prototypical VOG conditions

Three tests are planned for the upcoming fiscal year. These include (1) replication of $\mathrm{I}_{2}$ testing because of the process upset, (2) adsorption of $\mathrm{I}_{2}$ onto $\mathrm{Ag}^{0}$-aerogel, and (3) adsorption of a longer-chain alkyl iodide onto AgZ. 
This page intentionally left blank. 


\section{Waste Form Development and Performance}


This page intentionally left blank. 


\title{
5. WASTE FORM DEVELOPMENT AND PERFORMANCE
}

\subsection{Characterization of Ceramic Produced from a Cold Crucible Induction Melter Test}

\author{
V. Maio, INL; M. Tang, LANL; J. Amoroso, SRNL
}

Melt-processed reference ceramic waste forms were developed for treatment of waste streams generated by reprocessing commercial spent nuclear fuel. The waste form is designed to crystallize upon cooling from a melt (melt-processing) into a multiphase ceramic. Compositions are designed based on combinations of the waste and additives to target various phases. Elements with a +3 or +2 valance form perovskite $\left(\left(\mathrm{A}^{+2}\right) \mathrm{TiO}_{3}\right)$ and pyrochlore $\left(\left(\mathrm{A}^{+3}\right)_{2} \mathrm{Ti}_{2} \mathrm{O}_{7}\right)$ type phases. ${ }^{1,2}$ Zirconium $(+4$ valence $)$ partitions to a zirconolite $\left(\mathrm{CaZrTi}_{2} \mathrm{O}_{7}\right)$ phase. ${ }^{3} \mathrm{Cs}, \mathrm{Ba}$, and $\mathrm{Rb}$ elements partition to a hollandite structure based on the general formula $\mathrm{Ba}_{\mathrm{x}} \mathrm{Cs}_{\mathrm{y}} \mathrm{M}_{\mathrm{z}} \mathrm{Ti}^{+4}{ }_{8-\mathrm{z}} \mathrm{O}_{16}$ where $\mathrm{z}=2 \mathrm{x}+\mathrm{y}$ for trivalent cations and $\mathrm{z}=\mathrm{x}+\mathrm{y} / 2$ for divalent cations for charge compensation. ${ }^{4-6}$

The first scaled proof of principle test for processing multi-phase crystalline waste forms from a melt was completed using the cold crucible induction melter (CCIM) at INL in October 2014. ${ }^{7}$ During this initial test, although the drain operation could not be completed, a ceramic was fabricated from a melt process for treating the HLW stream generated from an envisioned commercial spent nuclear fuel reprocessing flow sheet. Core samples at various radial locations from the center of the CCIM were taken. These samples were also sectioned and analyzed vertically. Characterization performed throughout various locations (both vertically and radially) in the processed material confirmed that the ceramic material was highly crystalline, durable, compositionally homogenous, and the target phases were formed.

The CCIM material composition was comparable to the target composition (Table 8). Cs retention was measured at $\sim 70 \%$, which compares favorably to laboratory experiments which generally indicated about $50 \%$ Cs retention. Note that in a production facility, the melt will be operated with a cold-cap that have been demonstrated to significantly reduce volatility of $\mathrm{Cs}$ and other semivolatile components. Fe redox measurements indicated that the CCIM material was partially reduced $\left(\sim 20 \% \mathrm{Fe}^{2+}\right)$. The redox state is important because reduced melts are known to have positive effects on the final properties of the ceramic. $^{8,9}$

Table 8. Measured elemental concentrations (wt. \%) in the bulk CCIM sample.

\begin{tabular}{|c|c|c|c|c|c|}
\hline Element & Target & Measured & Element & Target & Measured \\
\hline Al & 0.00 & 2.21 & Nd & 4.19 & 4.02 \\
\hline $\mathbf{B a}$ & 10.69 & 10.54 & Pr & 1.16 & 1.21 \\
\hline $\mathbf{C a}$ & 0.93 & 0.93 & $\mathbf{R b}$ & 0.36 & n.m. \\
\hline Cd & 0.09 & $<0.10$ & Se & 0.05 & $<0.10$ \\
\hline $\mathrm{Ce}$ & 2.48 & 2.47 & $\mathbf{Z r}$ & 2.07 & 1.97 \\
\hline Cs & 2.54 & 1.73 & Sm & 0.87 & 0.85 \\
\hline $\mathbf{E u}$ & 0.14 & 0.12 & Sn & 0.05 & n.m. \\
\hline $\mathbf{F e}$ & 10.00 & 9.88 & $\mathrm{Sr}$ & 0.78 & 0.99 \\
\hline Gd & 0.13 & 0.12 & Te & 0.49 & 0.13 \\
\hline La & 1.26 & 1.22 & $\mathbf{T i}$ & 27.55 & 30.13 \\
\hline Мo & 0.53 & 0.15 & $\mathbf{Y}$ & 0.46 & 0.40 \\
\hline
\end{tabular}

X-ray diffraction (XRD) and scanning electron microscopy (SEM) confirmed three primary phases in the core samples were hollandite, pyrochlore, and zirconolite. In general, the XRD results indicate material in 
the CCIM was homogenous throughout (vertically and radially) the melt. Phase abundances calculated from the XRD patterns are summarized in Figure 39 and indicate the phases are formed as desired. Figure 40 shows elemental maps and Table 9 lists the corresponding chemical analysis in which the target phases are identified by stoichiometry.

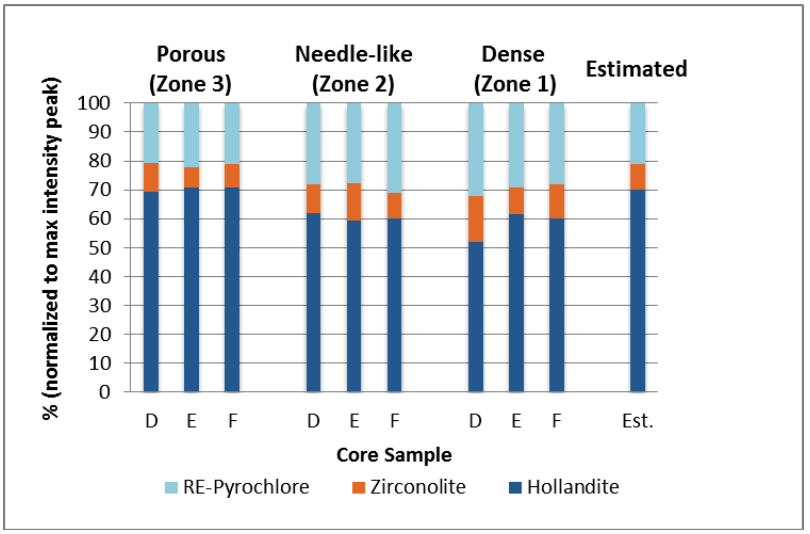

Figure 39. Summary of primary phase abundances in core samples compared to estimated abundances based on feed composition and target phase assemblage.
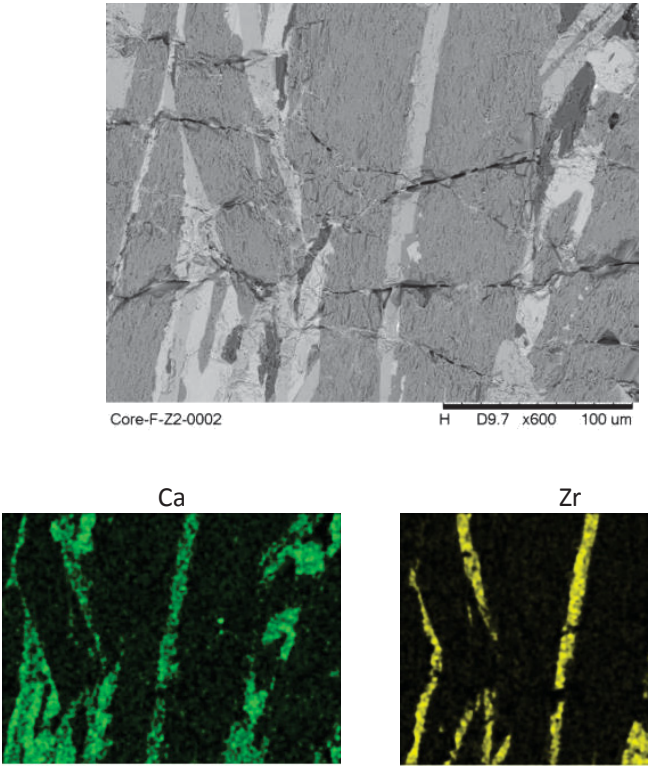

$100 \mu \mathrm{m}$

Mo

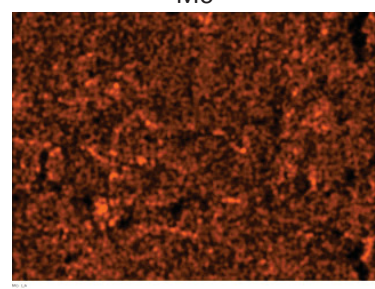

$100 \mu \mathrm{m}$
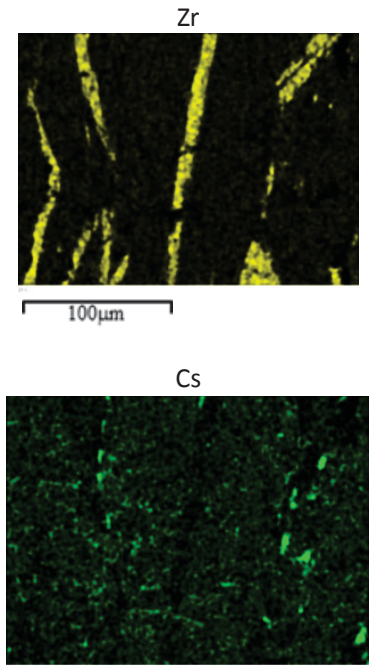

$100 \mu \mathrm{m}$

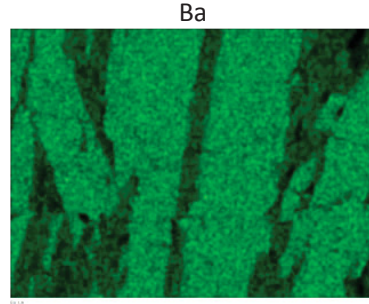

$\longdiv { 1 0 0 \mu \mathrm { m } }$

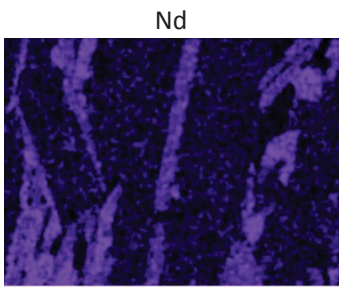

$100 \mu \mathrm{m}$

$\mathrm{Ce}$

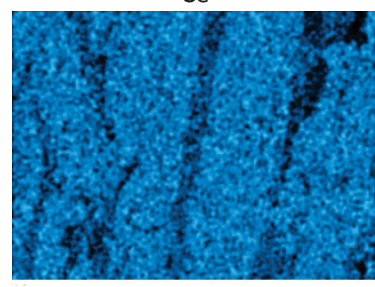

$100 \mu \mathrm{m}$

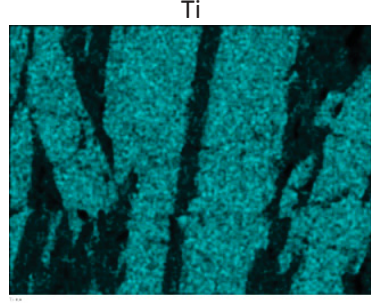

$100 \mu \mathrm{m}$

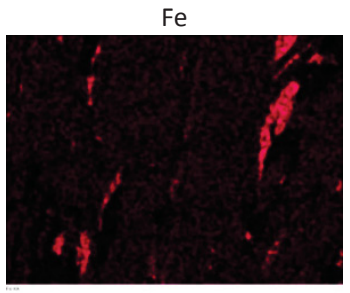

$100 \mu \mathrm{m}$

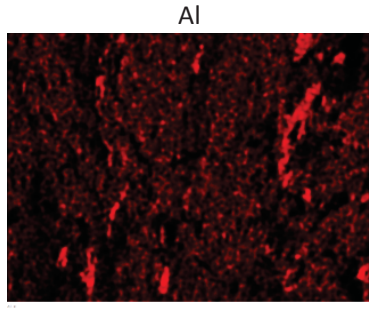

$100 \mu \mathrm{m}$

Figure 40. Representative EDS elemental (600X magnification). 
Table 9. Semi-quantitative EDS analysis of spot locations corresponding to Figure 41.

\begin{tabular}{|c|c|c|c|c|c|c|c|c|}
\hline & \multicolumn{8}{|c|}{ Spot / Atom \% } \\
\hline \multirow{9}{*}{$\begin{array}{c}1 \\
-1 \\
3\end{array}$} & & 1 & & 2 & & 3 & & 4 \\
\hline & $\overline{\mathrm{Ti}}$ & 63.2 & Ti & 40.6 & $\overline{\mathrm{Ti}}$ & 73.5 & $\mathrm{Ti}$ & 254.3 \\
\hline & $\mathrm{Nd}$ & 11.6 & $\mathrm{Fe}$ & 38.9 & $\mathrm{Fe}$ & 14.2 & $\mathrm{Zr}$ & 12.8 \\
\hline & $\mathrm{Ca}$ & 11.3 & $\mathrm{Al}$ & 14.9 & $\mathrm{Al}$ & 8.7 & $\mathrm{Fe}$ & 12.4 \\
\hline & $\mathrm{Fe}$ & 9.3 & $\mathrm{Cs}$ & 1.2 & $\mathrm{Ba}$ & 3.5 & $\mathrm{Nd}$ & 6.0 \\
\hline & $\mathrm{Al}$ & 7.5 & $\mathrm{Zr}$ & 0.9 & Cs & 2.2 & $\mathrm{Ca}$ & 5.3 \\
\hline & $\mathrm{Ce}$ & 7.1 & Mo & 0.3 & $\mathrm{Ce}$ & 1.8 & $\mathrm{Al}$ & 4.8 \\
\hline & Cs & 4.3 & $\mathrm{Ca}$ & 0.1 & Mo & 0.7 & $\mathrm{Ce}$ & 3.9 \\
\hline & Mo & 1.2 & $\mathrm{Ce}$ & 0.0 & $\mathrm{Zr}$ & 0.5 & Cs & 1.0 \\
\hline \multirow[b]{3}{*}{ Possible Phase(s) } & $\mathrm{Zr}$ & 0.9 & $\mathrm{Ba}$ & 0.0 & $\mathrm{Ca}$ & 0.0 & Mo & 0.7 \\
\hline & $\mathrm{Ba}$ & 0.0 & $\mathrm{Nd}$ & 0.0 & $\mathrm{Nd}$ & 0.0 & $\mathrm{Ba}$ & 0.0 \\
\hline & \multicolumn{2}{|c|}{$\mathrm{A}^{3+} /^{2+}$ Titanate } & \multicolumn{2}{|c|}{ Fe-Al-Ti-O } & \multicolumn{2}{|c|}{ Hollandite } & \multicolumn{2}{|c|}{$\begin{array}{c}\text { Zirconolite/ } \\
\mathrm{A}^{3+} 2^{2+} \text { Titanate }\end{array}$} \\
\hline
\end{tabular}

Transmission electron microscopy (TEM) and selected area electron diffraction (SAED) confirmed the crystallinity of the phases present. Interfaces between phases were sharp, indicating parasitic phases were not abundant at the grain boundaries.
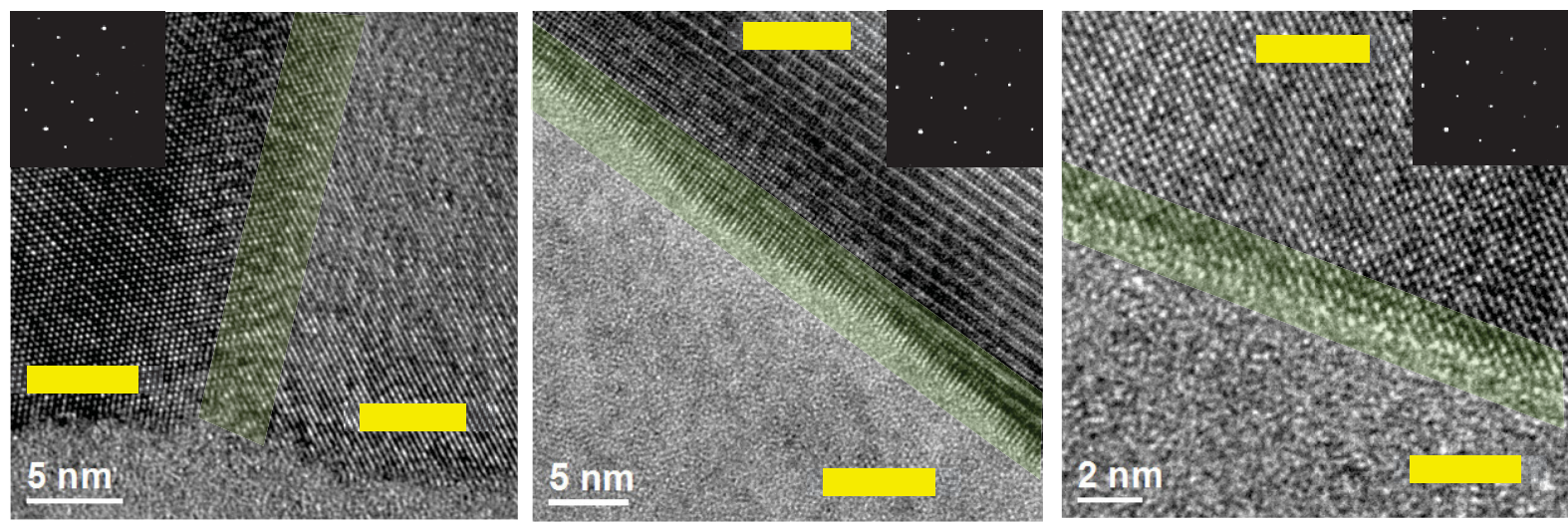

Figure 41. SAED pattern inset corresponds to the phase in which the inset is located.

\section{Radiation Damage Analyses}

Figure 42 shows the results of TEM/electron irradiation on the zirconolite phase (Ca-Zr-Ti-Nd-Fe-O) in representative multi-phase ceramic waste form sample. The irradiation simulates beta and gamma radiations in a waste form incorporating fission products. A sequence of high resolution TEM images as a function of doses and corresponding fast Fourier transforms (FFT) exhibit microstructural evolution of zirconolite phase under $300 \mathrm{keV}$ electron irradiations at room temperature. The results suggest that up to a dose of $1.6 \times 10^{13}$ Gy which is equivalent to over 1000 years waste storage time for $\mathrm{Cs} / \mathrm{Sr}$ waste form, amorphization is initiated, at the same time, there is unit cell swelling up to $1 \%$. 


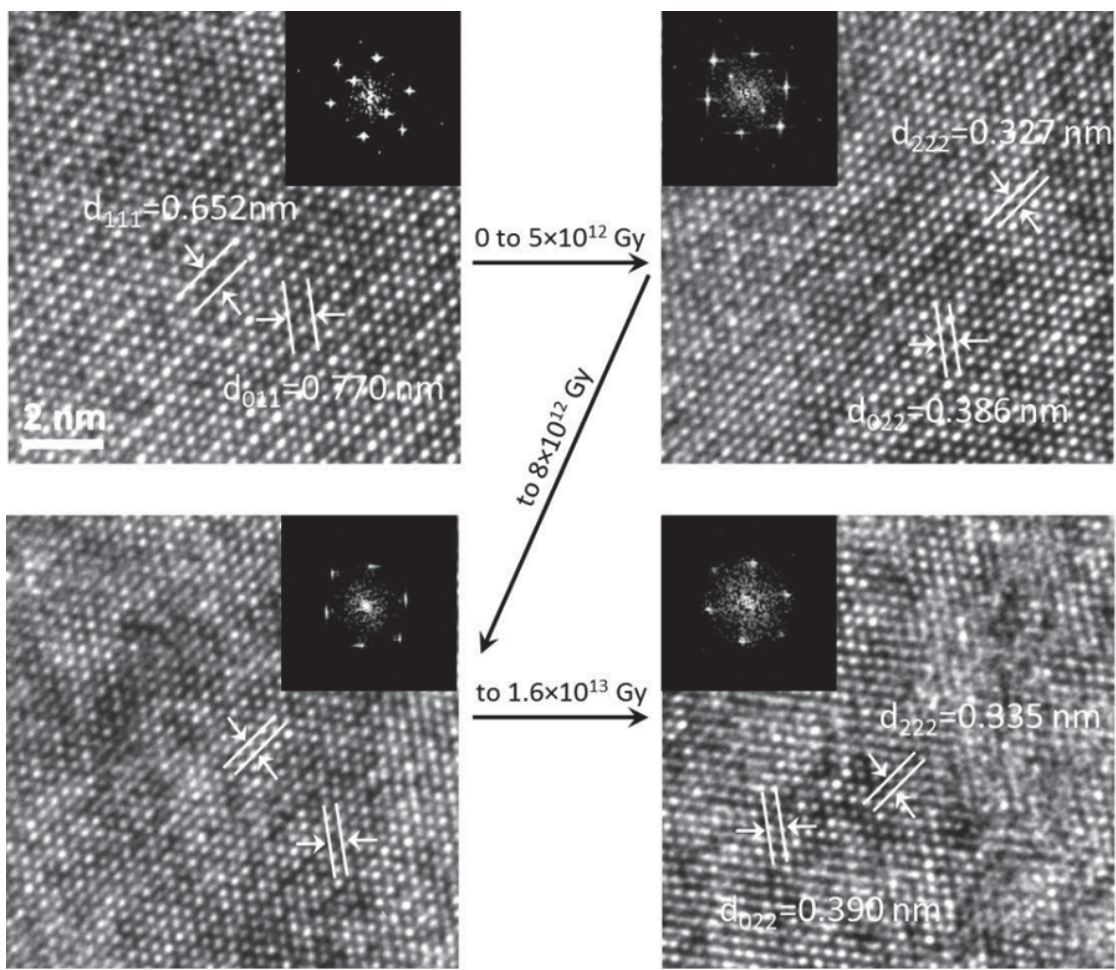

Figure 42. Sequence of high-resolution TEM images as a function of doses/irradiation of zirconolite phase (Ca-Zr-Ti-Nd-Fe-O) in a multi-phase ceramic waste form sample. Corresponding fast Fourier transforms (FFT) are shown inset.

\section{Synergistic Activities}

This work package is augmented by a DOE-NEUP project that is being conducted collaboratively with Alfred University (AU). AU is performing property characterization of melt-processed material including high-temperature XRD and thermal analysis. Additionally, AU is fabricating samples with Spark Plasma Sintering (SPS) for comparison to melt-processed samples. Two students from Alfred University worked at SRNL during the summer to prepare, test, and analyze "designer" waste forms to improve the performance of ceramic waste forms. The "designer" waste forms are being explored as a strategy to optimize the ceramic waste form through tailoring the amount of each crystalline phase in the final waste form. Preliminary results indicate the retention of certain mobile species in aqueous environments can be significantly affected by the ratio of the four primary titanate phases that constituent the waste form.

A Cooperative Research and Development Agreement (CRADA) with the Australian Nuclear Science and Technology Organization (ANSTO) has also been in place in FY-15 to support the project. As part of that CRADA, the compositions developed at SRNL were prepared (HIPed) by ANSTO and subsequently characterized. Preliminary results indicate excellent durability when processed with excess $\mathrm{Ti}^{-\mathrm{TiO}_{2}}$ to reduce the overall product. Characterization of those materials is ongoing at ANSTO and results will be compared to melt-processed materials produced at SRNL in FY-16.

\section{References}

1. D. S. D. Gunn, N. L. Allan, H. Foxhall, J. H. Harding, J. A. Purton, W. Smith, M. J. Stein, I. T. Todorov and K. P. Travis, "Novel Potentials for Modelling Defect Formation and Oxygen Vacancy Migration in $\mathrm{Gd}_{2} \mathrm{Ti}_{2} \mathrm{O}_{7}$ and $\mathrm{Gd}_{2} \mathrm{Zr}_{2} \mathrm{O}_{7}$ Pyrochlores," Journal of Materials Chemistry 22(11), 2012: 4675-4680.

2. R. Ubic, I. M. Reaney and W. E. Lee, "Perovskite $\mathrm{NdTiO}_{3}$ in $\mathrm{Sr}$ - and Ca-doped $\mathrm{BaO}-\mathrm{Nd}_{2} \mathrm{O}_{3}-\mathrm{TiO}_{2}$ Microwave Dielectric Ceramics," Journal of Materials Research 14(04), 1999: 1576-1580. 
3. H. F. Xu and Y. F. Wang, "Crystallization Sequence and Microstructure Evolution of Synroc Samples Crystallized from $\mathrm{CaZrTi}_{2} \mathrm{O}_{7}$ Melts," Journal of Nuclear Materials 279(1), 2000: 100-106.

4. V. Aubin-Chevaldonnet, D. Caurant, A. Dannoux, D. Gourier, T. Charpentier, L. Mazerolles and T. Advocat, "Preparation and Characterization of $(\mathrm{Ba}, \mathrm{Cs})(\mathrm{M}, \mathrm{Ti})_{8} \mathrm{O}_{16}\left(\mathrm{M}=\mathrm{Al}^{3+}, \mathrm{Fe}^{3+}, \mathrm{Ga}^{3+}, \mathrm{Cr}^{3+}, \mathrm{Sc}^{3+}\right.$, $\mathrm{Mg}^{2+}$ ) Hollandite Ceramics Developed for Radioactive Cesium Immmobilization," Journal of Nuclear Materials 366(1-2), 2007: 137-160.

5. M. L. Carter, E. R. Vance and H. Li, "Hollandite-rich Ceramic Melts for Immobilization of Cs," Materials Research Society Symposium Proceedings 807, 2003: 249-254.

6. M. L. Carter, E. R. Vance, D. R. G. Mitchell and Z. Zhang, "Mn Oxidation States in $\mathrm{Ba}_{\mathrm{x}} \mathrm{Cs}_{\mathrm{y}} \mathrm{Mn}_{\mathrm{z}} \mathrm{Ti}_{8-}$ ${ }_{z} \mathrm{O}_{16}, "$ Materials Research Society Symposium Proceedings 824, 2004: CC4.6.1 - 6.

7. V. C. Maio, 2014, "Production of a Low Temperature SYNROC All Ceramic Surrogate High Level Waste Form in INL's Cold Crucible Induction Melter Pilot -Validation of Test Completion," INL/MIS-14-34012, FCRD-SWF-2015-00256, INL.

8. J. Amoroso, J. Marra, S. D. Conradson, M. Tang and K. Brinkman, "Melt Processed Single Phase Hollandite Waste Forms for Nuclear Waste Immobilization: Ba1.0Cs0.3A2.3Ti5.7O16; A = Cr, Fe, Al," Journal of Alloys and Compounds 584, 2014: 590-599.

9. K. Brinkman, J. Amoroso, J. Marra, and M. Tang, 2013, "Crystalline Ceramic Waste Forms: Comparison of Reference Process for Ceramic Waste Form Fabrication," SRNL-STI-2013-00442, FCRD-SWF-2013-000229, SRNL.

\section{Publications}

Tumurugoti, P., S. K. Sundaram, S. T. Misture, J. C. Marra, and J. Amoroso, "Melt Processed Multiphase Ceramic Waste Forms for Nuclear Waste Immobilization," Journal of Nuclear Materials, submitted, July 2015.

\subsection{Glass Ceramic Waste Form Development for Fission Products from Used Nuclear Fuel (Client NE)}

\section{J. V. Crum, PNNL; M. Tang, LANL; and C. Crawford, SRNL}

Borosilicate glass ceramic waste form is being developed as an alternative to single-phase borosilictate glass for immobilization of the HLW fission products generated during aqueous separation of used nuclear fuel. ${ }^{1,2}$ Development to date has shown that the glass ceramic accommodates $>2 \times$ the waste loading relative to single-phase glass. This is accomplished by tailoring the chemistry such that a large fraction of the insoluble $\mathrm{MoO}_{3}$ and lanthanides crystallize upon cooling into durable crystalline phases (oxyapatite, powellite, and Ln-borosilicate). Based on electron, proton, and alpha particle irradiation testing these crystalline phases are expected to be quite tolerant to gamma and alpha radiation. ${ }^{3}$ Increases in waste loading and the radiation tolerance the glass ceramic make it a good alternative to single-phase glass. At this point the major shortfall of the glass ceramic waste form is its immaturity in terms of processing data and corrosion data.

For this reason a technology maturation plan was developed to provide a frame work to begin maturing the glass ceramic waste form. ${ }^{4}$ A composition variability matrix (Phase I and II) was designed and fabricated to collect melt and waste form performance property data as a function of composition. The matrix was statistically designed to cover the composition space of interest utilizing a centroid, inner, and 
outer layer of extreme vertices; where additives $\left(\mathrm{Al}_{2} \mathrm{O}_{3}, \mathrm{~B}_{2} \mathrm{O}_{3}, \mathrm{Li}_{2} \mathrm{O}, \mathrm{Na}_{2} \mathrm{O}, \mathrm{CaO}\right.$, and $\left.\mathrm{SiO}_{2}\right)$ and key waste components $\left(\mathrm{Ln}_{2} \mathrm{O}_{3}, \mathrm{ZrO}_{2}, \mathrm{MoO}_{3}\right.$ and Others) were independently varied. This matrix will provide valuable laboratory scale data as a function of composition space. The following properties were measured: viscosity, electrical conductivity (ongoing), phase assemblage upon cooling, and corrosion testing, with highlights given below.

Viscosity of each matrix composition was measured as a function of temperature over the full range of the viscometer. Almost all of the melts showed sign of crystallization (abrupt increase in viscosity) as temperature was lowered. Viscosity data were examined in an attempt to exclude data impacted by crystallization. Then the viscosity versus temperature data was fit with the Arrhenius equation. For some glasses the temperature range that was crystal free was very narrow $\left(50^{\circ} \mathrm{C}\right)$ and were not fit. A first order regression was performed to the fitted Arrhenius parameters to determine the component effects on viscosity. Figure 43 shows the component effects on viscosity at $1350^{\circ} \mathrm{C}$ and $1250^{\circ} \mathrm{C}$. The components that appear to increase viscosity are $\mathrm{Al}_{2} \mathrm{O}_{3}, \mathrm{SiO}_{2}$ and $\mathrm{Ln}_{2} \mathrm{O}_{3}$, while $\mathrm{Li}_{2} \mathrm{O}, \mathrm{B}_{2} \mathrm{O}_{3}$, Others, $\mathrm{ZrO}_{2}, \mathrm{MoO}_{3}$, $\mathrm{Na}_{2} \mathrm{O}$, and $\mathrm{CaO}$ all lower viscosity. The behavior of $\mathrm{ZrO}_{2}$ is odd; $\mathrm{ZrO}_{2}$ normally increases viscosity in single-phase borosilicate waste glass.

Phase assemblage was determined by powder X-ray diffraction for each composition upon cooling at the canister centerline cooling rate of a $0.61 \mathrm{~m}$ diameter canister. The measured crystalline phases and ranges were: $0-24$ mass $\%$ oxyapatite, $0-16$ mass $\%$ Ln-borosilicate, $0-13$ mass $\%$ powellite, $0-8$ mass $\%$ pollucite, and $0-2.5$ mass $\%$ cerianite.
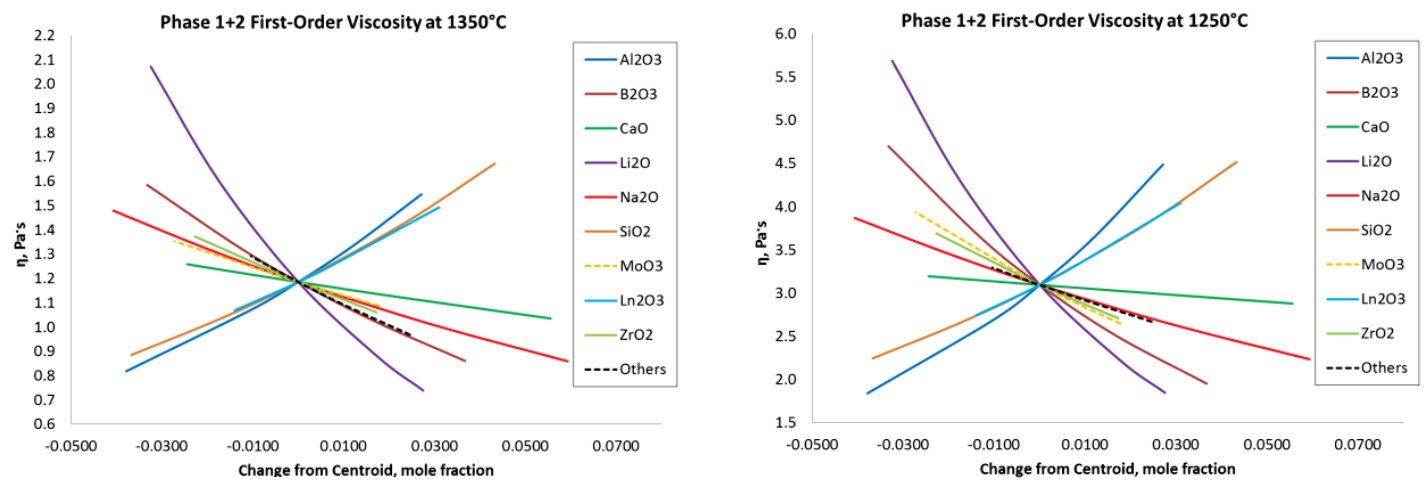

Figure 43. First-order component effect on viscosity at temperatures of $1350^{\circ} \mathrm{C}$ (left) and $1250{ }^{\circ} \mathrm{C}$ (right)

Corrosion testing was performed in static and dilute conditions, product constancy test (PCT) and singlepass flow-through (SPFT) respectively.

Ongoing static corrosion tests with glass ceramics fabricated at crucible scale (Phase I at PNNL, Phase II at both PNNL and SRNL) have been recently summarized. ${ }^{5,6}$ Long-term PCT's through 448 days using the ASTM C1285 have been completed on Phase I glass ceramics. Figure 44 shows the normalized concentration for boron vs. time from these tests. Boron is essentially all in the glass phase and is a good indicator of glass corrosion rate. Two of the glass ceramics (Outer 3 and Inner 14) show significantly higher release than the other samples that are all below $3 \mathrm{~g} / \mathrm{L}$. The overall trend in these longer term corrosion data is similar to durable HLW glass waste forms that show relatively high initial release (Stage I), followed by a longer term, lower residual release (Stage II). Similar data is being generated through long-term corrosion tests on the Phase II glass ceramics. 


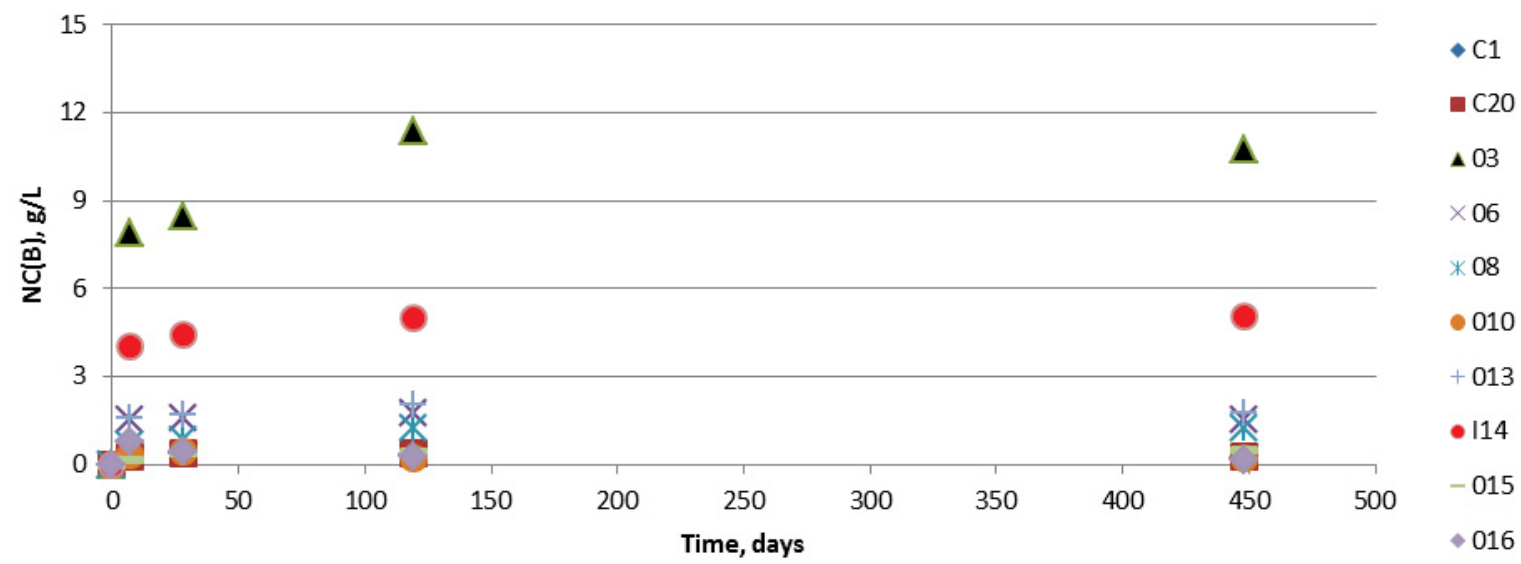

Figure 44. Phase I Normalized Concentration Based on Boron through 448 Days

All of the 7-day PCT data for both Phase I and Phase II glass ceramic boron releases were normalized using the surface area calculated from measured densities (average glass ceramic density of $3.4 \mathrm{~g} / \mathrm{cc}$ ) and compared to the Environmental Assessment (EA) glass. ${ }^{8}$ The EA glass is cited as an upper limit comparative vitrified (glass) waste form by the Waste Acceptance Product Specification (WAPS) for vitrified high level waste forms. ${ }^{9}$ Figure 45 shows that most all (24 out of 29 formulations) of the normalized release for the glass ceramics based on boron are nominally $1 \mathrm{~g} / \mathrm{m}^{2}$ or less, with four of the formulations showing higher release in the range of 2 to $5 \mathrm{~g} / \mathrm{m}^{2}$. All of these values are less than the EA glass normalized boron release of $8.39 \pm 0.61 \mathrm{~g} / \mathrm{m}^{2}$ shown at the far right of the plot.

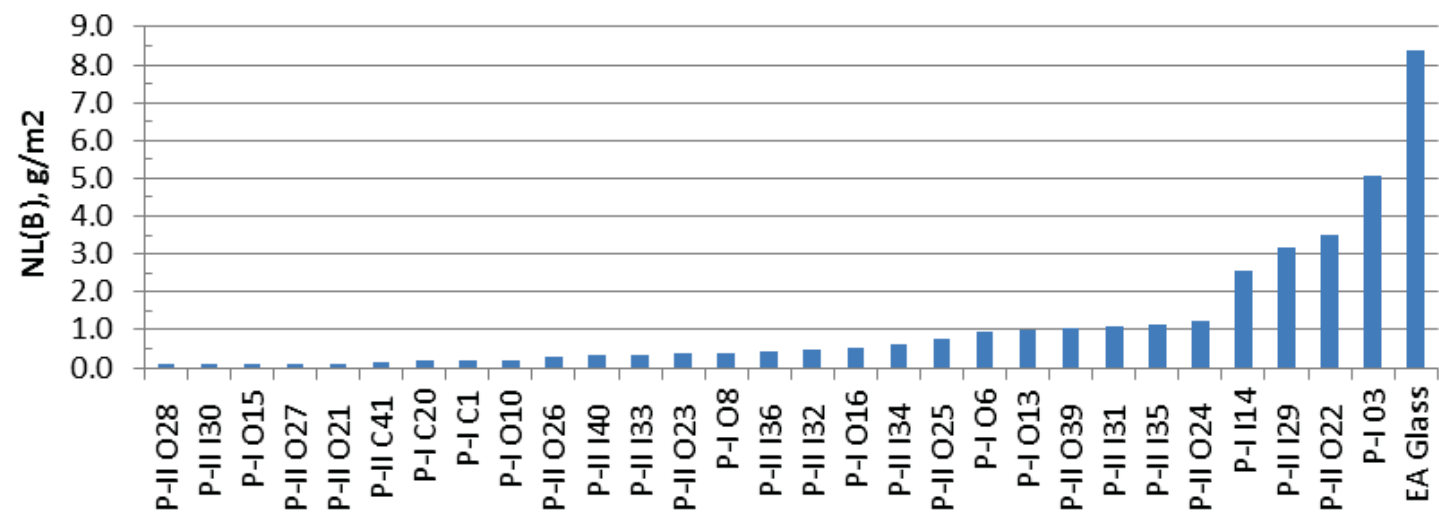

Phase I and Phase II Glass Ceramic Matrix

Figure 45. Normalized Release (7-day) Based on Boron for Phase I and Phase II Glass Ceramics Compared to EA Glass

Single-pass flow-through corrosion test was performed on the centroid composition at $90{ }^{\circ} \mathrm{C}$ where the solution flow rate to sample surface area $(\mathrm{q} / \mathrm{s})$ ranged from $1.18 \times 10^{-2}$ to $1.06 \times 10^{-5} \mathrm{~m} / \mathrm{s}$. Tests were performed on the centroid composition cooled at slow cooling rates of $4 \times, 1 \times$, and $1 / 4 \times$ to evaluate the impact of morphology on corrosion. These tests were performed on the centroid in response to results obtained in FY-14 where crystal-to-glass (C-to-G) interface corrosion was observed for the centroid glass by SPFT, see Figure 46a.

The C-to-G interface before and after SPFT testing was investigated to determine the cause of enhanced corrosion and its ultimate impact. This interface corrosion only occurred on SPFT testing of the centroid. The morphology of centroid was unique where oxyapatite crystals grow in clusters with the same 
crystallographic origination and powellite crystals are also inside the cluster Figure 46b. The close proximity of the glass, oxyapatite, and powellite with different anisotropic thermal expansions leads to stress at the C-to-G interface. When this clustering microstructure doesn't occur, the enhanced C-to-G interface corrosion isn't observed.

During the SPFT tests on the centroid at different cooling rates of $4 \times, 1 \times$, and $1 / 4 \times$, only the $4 \times$ slow cooled sample showed the same morphology as was observed in FY-14 and again enhanced C-to-G interface corrosion was observed. Despite the enhanced C-to-G interface corrosion the $4 \times$ sample still had a lower normalized $B$ release than the $1 / 4 \times$ and $1 \times$ samples that didn't have enhanced C-to-G interface corrosion as shown in Figure 47.
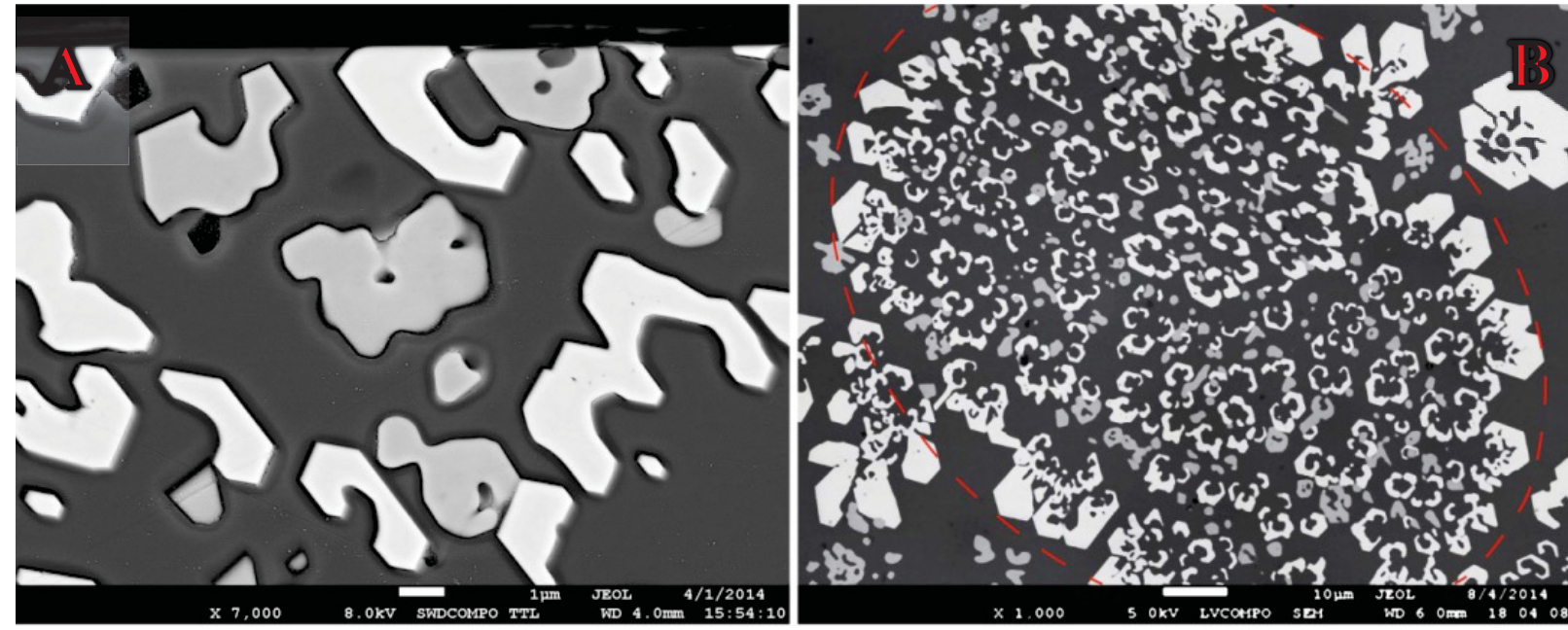

Figure 46. Backscattered electron micrographs of C1 morphology; a) crystal-to-glass corrosion (halo around crystals) after SPFT testing at $7000 \times$, b) oxyapatite cluster with powellite and glass inside C1 at 1000x. Oxyapatite within the superstructure all grow at the same crystallographic orientation.

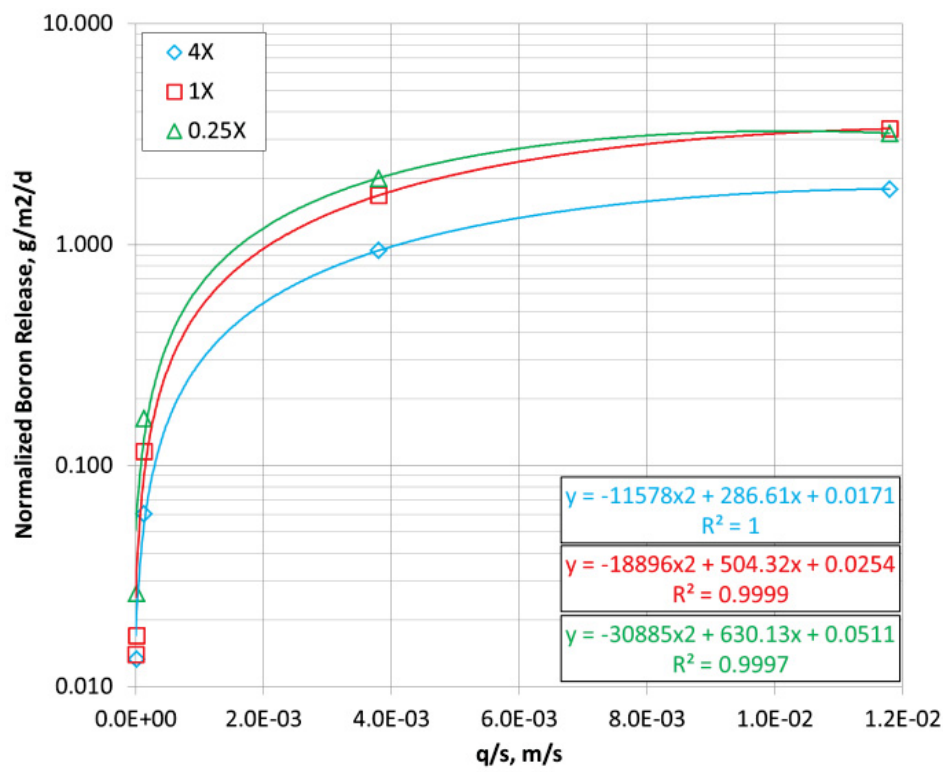

Figure 47. Normalized elemental release of $B$ as a function of $q / s$ and canister centerline cooling rate $(4 \times, 1 \times$, and $0.25 \times)$ for glass ceramic $\mathrm{C} 1$.

The enhanced C-to-G interface corrosion observed for the centroid composition was examined by a host of techniques (SEM, STEM, EBSD, EDS, and nano-indentation) to determine if the cause is chemical or 
mechanical. Samples were examined before and after SPFT testing. SEM-EDS and STEM-EDS both confirm that before corrosion testing the C-to-Glass interface is abrupt, meaning there isn't a chemically unique interface layer. High resolution TEM images also show an abrupt interface and EBSD didn't show significant crystal misorientation at the C-to-G interface. Nano-indentation was also performed in an attempt to identify stress in the glass phase near the C-to-G interface but no significant changes were observed. That said the interface may be too small to observe by nano-indentation (which in reality is a measurement on a micro scale). Based on the examination before SPFT testing, there is no evidence of a chemically different interface or significant mechanical stress at the outer edges of the crystals.

The same examinations were performed after SPFT testing on the C-to-G interface. SEM-EDS and STEM-EDS revealed a tiny gap between the crystal and the glass (Figure 48a) and a region (green colored zone) of glass that is depleted in alkali (Figure 48b, c, and d). Nano-indentation was performed starting at the outer edge of the coupon (altered region) progressing inward into the unaltered region. The nano-indentation data shown in Figure 49 revealed that the hardness and Young's modulus of the glass phase and oxyapatite decrease in the altered region relative to the unaltered region.
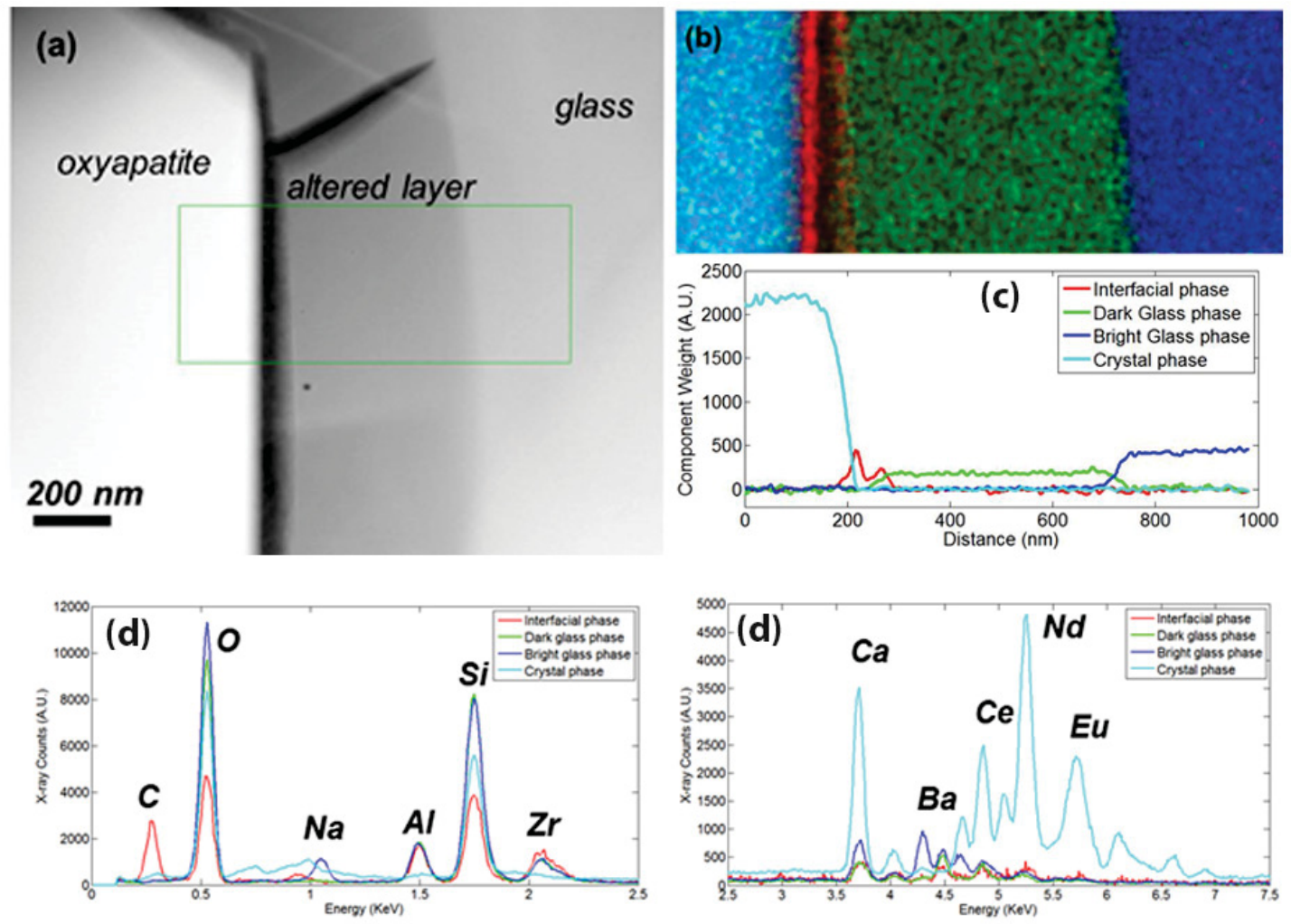

Figure 48. STEM-EDS analysis of oxyapatite-to-glass interface in centroid sample after SPFT testing: a) image with HAADF detector, b) elemental dot map of interface, c) component line scan from elemental map, and d) component elemental compositions.

At this time the enhanced C-to-G interface corrosion appears to be caused by mechanical stress at the interface when the oxyapatite clusters form with powellite crystals inside the clusters. Of all the compositions tested to date this phenomena has only occurred to the centroid composition in dilute conditions when cooling rates are in the stage I regime. The impact of the enhanced C-to-G interface on release rate is small. The samples with interface corrosion actually have lower release rates than samples that didn't have interface corrosion. 

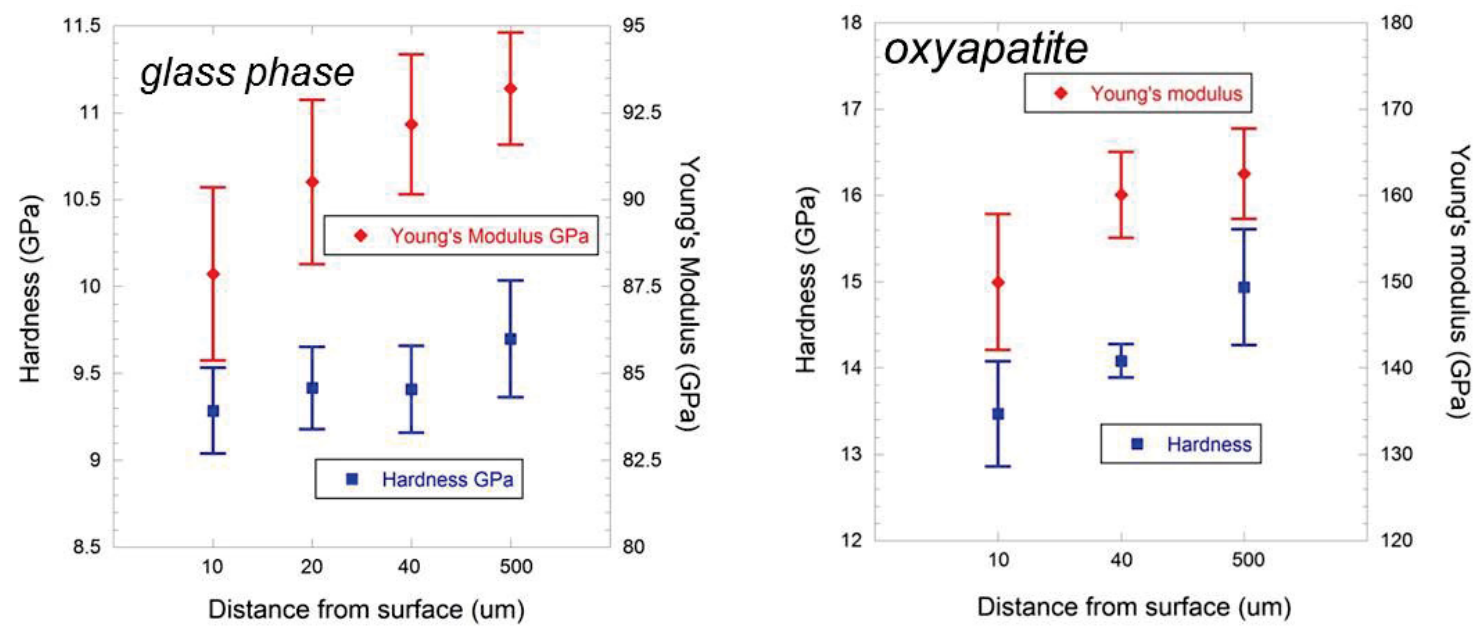

Figure 49. Mechanical properties evolution of SPFT glass ceramic as a function of distance from surface.

\section{References}

1. J. V. Crum, L. R. Turo, B. J. Riley, M. Tang, A. Kossoy and K. E. Sickafus, 2010, Glass Ceramic Waste Forms for Combined CS $+L N+T M$ Fission Products Waste Streams, Richland, Washington, Pacific Northwest National Lab.

2. J. V. Crum, B. J. Riley, L. R. Turo, M. Tang and A. Kossoy, 2011, Summary Report: Glass-Ceramic Waste Forms for Combined Fission Products, Richland, Washington, Pacific Northwest National Laboratory: 41.

3. M. Tang, A. Kossoy, G. Jarvinen, J. Crum, L. Turo, B. Riley, K. Brinkman, K. Fox, J. Amoroso and J. Marra, "Radiation stability test on multiphase glass ceramic and crystalline ceramic waste forms," Nuclear Instruments and Methods in Physics Research Section B: Beam Interactions with Materials and Atoms 326(0), 2014: 293-297.

4. J. D. Vienna, J. V. Crum, G. J. Sevigny and G. L. Smith, 2012, Preliminary Technology Maturation Plan for Immobilization of High-Level Waste in Glass-Ceramics. Richland, WA, Pacific Northwest National Laboratory: 36.

5. C. L. Crawford, 2013, Letter Report on Glass Ceramic Waste Form Durability Tests, Aiken, SC, Savannah River National Laboratory: 27.

6. C. L. Crawford, 2015, Letter Report on PCT/Monolith Glass Ceramic Corrosion Tests, Aiken, SC, Savannah River National Laboratory: 27.

7. ASTM, 2002, "Standard Test Methods for Determining Chemical Durability of Nuclear, Hazardous, and Mixed Waste Glasses and Multiphase Glass Ceramics: The Product Consistency Test (PCT)," West Conshohocken, Pennsylvania, ASTM International.

8. C. M. Jantzen, N. E. Bibler, D. C. Beam, C. L. Crawford, and M. A. Pickett, 1993, "Characterization of the Defense Waste Processing Facility (DWPF) Environmental Assessment (EA) Glass Standard Reference Material (U)," Aiken, SC, Westinghouse Savanna River Company: 96.

9. WAPS, 2012, "Waste Acceptance Product Specifications (WAPS) for Vitrified High-Level Waste Forms," U. S. Department of Energy, Office of Environmental Management, 42. 


\title{
5.3 Electrochemical Waste Forms
}

\author{
B. Ebert, ANL; S. Frank, INL; B. Riley, PNNL; L. Olson, SRNL
}

\section{Electrochemical Waste Forms}

The objectives of research addressing electrochemical process waste forms are to improve the production, performance, and modeling of waste forms required to immobilize the range of salt and metallic waste streams that are generated by electrochemical treatment of used metallic fuel. The waste forms developed at ANL in the 1990s for these waste streams are being modified for use in advance fuel cycle operations; the ceramic waste form (CWF) developed for salt wastes is made with a new binder glass to increase the salt waste loading and the metal waste form (MWF) developed for metallic wastes is being made using HT9 cladding and additives to improve corrosion resistance. On-going research includes evaluating the chemical durability and degradation mechanisms of these advanced waste form materials to optimize the formulations and developing degradation models. The corrosion mechanisms being determined by testing to provide confidence in the durabilities of those formulations over very long disposal times and support the development of radionuclide source term models for use in performance assessment (PA) calculations. Progress in testing and modeling waste forms for salt and metallic waste streams are discussed separately.

\section{Advanced Ceramic Waste Form for Waste Salt}

\section{W.L. Ebert, ANL; B. J. Riley, PNNL; S.M. Frank, INL}

The main issues being addressed for salt wastes are to (1) more efficiently immobilize both the halides and radionuclides in durable phases to increase waste salt loading and (2) reduce the complexity and cost of the process. The ceramic waste form developed for Experimental Breeder Reactor (EBR)-II waste salt sequesters halides and most radionuclides in separate phases: $\mathrm{Cl}^{-}$and $\mathrm{I}^{-}$are immobilized in sodalite, whereas cationic fission products are immobilized in the binder glass. Producing the waste form is a multi-step operation that is relatively complex and results in a low waste loading. The waste loading is limited by the stoichiometry of the reaction between zeolite $4 \mathrm{~A}$ and $\mathrm{NaCl}$ to produce sodalite. Reactions with other cations in the salt preferentially generate aluminosilicate phases that do not contain $\mathrm{Cl}^{-}$(e.g., spodumene $\mathrm{LiAlSi}_{2} \mathrm{O}_{6}$, leucite $\mathrm{KAlSi}_{2} \mathrm{O}_{6}$, and Cs-pollucite $\mathrm{Cs}_{2} \mathrm{Al}_{2} \mathrm{Si}_{4} \mathrm{O}_{12} \cdot 2 \mathrm{H}_{2} \mathrm{O}$ ). The salt loading is limited by the amount of sodalite that can be produced, which is limited by the amount of available $\mathrm{NaCl}$. Because the waste salt contains much less $\mathrm{Na}^{+}$than $\mathrm{Cl}^{-}$, an additional source of $\mathrm{Na}^{+}$is required to generate enough sodalite to accommodate even moderate salt loadings. The additional $\mathrm{Na}^{+}$is provided by the binder glass. The exchange of cationic radionuclides from the salt with $\mathrm{Na}^{+}$from the glass provides the $\mathrm{Na}^{+}$to produce sodalite and the charge balance for the radionuclides to dissolve into the glass. The P57 glass that was used to make CWF materials since the 1990s contained about 5 mass $\%$ Na, and most of that was consumed by the sodalite generated at a salt waste loading of about 8 mass\%. Producing advanced CWF (ACWF) materials with significantly higher salt waste loadings (e.g., 12 mass\%) requires a binder glass having a higher Na content than P57 glass. The development of such a binder glass and ACWF materials was initiated in FY-15 as a collaborative effort at ANL, INL, and PNNL.

The first step taken to increase the salt waste loading was to demonstrate our understanding of the chemistry of salt immobilization in sodalite and glass and the benefit of using a binder glass having a higher $\mathrm{Na}_{2} \mathrm{O}$ content than P57 to generate more sodalite. New binder glasses with about $15 \mathrm{mass} \% \mathrm{Na}$ (about 20 mass $\% \mathrm{Na}_{2} \mathrm{O}$ ) were formulated at PNNL to have glass transition temperatures and viscosities similar to those of P57 glass so the ACWF materials could be processed using established conditions. The suitabilities of four new glasses produced at PNNL for producing ACWF were then evaluated and compared by making prototype materials and characterizing their physical and chemical properties. Materials were made with 11 mass\% salt loading at INL using a surrogate waste salt formulated and 
mixed at INL and glasses NBS-2, $-3,-4$, and -5 that were provided by PNNL. Materials were also made with P57 glass at the same salt loading to compare the amounts of sodalite and halite that were generated in ACWF made with the different glasses. These initial materials were made with salt loadings less than the expected maximum to differentiate the four new glasses and demonstrate the chemistry controlling generation of the constituent phases. Binder glass NBS-4 was selected for further development based on comparisons of the physical and chemical properties of these prototype ACWF materials.

The results of X-ray diffraction analyses summarized in Table 10 indicate the use of all four new binder glasses result in the generation of more sodalite (and less halite) than P57 glass. Halite inclusions are produced by the decomposition of sodalite during production and unreacted $\mathrm{NaCl}$. Halite concentrations up to $5 \%$ in the ACWF are desirable because that allows for higher waste loading by decreasing the amount of zeolite 4A. In fact, these prototype ACWF materials were formulated to generate $72 \mathrm{mass} \%$ sodalite and 2.3 mass $\%$ halite. The measured sodalite contents are much higher in ACWFs made with each of the NBS glasses than that made with P57 and the halite contents are lower. This demonstrates the benefit of the higher Na contents in the NBS glasses, but indicates the reaction is not complete and the processing conditions remain to be optimized. Figure 50 shows the microstructure of the ACWF made with NBS-2, wherein sodalite domains are encapsulated by a continuous glass phase. All materials had small pores in both phases and large pores throughout. The large pores are currently attributed to the density of the sodalite domains that prevent densification during processing. The porosities measured using the Archimedes method were $39,44 \%, 45 \%$, and 38 for ACWF made with NBS-2, $-3,-4$, and -5 glasses, respectively, and that for the ACWF made with P57 glass was 30\%. These are significantly higher than the $\sim 12 \%$ porosities of standard CWF materials and is probably due to the higher volume fraction of sodalite in the ACWF materials. This will be addressed in formulating the next series of ACWF materials made for testing.

Table 10. Results of XRD analyses of ACWF materials

\begin{tabular}{|c|c|c|c|}
\hline & \multicolumn{3}{|c|}{ Phase Distribution, mass\% } \\
\hline $\begin{array}{c}\text { Binder } \\
\text { Glass }\end{array}$ & Sodalite & $\begin{array}{c}\text { Halite } \\
(\mathrm{NaCl})\end{array}$ & $\begin{array}{c}\text { XRD- } \\
\text { Amorphous }\end{array}$ \\
\hline NBS-2 & 57 & 2.9 & 40 \\
\hline NBS-3 & 62 & 2.9 & 35 \\
\hline NBS-4 & 63 & 3.1 & 34 \\
\hline NBS-5 & 62 & 2.6 & 35 \\
\hline P57 -6 & 39 & 4.2 & 57 \\
\hline
\end{tabular}

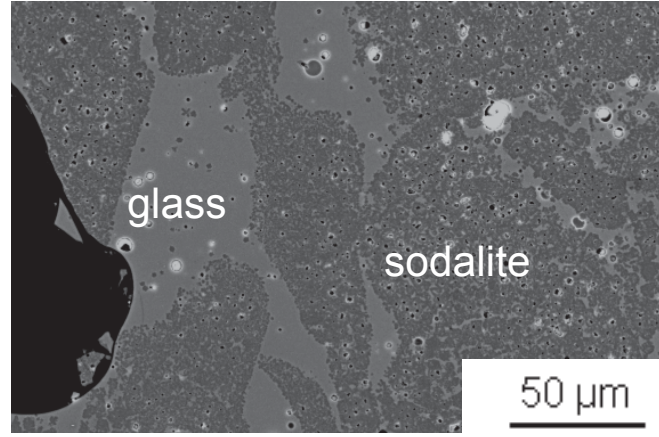

Figure 50. Microstructure of ACWF-N2. 


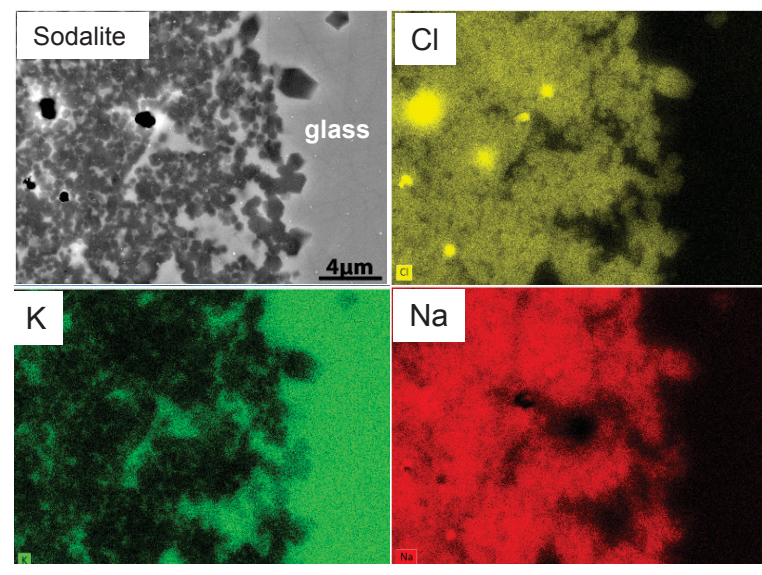

Figure 51. Concentration maps for ACWF-N2.

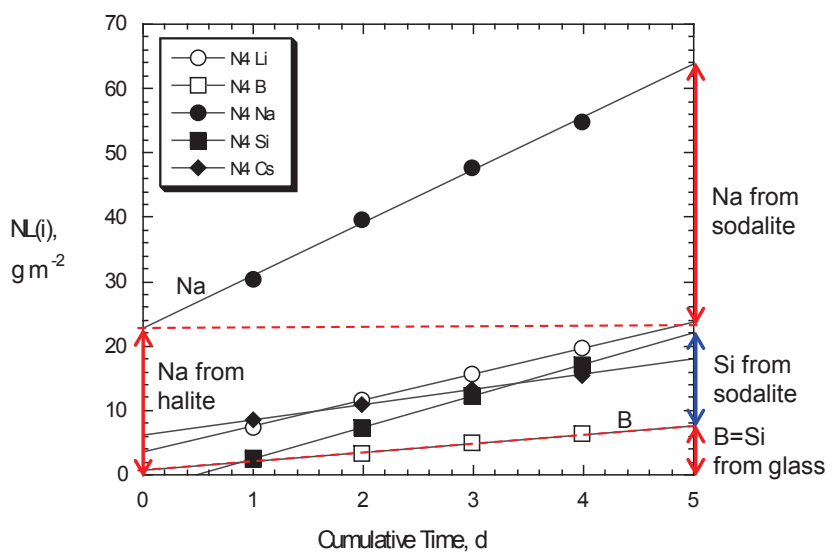

Figure 52. Results of ASTM C1308 tests with ACWF-N4.

Figure 51 provides an SEM photomicrograph of the interface of sodalite and glass regions and X-ray emission maps showing the distributions of $\mathrm{K}, \mathrm{Na}$, and $\mathrm{Cl}$ between those phases. Essentially all of the $\mathrm{Cl}$ from the salt and all the $\mathrm{Na}$ from the glass are incorporated into sodalite and all the $\mathrm{K}$ from the salt is incorporated into the glass. The small bright regions in the $\mathrm{Cl}$ map are due to halite inclusions and the large bright regions in the $\mathrm{Cl}$ map are attributed to the accumulation of $\mathrm{Cl}$ in pores during polishing. All of the $\mathrm{Sr}$ is incorporated into the glass; the Cs concentrations are too low to distinguish its distribution by solids analysis and $\mathrm{Li}$ is not detectable, but dissolution tests indicate both are in the glass.

Dissolution tests were conducted at ANL to evaluate the dissolution behaviors and compositions of the constituent phases. A modified ASTM C1308 test procedure was used in which monolithic specimens were immersed in demineralized water at $90{ }^{\circ} \mathrm{C}$ and the solution was replaced with fresh water daily. Test specimens were prepared using absolute ethanol as a cutting and polishing fluid to minimize halite dissolution. These test results provide insights into the dissolution behaviors and rates of the three dominant phases (sodalite, glass, and halite) as illustrated in Figure 52, which show the results of the test with ACWF made with NBS-4 in terms of the mass CWF dissolved. The normalized mass loss is calculated by dividing the mass of an element measured in the solution by its gross mass fraction in the CWF and by the geometric surface area of the specimen. Values of NL(i) calculated using different elements can be compared directly and differences in the releases of $\mathrm{B}, \mathrm{Na}$, and $\mathrm{Si}$ can be used to distinguish the dissolution of the different phases. Dissolution of halite exposed at the surface occurs immediately and dominates the initial solution concentrations of $\mathrm{Na}$ and $\mathrm{Cl}$. The NL(i) values based on these elements all increase linearly with the test interval. This indicates the dissolution kinetics for all phases are linear and probably controlled by surface dissolution mechanisms with negligible mass transport limitations. Extrapolation of the releases measured after the first four intervals back to time-zero provides a good estimate of the amount of halite dissolved as indicated by $\mathrm{NL}(\mathrm{Na})$ and $\mathrm{NL}(\mathrm{Cl})$ (not shown). An NL(i) value of $20 \mathrm{~g} \mathrm{~m}^{-2}$ implies about 1 mass $\%$ of the CWF (and about $1 \%$ of the amount of $i$ in the CWF) has dissolved. Since B is only present in the glass phase, NL(B) provides a direct measure of glass dissolution. The $\mathrm{Si}$ is distributed between the glass and sodalite phases, but the release of Si from the glass can be assumed stoichiometric with the release of B under these test conditions. Therefore, values of NL(B) can be used to estimate the contributed of Si released from the glass to NL(Si), and the contribution of Si released from sodalite calculated as NL(Si) - NL(B). The contribution of Na from glass dissolution to NL(Na) is assumed to be negligible because the glass is almost completely depleted of Na. The releases of other constituents can be evaluated by comparison. For example, Figure 53 shows the releases of B and Cs from the various ACWF materials and from a standard CWF (specimen C1) made with $8 \%$ salt loading. The release behaviors of Cs are very similar to those of B from each material, which 
indicates most of the Cs is in the glass phase. The positive $\mathrm{y}$-intercepts indicate a small fraction of Cs remained as unreacted salt. Similar analyses indicate most of the Li is contained in the glass phase.

These scoping studies provide confidence that ACWFs can be made with high salt loadings by using a binder glass with a high $\mathrm{Na}$ content, although the processing method and formulations of the binder glass and ACWF mixtures must be optimized to decrease the porosity. These issues will be addressed in FY16. Another issue to be addressed is the flexibility of ACWFs to variations in the salt waste composition. The current understanding of the chemistry controlling the generation of sodalite and other phases will be used to formulate ACWFs to accommodate extreme variations in salt compositions that could occur during electrochemical reprocessing, such as very high concentrations of $\mathrm{LiCl}, \mathrm{CsCl}$, or $\mathrm{SrCl} 2$. That range of salt compositions will be calculated as described in the next section.

\section{Domestic Electrochemical Flowsheet Simulation Software}

\section{T. S. Yoo, INL}

New software was developed to simulate an electrochemical separation process flowsheet by integrating commercially available MATLAB and Microsoft Office Excel software development environments. Microsoft Office Excel provides the user interface capability and MATLAB performs computational tasks behind the scene. The model implemented in the simulation software uses reported thermodynamic separation factors to eliminate dependency on inputs by domain experts for tracking the actinides and the lanthanides. On the other hand, the simulation software relies on inputs provided via the user interface when experience supersedes thermodynamic calculations, such as the partitioning of bond sodium and off-gas. Selected operational constraints due to the physical size of the cell and criticality-related constraints induced by the fissile materials also implemented and adjustable. This feature allows the user to assess the impact of the physical cell design and criticality considerations to the performance of the flowsheet. The correctness of the developed simulation software is partly established through the mass balance check of the inventory. This simulation software will be used to identify the range of waste salt compositions used to determine the compositional flexibility of ACWF materials.
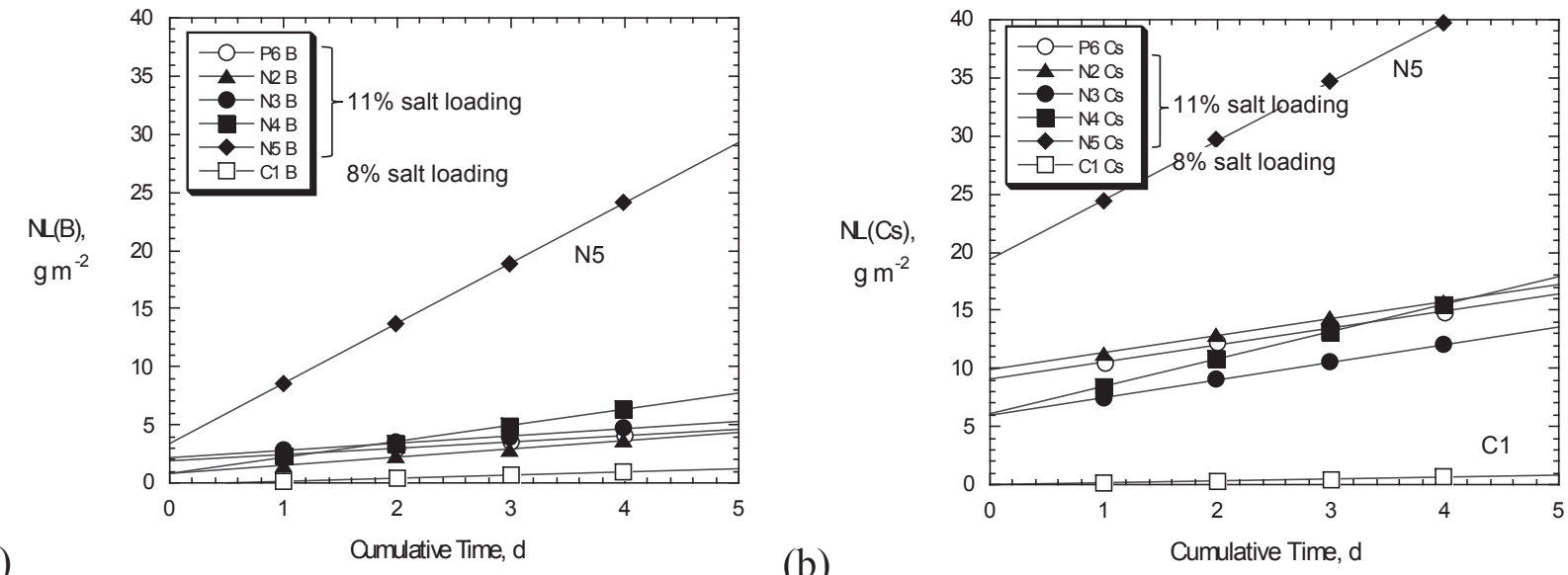

(a)

Figure 53. Release behaviors of (a) boron and (b) cesium for ACWF materials and standard CWF. 


\title{
Advanced Metallic Waste Form for EChem Waste
}

\author{
W.L. Ebert, ANL, and L. Olson, SRNL
}

Less than 30 mass \% of the metallic waste stream from electrochemical treatment of advanced fuels is expected to be composed of wastes from the fuel (primarily $\mathrm{Zr}$ ) with the balance being cladding and other hardware. The radionuclide content in the waste will be dominated by Tc-99, with only small amounts of residual U/TRU due to processing inefficiencies and activation products in the cladding. These waste streams are most efficiently immobilized by direct melting to alloy the waste metals with the hulls and minimum amounts of trim metals added to improve processing and performance. The waste form developed for the EBR-II metallic waste streams were based on stainless cladding steel cladding (primarily Type 316L) and treated U-15Zr fuel. The gross composition targeted an $85 \mathrm{SS}-15 \mathrm{Zr}$ mixture to utilize the eutectic composition of Fe-15Zr in binary system so that waste forms could be processed at $1600{ }^{\circ} \mathrm{C}$ using an induction furnace. The cladding for advanced fuels is expected to be similar to HT-9, which has less Mo, Ni, and $\mathrm{Cr}$ than Type 316L. Scoping work conducted at ANL and SRNL has indicated that essentially the same waste form can be made by alloying HT-9 and wastes from advanced fuels using the same process if small amounts of $\mathrm{Mo}, \mathrm{Ni}$, and $\mathrm{Cr}$ are added to the mixture. These trim metals are needed to passivate the waste form over the full range of Eh values that could occur in a disposal system. Advances addressing production, radionuclide distributions, electrochemical corrosion behavior, and radionuclide release from representative 316L-based alloys are being applied directly to surrogate waste forms made with HT-9 cladding. Likewise, the source term model developed for use in PA and the testing protocol developed to parameterize that model and measure parameter values is being applied to HT-9based waste forms.

Work is in progress to formulate durable HT-9-based waste forms, demonstrate their long-term durabilities in possible disposal environments, and parameterize a degradation model based on wellestablished electrochemical theories to predict long-term corrosion behavior. Degradation occurs by a two-step oxidative-dissolution mechanism in which metals are oxidized and the oxides dissolve. Some metals are intrinsically resistant to oxidation (e.g., Pd) and others are stabilized by the durability of the alloy (e.g., Tc and U). Therefore, the advanced metal waste form (AMWF) materials are being formulated to generate durable host phases for radionuclides.

Compared with 316L, HT-9 steel contains lower levels of Cr, Mo, and Ni, and higher levels of C. These differences result in HT-9 being less durable than 316L. (HT-9 steel was developed for performance in a reactor, not corrosion resistance in a disposal system.) Figure 54 shows potentiodynamic (PD) scans for HT-9 cladding that was remelted, 410 stainless steel, which has a composition similar to HT-9 except it contains no Ni or Mo, 410 stainless steel with added Mo and Zr, and 410 stainless steel with added Zr, $\mathrm{Mo}, \mathrm{Ru}, \mathrm{Pd}$, and lanthanide oxides. The PD curves show the current density (which is proportional to the mass corrosion rate through Faraday's Law) as a function of the imposed surface potential, which represents the Eh of the solution contacting the waste form in the disposal environment. Comparison of the curves in Figure 54a indicates regions of potential in which the presence of Mo or Ni increases the corrosion resistance of the alloy by more than two orders of magnitude; the Cr levels are the same in HT9 and 410 stainless steel, but the shape of the PD curve for 410 stainless steel indicates the region influenced by $\mathrm{Cr}$. Figure 54b shows the benefits of adding $\mathrm{Zr}$ and Mo (green curve) and adding $\mathrm{Ru}$ and $\mathrm{Pd}$ (purple curve). In addition to lower current densities (corrosion rates), the potential threshold for alloy corrosion to occur increases significantly with these additions. The thresholds are indicated by the potentials at which the current quickly drops to zero (e.g., at about $-0.36 \mathrm{~V}$ for remelted HT -9 and +0.03 $\mathrm{V}$ for $410+\mathrm{Zr}+\mathrm{Mo}+\mathrm{Ru}+\mathrm{Pd}+$ oxides). Corrosion at potentials above the threshold are dominated by anodic corrosion of the alloys and corrosion at potentials below the threshold are dominated by cathodic reactions of solution constituents. Comparison of PDs for AMWF made with 316L stainless steel indicate the addition of Ni and more $\mathrm{Cr}$ will further stabilize AMWF made with HT-9 cladding in extremely 
oxidizing environments up to $1.2 \mathrm{~V}$. The fuel waste stream itself will provide beneficial amounts of $\mathrm{Zr}$, $\mathrm{Mo}, \mathrm{Ru}$, and Pd to the alloyed waste forms. This was demonstrated by two prototype AMWF materials made with HT-9 cladding and surrogate fuel waste with different $\mathrm{Zr} / \mathrm{U}$ ratios; the PD scans are compared with remelted HT-9 cladding in Figure 54c. These indicate that small amounts of added Ni will be needed to increase the corrosion resistance of AMWF in oxidizing environments.

The PD scans shown in Figure 54 represent the corrosion rates of the bare metal surfaces in acidic brine. Corrosion may alter the composition and structure of the surface and attenuate the corrosion rate by forming passivating layers. The corrosion rates of interest to long-term repository performance include the effects and stabilities of passivated surfaces formed on AMWF materials, which may differ over time for each constituent phase and with changes in the environment. A testing protocol and model developed at ANL are being used to evaluate the long-term corrosion behavior of AMWF materials. The electrochemical testing protocol provides a direct measure of oxidation rate and values used to model environmental effects on oxidation processes, quantify the attenuating effects of passivation, and determine the ranges of active and passivation corrosion in different environments. The degradation model is based on electrochemical corrosion theory to provide confidence in long-term predictions using experimental data. Tests are conducted with electrodes made from the alloy materials for several weeks under open circuit conditions or at various imposed potentials. The corrosion current is measured continuously to monitor stabilization of the surface. The surface corrosion properties (the corrosion potential, polarization resistance, Tafel constants) are measured and the surface layer is characterized with electrochemical impedance spectroscopy periodically. The solution is also sampled occasionally to directly measure the releases of $\mathrm{U}$ and $\mathrm{Tc}$ and correlate the alloy oxidation rates measured electrochemically with the radionuclide release rates used to assess waste form performance.

(a)
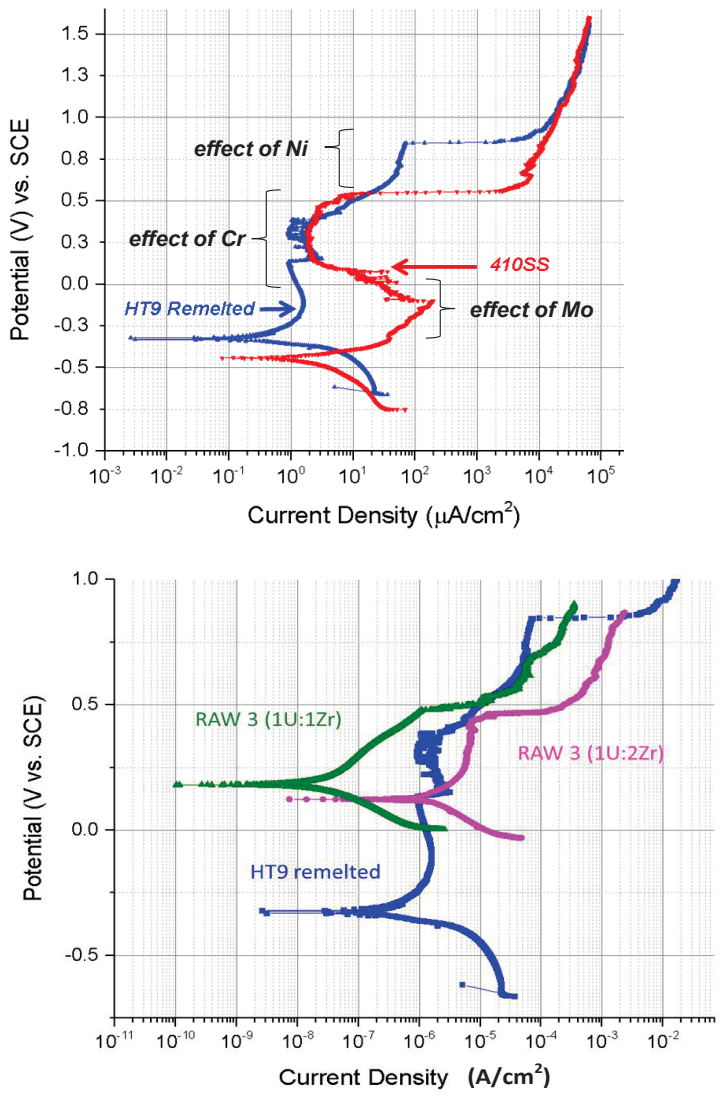

(b)

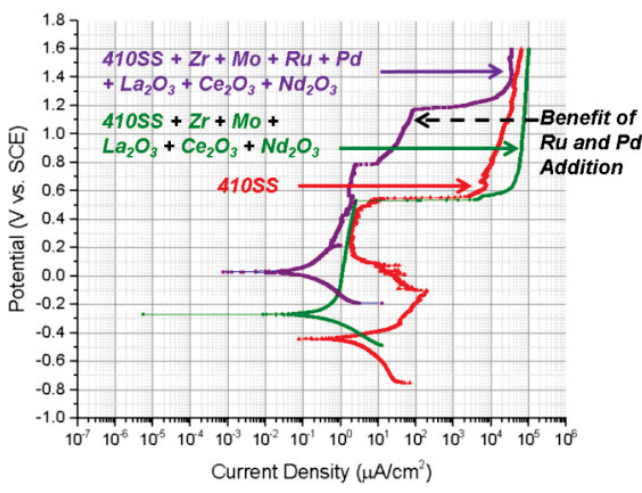

Figure 54. Potentiodynamic scans showing benefits of (a) $\mathrm{Mo}, \mathrm{Cr}$, and $\mathrm{Ni}$, and (b) Ru and Pd to corrosion resistance of HT-9, and (c) metallic fuel wastes in HT-9 based RAW 3 materials.

(c) 
Examples of test results are shown in Figure 55 for corrosion of a 316L-based material in acidic brine at $250 \mathrm{mV}$. The PD curve in Figure 55a shows two passive regions at about $150-400 \mathrm{mV}$ and about 600 $\mathrm{mV}-900 \mathrm{mV}$. Holding the potential at $250 \mathrm{mV}$ results in the corrosion current densities plotted in Figure $55 \mathrm{~b}$ during a 6-h experiment. The current density dropped from about $50 \mu \mathrm{A} \mathrm{cm}^{-2}$ to about $0.5 \mu \mathrm{A} \mathrm{cm}^{-2}$ almost immediately. Examination of the reacted surface after the test, shown in Figure 55c, indicated the spikes in the current are due to pitting of the intermetallic; the adjacent steel phase is not corroded at this potential. Figure 55d shows the results of electrochemical impedance spectroscopy (EIS) before and after the test, which characterize the evolution in surface properties as the specimen corrodes at $250 \mathrm{mV}$. These results reveal the initial stabilization of the surface by developing capacitive character.

These series of electrochemical corrosion tests have demonstrated that (1) corrosion resistant waste forms can be produced from HT-9 cladding and (2) the degradation behavior can be modeled for a wide range of environmental conditions. An improved waste form will be formulated with HT-9 steel, surrogate fuel wastes, and trim metals demonstrated to improve the corrosion resistance. New alloys will be made in FY-16 with $U$ and with Tc and $U$ to determine the particular phases hosting each radionuclide and measure the corrosion behaviors of those and other phases. Suites of electrochemical tests will be conducted at ANL and SRNL to generate the data base needed to parameterize the AMWF degradation model. Most tests will be conducted in acidic and acidic brine solutions to represent the most likely environments in a breached waste package.

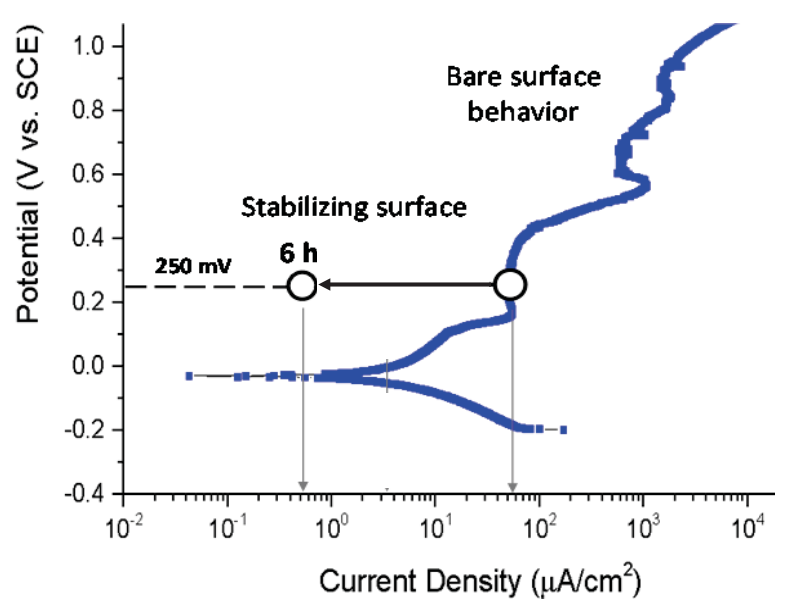

(a)

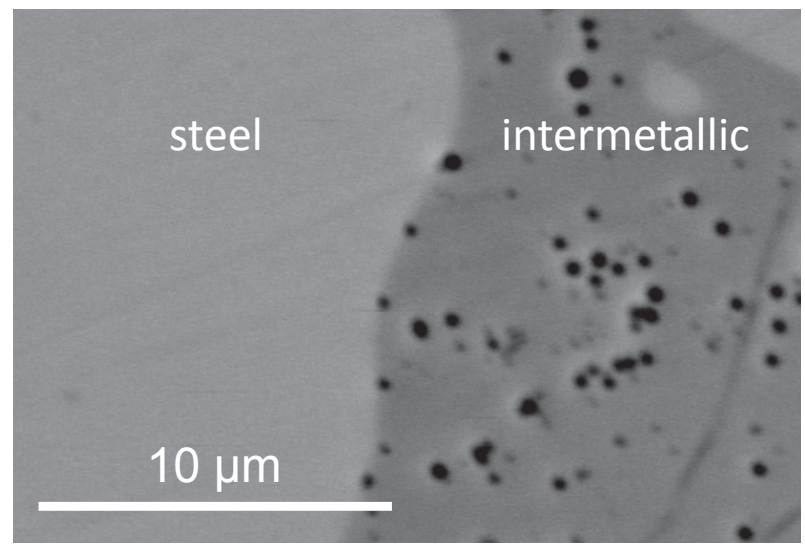

(c)

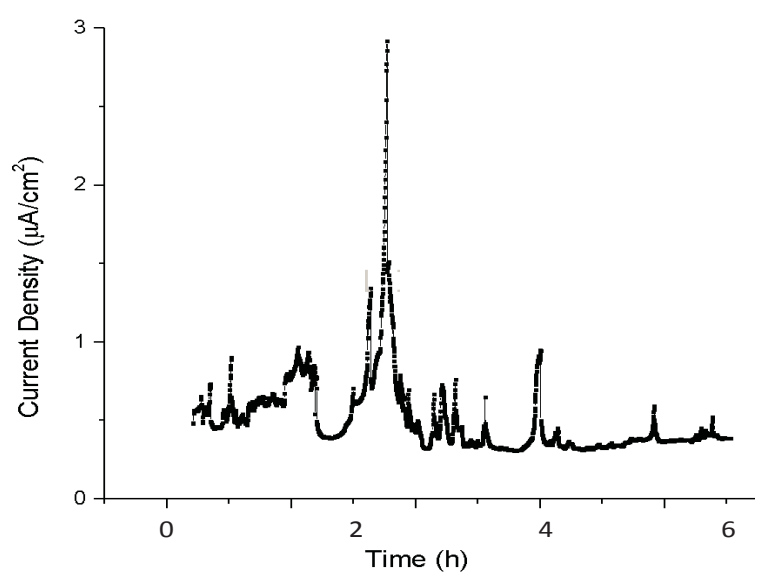

(b)

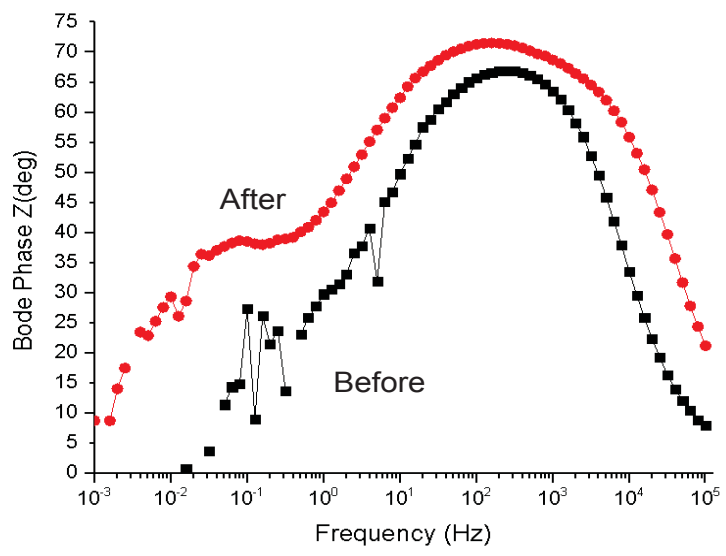

(d)

Figure 55. (a) PD for bare surface of a 316L-based MWF in acidic brine, (b) current density over time at $250 \mathrm{mV}$, (c) pits formed in intermetallic phases during potentiostatic experiment, and (d) EIS analyses of surface before and after test. 


\section{Publications}

Ebert, W. L., 2015, "Production and Initial Testing of HT9-Based Alloy Waste Forms," FCRD-MRWFD2015-000144.

Ebert, W. L., 2015, “Electrochemical Testing of 316L-Based Alloy Waste Forms,” FCRD-MRWFD2015-000146.

Ebert, W. L. and C. T. Snyder, 2015, "Corrosion Tests with Waste Forms Developed for EChem Salt Wastes," FCRD-MRWFD-2015-000145.

\subsection{Glass Corrosion}

J. Ryan, S. Kerisit, P. Rieke, and J. Neeway, PNNL; W. Ebert, ANL;C. Crawford and C. Jantzen, SRNL

Borosilicate glass is being used to immobilize HLW in the US and internationally. The source term for the release of radionuclides into the environment from borosilicate glass waste forms is the product of the radionuclide inventory (known), the glass surface area (well parameterized), and the corrosion of the glass network by exposure to groundwater. This source term is being addressed in the Material Recovery and Waste Form Development campaign while subsequent transport, determined by environmental factors including advection, sorption, precipitation, colloid formation, size filtration, etc., is being addressed in the Used Fuel Disposition (UFD) campaign. The team is working closely with the modelers in UFD to ensure that the source term fits their computational requirements.

The mechanisms behind glass corrosion are a source of scientific non-consensus, requiring significant conservatism in the currently used models. These include the effects of a decreasing reaction affinity due to increasing solution concentrations, mass transport limitations imposed by developing surface alteration layers, and the impact of precipitating alteration phases on all the mechanisms. The objective of activities in this activity is to develop the scientific data base and mechanistic understanding of glass degradation necessary to reach an international consensus on how to model the corrosion behaviors of glass waste forms over geologic time scales and calculate radionuclide source terms for a variety of relevant disposal environments.

Recently, the progress of the model development was reported (Ryan et al. 2014), which details the logical process necessary to provide a rate simple enough to insert into a broad performance assessment calculation, yet based on sound scientific bases. Based on the same science as is given in recent review papers (Gin et al. 2013, Vienna et al. 2013), the document presented five mechanistic processes that have the potential to significantly impact radionuclide release at certain points in the glass corrosion timeline: dissolution, secondary phase precipitation, solid-state transport, gel transport, and the evolution of the glass-solution interphase.

The FY-15 scope included experiments designed to address particular aspects of glass corrosion with modeling efforts performed at the atomic and continuum scales to help interpret the experiments, apply the results to the degradation model, and interface the degradation model with disposal system performance assessment calculations. Key among these was the determination of analytical forms for ion exchange interdiffusion and proposing a form to capture Stage III. Experimental and modeling activities are in progress to address these factors in the glass dissolution rate law.

As mentioned in the Collaboration section, the glass corrosion efforts benefit from co-funding from DOEEM. Additionally, many of the activities benefit by collaborations with NEUP-funded research being conducted at several universities in the U.S. The annual international workshop was held in May in Miami, Florida with our partners from France (CEA, Subatech, AREVA), Belgium (SCK-CEN), U.K. 
(NNL, Amec, Univ. of Sheffield, Imperial College), and Japan (Kyushu, JAEA). More minor collaborations are underway with researchers in Germany and Italy and the leading glass company, Corning, Inc. has recently begun interacting with the group as well. These collaborations are yielding scientific advances more quickly and fostering consensus in the scientific understanding of waste glass corrosion and the development of an effective mechanistic rate law. The work completed in FY-15 provided key structural findings and databases that will define the potential mechanisms responsible for the various stages of glass degradation. Development of a holistic model that accounts for observed glass degradation behavior continues. Although work continues to target the majority of mechanisms, only summary descriptions of selected experimental and modeling results follow.

\section{Stage III Model and Supporting Experiments}

\section{W. Ebert, $A N L$}

Waste glass corrosion behavior can be roughly broken into three stages in which markedly different corrosion rates are observed (Figure 56). Stage I behavior is that experienced by glass dissolving into a dilute solution through hydrolysis and ion exchange reactions with no transport or reaction affinity limitations. As the solution ionic strength increases, a transition to Stage II behavior is observed, which represents the very low "residual" rate observed at long times in static conditions. In certain combinations of glass composition and environment, a marked increase in the rate of glass alteration after a period of time at the relatively low "residual" rates can be observed. This is Stage III behavior, and its cause is currently uncertain.

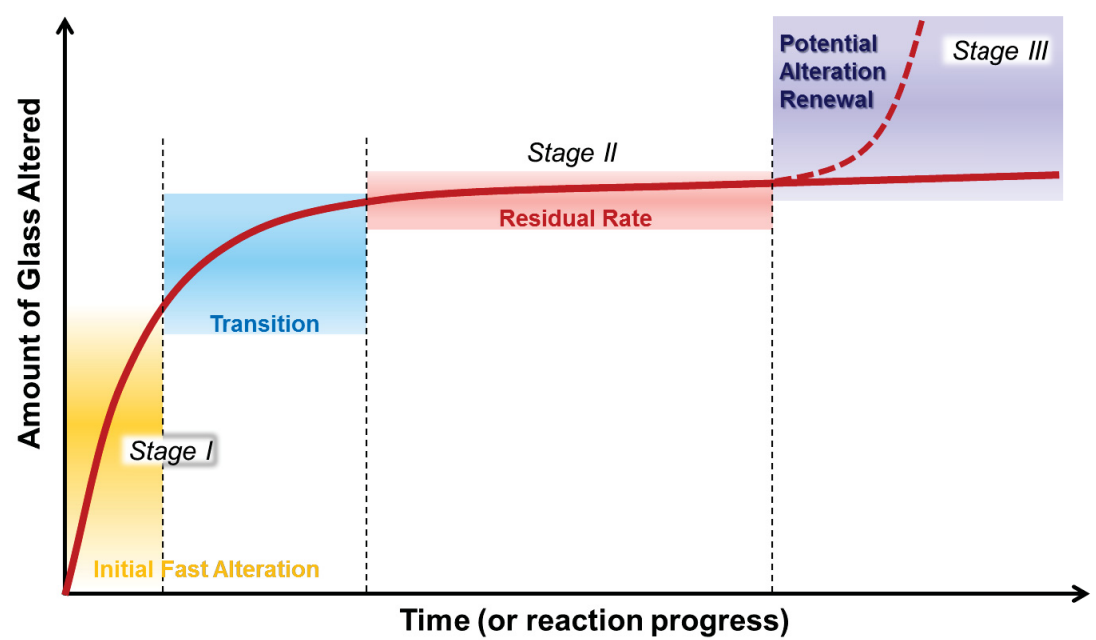

Figure 56. Schematic of glass corrosion process (from Vienna et al. 2013)

Work at ANL was focused on developing a model to take Stage III behavior into account within the HLW glass degradation model by identifying the conditions that trigger the increased glass dissolution rate and the effective long-term Stage III rate. Stage III behavior is often observed in laboratory tests to occur coincidentally with the formation of certain (usually zeolitic) secondary phases. Challenges include identifying the reaction conditions that lead to the sudden change in behavior based on experimental results and representing that rate change in model simulations. A conceptual Stage III model was developed based on the coupling between glass dissolution and secondary phase precipitation kinetics through the transfer of common constituents. That model differentiates between secondary phases that lead to Stage III behavior and those that do not based on the relative kinetics of glass dissolution and secondary phase precipitation: secondary phases that precipitate slower than the glass dissolves will establish a low steady-state rate referred to as the residual rate, whereas secondary phases that precipitate 
faster than the glass dissolves will establish the high steady-state rate referred to as Stage III. The inhibiting and accelerating effects of different secondary phases are attributed to the same mechanism that couples the two processes. Glass dissolution and secondary phase precipitation are both represented by reaction affinity models in which kinetic terms for the individual dissolution and precipitation reactions are attenuated by thermodynamic terms related to the stability of the overall system. Whereas the environmental dependencies of the kinetic terms remain constant (e.g., on the solution composition and surface area), the thermodynamic driver affecting all reactions changes significantly when new phases are generated. The dissolution and precipitation rates of various reactions are coupled by transfer of species common to both phases through the shared solution. A generic formulation of the rate of coupled dissolution and precipitation reactions that is consistent with experimental observations of the residual rate and Stage III behavior is

$$
\text { rate }_{\text {coupled }}=\frac{\operatorname{rate}_{\mathrm{f}}^{\text {(glass) }} \operatorname{rate}_{\mathrm{f}}^{\text {(secondary phase) }}}{\operatorname{rate}_{\mathrm{f}}^{\text {(glass) }}+\operatorname{rate}_{\mathrm{f}}^{\text {(secondary phase })}}\left[1-\exp \left(\frac{\Delta G^{\text {(glass) }}+\Delta G^{(\text {secondary phase) }}}{R T}\right)\right],
$$

where "secondary phase" refers to the rate controlling secondary phase in the system and will change as glass degradation progresses. The terms rate $_{\mathrm{f}}{ }^{\text {(glass) }}$ and rate $_{\mathrm{f}}{ }^{\text {(secondary phase) }}$ represent the forward rates for each of those reactions. The terms $\Delta G^{\text {(glass) }}$ and $\Delta G^{\text {(secondary phase) }}$ represent the free energy contributions for dissolving glass constituents into solution and growing the rate controlling secondary phase, which are related to the solution composition through the saturation indexes. The functional dependence of the term in brackets on the solution composition remains to be determined. Discontinuities will occur each time a new secondary phase is formed to establish new values of $\Delta G^{\text {(secondary phase) }}$ and rate (secondary phase) $^{\text {Glass }}$ dissolution may be coupled to the precipitation of several secondary phases and the relative effect of each phase on the glass dissolution rate may change as the transformation proceeds.

Laboratory tests indicate two dominant steady-state reaction rates occur as glass corrodes in a static system: the residual rate and the Stage III. However, but both rates depend on the $\mathrm{pH}$, temperature, and perhaps the solution composition. An important nuance of the conceptual model is that Stage III is triggered by nucleation of a critical secondary phase (or precursor) that may be different than the phase establishing the Stage III rate and may have a different dependence on the solution composition. Therefore, representative kinetic and affinity terms must be determined separately for the residual rate, the Stage III trigger, and the Stage III rate to model long-term glass degradation. Modified PCTs are being conducted to quantify the relationships between the solution composition, secondary phase formation, and the glass dissolution rate to derive analytical functions for modeling those processes.

\section{In-Situ Monitoring of Glass Corrosion Using Raman Spectroscopy}

\section{J. Ryan, S. Bryan, S. Devranathan, J. Neeway, and A. Casella, PNNL}

One important development has been the development of a real-time monitoring technique for static corrosion experiments. Based on a paper on the monitoring solution $\mathrm{pH}$ for medical applications using the Raman spectroscopic signatures for boron speciation, we evaluated the adaptation of this technique in corrosion conditions. Initial examination of the correlation of speciation vs. $\mathrm{pH}$ revealed the fact that the ratio could be used to determine $\mathrm{pH}$ with great accuracy between approximately 6 and 11 . To test this theory in a real system, we coupled a Teflon container with the Raman probe and monitored the corrosion of the Environmental Assessment (EA) glass. The EA glass dissolves quite quickly in these conditions, which was ideal to ensure the presence of signal in a reasonable time frame. The Teflon vessel was leaky, necessitating water additions, but served to prove the principle as the increase in boron concentration in 
solution was prominent. The $\mathrm{pH}$ monitoring was predictably not possible, as the $\mathrm{pH}$ for dissolving EA glass is quickly $>11$, leaving the boron entirely as the $\mathrm{B}(\mathrm{OH})_{3}$ species.

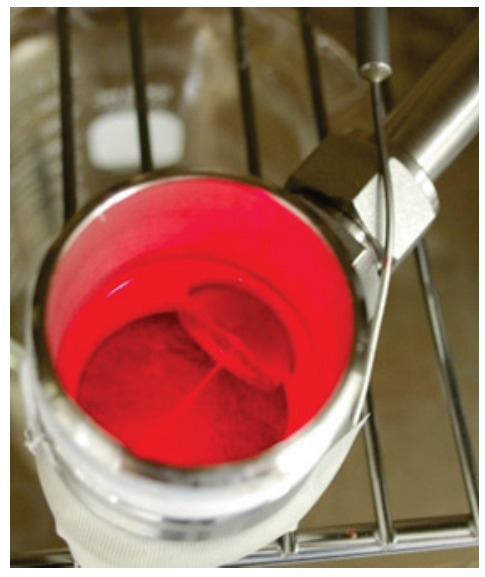

Figure 57. Stainless steel vessel for in-situ Raman spectroscopy of solutions contacting corroding glass.

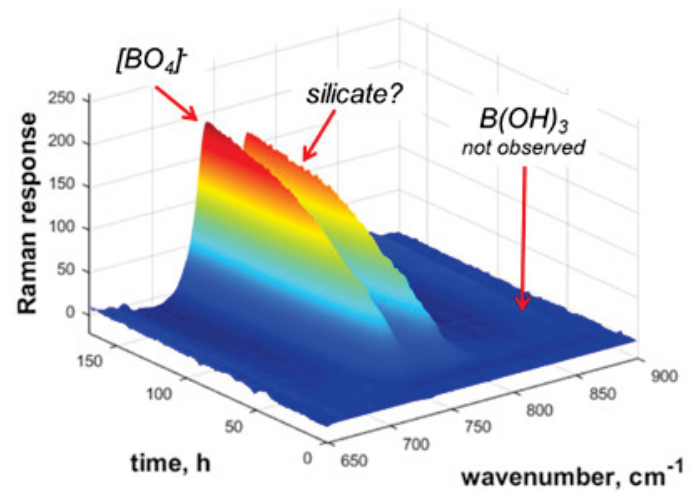

Figure 58. Time-dependent Raman spectra of the solution contacting corroding EA glass at $90^{\circ} \mathrm{C}$. Glass was added to system at 35 hours.

Following this success, we redesigned the system to consist of stainless-steel vessels (Figure 57) with Teflon seals to minimize water loss. Two conditions were examined. In the first, the experiment from the initial test was redone. In the second, $250 \mathrm{ppm}$ boron was added to the solution to evaluate the potential of using a boron "spike" to enable concentration measurement at low reaction progress. The revised vessel worked well, with no apparent water loss. The boron concentration increased rapidly to 1,200 ppm over 7 days, as expected from previous EA data. More importantly, even in the system with no boron spike the increase in boron was apparent at levels well below $50 \mathrm{ppm}$. This is more in line with the values expected when monitoring the more durable waste glasses that typically do not result in levels much greater than $250 \mathrm{ppm}$ even at long times. While the boron concentration in these tests was based on simple peak height (albeit calibrated), in the future we plan chemometric analyses based on the values from appropriate standards in the concentration range to bound observed Raman signal. Again, the $\mathrm{pH}$ value for this test was too high to measure using boron speciation, but we did note that $\mathrm{pH}$ monitoring was still possible by measuring the $\mathrm{OH}^{-}$signal itself.

The boron spike test did not substantially increase the accuracy of the boron measurement, but did have a large buffering effect on the system. While this is detrimental to a corrosion study, it did allow us to illustrate the high-accuracy $\mathrm{pH}$ monitoring capability by lowering the solution $\mathrm{pH}$ to between 8.7 and 9.9 over the course of the experiment. Interestingly, another band was observed from approximately 775 to $850 \mathrm{~cm}^{-1}$, or between the two boron speciation bands. This band is likely due to silicate bonding and may represent another avenue for characterization in the future.

This technique holds strong promise for the performance evaluation for all waste forms; not just glass. The continuous nature of the corrosion data will be much more helpful when using inverse modeling of the datasets to parameterize rate laws. The technique could be used for glass or cementitious wastes, and possibly even for other systems. The system itself is scalable, with each spectrometer capable of running 12 probes. We will continue to develop the technique, improving our calibration and exploring the use of additional Raman signatures to more completely characterize the solution. Ideally, the technique will be highly useful in examining Stage III behavior as described above. With near-instant knowledge of the abrupt transition to the accelerated rate and information about the solution speciation as well, we can stop the tests and examine them to find the identity of the triggering mechanism. 


\section{Ion Exchange Parameterization}

\section{J. Neeway, S. Kerisit, and J. Ryan, PNNL}

Ion exchange is recognized as an integral, if underrepresented, mechanism influencing glass corrosion. However, due to the formation of various alteration layers in the presence of water, it is difficult to conclusively deconvolute the mechanisms of ion exchange from other processes occurring simultaneously during corrosion. This complexity highlights the need for a better fundamental understanding of ion exchange, leading to an avenue of research that culminated in "Ion exchange in simulated nuclear waste glasses" (FCRD-MRWFD-2015-000114), a comprehensive report on the parameterization of the ion exchange mechanism to fulfill milestone M2FT-15PN0307131.

Ion exchange is defined as the exchange of charged species (most likely a hydrogen species) between the fluid and the glass. At short time periods in an initially dilute, closed system, this process results in the depletion of alkalis at the surface. The net effect is consumption of $\mathrm{H}_{3} \mathrm{O}^{+}$from solution, which raises the solution $\mathrm{pH}$ and promotes hydrolysis of the silicate network. In the studies presented in the $\mathrm{M} 2$ report, the ion exchange process was isolated from matrix dissolution at relatively low temperatures $\left(25-150^{\circ} \mathrm{C}\right)$ in several different glasses with compositions based on the simulated French high-level waste glass -SON68. For the majority of the experiments, lithium, the lightest and smallest of the alkali metals, was added to a functionally inert solution of dimethyl sulfoxide (DMSO) and the lithium from the fluid was allowed to diffuse into the glass surface. The use of DMSO allowed the alkali ion exchange process to be measured independently from matrix dissolution. A chemical interdiffusion model based on Fick's $2^{\text {nd }}$ law successfully reproduced compositional depth profiles measured using time-of-flight secondary ion mass spectrometry (ToF-SIMS). Through changes in the chemical composition of the glass and ions in the source solution, various combinations of diffusing alkali ions were examined, from like alkali with different isotopics (reproduced with a simple isolated diffusion model) to the exchange of lithium from solution with sodium and potassium in the glass (requiring a more complex interdiffusion model). The diffusion coefficient for any particular alkali was dependent on the element, its structural role in the glass, and temperature. Values ranged from $10^{-25} \mathrm{~m}^{2} / \mathrm{s}$ for the slowest diffusing ion at $25^{\circ} \mathrm{C}$ to $10^{-18} \mathrm{~m}^{2} / \mathrm{s}$ for the fastest diffusing ion at $150^{\circ} \mathrm{C}$. The activation energy for the process was similar for each glass and ranged from 105 to $128 \mathrm{~kJ} / \mathrm{mol}$ for those with at least three temperature data points, in agreement with literature values from measurements made at higher temperatures with other borosilicate glasses.

Lastly, a few preliminary studies were performed where an attempt was made to measure the ion exchange of $\mathrm{H}^{+}$with alkali elements in the glass without the formation of surface layers intrinsic to glass alteration in aqueous environments. The experiments again use DMSO as a solvent and citric acid as the $\mathrm{H}^{+}$source. The initial results are promising and suggest that this method can be used to bound the ion exchange rate of $\mathrm{H}^{+}$from solution with alkali ions in the glass. This result is critical to understand the long-term performance of glass in a geological repository because the ion exchange process may be the rate-controlling mechanism of glass corrosion under some conditions.

The models developed from the alkali-alkali ion exchange experiments are readily available for implementation into a model of $\mathrm{H}^{+}-\mathrm{M}^{+}$exchange. These models can then be easily implemented into glass corrosion models using diffusion coefficients and activation energies obtained from this experimental method. The most complete of these is a 2-species interdiffusion construct, with sodium and hydrogen as the opposing species. In this model, the interdiffusion coefficient of species A at time $t$ and depth $x, \widetilde{D}_{A}$,

is defined as:

$$
\widetilde{D}_{\mathrm{A}}=\left(1+\alpha\left(1-C_{\mathrm{B}}\right)\right) \frac{D_{\mathrm{A}}^{\mathrm{s}} D_{\mathrm{A}}^{\mathrm{b}}}{C_{\mathrm{B}} D_{\mathrm{A}}^{\mathrm{s}}+\left(1-C_{\mathrm{B}}\right) D_{\mathrm{A}}^{\mathrm{b}}}
$$


where $D_{\mathrm{A}}^{\mathrm{s}}$ and $D_{\mathrm{A}}^{\mathrm{b}}$ are the surface and bulk diffusion coefficient of species A, respectively, and $C_{\mathrm{B}}$ is the bulk normalized concentration of species $\mathrm{B}$. Because the diffusion of species $\mathrm{A}$ and $\mathrm{B}$, here $\mathrm{H}^{+}$and $\mathrm{Na}^{+}$ ions, are not independent, $\widetilde{D}$ varies with their relative concentrations. The results of this study suggest model parameters at room temperature for the studied glasses should be on the order of $D=1 \times 10^{-24} \mathrm{~m}^{2} / \mathrm{s}$ and $E_{a}=100-120 \mathrm{~kJ} / \mathrm{mol}$, regardless of the ion. Using this model, the release of sodium into solution can then be incorporated into other aspects of corrosion modeling, impacting the $\mathrm{pH}$ of the contacting fluid and the availability of sodium towards the precipitation of secondary phases. It is important to note that dedicated parameterization work should be performed for any glass of interest to obtain the highest performing model calculations. This is particularly important the farther in composition space the glasses are from the SON68/R7T7 glass system as the results of this study showed some variability even though all the studied glasses were compositionally related.

One key complication still remains. By isolating the interdiffusion portion of ion exchange from the mechanisms of corrosion as was done in the experiments presented in the M2 report, a different activation energy for the studied mechanism was obtained compared to prior studies where no attempt was made to isolate the ion exchange reaction. This strongly suggests that ion exchange is a coupled process: the fluidsolid exchange reaction and the solid-state interdiffusion of those ions. Ongoing efforts are attempting to unlock this coupling and increase our fundamental knowledge of the process. Additionally, there is also some uncertainty as to the role that hydrogenated (exchanged) glass plays in various mechanisms.

Even though the ion exchange reaction may not be the mechanism controlling the release of radionuclides from a HLW glass at all time periods, it is important to note that it does persist in all chemical environments and time periods and has an important impact on other mechanisms. The effect on these other mechanisms is through the supply of key constituents from the glass with a potential minor effect of changing the structure of the glass thus affecting the dissolution. The process is especially important in conditions near saturation with respect to amorphous silica and at low temperatures. Both of these conditions are expected to be present in a HLW repository at long time periods

\section{Morphological Evolution Model for Stage II Dissolution}

\section{J. Ryan, PNNL}

Several models have been developed over the years to predict glass performance over the long-term, including reaction affinity models generally based on the transition state theory of mineral dissolution, transport limitation models that posit that the transport of reactants and/or products is limited by a barrier layer within the alteration products, and a dissolution/reprecipitation model suggesting the presence of a fluid layer at the boundary of the glass and alteration products. Each of these models has significant shortcomings with regards to some of the observed behaviors, most generally related to the nearly ubiquitous formation of an amorphous, porous gel. The discrepancies of these models evoke the need for an explanation that accounts for the formation and evolution of all the observed structures as well as the observed behaviors.

In FY-15, task scientists have proposed a new model of glass dissolution based on the theory of morphological evolution. In this model, mobile elements such as sodium, lithium, and boron are rapidly dissolved from the surface of the glass during the initial contact of the glass material with water by an ion exchange process, leaving a silicate network with ion scale pores. This scale of porosity is unstable in a hydrated silicate system; when the radius of curvature in a porous hydrated silicate is extremely small, the structure will collapse into a dense hydrated silicate material. The thickness of this layer is dependent on the access of water to the mobile ions dissolved from the network, which is itself determined by the composition and structure. The solubility of hydrated silicates tends to reach saturation around 20-30 
ppm. Due to this, the rate of dissolution of this layer is negligible in a saturated silica solution. We posit that diffusion of ions through this layer through solid-state diffusion is also slow enough so as to be irrelevant when compared to the rates of other mechanisms.

Hydrated silicates are measurably susceptible to creep, even at low temperature, and their most stable form is a three-dimensional gel. The model proposes that this film is driven by interfacial energy minimization to change its morphology, exposing new areas of glass that are then subject to further corrosion by the contacting solution. Therefore, the long-term dissolution rate is dictated by the movement of the altered glass at this interfacial region.

The benefit of this model is that it explains the vast majority of the observed phenomenon for glass corrosion. One observation is the Stage II or "residual rate" behavior. This has been modeled alternately as a constant or as a square root time relationship. It is difficult to differentiate between these in laboratory experiments, as the levels of error in even the best measurement techniques exceed the differences between the two, although a study of ancient natural analogue materials suggests that a constant rate is more appropriate. In the morphological evolution model, a constant residual rate results from the continual the wetting of the interface material from regions of fresh glass. As long as the solution and environmental conditions remain roughly constant, this process would be expected to continue indefinitely. An important point is that there is little relation between the speed of this process and the concentration of silica and in solution. Differences in the residual rate observed in different systems can be explained by suggesting that the viscosity of the interface material would be different for different composition glasses. The real strength of this model is in the prediction of gel formation as well as gel structure. Other models either do not explicitly form a gel layer (Affinity-only models, original GRAAL) or produce a gel through the reprecipitation of dissolved species (new GRAAL, dissolution/reprecipitation). In the morphological evolution model, the production of the gel is the key mechanism that controls further glass corrosion.

Rather than being a new alternative to rate laws currently in use, this model provides an explanation for a term that has been used in glass corrosion rate laws for decades. In some of the original affinity-based rate laws, it was understood that corrosion proceeded even when the concentration of silicon in solution was high. A fit parameter was added to the affinity-based equations to account for this observation, and was usually termed the residual rate. There was never a consensus on what this rate represented, but one of the leading theories was that since waste glass is a complex amorphous solid that cannot be precipitated from solution, the thermodynamics drive a slow alteration. While it is indisputable that waste glass is not the lowest thermodynamic energy state, it does not necessarily follow that the reaction must proceed. Indeed additional amorphous solids (in the form of the gel and amorphous calcium-silicate-hydrate precipitates) form from the corroding solid phase and are thermodynamically more stable than the glass itself. In the next fiscal year, we plan to evaluate this model mathematically with available datasets and work it into conversations about a consensus rate law.

\section{International Simple Glass Summary Report}

\section{T. Kaspar, J. Ryan, PNNL}

One of the primary objectives of this research has been to develop robust models based on a scientific and mechanistic understanding of the processes responsible for glass degradation and radionuclide release. These models will be used to calculate the long-term behavior of a glass waste form and its ability to control the release of radionuclides to the ground water at some reasonable margin of safety below that required in the applicable regulations for any given country and locale. The value of such an understanding has been recognized by the international scientific community. Since 2009, a wide and largely informal grouping of scientists has met regularly both to define and focus the efforts towards key 
scientific problems and to coordinate both the impact and dissemination of knowledge. Given the complexity of the various mechanisms of glass corrosion, this community recognized the usefulness of analyzing simpler glass compositions to remove potentially complex interactions. To that end, a sixcomponent glass was designed in 2011 to be a compromise between simplicity and relation to waste glasses. This became known as the International Simple Glass (ISG). The composition was chosen such that the ratio of the main components was equal to those of the inactive reference glass for the R7T7 under production at the AREVA La Hague plant in France, SON68. This was chosen because of the wealth of data already obtained worldwide on the SON68 composition, its similarity to other borosilicate glasses under consideration, and the fact that the simplified glass had recently been subjected to a 16 year static dissolution test.

Since that point, a large common batch of that composition was fabricated and distributed to many international partners. Most of the characterization and corrosion work performed on the ISG glass to date, both previously published and unpublished, was summarized in a report titled "Summary of experiments and modeling of the International Simple Glass" (milestone M4FT-15PN0307138). The document sources more than twelve institutions with information on the material running from the mundane (density, composition) to the advanced (atom-probe structure, phase separation studies, NMR and Raman spectra). The document, after a DOE review, will be reviewed by all the submitting institutions before final submission. It will be an invaluable resource to the international glass corrosion community as it is expected that, through closely coupled theory, experimental, and modeling, the work performed on the ISG composition will help to provide understanding of key mechanisms at different time periods, ultimately resulting in the development of robust corrosion models that can predict the extent of glass alteration throughout the lifetime of a geologic repository.

\section{Publications}

Ebert, W. L., "Implementing the Glass Degradation Model in Generic Disposal System Analyses," FCRD-MRWFD-2015-000546, 2015.

Ebert, W. L., "Stage 3 Model for Coupled Glass Dissolution and Secondary Phase Precipitation Reactions," FCRD-SWF-2014-000246, 2015.

Gin, S., P. Jollivet, M. Fournie, Z. Wang, Z. Zhu, A. V. Mitroshkov, and J. V. Ryan, 2014, "The Fate Of Silicon During Glass Corrosion Under Alkaline Conditions: A Mechanistic And Kinetic Study With The International Simple Glass," Geochimica et Cosmochimica Acta, 151, 2015: 68-85.

Jantzen C, C Crawford, J Pareizs, J Pickett, “Accelerated Leach Testing of GLASS: II. LeachateHydrogel Interactions, Glass Structure, and Accelerated Dissolution," International Journal of Applied Glass Science (in revision)

Jantzen, C., C. Crawford, J. Pareizs, J. Pickett, “Accelerated Leach Testing of GLASS: I. Waste Glass Hydrogel Compositions and the Resumption of Accelerated Dissolution," International Journal of Applied Glass Science (in revision)

Kaspar, T. C., J. V. Ryan, C. Corkhill, C. Crawford, J. Du, W. Ebert, K. Ferrand, T. Geisler, S. Gin, M. Harrison, N. Hyatt, J. Icenhower, Y. Inagaki, C. Jantzen, S. Kerisit, K. Lemmens, C. Lenting, T. Maeda, N. Mellott, S. Mitsui, J. Neeway, C. Pantano, B. Parruzot, P. Rieke, J. Schofield, N. Wall, N. Washton, P. Zapol, "Summary of experiments and modeling of the International Simple Glass," FCRD-MRWFD-2015-000683, 2015 (still under review).

Kerisit, S. N., E. M. Pierce, and J. V. Ryan, "Monte Carlo Simulations of Coupled Diffusion and Surface Reactions during the Aqueous Corrosion of Borosilicate Glasses," Journal of Non-Crystalline Solids, 408, 2015: 142-149. 
Neeway, J. J., S. N. Kerisit, J. Liu, Z. Zhu, J. V. Ryan, "Ion exchange in simulated nuclear waste glasses,” FCRD-SWF-2015-000114, PNNL-24420, 2015.

Reiser, J., L. M. Neill, J. Weaver, C. Musa, J. J. Neeway, J. V. Ryan, N. Qafoku, S. Gin, N. A. Wall, "Glass corrosion in the presence of iron-bearing materials and potential corrosion suppressors," MRS Proceedings 2014.

Ryan, J. V., Ebert, W. L., J. J. Neeway, S. N. Kerisit, and P. C. Rieke, “A Mechanistic Approach to the Calculation of Glass Behavior over Geologic Time Scales,” FCRD-SWF-2014-000029, PNNL23691, 2014.

Schreiber, D. K. and J. V. Ryan, “Atom Probe Tomography,” Modern Glass Characterization, Edited by M. Affatigato. Wiley, 2015.

Wang, Y. C., D. K. Schreiber, J. J. Neeway, S. Thevuthasan, J. E. Evans, J. V. Ryan, Z. Zhu, and W. Wei, "NanoSIMS Imaging Alternation Layers Of A Leached SON68 Glass Via A FIB-made Wedged Crater," Surface and Interface Analysis, 46, 233-7, 2014. doi:10.1002/sia.5585

Wang, Z., J. V. Ryan, Z. Zhu, et al., "High Sputter Rate and Accurate Interfacial Chemical Information: Using Argon Cluster Sputtering Source in ToF-SIMS Depth Profiling of Leached Nuclear Waste Glass and Functional Metal Oxide Films," Journal of The American Society for Mass Spectrometry, 26(8), 2015.

\title{
Document References
}

Gin, S., A. Abdelouas, et al., "An international initiative on long-term behavior of high-level nuclear waste glass," Materials Today 16(6): 243-248, 2013.

Vienna, J.D., J.V. Ryan, S. Gin, Y. Inagaki, "Current Understanding and Remaining Challenges in Modeling Long-Term Degradation of Borosilicate Nuclear Waste Glasses," International Journal of Applied Glass Science, 4(4) 283-294, 2013.

Ryan, J.V., WL Ebert, JJ Neeway, SN Kerisit, and PC Rieke, "A Mechanistic Approach to the Calculation of Glass Behavior over Geologic Time Scales,” FCRD-SWF-2014-000029, 2014.

\subsection{Advanced Waste Forms (Zirconium Recycle)}

\author{
E. D. Collins, G. D. Del Cul, B. B. Spencer, R. D. Hunt, R. R. Brunson, and C. Ausmus, ORNL
}

Process development studies are being conducted to recover, purify, and reuse the zirconium (98.5\% by mass) in used nuclear fuel (UNF) zirconium alloy cladding. Accomplishments in FY-15 included (1) the study of zirconium purification and (2) preparations of equipment for large-scale demonstrations of the chlorination of actual UNF cladding in hot cell experiments.

\section{Zirconium Purification}

A summary report was prepared to describe the measured impurity concentrations in UNF cladding, the degree of purification obtained by chlorination of the cladding and conversion of the zirconium to volatile $\mathrm{ZrCl}_{4}$ salt, followed by condensation to a dry salt product. Substantial decontamination of the salt product from radioactive fuel components that are embedded within the UNF cladding is achieved because the impurities are present as oxides that are resistant to chlorination or are chlorinated to non-volatile species. The measured decontamination factor from radiation sources typically has exceeded $10^{3}$ and the $\mathrm{ZrCl}_{4}$ product salt can be handled without shielding. However, the product salt still contains excessive residual concentrations of some of the alloying elements, primarily niobium, tin, iron, and chromium, as well as radioactive cesium, antimony, and possibly uranium. 
Very little decontamination is achieved from niobium during the chlorination of zirconium in the UNF cladding because the niobium is likely present as the oxychloride, $\mathrm{NbOCl}_{3}$, which has volatility similar to $\mathrm{ZrCl}_{4}$. Iron is likely present initially as non-volatile $\mathrm{FeCl}_{2}$, but is converted to volatile $\mathrm{FeCl}_{3}$ during the course of the batch chlorination. The initial reduced state is believed to be maintained by the presence of the metallic zirconium, and as the zirconium is chlorinated and removed as volatilized $\mathrm{ZrCl}_{4}$, the iron is oxidized to its volatile form. Such a phenomenon was indicated in nonradioactive tests made by Jeon, 2012 (Figure 59), in which the volatilization of iron and chromium begins to follow after much of the zirconium has been converted to volatile $\mathrm{ZrCl}_{4}$ and removed from the reactor. This is also consistent with the observed darkening of the salt product as iron is converted to volatile $\mathrm{FeCl}_{3}$ (Figure 60).

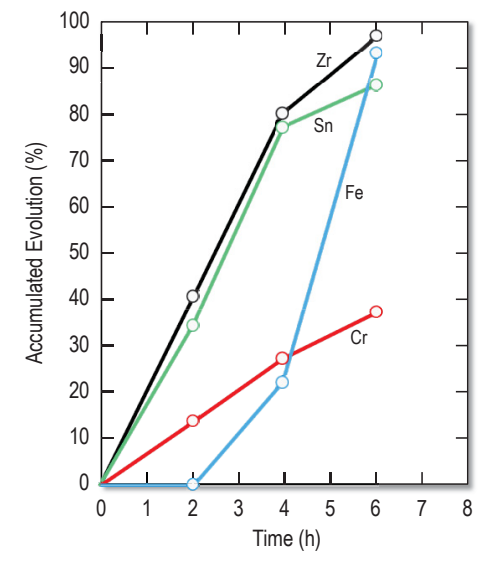

Figure 59. Time dependent volatization of cladding alloy component (derived from Ref. 1).

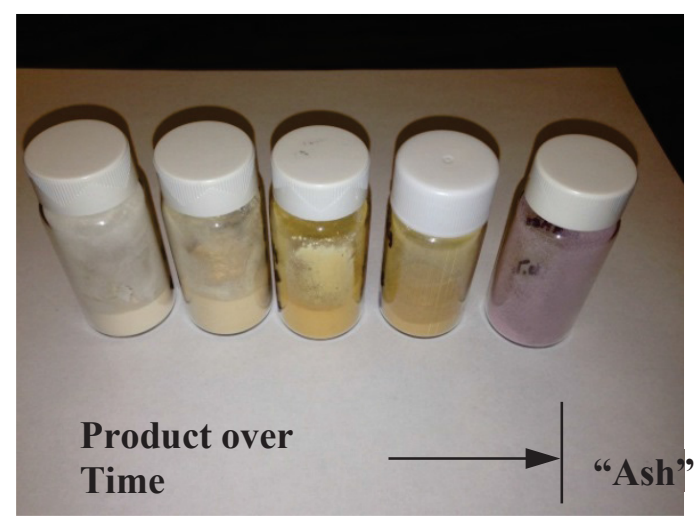

Figure 60 . Color changes over time from nonradioactive $\mathrm{Kg}$ scale chlorination test.

Based on the results and analyses of the chlorination studies, a secondary purification of the $\mathrm{ZrCl}_{4}$ will be required, especially if the salt is to be incorporated into the manufacture of cladding for new or recycled nuclear fuel. The primary elements of concern are niobium, iron, chromium, cesium, antimony, and possibly uranium. Accordingly, two series of $\mathrm{ZrCl}_{4}$ purification tests were initiated and completed.

Results of the purification tests indicated that most of the impurities can be sufficiently removed, either during the chlorination of zirconium in the UNF cladding, or by a re-sublimation of the $\mathrm{ZrCl}_{4}$ chlorination product. Tin, which is the largest zirconium alloy component in Zircaloy-2 and Zircaloy-4, is predominately in the form of $\mathrm{SnCl}_{4}$, which is more volatile than $\mathrm{ZrCl}_{4}$, and is likely only present in the chlorination product because of occlusion with $\mathrm{ZrCl}_{4}$ in the condenser. Simple re-sublimation and condensation in a reducing atmosphere was sufficient to lower the tin concentration to an acceptable level.

As previously indicated, iron is likely present as $\mathrm{FeCl}_{3}$, formed during the latter stages of the batch chlorination after most of the zirconium contained in the cladding has been converted to $\mathrm{ZrCl}_{4}$ and removed from the reactor by volatilization. In the case of chlorination with hydrogen chloride as the chlorinating agent, iron is also retained in the non-volatile form of $\mathrm{FeCl}_{2}$ by the presence of $\mathrm{H}_{2}$ that is generated; but, as the reaction nears completion and $\mathrm{H}_{2}$ generation subsides, the $\mathrm{FeCl}_{2}$ is oxidized to volatile $\mathrm{FeCl}_{3}$. Once formed within the $\mathrm{ZrCl}_{4}$ product, resublimation in the presence of pure $\mathrm{H}_{2}$ or with $\mathrm{ZrH}_{2}$ or tin, added as reductants was necessary to reduce the $\mathrm{FeCl}_{3}$ back to non-volatile $\mathrm{FeCl}_{2}$.

The use of molten tin as the reductant produced a purified $\mathrm{ZrCl}_{4}$ product from all impurities except tin itself. In the test made, a specially designed reactor was used to provide contact of the $\mathrm{ZrCl}_{4}$ gas with the liquid tin, but excessive tin was entrained into the $\mathrm{ZrCl}_{4}$ product. Improvement in design of the reactor will be required if this method is to be used. 
Of the purification methods tested, only the use of $\mathrm{ZrCl}_{2}$ or molten tin as chemical reductant successfully removed niobium from the $\mathrm{ZrCl}_{4}$ product. The test made with molten tin reintroduced excessive amounts of tin into the product. Of the three tests made with $\mathrm{ZrCl}_{4}$, one was only partially successful.

Resumption of radioactive tests with larger amounts, higher burnup, and shorter-decayed UNF cladding is planned to begin in FY-16. Emphasis will be primarily on achieving further purification from ${ }^{137} \mathrm{Cs}$ and, possibly ${ }^{125} \mathrm{Sb}$. Based on the mass analysis of the $\mathrm{ZrCl}_{4}$ product from the one feasibility test made on chemical decladding with high concentrations of uranium present, future purification tests may need to include further decontamination from uranium, if the $\mathrm{ZrCl}_{4}$ is to be recycled to manufacture of new cladding tubes.

\section{Preparation of Large-Scale Metal Equipment for Hot Cell Tests}

During FY-15, nickel-plated, stainless-steel reactor and stainless-steel condenser were assembled on a support stand with the reactor in the horizontal position and the condenser in the vertical position as shown in Figure 61. Components were added to enable hot cell operations with manipulators. The components included a charging door and ceramic insulators, a removable boat to support cladding hulls or fuel rods and collect residual "ash" for weight measurement and sampling, a double filter to prevent entrainment of non-volatile impurities, and a removable salt collector bottle to enable weight, sampling, and transfer to a unshielded dry box for final purification. A set of multi-zone heating mantles was procured to provide heat to the reactor. Operational testing was begun in a non-radiological laboratory to determine if the unit can be operated efficiently and if modifications are necessary.
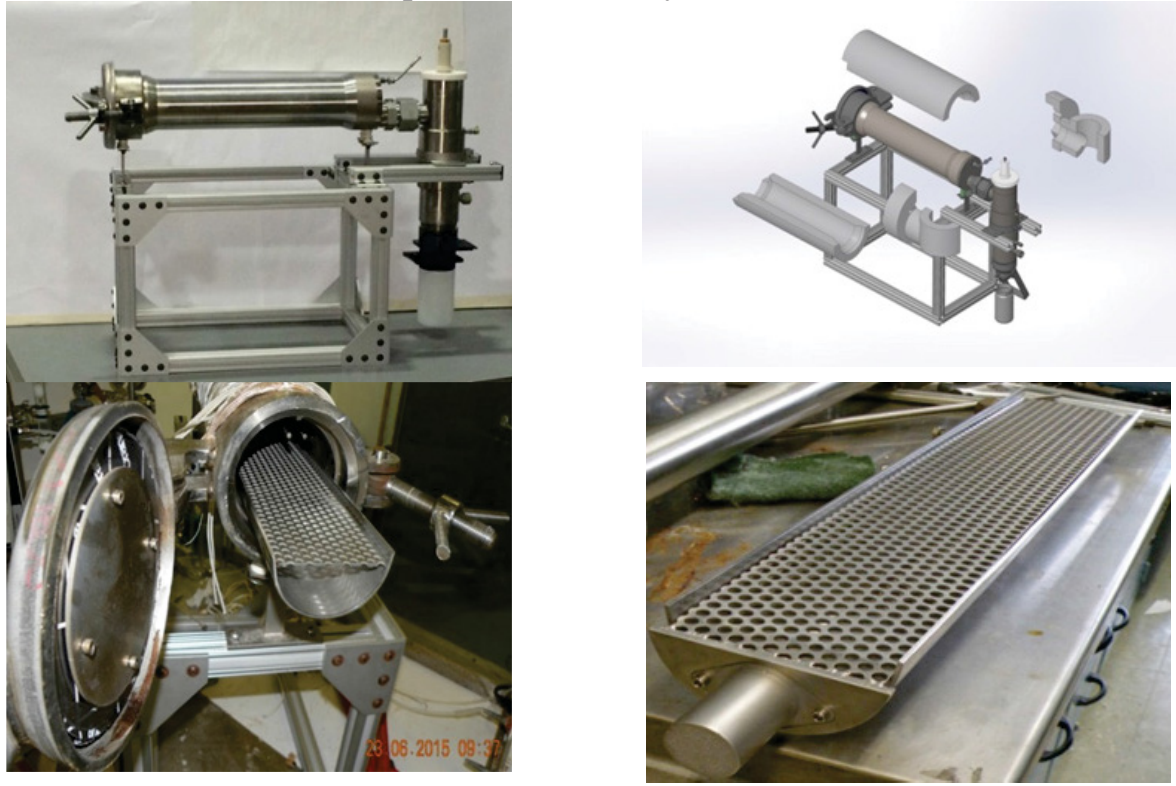

Figure 61. New metal test equipment for hot cell tests with 100-500g UNF cladding per test.

\section{References}

1. M. K. Jeon, K. H. Kang, C. M. Has, J. H. Young, C. H. Lee, and G. I. Park, "Effect of Oxidation Conditions on Chlorination Reaction of Zircaloy-4 Hulls," Journal of Nuclear Materials 42A, 2012: 153-57.

\section{Publication}

Collins, E. D., G. D. Del Cul, B. B. Spencer, R. R. Brunson, and C. Ausmus, "Chlorination in Process Development for Zirconium from Used Fuel Cladding," 2015 International High Level Waste Management Conference (April 2015). 


\subsection{First-Principles Modeling of Hydrolysis Reactions}

\section{P. Zapol and D. Ford, ANL}

The objective of this project is development of models based on first-principles calculations to support constitutive relations used in performance assessment of glass waste forms. Waste form long-term behavior is characterized by hydrolysis reactions of the silicate network coupled to the interdiffusion of glass and aqueous solution species, and to the formation of secondary phases. The ANL modeling effort is focused on mechanisms of chemical reactivity of the glasses in aqueous solutions and mechanisms of proton exchange with alkali in glass.

First-principles calculations of hydrolysis reactions on alkali-borosilicate glass surfaces are used to determine reaction energies and barriers for breaking bonds between network formers and oxygen ions. The network connectivity of glass is described by the coordination number of network forming atoms $Q^{n}$ to $\mathrm{n}$ bridging oxygen atoms. Thus, reaction barriers of all elementary reactions for all network former pairs $Q^{n}-O-Q^{m}$ and site distribution in the glass provide information for kinetic modeling of the overall dissolution rate as a function of composition, temperature and $\mathrm{pH}$. The models of glass structures in bulk and slab geometries were optimized using density functional theory within generalized gradient approximation. Climbing-image nudged elastic band method was used to calculate reaction barriers.

In FY-13 and FY-14, we performed calculations of reaction barriers and energies of B-O-B and B-O-Si bonds on sodium borosilicate glasses with composition $\mathrm{SiO}_{2}(68 \%), \mathrm{B}_{2} \mathrm{O}_{3}(18 \%)$ and $\mathrm{Na}_{2} \mathrm{O}(14 \%)$ using glass structures obtained from classical molecular dynamics simulations with composition-dependent force fields. In FY-15, we have performed calculations of reaction barriers and energies for Si-O-Si on sodium borosilicate glasses. Calculated reaction energies and barriers are summarized in Figure 62. Obtained reaction barriers for B-O-B hydrolysis reactions in a sodium borosilicate glass indicate that in the presence of protons (acidic conditions) the reaction barriers $(18-60 \mathrm{~kJ} / \mathrm{mol})$ are decreased considerably relative to neutral conditions (98-102 kJ-mol). In contrast, extra $\mathrm{OH}$ groups (basic conditions) do not result in lower barriers with exception of $\mathrm{B}\left(\mathrm{Q}^{1}\right)$ site. Similar trends are obtained for hydrolysis of B-O-Si bonds. FY-15 calculations for Si-O-Si bonds indicate that $\mathrm{Si}-\mathrm{O}$ bonds have lower barriers for hydrolysis reactions at both acidic (68-147 kJ-mol) and basic (25-66 kJ-mol) conditions relative to neutral conditions $(>150 \mathrm{~kJ}-\mathrm{mol})$.

Nuclear waste glasses of different compositions were previously observed to undergo a change in dissolution mechanism with increase in $\mathrm{pH}$. The first-principles results support our suggested mechanistic explanation for change of mechanism from incongruent to congruent dissolution at higher $\mathrm{pH}$ from calculated reaction barrier difference between Si and B bonds being smaller under basic conditions. Firstprinciples calculations of activation energies for $\mathrm{Na}^{+}-\mathrm{H}^{+}$exchange in the glass are illustrated in Figure 63 . Calculations of interdiffusion activation energies of alkali and protons with alkali species in the glass suggest that protons have lower barriers for the exchange with $\mathrm{Na}^{+}$compared to $\mathrm{Na}^{+}-\mathrm{Na}^{+}$exchange. Calculated values for the proton-sodium exchange activation energies $(\sim 130-180 \mathrm{~kJ}-\mathrm{mol})$ are somewhat higher than the values derived from experimental diffusion profiles. Calculated parameters are useful for further kinetic modeling of glass dissolution. 

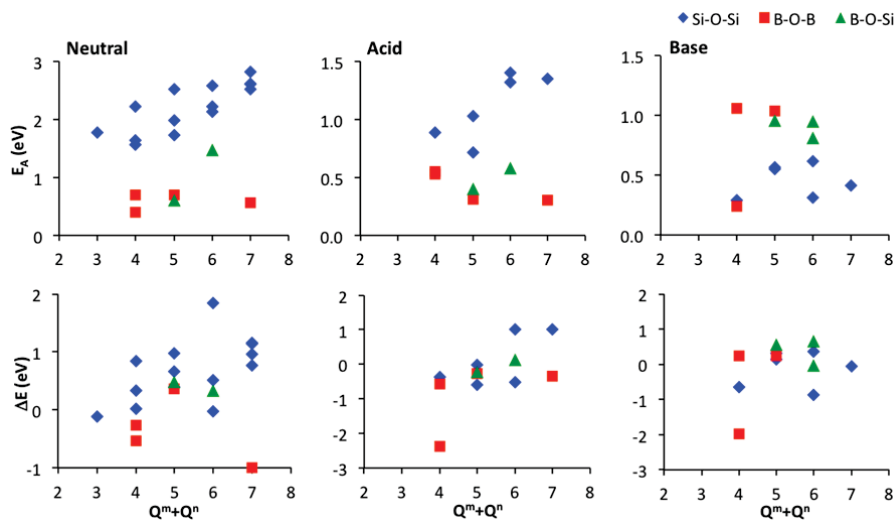

Figure 62. Hydrolysis reaction barriers (top row) and reaction energies (bottom row) calculated with first-principles methods for different reaction conditions.

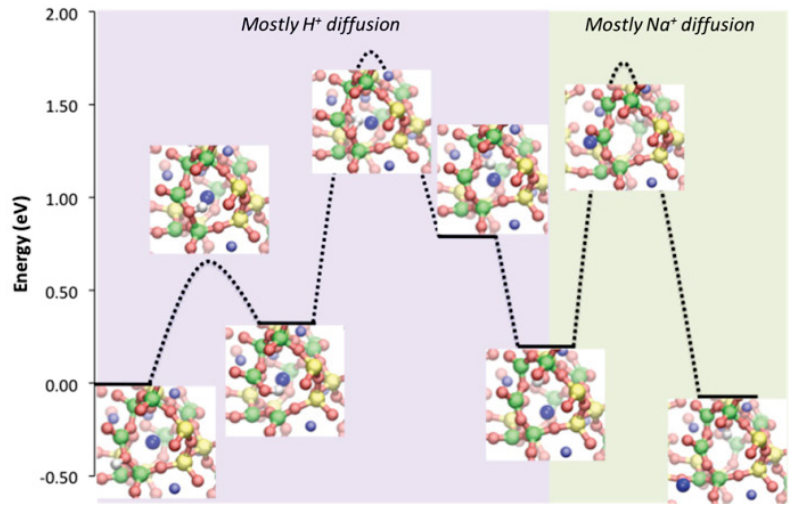

Figure 63. Illustration of energy barriers along $\mathrm{Na}+-\mathrm{H}+$ exchange barrier calculated with first-principles methods

\subsection{Glass Performance Modeling}

\section{S. Kerisit, P.C. Rieke, PNNL}

The ability of PA models to predict with confidence the rates of release of radionuclides from breached nuclear waste packages relies heavily on a comprehensive understanding of glass corrosion. Although the corrosion model that enters the larger PA model will have to be sufficiently simple to allow for largescale simulations, its formulation has to be grounded in detailed, validated mechanistic models. New insights from MRWFD will facilitate the development of improved mechanistic models but a computational tool is needed to leverage this information and develop a formalism that captures both thermodynamic and kinetic drivers. Therefore, the long-term objective of this task is to create a computational tool for developing, parameterizing, and assessing mechanistic corrosion models. Following this objective, the work carried out under this work package this FY (January start) was divided into two main thrust areas. The first thrust area (Evaluation of Mechanistic Models) aimed to implement and evaluate existing models against a range of glass compositions and test conditions. The second thrust area (Development of the Modeling Tool) aimed to develop the modeling tool to enable increasingly realistic simulations with a single multi-scale framework.

\section{Evaluation of Mechanistic Models}

A set of four models was decided on, namely, the Aagaard-Helgeson (AH), Residual Rate (RR), Grambow-Müller (GM), and GRAAL (Glass Reactivity with Allowance for the Alteration Layer) models, and implemented in the glass corrosion modeling tool (GCMT) in preparation for the model evaluation. A large body of 200+ experimental datasets was gathered and formatted for use. These datasets focused on time-dependent solution data for $\mathrm{Si}, \mathrm{B}, \mathrm{Na}$, and $\mathrm{Al}$. A majority of the datasets was taken from the ATLGLASS database, which was kindly provided to us by Dr. Carol Jantzen (SRNL). Data for SON68, the International Simple Glass (ISG), and the CJn series were taken from CEA publications. Finally, data for ILAW glasses were also collected from PNNL reports by Pierce and co-workers; although not the focus of this campaign, these glasses provide interesting compositional ranges for model testing purposes. 

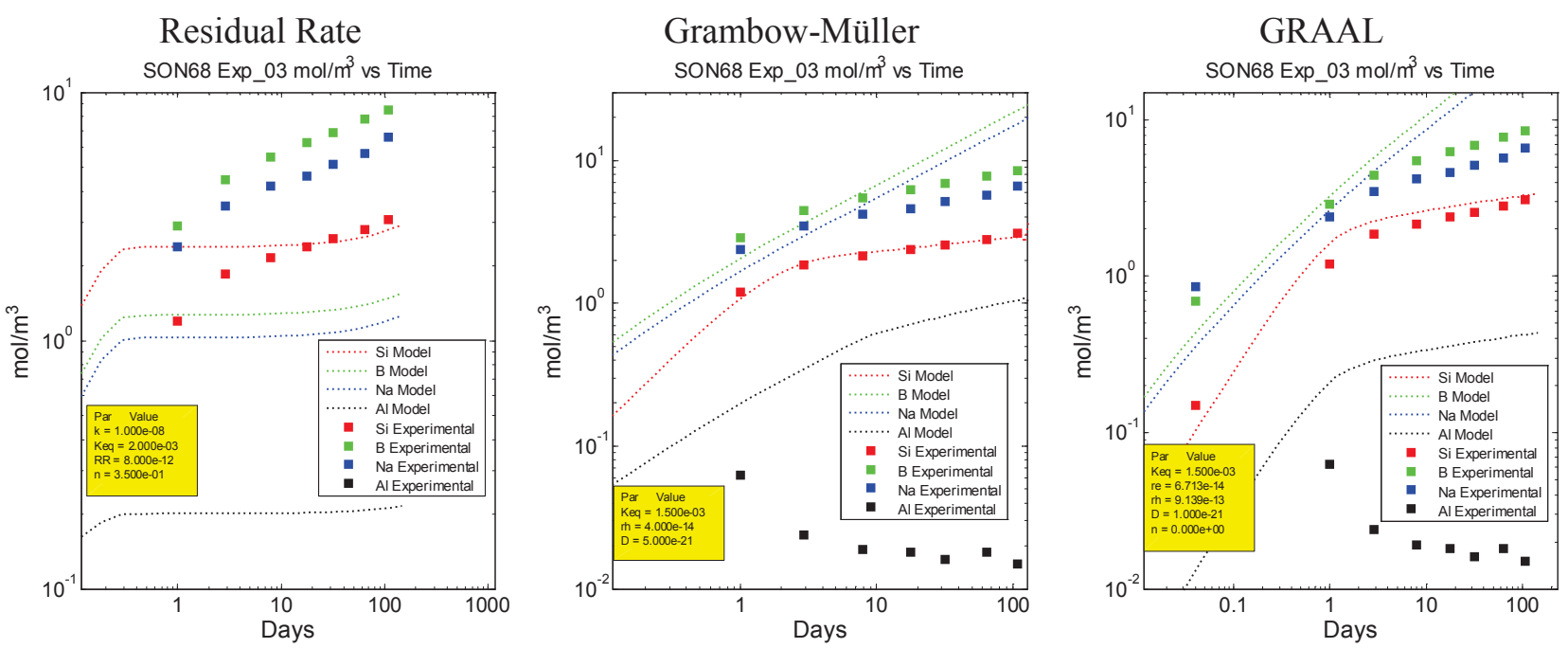

Figure 64. Model fits with the RR, GM, and GRAAL models to SON68 data published by Frugier et al. (Ref. 1) and obtained from a static test at $90^{\circ} \mathrm{C}$ and $200 \mathrm{~m}^{-1}$.

Model fits with the four models listed above were carried out for several glasses and can be divided into two main series. The first series consisted of fits to SON68 data for test conditions in which the flow rate and the surface-area-to-volume ratio was varied. The second series consisted of fits to data on the CJn family of glasses, in which composition was varied by adding combinations of $\mathrm{Ca}, \mathrm{Al}, \mathrm{Zr}, \mathrm{Ce}$, and $\mathrm{Li}$ to a sodium borosilicate base glass. To put all the models on the same footing, the same solution mass balance equation was used in all cases, with the different models providing the glass source term.

Figure 64 shows examples of fits to the first series and illustrates some of the general findings. Firstly, the RR model was not able to model incongruent dissolution with a single equation (the AH model suffered from the same problem). Secondly, the GM and GRAAL models generally yielded good qualitative agreement with experimental data for $\mathrm{Si}, \mathrm{B}$, and $\mathrm{Na}$; but, quantitative agreement could not be obtained for all three elements simultaneously. As a result, none of the models reproduced the experimental data sufficiently well to obtain meaningful correlation coefficients, indicating that improvements are needed to achieve reliable quantitative predictions. Although Al data points are shown in Figure 64, they were not included in the fitting procedure, as they led to grossly distorted fits. Generally, the ability to reproduce data for insoluble/sparingly soluble elements other than Si was an issue for all models. A presentation describing these results was given at the $8^{\text {th }}$ International Glass Corrosion Workshop in Miami, FL on 05/21/2015 to complete Milestone M3FT-15PN0307161.

Figure 65 shows an example of a fit to CJ1, a simple ternary glass from the CJn series. This fit demonstrates that, for the simplest compositions, the models can yield very good quantitative agreement. Fits to the entire CIn series with GRAAL showed a synergetic effect of Ca and Al, whereby the decrease of the $\mathrm{Na}$ and $\mathrm{B}$ release rates when both $\mathrm{Ca}$ and $\mathrm{Al}$ were added to the ternary glass was greater than expected based on the glasses in which either element was added to the ternary glass. In these fits, the GRAAL model showed a diminished passivating reactive interphase, which led to a decrease in the degree of incongruence. 


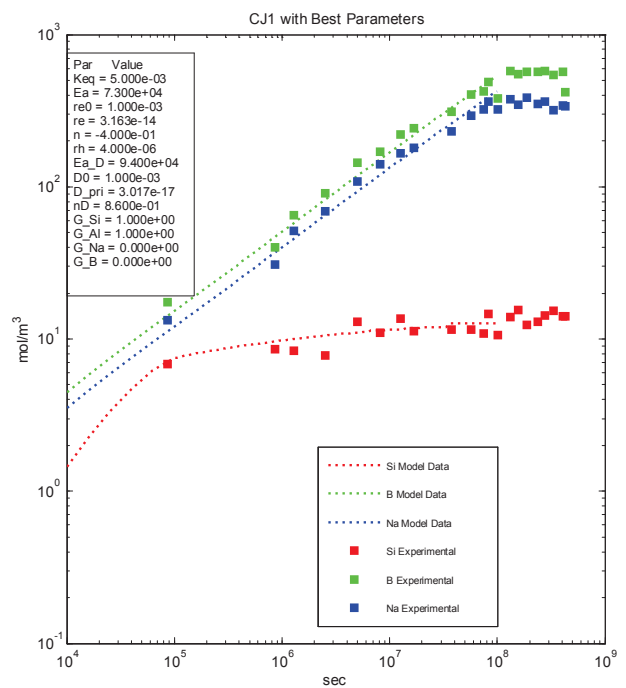

Figure 65. Model fit with GRAAL to CJ1 data from Gin et al. 2012 (Ref.2) obtained from a static test at $90^{\circ} \mathrm{C}, 8000 \mathrm{~m}^{-1}$, and $\mathrm{pH}=9$.

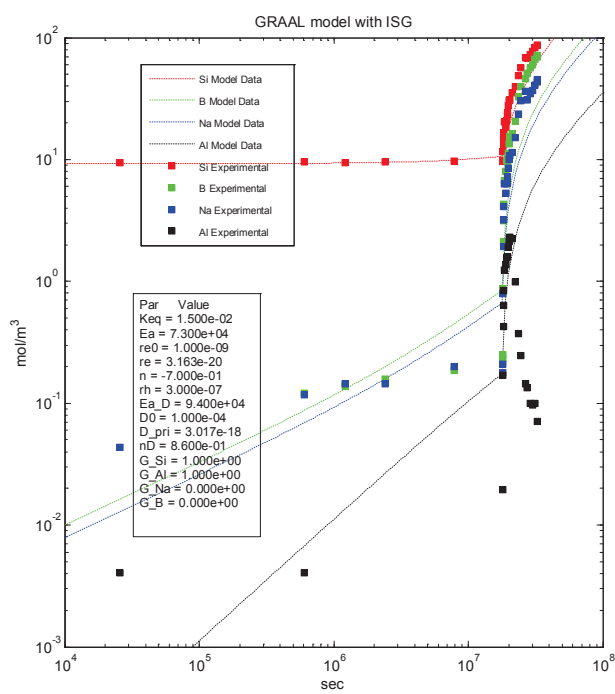

Figure 66. Model fit with GRAAL to ISG data from Gin et al. 2015 (Ref. 3) obtained from a static test at $\mathrm{SiO}_{2}(\mathrm{am})$ saturation and with pH jump to 11.5 at 209 days.

A similar effect occurred in the presence of Zr. In addition, for CJ4 (aka ISG), good agreement was obtained with GRAAL for experimental data on a static test conducted in amorphous silica-saturated conditions and in which the $\mathrm{pH}$ was increased to 11.5 after 209 days (Figure 66). In contrast, the GM model showed poorer agreement. GRAAL was able to reproduce the large perturbation because it has $\mathrm{pH}-$ dependent hydrolysis and diffusion terms.

\section{Development of the Modeling Tool}

The main emphasis of this FY's work was on the model evaluation; but, some important developments of the modeling capabilities were achieved or initiated. Specifically, the ability to have user-specified nucleation and growth rates of secondary phases was added to GCMT. Progress was also made toward transferring GCMT to Unix platforms for eventual use with supercomputers and toward modifying the Monte Carlo module to allow for carrying out simulations with glass structures derived from molecular dynamics simulations (in collaboration with Dr. Jincheng Du's University of North Texas NEUP project).

\section{References}

1. P. Frugier, T. Chave, S. Gin, and J-E. Lartigue, "Application of the GRAAL Model to Leaching Experiments with SON68 Nuclear Glass in Initially Pure Water," Journal of Nuclear Materials 392, 2009: 552-567.

2. S. Gin, X. Beaudoux, F. Angéli, C. Jégou, N. Godon, "Effect of composition on the short-term and long-term dissolution rates of ten borosilicate glasses of increasing complexity from 3 to 30 oxides," Journal of Non-Crystalline Solids 358(18-19), 2012: 2559-2570.

3. S. Gin, P. Jollivet, M. Fournier, C. Berthon, Z. Wang, A. Mitroshkov, Z. Zhu, J. V. Ryan, "The Fate of Silicon During Glass Corrosion under Alkaline Conditions: A Mechanistic and Kinetic Study with the International Simple Glass," Geochimica et Cosmochimica Acta 151, 2015: 68-85. 


\section{Fundamental Separation Data / Methods}


This page intentionally left blank. 


\section{FUNDAMENTAL SEPARATION DATA / METHODS}

\subsection{F-element Metrics}

\section{P. Zalupski, J. Law, INL}

Research efforts encompassed by the $f$-element metrics project assembles data / trends / relationships / libraries of knowledge of particular interest to current experimental efforts supported by the Materials Recovery and Waste Forms Campaign. This collaborative effort (INL, ANL) is based on the collection of comprehensive datasets of metrics to be used by scientists to streamline the process of thermodynamic inquiry of solution mixtures containing $f$-elements. The project entails a variety of experimental activities to collect $f$-element spectral signatures (absorbance), stability constants (potentiometry, UV/Vis), and extraction constants of relevance to the campaign. The assembled thermodynamic data would potentially streamline research activities in the area of aqueous separations, such as monitoring $f$-elements in solution mixtures, designing improvements in liquid-liquid partitioning schemes, while maintaining the opportunities for new discoveries. At present, the project entails two directions: (1) spectrophotometric construction of cross-actinide matrix of extinction coefficients, and (2) development of structure-function relationships for the $f$-element complexation by modified aminopolycarboxylate aqueous holdback reagents. The extinction coefficient database will support $f$-element monitoring in solution mixtures. Thermodynamic trends established for alternative structures of aqueous holdback complexants will enable improvements in liquid-liquid partitioning of actinides.

\section{Highlight accomplishments}

Collection of extinction coefficient trend for Am3+ in aqueous mixtures of perchloric acid. Reliable determinations of actinide content in a variety of aqueous mixtures may be conveniently realized through a simple spectrophotometric measurement when the experimental design relies on the actinide presence in the ppm-ppt concentration range. Such determinations are based on an accurate knowledge of an extinction coefficient for an investigated absorbance in order to use the Beer-Lambert law $(\mathrm{A}=\varepsilon b c)$ with confidence. This approach typically faces a dilemma of the correct choice of the published value for the extinction coefficient. For example, a literature survey of optical absorption studies for trivalent americium ion yields a range of molar absorptivity values at $503 \mathrm{~nm}$ between 350 and $430 \mathrm{~cm}^{-1} \mathrm{M}^{-1}{ }^{1}$. The listed range of extinction coefficients is mainly due to the effects of aqueous complexation of americium ion. The difficulty then rests with the proper choosing of a relevant value if accurate actinide concentration in solution is to be deciphered using spectrophotometry. The experimental efforts initiated under the umbrella of f-element metrics project will reduce such uncertainties through a systematic collection of extinction coefficients in multiple aqueous electrolyte mixtures. The initial efforts are focused on the characterization of americium ion. Prior to any consideration of aqueous complexation effects a "baseline" trend for optical absorbance features of $\mathrm{Am}^{3+}$ was determined in non-complexing perchloric acid medium at $0.1,0.5,1.0,2.0,3.0,4.0,5.0$ and $6.0 \mathrm{~mol} \mathrm{~L}^{-1}$. Figure 67 a illustrates representative spectra for the absorption peak characterized by the $\lambda_{\max }$ of $503 \mathrm{~nm}$ for trivalent americium in $2.0 \mathrm{~mol} \mathrm{~L}^{-1}$. The inset in the figure shows that this absorption follows the Beer-Lambert law, yielding the extinction coefficient of $419 \mathrm{~cm}^{-1} \mathrm{M}^{-1}$. The number agrees statistically $(1 \sigma)$ with recent study by Tian and Shuh. ${ }^{1}$ A slight acid dependency of the molar absorptivity of $\mathrm{Am}^{3+}$ at $503 \mathrm{~nm}$ was observed across the $0.1-6.0 \mathrm{M} \mathrm{HClO}_{4}$ range, as illustrated in Figure 67b. This demonstrates the importance of careful collection of a library of extinction coefficients across wide aqueous electrolyte concentrations. 

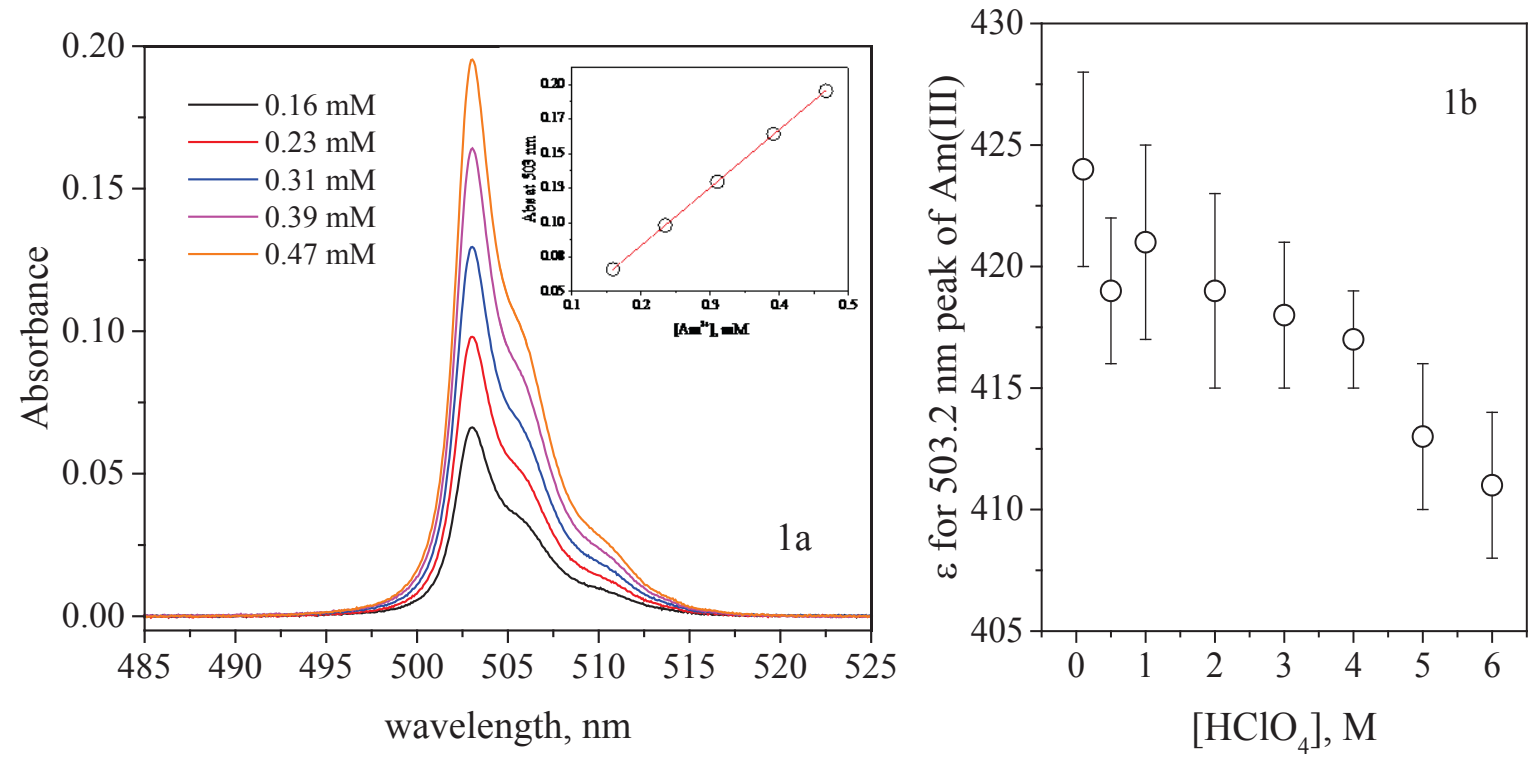

Figure 67. (a) Absorption spectra of $\mathrm{Am}^{3+}$ collected at varying concentrations in $2.0 \mathrm{M} \mathrm{HClO}_{4}$, inset: Beer-Lambert relationship determined using the maximum absorption for the $503 \mathrm{~nm}$ peak. (b) The dependence of the molar absorptivity for the 503 $\mathrm{nm}$ peak on the concentration of $\mathrm{HClO}_{4}$.

An assumption of a constant $\varepsilon$ throughout the investigated concentrations of perchloric acid may produce up to $4 \%$ deviation in the $\mathrm{Am}^{3+}$ content. The delineated perchlorate baseline will be translated onto the complexing nitrate medium in FY-16.

Thermodynamic characterization of new aminopolycarboxylate aqueous holdback reagent. MRWFD will benefit from the development of structure-function relationships for the f-element complexation by modified aminopolycarboxylate aqueous holdback reagents. Such studies are focused on answering what structural features of these complexants speed up the liquid-liquid phase transfer equilibrium. To build such structure-kinetic relationships the first of many structural changes has been performed to the conventional aminopolycarboxylate framework. A new holdback complexant, containing an EDTA-like ethylenediamine backbone and two glycine-like amide groups in place of typical carboxylate pendant arms, has been synthesized and thoroughly characterized at INL. The simplified abbreviation of the new reagent is EDTA-BA, where BA symbolizes the bisamide functionalization. The reagent is similar to NTA (nitrilotrisacetic acid) when the thermodynamic stability of trivalent f-element binding is used as a comparison platform. The complexes of EDTA-BA readily protonate suggesting that carboxylate groups of the two amide pendant arms do not participate in the metal ion coordination. Time-resolved lifetime fluorescence studies demonstrated that EDTA-BA maintains a similar binding pocket throughout the investigated range of aqueous acidity $(2<\mathrm{pH}<5)$. EDTA-BA consistently displaces 6 waters of hydration, indicating that the two amide oxygens do participate in the complex formation, but the fivemembered rings formed due to this participation must be weaker, relative to the conventional rings involving amine nitrogens. This is perhaps the reason for a much weaker overall complex stability observed for the new reagent, relative to EDTA, which also is known to displace 6 waters from a trivalent f-block metal ion. ${ }^{2}$ Figure 68 shows the sequential optical absorptions collected for the titration of EDTA-

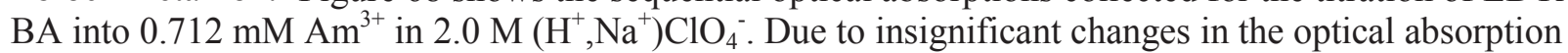
characteristics for the protonated complexes, relative to the deprotonated structure, the stability constant for the initially formed 1:2:1 complex (metal:proton:ligand) was fully resolved. Potentiometric titrations, performed across the entire family of lanthanides, yield well-resolved $\beta_{101}, \beta_{111}, \beta_{121}$ values due to the ability of a glass electrode to detect $\mathrm{pH}$-metric changes throughout changes in the speciation. Based on this assumption $\log \beta_{111}=\log \beta_{121}-\mathrm{pK}_{\mathrm{a} 2}$, 


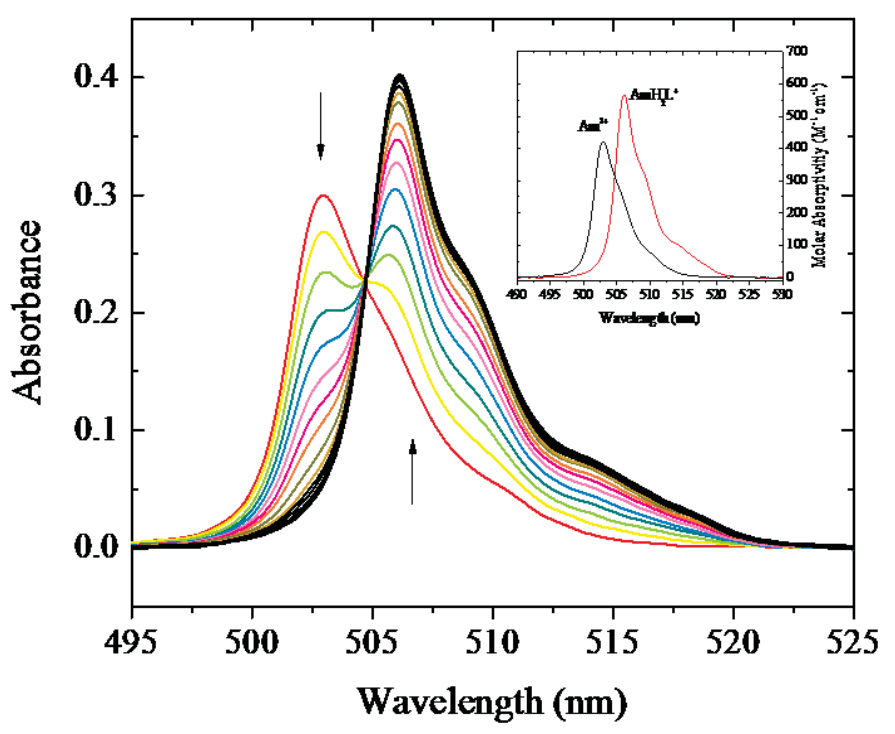

Figure 68. Spectrophotometric investigation of trivalent americium complexation with EDTA-BA, $\mathrm{T}=20 \pm 1{ }^{\circ} \mathrm{C}, \mathrm{I}=\mathbf{2 . 0} \mathrm{M}$ sodium perchlorate.

remains in the aqueous phase. $\left(\mathrm{SF}_{\mathrm{Am}}{ }^{\mathrm{Ce}}=13.2, \mathrm{SF}_{\mathrm{Am}}{ }^{\mathrm{Eu}}=145\right)$. and $\log \beta_{101}=\log \beta_{121}-\left(\mathrm{p} K_{a 2}+\mathrm{p} K_{a 3}\right)$, consistently indicating a higher stability for the complexation of $\mathrm{Am}^{3+}$, relative to $\mathrm{Nd}^{3+}$. To compare, $\log \beta_{121}$ of $17.23 \pm 0.02$ and $18.60 \pm 0.01$ for the complexation of neodymium and americium, respectively, suggest that the presence of nitrogens in the ethylenediamine backbone of EDTA-BA maintains the soft-bonding influence responsible for the differentiation of trivalent actinides from trivalent lanthanides. The theoretical separation factor expected based on the observed difference in the abovementioned stability constants was well reproduced experimentally, when $0.2 \mathrm{M}$ $\mathrm{HEH}[\mathrm{EHP}]$ was equilibrated with the aqueous electrolyte mixtures containing 20 mM EDTA-BA, $0.5 \mathrm{M}$ malonate, $1.0 \mathrm{M}$ $\mathrm{NaNO}_{3}$, at $\mathrm{p}\left[\mathrm{H}^{+}\right]=3$. The liquid-liquid distribution ratios collected for this recipe revealed that all lanthanides preferentially partition to the organic phase, while $\mathrm{Am}^{3+}$

To begin the translation of the accomplished structural modification onto a kinetic scale the Am and Pm back-extraction from the ALSEP solvent using EDTA-BA was investigated at ANL. Preliminary results are reported in Figure 69.

The results indicate that the EDTA-BA shows some kinetic advantage over the DTPA-containing strip solution $^{3}$, as the system approaches equilibrium quicker. A separate test was performed to look at the ${ }^{139} \mathrm{Ce} /{ }^{241} \mathrm{Am}$ separation factor at equilibrium and the observed value of 13.5 matched the originally obtained value at INL. The traditional use of DTPA as an aqueous holdback complexant returns a $\mathrm{SF}_{\mathrm{Am}} \mathrm{Ce}$ between 60 and 100, depending on the $\mathrm{pH}$ and other conditions. Therefore, future research should build on promising kinetic features observed for EDTA-BA, but also focus on the design of ligands that have lower affinity for light lanthanides. The structures to be investigated in FY-16 will resemble that of DTPA more closely, with similar bisamide pendant arms as a means of "switching off" some complexation strength. To continue building the structure-function relationships of use to the MRWFD researching community other structural modifications will also be studied. To streamline this process two aminopolycarboxylate structures will be isolated from MRI contrast agent formulations, one containing an aliphatic group on the ethylenediamine backbone, and the other a similar R group on the carboxylate pendant arm. To expand the relationship further a peptide containing four linked up aspartic acids is being currently investigated. 


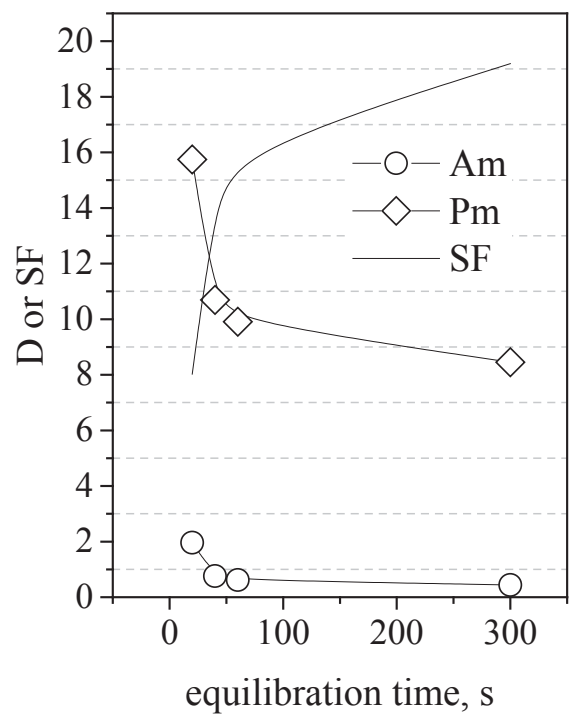

Figure 69. Stripping tests for ${ }^{241} \mathrm{Am}$ and ${ }^{147} \mathrm{Pm}$ from $0.033 \mathrm{M} \mathrm{T}$ EHDGA/0.5 M HEH[EHP] using 0.02 M EDTA-DA in 0.5 M Malonate at $\mathrm{pH} 3.0, \mathrm{~T}=25^{\circ} \mathrm{C}$. The vortex mixer was set to $3600 \mathrm{rpm}$.

1. G. Tian and D. K. Shuh, "A Spectrophotometric Study of Am(III) Complexation with Nitrate in Aqueous Solution at Elevated Temperatures, Dalton Trans., 2014, DOI: 10.1039/c4dt01183j.

2. G. A. Choppin, "Half-Century of Lanthanide Aminopolycarboxylates," Journal of Alloys and Compounds 192, 1993: 256-261.

3. B. Weaver, F. A. Kappelmann, "Preferential Extraction of Lanthanides over Trivalent Actinides by Monoacidic Organophosphates from Carboxylic Acids and from Mixtures of Carboxylic and Aminopolyacetic Acids," Journal of Inorganic and Nuclear Chemistry 30, 1968: 263-272.

\subsection{Fundamental Radiation Chemistry}

\section{B. Mincher, INL}

The radiation chemistry program took on a significant international component in FY-15, including collaborative studies of DGA (diglycolamide) radiolysis with the European SACSESS (Safety in Actinide Separations) program, and a collaborative study of monoamide radiolysis with partners at CEA (French Atomic Energy Agency). The scope of the FY-15 work package was increased through added collaborative work in which INL provided expertise toward the interpretation of data generated in Germany, and by hosting the Radical Behavior Workshop at INL in July. Finally, a collaborative test loop irradiation with SACSESS participation is also in progress. The results are described by task below.

\section{DGA Radiolysis}

The manuscript entitled, "Gamma-radiolytic stability of new methylated TODGA derivatives for minor actinide recycling," was submitted to the journal Dalton Transactions in June. The paper, with co-authors from INL, Forschungszentrum Jülich, University of Twente, and CIEMAT (Center for Energy Investigations in Madrid) received only minor review comments and is expected to be accepted for publication. It describes the radiolytic degradation rates and products of the MeTODGAs, designed at 
Jülich to improve radiation stability and to mitigate fission product extraction. Product identification was compared at INL, Jülich, and CIEMAT with good agreement. The presence of nitric acid appears to enhance degradation of Me2TODGAs, but not MeTODGA, or TODGA itself. Figure 70 shows the four possible products of MeTODGA ether bond rupture, all of which were detected in irradiated samples.

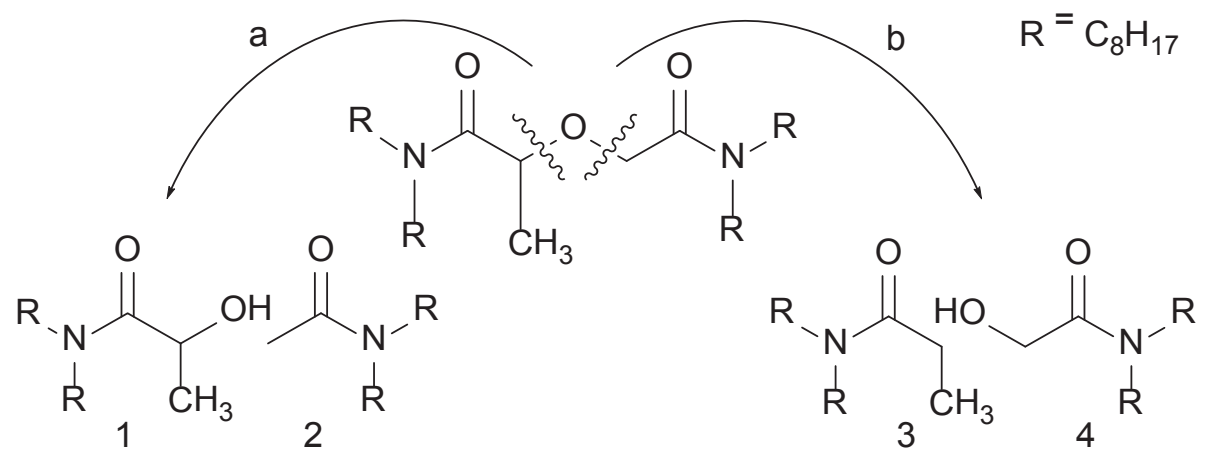

Figure 70. The four possible products of ether linkage rupture for the unsymmetrical MeTODGA.

\section{Monoamide Radiation Chemistry}

Diethylhexylbutyramide (DEHBA) and diethylhexylisobutyramide (DEHiBA) are under investigation as possible replacement compounds for tributylphosphate at CEA. A program with CEA was initiated in which INL irradiated these compounds, and performed extraction with uranium to investigate the effects on performance. Aliquots of these samples were also sent to France for mass spectroscopy work to identify products of monoamide radiolysis. Figure 71 shows the mass spectra of non-irradiated and 203kGy-irradiated $1 \mathrm{M}$ DEHBA in dodecane. The new peaks in the irradiated samples correspond to addition products of dodecane and/or diethylhexylamine to the parent compound, as described in the cited report. This work will continue in FY-16, with plans to publish a collaborative paper in the peer-reviewed literature.

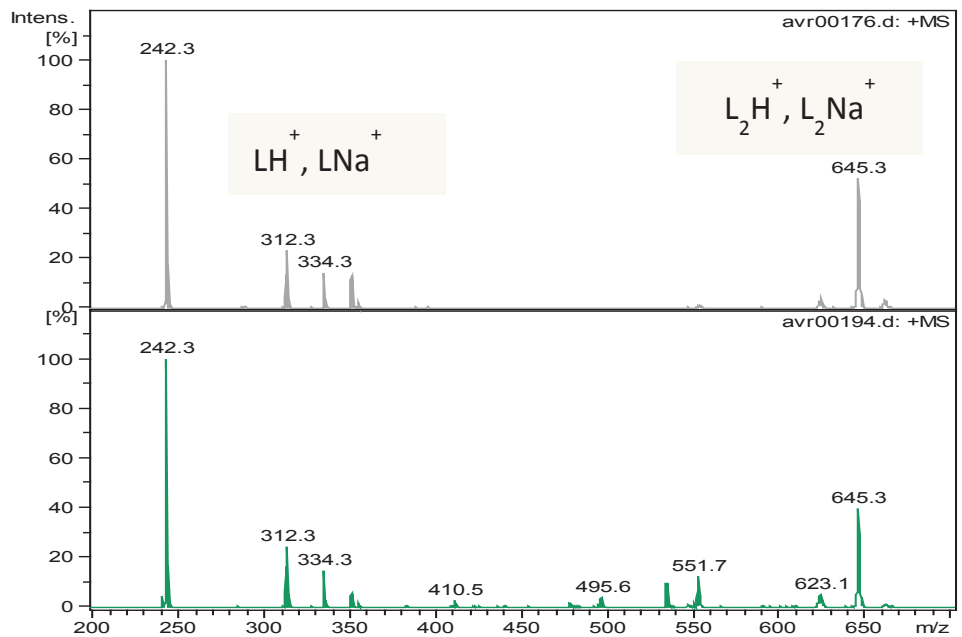

Figure 71. Mass spectra for unirradiated DEHBA (top) and $\gamma$-irradiated to an absorbed dose of 203 kGy (bottom).

\section{Dodecane Radical Cation Rate Constants}

Building on the novel methods developed in FY-14, work in FY-15 in collaboration with Brookhaven National Lab measured the rate constants for the reactions of additional compounds with the dodecane 
radical cation. The first such rate constant ever measured was that for the reaction with TODGA, which was fast, at $9.7 \times 10^{9} \mathrm{M}^{-1} \mathrm{~s}^{-1}$. The rate constant for the reaction with CMPO has now been measured, and is also fast at $1.3 \times 10^{10} \mathrm{M}^{-1} \mathrm{~s}^{-1}$. These suggest that the electron transfer reaction is an important one for solvent extraction ligands in dodecane, however, it is only now possible to observe these reactions. When these rate constants were re-measured after pre-equilibration of the organic phase with nitric acid it was found that they were unchanged. The CMPO and TODGA results are summarized in the manuscript, "The role of organic solvent radical cations in separations ligand degradation," by Mezyk et al., which is currently in the review process with the Journal of Radioanalytical and Nuclear Chemistry. Additionally, the rate constant for the MeTODGA was evaluated, which may be slightly slower at $(8.24 \pm 0.46) \times 10^{9}$ $\mathrm{M}^{-1} \mathrm{~s}^{-1}$.

\section{Alpha Radiolysis Testing}

Previous work in FY-12 through FY-14 compared $\alpha$-radiolysis techniques using four sources. However, the irradiations were performed on solvent extraction ligands, especially CMPO, which suffered little degradation. This is obviously a positive result from a process point of view, but impedes quantitative comparison of the techniques. Consequently, they were re-investigated, using methylene blue radiobleaching as the metric for radiation damage. The decrease in methylene blue absorbance with absorbed dose is easily measured by UV/Vis spectrophotometry, and this dye compound suffers measurable degradation at much lower absorbed doses than does CMPO, allowing for facile determination of $G$ values for comparison of the methods. The INL portion of this work was to measure Am- $\alpha$-radiobleaching of methylene blue under the same experimental conditions as the work done by Cal State using other sources. The americium photo-bleaching of methylene blue is shown in Figure 72. Similar work using ${ }^{211}$ At as the $\alpha$-source is currently underway at Chalmers University in Sweden.

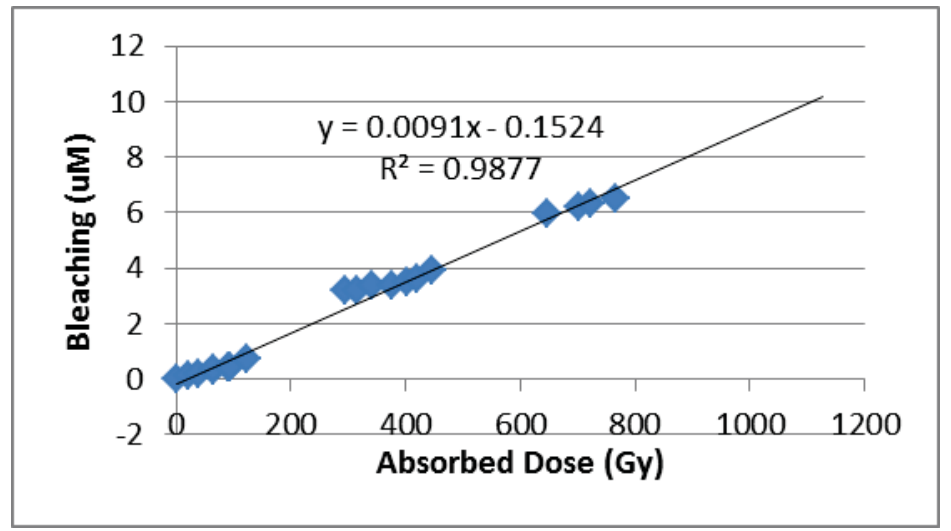

Figure 72. The radio-bleaching of methylene blue using ${ }^{243} \mathrm{Am}$ as an $\alpha$-source.

In addition to the scope of the FY-15 work package, INL participated in writing a manuscript with the Jülich partners, "Gamma-radiolytic stability of solvents containing C5-BPP (2,6-Bis(5-(2,2dimethylpropyl)-1H-pyrazol-3-yl)pyridine) for actinide(III)/lanthanide(III) separation," by Wilden et al., for submission to Solvent Extraction and Ion Exchange. This paper received favorable review comments and publication is expected soon. In July, INL hosted the workshop "Radical Behavior." Approximately 40 scientists from the USA and Europe, including representatives from most of our collaborating organizations, participated. The workshop was a venue for the collaborators to meet in person to discuss results, plan experiments, and for new potential collaborators to see each other's work. 


\subsection{Extractant Design by Covalency}

A. J. Gaunt, E. R. Batista, S. A. Kozimor, A. Olson, J. Macor, J. Cross, LANL; D. R. Peterman, T. Grimes, $I N L$

\section{Importance of Work and Context to DOE-NE Mission}

This project aims to provide an electronic structure-to-function understanding of extractants for actinide selective separation processes. The research entails a multi-disciplinary approach that integrates chemical syntheses, structural determination, K-edge X-ray Absorption Spectroscopy (XAS), and Density Functional Theory (DFT) calculations. In FY-15, the project reached the final stage of testing the extraction performance of a new ligand design and preparing an americium-extractant complex for analysis.

\section{Summary of Research Accomplishments and FY-15 Result}

Two key advances were successfully completed: (1) Based upon the previous deciphering of electronic structure from sulfur K-edge XAS data, a new extractant design proposed by a 'rational' chemical bonding knowledge driven process (as opposed to the traditional trial and error approach) was synthesized on a multi-gram scale and predicted to be actinide selective; solvent extraction tests confirmed this hypothesis to be correct. (2) The first americium-dithiophosphinate extractant complex was isolated and structurally characterized. This is expected to be a vital step in demonstrating direct spectroscopic proof of the enhanced covalency in Am-S versus Ln-S bonds that is hypothesized to be responsible for observed $\mathrm{Am} / \mathrm{Ln}$ separation factors in separation studies.

Research in previous years had focused on probing the sulfur K-edge in dithiophosphinate extractant molecules, and uncovered clear electronic structure differences that correlate to differences in observed $\mathrm{Am} / \mathrm{Ln}$ separation factors. It appeared that the steric repulsion imparted by the o- $\mathrm{CF}_{3}$ substituents causes the phenyl rings to twist with respective to each other. A consequence of this geometrical arrangement (which is different from other less selective dithiophosphinate extractants) is enhanced orbital mixing in the highly actinide-selective $\left[\mathrm{S}_{2} \mathrm{P}\left(\mathrm{o}-\mathrm{CF}_{3} \mathrm{C}_{6} \mathrm{H}_{4}\right)_{2}\right]^{-}$extractant and this facilitates increased negative charge delocalization, and therefore provides a rational basis from which to propose new extractant designs/modifications. Specifically, the hypothesis was that if the two aryl rings could be chemically tethered through a carbon-chain linker to 'lock-in' the ring twist then orbital mixing and negative charge delocalization will be enhanced, which should render the molecule highly actinide selective on the basis of sulfur K-edge XAS analysis and DFT predictions. In FY-14, a new 'ring-tethered extractant design, $\left[\mathrm{S}_{2} \mathrm{P}\left(\mathrm{C}_{12} \mathrm{H}_{8}\right)_{2}\right]^{-}(1)$, was developed but suffered from poor solubility in organic diluents. This problem was overcome in FY-15 by installation of tert-butyl groups on the phenyl rings to form new extractant 2 (Figure 73) on a multi-gram scale. 


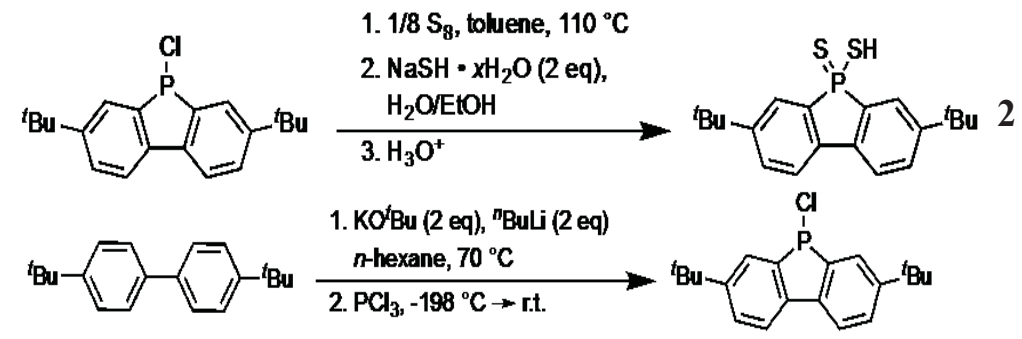

Figure 73. Synthetic steps for the preparation of new extractant design 2 in gram quantities.

Biphasic solvent extraction separation measurements performed at INL confirmed that the new 'rational' design process developed by this project, based upon electronic structure properties, does indeed result in a new extractant design that exhibits Am(III) versus Ln(III) selectivity. The chosen organic diluent was the sulfone 'FS-13' to be consistent with the Separation Factor (SF) measurements in the literature for other dithiophosphinates. At a pH value of 3, and an extractant (2) concentration of $0.05 \mathrm{M}$ in sulfone FS13 organic diluent the measured SF was 14 (Figure 74). While the SF value was much lower than the $o$ $\mathrm{CF}_{3}$ substituted diphenyldithiophosphinate, it is higher than the unsubstituted diphenyldithiophosphinate, $\left[\mathrm{S}_{2} \mathrm{PPh}_{2}\right]^{1-}$, and demonstrates the principle that tethering the aryl rings together to restrict geometric rotation allows a rational design process whereby the desired electronic structure and orbital mixing can be 'dialed in' to achieve actinide selectivity. Other factors such as solubility may account for why the SF is not as high as expected and further research may allow optimization of the SF.

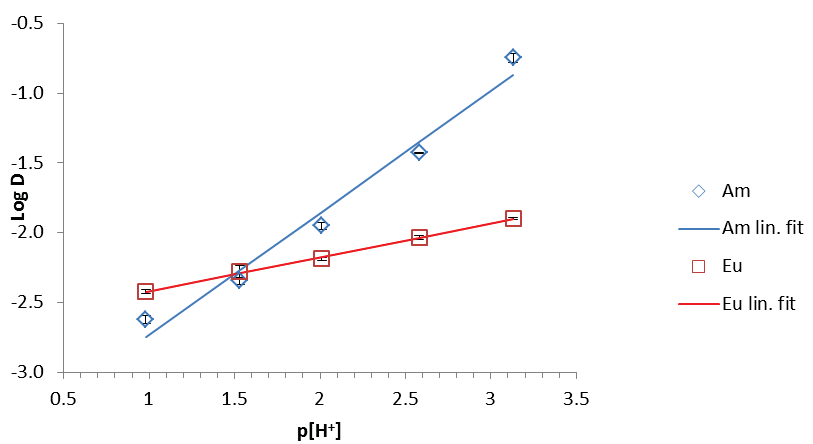

Figure 74. Plot of distribution ratios (between the organic and aqueous phase - logD) against pH of the aqueous phase, for the 'rationally-designed' tethered extractant 2.

In FY-15 the coordination chemistry of the new extractant 2 was investigated with lanthanides and actinides in order to begin to gain an understanding of the complexes and bonding properties that may be formed in separations. Significantly, the first complex of a dithiophosphinate with americium(III) was isolated and structurally characterized (Figure 75). This result provides the basis for electronic structure calculations and covalency interpretation of sulfur K-edge XAS measurements, which are anticipated to reveal the first direct experimental evidence of increased metal-ligand orbital mixing in the Am-S versus Ln-S bond. Approval to ship high specific-activity ${ }^{243}$ Am-containing samples to the Stanford Synchrotron Radiation Laboratory for XAS measurements was obtained after years of safety and containment testing with lanthanide, uranium, neptunium and plutonium samples. An initial Am-dithiophosphinate sample was shipped to the beamline and tested, but future measurements on higher purity samples will needed to provide sufficient data for covalency interpretation. 


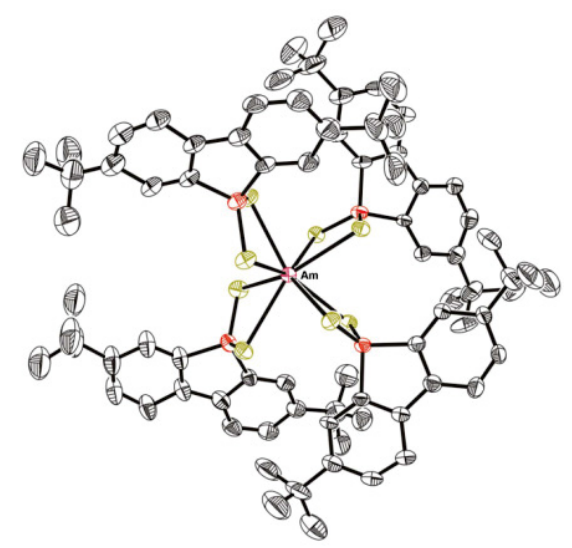

Figure 75. Solid-state structure of $\mathrm{Am}^{\mathrm{III}}\left[\mathrm{S}_{2} \mathrm{P}\left(\mathrm{C}_{12} \mathrm{H}_{6}{ }^{\mathrm{t}} \mathrm{Bu}_{2}\right)\right]_{4}{ }^{1-}$, an anionic tetrakis complex of $\mathrm{Am}$ (III) with 2.

In summary, the project has demonstrated that K-edge XAS is a tool that can be successfully utilized to correlate electronic structure to separation behavior and rationally propose new actinide selective ligand designs.

\subsection{Separation Process Thermodynamics and Kinetics: Development of Microfluidic Devices for Solvent Extraction Studies and Radioanalytical Applications}

\section{A. Gelis, C. Launiere, ANL}

Solvent extraction kinetics experiments have three primary uses of interest to the FCT program: (1) providing insight into the mechanism of complex solvent extraction chemistries; (2) establishing reaction rates for kinetically limited extraction chemistries for use in process modeling and design; and (3) characterizing the efficiency of solvent extraction process equipment.

In this project, a plug-based microfluidic system with aqueous droplets surrounded by an organic phase was used to measure absolute rate constants for interfacial mass transfer for each metal ion in model mixtures of used nuclear fuel. The system has the mixing speed, large specific interfacial area, and temporal resolution of highly stirred tanks, the control of a Lewis cell, and the rapid and complete phase separation that is unique to microfluidics. In FY-15, the microfluidic system was used to determine interfacial mass transfer rate constants for lanthanides and americium for different variations of the ALSEP and TALSPEAK processes.

In order to determine the absolute interfacial mass transfer coefficients, the interfacial area available for mass transfer must be measured. In the slug flow regime, a carrier phase completely wets the channel walls and forms a thin film between the channel wall and the second phase. The surface area of this film may be excluded in the total interfacial area measurement in cases where the mass transfer occurring at this film is insignificant compared to mass transfer occurring at the caps of the slug. Because the film is very thin and to a certain extent stagnant, the film can quickly become saturated or depleted of analyte and as a result contributes little to the overall mass transfer. 


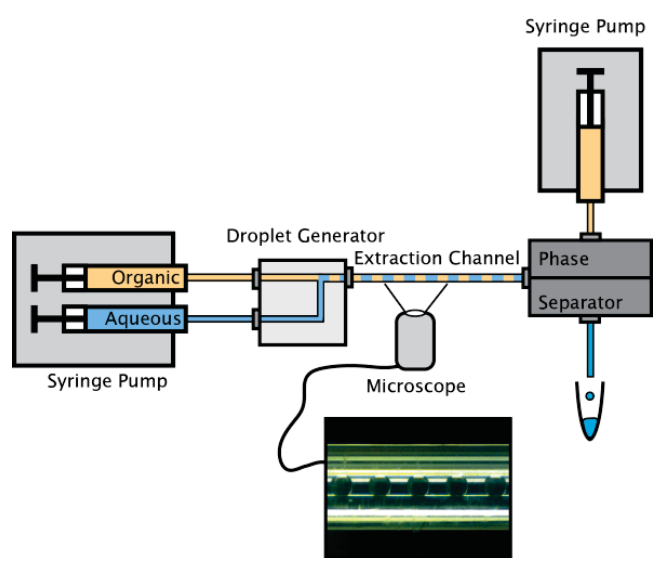

Figure 76. ANL microfluidic solvent extraction system.

To minimize thin film contributions to mass transfer in this study, $250 \mu \mathrm{m}$ ID PTFE capillaries were used as extraction channels and flow velocities were in the tens of millimeters per second range. As depicted in Figure 76, slug generation was achieved using a commercially available t-junction droplet generator

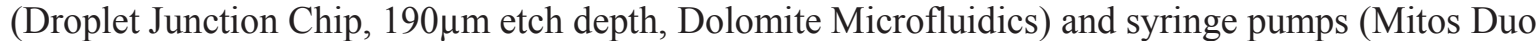
Syringe Pump, Dolomite Microfluidics). Rapid and complete phase separation was achieved using a commercially available phase separator (3000135, Dolomite Microfluidics). This phase separator contains a hydrophobic membrane which allows the organic phase to pass through upon the application of a negative pressure (applied using another syringe pump), while capillary forces prevent the aqueous phase from exiting through the membrane pores. Flow rate ratios of 1:1 were used for all flow studies. Different phase contact times were achieved by varying the flow rate. Aqueous outflow was collected from the phase separator and offline analysis was used to determine the extent of interfacial transfer at each contact time. Am, Pm and Eu activity was measured by liquid scintillation counting, while lanthanide concentrations were determined by ICP-MS. Equilibrium points were acquired using test tube experiments. To determine the forward and backward interfacial mass transfer rate constants, the data was fit to a pseudo-first order mass transfer rate equation derived from the mass balance:

$$
\frac{\mathrm{d} C_{a q}}{\mathrm{~d} t}=\left(\frac{A}{V}\right) *\left(k_{o a} C_{o r g}-k_{a o} C_{a q}\right)
$$

Where $\mathrm{C}_{\mathrm{aq}}$ and $\mathrm{C}_{\text {org }}$ are the concentrations or activities of the metal ions in the aqueous and organic phases, respectively, $\mathrm{A}$ is the specific interfacial area, $\mathrm{V}$ is the volume of an aqueous phase droplet and $\mathrm{k}_{\mathrm{oa}}$ and $\mathrm{k}_{\mathrm{ao}}$ are the forward and backward rate constants, respectively.

At equilibrium, the distribution ratio $\mathrm{K}_{\mathrm{D}}=\mathrm{k}_{\mathrm{ao}} / \mathrm{k}_{\mathrm{oa}}=\mathrm{C}_{\text {org.eq }} / \mathrm{C}_{\mathrm{aq} . \text { eq. }}$. Integrating gives the equation:

$$
\ln \left(1-\left(\frac{\mathrm{C}_{a q}}{\mathrm{C}_{a q . e q}}\right)\right)=-\frac{\mathrm{A}}{V} *\left(1+\frac{1}{K_{d}}\right) * \mathrm{k}_{a o} * \mathrm{t}
$$

A linear regression of a plot of $\mathrm{A} / \mathrm{V}^{*} \mathrm{t}$ (or $\mathrm{t}$ if $\mathrm{A} / \mathrm{V}$ is constant) versus $\ln \left(1-\left(\mathrm{C}_{\mathrm{aq}} / \mathrm{C}_{\mathrm{aq}, \mathrm{eq}}\right)\right)$ has a slope of $\mathrm{k}_{\mathrm{ao}} *\left(1+\left(1 / \mathrm{K}_{\mathrm{d}}\right)\right)$, from which the forward and backward rate constants can be calculated. The reported error on the rate constant data is the $95 \%$ confidence interval on the linear regression.

Some examples of the calculated extraction rates are given in Figure 77b. Figure 77a shows that, by decreasing the HEH[EHP] concentration, the Am back-extraction kinetics can be significantly accelerated. Figure $77 \mathrm{~b}$ shows that the $\mathrm{pH}$ of the aqueous phase should be kept as low as feasible. Overall, the designed microfluidic setup has proven to be very important for understanding the process kinetics of ALSEP and other chemistries. 

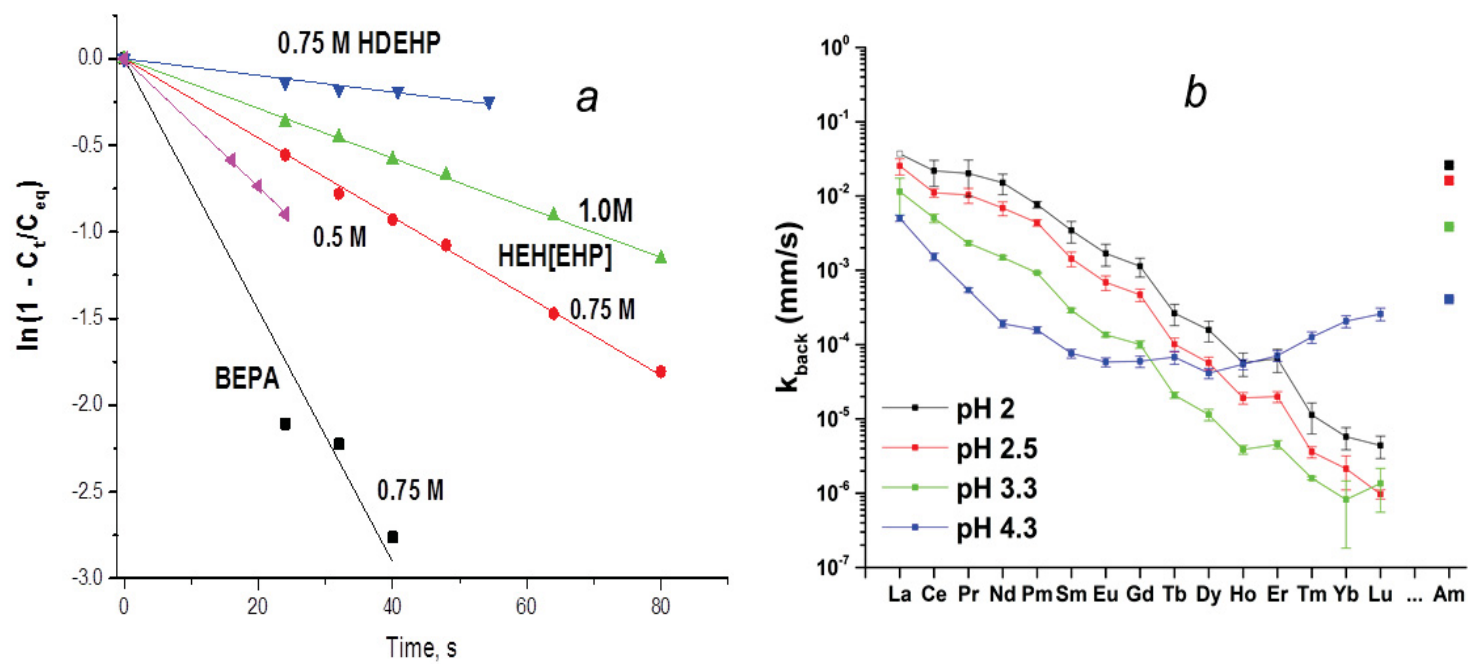

Figure 77. (a) Observed Am back-extraction rates for HDEHP, HEH[EHP] and Bis-2ethylhexyl Phosphinic acid with 10mM DTPA/Malonate, pH 2.78, 1M IS; (b) pH dependence for Am and Ln back-extraction rate constants by 0.75M HEH[EHP] from 25mM DTPA/0.5M citrate.

\subsection{Thermodynamics and Kinetics}

\section{R. Martin, INL}

Research into the thermodynamics and kinetics of advanced separations systems is an INL-led effort in conjunction with Lawrence Berkeley National Laboratory (LBNL), SRNL, and ANL. The focus has begun to significantly shift the research performed towards understanding the fundamental chemistry behind separations systems more aligned with the current reference technologies.

Understanding some of the thermodynamic and kinetics issues that arise with mixed extractant separations systems, such as the Actinide Lanthanide Separation Process (ALSEP) ${ }^{1}$ has been a primary focus. In addition to the knowledge that these extractants can interact with each other ${ }^{1,2}$ there is recent evidence $^{3}$ that when conditions change in the organic phase make-up, or the aqueous phase, the coordination environment around the metal ion in the organic phase can also change. Currently very little exploration has been performed on this phenomenon. Indeed, studying complexation kinetics, or rather complexation interchange, in a purely organic diluent has received little attention at all in the literature.

To determine if such kinetic measurements are even possible, an initial set of experiments were performed using the lanthanide neodymium. Neodymium was extracted into a $0.2 \mathrm{M} \mathrm{HEH}[\mathrm{EHP}] /$ dodecane organic phase from $0.01 \mathrm{M} \mathrm{HNO}_{3}$, this solution was then rapidly mixed 


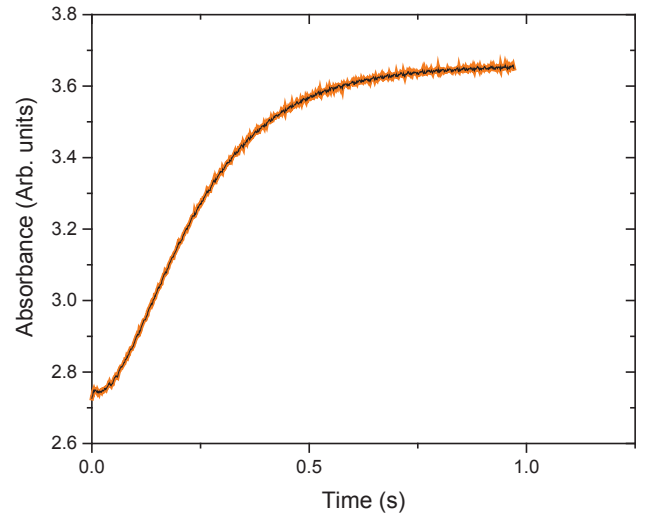

Figure 78. Fitted dodecane stopped-flow kinetics measured across the absorbance range of 450-675 nm. Measured absorbance change fitted to standard consecutive kinetic model $(A \rightarrow B \rightarrow C)$. with $0.4 \mathrm{M}$ TODGA in dodecane. Figure 78 shows the kinetic curve, and fit, that was obtained from the stopped flow experiments and the fit of the kinetic data. The data were not adequately fitted using a simple kinetic equation, but were adequately described by fitting a standard consecutive model of $\mathrm{A} \rightarrow \mathrm{B} \rightarrow \mathrm{C}$. The calculated rate constants for these consecutive processes were found to be 7.7 and $8.4 \mathrm{~s}^{-1}$. Although this is only preliminary data, the indications are already present that there can be at least 2 other metalligand species present in the organic phases that contain both TODGA and HEH[EHP].

In addition the kinetics work, experiments were performed using FTIR spectroscopy in tandem with organic phase calorimetry to probe the ligand interactions in the ALSEP solvent. Previous literature suggests that the two extractants, N,N,N',N'tetraoctyldiglycolamide (TODGA) and 2-ethylhexyl phosphonic acid mono(2-ethylhexyl)ester $(\mathrm{HEH}[\mathrm{EHP}])$ interact with one another however, this is only weak interaction but may still present issues for the separations system. Figure 79a depicts the results of the FTIR measurements on this system, it was found that this technique alone was not sensitive enough to reveal such weak interactions. When $\mathrm{HEH}[\mathrm{EHP}]$ was titrated into a $0.025 \mathrm{M}$ TODGA solution the resultant spectra was only found to be an additive spectra with no band shifts that might indicate interaction between the two species.
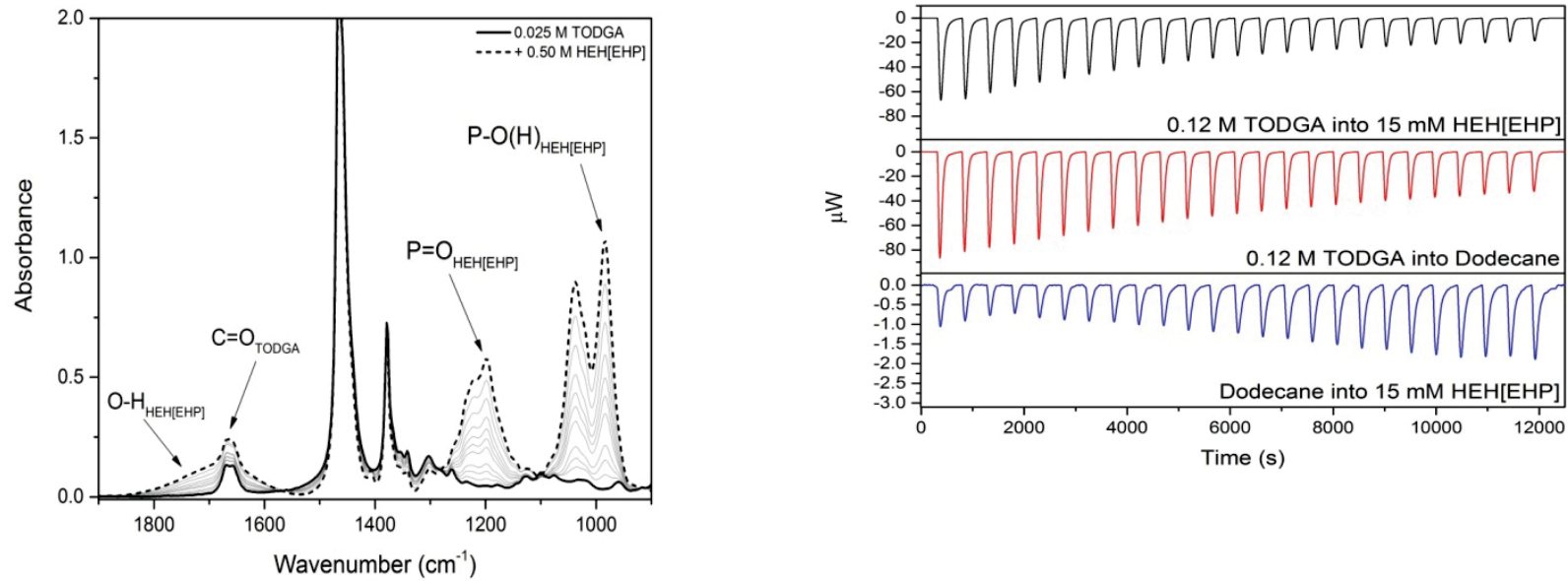

Figure 79. (a) results of the FTIR measurements on this system; (b) thermograms obtained from isothermal titration calorimetry experiments

Figure $79 \mathrm{~b}$ depicts the thermograms obtained from isothermal titration calorimetry experiments designed to probe the TODGA/ HEH[EHP] system. The thermodynamic data obtained appear to be a combination of processes. As such, further experiments are underway to probe the effects of HEH[EHP] dimerization and TODGA micellization to understand their contributions to the system under study. 


\section{References}

1. A. V Gelis and G. J. Lumetta, “Actinide Lanthanide Separation Process-ALSEP," Industrial \& Engineering Chemistry Research 53, 2014: 1624-1631.

2. G. J. Lumetta, A. V. Gelis, J. C. Braley, J. C. Carter, J. W. Pittman, M. G. Warner, G. F Vandegrift, "The TRUSPEAK Concept: Combining CMPO and HDEHP for Separating Trivalent Lanthanides from the Transuranic Elements," Solvent Extraction and Ion Exchange 31(3), 2013: 223-236.

3. A Johnson, K. L. Nash, "Partitioning of Used Nuclear Fuel Using Mixed Extractants: A Fundamental Study," 247th American Chemical Society Meeting, Dallas, TX, March 16 - 20, 2014.

\section{Publications}

X. Li, Z. Zhang, L. R. Martin, S. Luo, L. Rao, "Effect of Temperature on the Protonation of N-(2hydroxyethyl)ethylenediamine- $N, N^{\prime}, N^{\prime}$-triacetic Acid in Aqueous Solutions: Potentiometric and Calorimetric Studies," Journal of Chemical Thermodynamics 85, 2015: 35-41.

Guoxin Tian, Z. Zhang, L. R. Martin, and L. Rao, "Complexation of Curium(III) with DTPA at 10-70 ${ }^{\circ}$ C: Comparison with Eu(III)/DTPA in Thermodynamics, Luminescence and Coordination Modes," Inorganic Chemistry 54(4), 2015: 1232-1239.

\subsection{Thermodynamics and Kinetics, LBNL}

\section{Rao, LBNL}

In FY-15, thermodynamic studies were conducted on the complexation of HEDTA with $\mathrm{Np}(\mathrm{V})$ and $\mathrm{U}(\mathrm{VI})$. The results show the effect of temperature on the chemical speciation of $\mathrm{Np}(\mathrm{V})$ and $\mathrm{U}(\mathrm{VI})$ in the advanced TALSPEAK Process, and help to evaluate the effectiveness of the process when the operation envelope (e.g., temperature) varies. Eventually, the results from this study will help to achieve a better control of the separation process based on the HEDTA/HEH[EHP] combination.

\section{Complexation of $\mathrm{Np}(\mathrm{V})$ with HEDTA}

Stability constants. Spectrophotometric titration data are shown in Figure 80. The best fit of the spectra was achieved by assuming successive formation of three $\mathrm{NpO}_{2}^{+} / \mathrm{HEDTA}$ complexes, $\mathrm{NpO}_{2} \mathrm{HL}^{-}, \mathrm{NpO}_{2} \mathrm{~L}^{2-}$, and $\mathrm{NpO}_{2} \mathrm{H}_{-1} \mathrm{~L}^{3-}$ as shown by eq. 1,2 , and 3. 


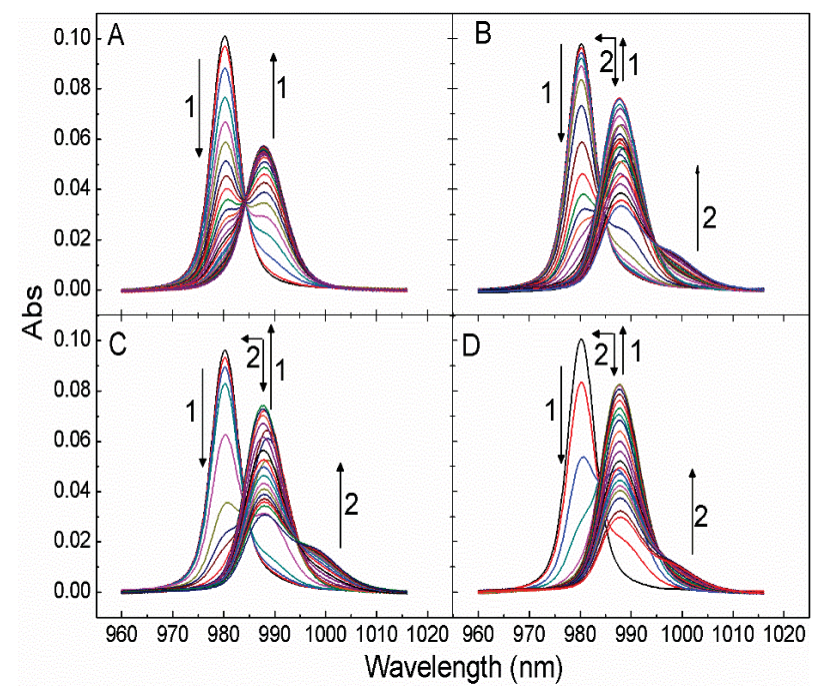

Figure 80. Spectrophotometric titration of $\mathrm{NpO}_{2}^{+} / \mathrm{HEDTA}_{\text {complexation. } I=1.0 \mathrm{M} \mathrm{NaClO}}$. (A) Initial solution in cuvette: 2.100 $\mathrm{mL} ; \mathrm{n}_{\mathrm{H}}=0.6201 \mu \mathrm{mol}, \mathrm{n}_{\mathrm{Np}}=0.5366 \mu \mathrm{mol}$; Titrant: $1.512 \mathrm{mM}$ HEDTA/ $0.3949 \mathrm{mM} \mathrm{H}^{+}$. (B) Initial solution in cuvette: $2.125 \mathrm{~mL}$; $\mathrm{n}_{\mathrm{H}}=4.366 \mu \mathrm{mol}, \mathrm{n}_{\mathrm{Np}}=0.5359 \mu \mathrm{mol}, \mathrm{n}_{\mathrm{L}}=1.249 \mu \mathrm{mol}$. Titrant: $0.01 \mathrm{M} \mathrm{NaOH}$. (C) Initial solution in cuvette: $2.150 \mathrm{~mL} ; \mathrm{n}_{\mathrm{H}}=8.113$ $\mu \mathrm{mol}, \mathrm{n}_{\mathrm{Np}}=0.5357 \mu \mathrm{mol}, \mathrm{n}_{\mathrm{L}}=2.498 \mu \mathrm{mol}$. Titrant: $0.015 \mathrm{M} \mathrm{NaOH}$. (D) Initial solution in cuvette: $2.100 \mathrm{~mL} ; \mathrm{n}_{\mathrm{H}}=0.6180 \mu \mathrm{mol}$, $\mathrm{n}_{\mathrm{Np}}=0.5344 \mu \mathrm{mol}$. Titrant: $4.902 \mathrm{mM}$ HEDTA/4. $454 \mathrm{mM} \mathrm{H}^{+}$.

$\mathrm{NpO}_{2}^{+}+\mathrm{H}^{+}+\mathrm{L}^{3-}=\mathrm{NpO}_{2} \mathrm{HL}^{-}$

$\mathrm{NpO}_{2}{ }^{+}+\mathrm{L}^{3-}=\mathrm{NpO}_{2} \mathrm{~L}^{2-}$

$\mathrm{NpO}_{2}{ }^{+}+\mathrm{L}^{3-}+\mathrm{H}_{2} \mathrm{O}=\mathrm{NpO}_{2} \mathrm{H}_{-1} \mathrm{~L}^{3-}+\mathrm{H}^{+}$

The equilibrium constants $(\log \beta)$ for eq. 1, 2, and 3 are shown in Table 11.

Table 11. Thermodynamic parameters for the complexation of $\mathrm{NpO}_{2}{ }^{+} /$HEDTA, $I=1.00 \mathrm{M} \mathrm{NaClO}_{4}, \mathrm{t}=25^{\circ} \mathrm{C}$.

\begin{tabular}{lllll}
\hline Reaction & $\log \beta$ & $\begin{array}{c}\Delta H \\
\mathrm{~kJ} \cdot \mathrm{mol}^{-1}\end{array}$ & \multicolumn{3}{c}{$\Delta S$} \\
$\mathrm{~J} \cdot \mathrm{mol}^{-1} \cdot \mathrm{K}^{-1}$ & \\
\hline$(1)$ & $13.46 \pm 0.02$ & $7.0 \pm 2.0$ & $234 \pm 8.0$ & \\
$(2)$ & $7.06 \pm 0.03$ & $-(19.0 \pm 2.0)$ & $199 \pm 8.0$ \\
$(3)$ & $-(4.74 \pm 0.03)$ & $/$ & $/$ \\
\hline
\end{tabular}

Enthalpy of complexation. Figure 81 shows the thermograms of the complexation titrations (upper) and the associated speciation diagrams (lower) for the $\mathrm{NpO}_{2}^{+} / \mathrm{HEDTA}$ systems. By using the stability constants determined by spectrophotometry, the enthalpies of complexation for the $\mathrm{NpO}_{2}^{+} / \mathrm{HEDTA}$ complexes were calculated, and are listed in Table 11. 


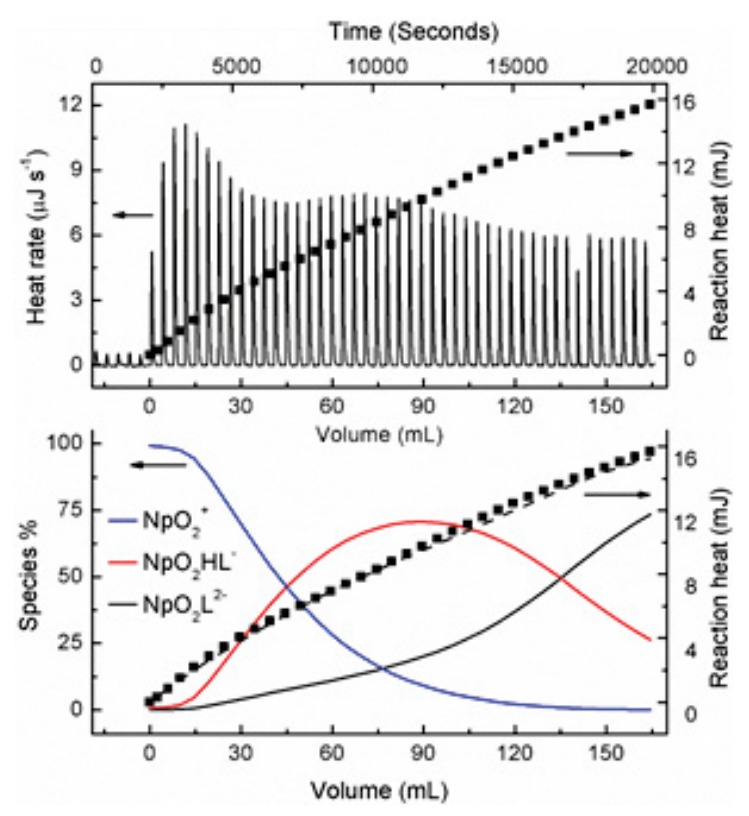

Figure 81. Calorimetric titration of $\mathrm{NpO}_{2}{ }^{+} / \mathrm{HEDTA}\left(t=25^{\circ} \mathrm{C}, I=1.0 \mathrm{M} \mathrm{NaClO}{ }_{4}\right.$ ). (Upper): thermogram (left y axis) and total reaction heat (right y axis); (Lower) total reaction heat (right y axis; experimental data; dashed line, fit) and speciation of $\mathrm{Np}$ (V) (left y axis; solid lines) versus the volume of the titrant.

\section{Complexation of $\mathrm{U}(\mathrm{VI})$ with HEDTA at $25-70^{\circ} \mathrm{C}$}

Stability constants. Potentiometric titrations were performed to determine the stability constants of $\mathrm{U}(\mathrm{VI}) / \mathrm{HEDTA}$ complexes at different temperatures (Figure 82). The HypQuad and HypSpec programs were used to calculate the equilibrium constants for reactions 4-6 (Table 12).

$$
\begin{aligned}
& \mathrm{UO}_{2}{ }^{2+}+\mathrm{H}^{+}+\mathrm{L}^{3-}=\mathrm{UO}_{2} \mathrm{HL}(\mathrm{aq}) \\
& \mathrm{UO}_{2}{ }^{2+}+\mathrm{L}^{3-}=\mathrm{UO}_{2} \mathrm{~L}^{-} \\
& \mathrm{UO}_{2}{ }^{2+}+\mathrm{L}^{3-}+\mathrm{H}_{2} \mathrm{O}=\mathrm{UO}_{2} \mathrm{H}_{-1} \mathrm{~L}^{2-}+\mathrm{H}^{+}
\end{aligned}
$$

Table 12. Thermodynamic parameters for reactions 4, 5, and 6, I = $1.0 \mathrm{M} \mathrm{NaClO}_{4}$. (a) van't Hoff, (b) calorimetry.

\begin{tabular}{lcccc}
\hline Reaction & $t,{ }^{\circ} \mathrm{C}$ & $\log \beta_{\mathrm{M}}$ & \multicolumn{2}{c}{$\Delta H, \mathrm{~kJ} \cdot \mathrm{mol}^{-1}$} \\
& & & $(\mathrm{a})$ & $(\mathrm{b})$ \\
\hline$(4)$ & 25 & $15.13 \pm 0.01$ & -3.58 & -5 \\
& 40 & $15.08 \pm 0.01$ & & \\
& 55 & $15.08 \pm 0.01$ & & \\
& 70 & $15.04 \pm 0.01$ & & \\
$(5)$ & 25 & $9.89 \pm 0.02$ & 15.6 & 17 \\
& 40 & $10.07 \pm 0.02$ & & \\
& 55 & $10.11 \pm 0.02$ & & \\
$(6)$ & 70 & $10.27 \pm 0.03$ & & \\
& 25 & $3.35 \pm 0.03$ & 36.9 & 39 \\
& 40 & $3.69 \pm 0.03$ & & \\
& 55 & $3.93 \pm 0.03$ & & \\
\hline
\end{tabular}



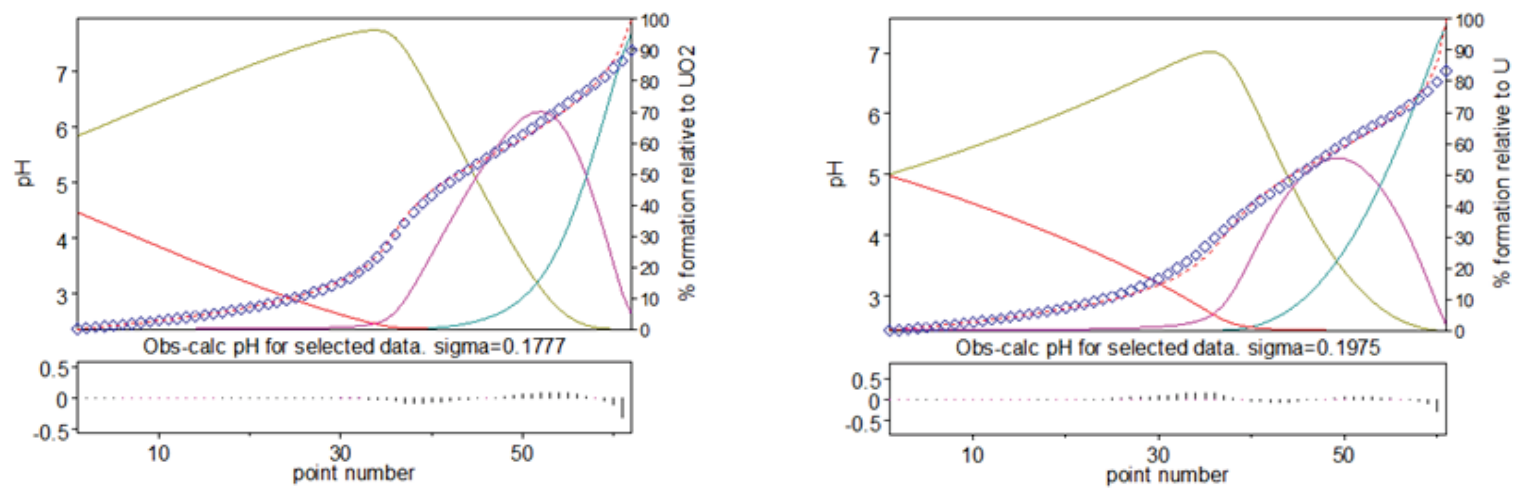

Figure 82. Representative potentiometric titrations for U(VI)/HEDTA complexation. (upper) $25^{\circ} \mathrm{C}$, In cup: $14.44 \mathrm{~mL}, 0.0221$ mmol U(VI), 0.0507 mmol HEDTA, $0.1771 \mathrm{mmol} \mathrm{H}$; titrant: $0.1003 \mathrm{mM} \mathrm{NaOH}$; (lower) $70^{\circ} \mathrm{C}$, In cup: $14.31 \mathrm{~mL}, 0.0221 \mathrm{mmol}$ $\mathrm{U}(\mathrm{VI}), 0.0255 \mathrm{mmol}$ L, $0.1016 \mathrm{mmol} \mathrm{H}$, titrant: $0.1003 \mathrm{mM} \mathrm{NaOH}$.

Enthalpy of complexation. The enthalpy of complexation between U(VI) and HEDTA was determined by microcalorimetry (Figure 83). The HypDH program was used to calculate the enthalpy of complexation. The enthalpies of complexation obtained by calorimetry are in excellent agreement with those calculated by van't Hoff equation (Table 12).

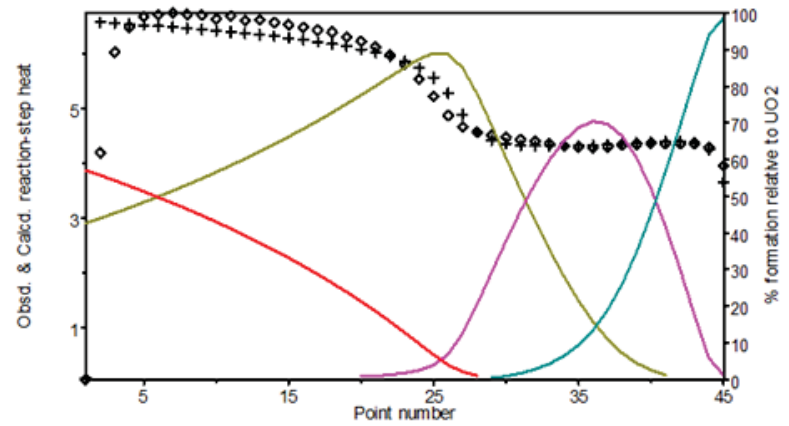

Figure 83. Calorimetric titration of U(VI)/HEDTA complexation at 25 oC. I = $1.0 \mathrm{M} \mathrm{NaClO4}$. Stepwise heat and corresponding speciation.

NMR experiments. ${ }^{1} \mathrm{H} /{ }^{13} \mathrm{C}$ NMR experiments have been conducted to help understand the coordination modes of $\mathrm{U}(\mathrm{VI})$ with HEDTA. Data processing is in progress.

\section{Publications}

X. Li, Z. Zhang, L. R. Martin, S. Luo, L. Rao, "Effect of Temperature on the Protonation of N-(2hydroxyethyl)ethylenediamine- $N, N^{\prime}, N^{\prime}$-triacetic Acid in Aqueous Solutions: Potentiometric and Calorimetric Studies," Journal of Chemical Thermodynamics 85, 2015: 35-41.

G. Tian, Z. Zhang, L. R. Martin, and L. Rao, "Complexation of Curium(III) with DTPA at 10-70 ${ }^{\circ}$ : Comparison with $\mathrm{Eu}(\mathrm{III}) / \mathrm{DTPA}$ in Thermodynamics, Luminescence and Coordination Modes," Inorganic Chemistry 54(4), 2015: 1232-1239. 


\title{
6.7 Theoretical Prediction Stability Constants of Lanthanum Lactate Complexes in Solution and Exploratory Calculations of Spectroscopic Properties of M-DTPA Complexes
}

\author{
L. E. Roy, SRNL
}

In FY-15, work focused on two different projects: calculations focused on understanding the coordination environment and relevant thermodynamics of $\mathrm{La}(\mathrm{III})$-actate complexes and continued scoping calculations to investigate the excited states and emission spectra of M-DTPA complexes. For the first task, the goal was to calculate the coordination modes for the complexes and changes in Gibbs free energy for complexation in solution. The goal for the second task was to evaluate if theoretical calculations of M-DTPA complexes are possible for systems with a large number of unpaired spins.

\section{Stability Constants of Lanthanum Lactate Complexes}

Initial focus is on the possible coordination modes of lactate with an 8-coordinate $\mathrm{La}$ (III) metal center with a detailed discussion on the role hydrogen bonding plays on the $\alpha$-hydroxyl group; the next section concentrates on hydration thermodynamics and stability of the 8-vs. 9-coordinate La(III)-lactate complexes; and finally a thermodynamic methodology for calculating stability constants is presented for $\mathrm{La}$ (III)-lactate complexes in solution.

\section{Binding mode of lactate with La(III)}

Three bidentate coordination modes are possible for a lanthanum lactate complex: A) coordination with the carboxylate group , B) with the carboxylate and deprotonated $\alpha$-hydroxyl group, or C) with the carboxylate and protonated $\alpha$-hydroxyl group . These calculations support metal complexation with the $\alpha$-hydroxyl group; both $\left[\mathrm{La}(\mathrm{lac})\left(\mathrm{H}_{2} \mathrm{O}\right)_{6}\right]^{2+}$ and $\left[\mathrm{La}(\mathrm{lac})_{2}\left(\mathrm{H}_{2} \mathrm{O}\right)_{4}\right]^{+}$are stabilized by $\sim 30$ and $\sim 33 \mathrm{kcal} \mathrm{mol}^{-1}$, respectively, when the $\mathrm{La}$ (III) binds to the $\alpha$-hydroxyl group. Interestingly, calculations suggest that the $\alpha$-hydroxyl group is deprotonated in the 1:1 complex and protonated in the 1:2/1:3 complexes, but that the $\alpha$-hydroxyl group is hydrogen bonded to a corresponding outer sphere water molecule. These results both confirm and contradict the recent work by Barkleit et al. who state that the $\alpha$-hydroxyl group should be deprotonated in the Eu(III) lactate $1: 1$ complex. ${ }^{1}$ The difficulties in correctly calculating hydrogen bonds using DFT are well known and a discussion into the performance of DFT methods for predicting hydrogen bonding energies is beyond the scope of this work. Atoms-in-Molecules (AIM) theory was used to provide information into the stabilization of the intermolecular interactions between the $\alpha$-hydroxyl group and water. Looking at the $\rho$ and $\nabla^{2} \rho$ in Table 12, the values vary from 0.04-0.06 a.u. and 0.10- 0.14 a.u., respectively, indicating the interactions are highly stable. The positive values of Laplacian charge density reveal that electronic charges are depleted in the interatomic path, which is indicative of closed shell interactions such as hydrogen bonding. When also including Jeffrey's hydrogen bond description, the hydrogen bonding interactions in these systems should be described as moderate to strong. ${ }^{2}$ Additional calculations of $\mathrm{La}(\mathrm{lac})_{3}\left(\mathrm{H}_{2} \mathrm{O}\right)_{2}$ show that the hydrogen bonding interactions continue in the series. In summary, it is entirely possible the $\alpha$-hydroxyl group in $\left[\mathrm{La}(\mathrm{lac})\left(\mathrm{H}_{2} \mathrm{O}\right)_{6}\right]^{2+}$ remains protonated in solution with the help of hydrogen bonding interactions. Therefore, a description of an unprotonated $\alpha$-hydroxyl group for a Ln-lactate 1:1 complex is not strictly correct and exclusion of explicit water molecules in the calculations could predict a doubly deprotonated ligand to help balance the overall charge.

\section{Hydration Thermodynamics}

Typical La(III) crystal structures have a preference for 9-coordinate geometries and for La(III) lactate complexes, it is expected that some water exchange will occur allowing for both 8-and 9-coordinate 
species to exist in solution. To assess the stability of the hydrated species, the free energies were calculated for the following reactions;

$$
\begin{array}{rl}
{\left[\mathrm{La}(\mathrm{lac})\left(\mathrm{H}_{2} \mathrm{O}\right)_{6}\right]^{2+}+\mathrm{H}_{2} \mathrm{O} \rightarrow\left[\mathrm{La}(\mathrm{lac})\left(\mathrm{H}_{2} \mathrm{O}\right)_{7}\right]^{2+}} & 1 \\
{\left[\mathrm{La}(\mathrm{lac})_{2}\left(\mathrm{H}_{2} \mathrm{O}\right)_{4}\right]^{+}+\mathrm{H}_{2} \mathrm{O} \rightarrow\left[\mathrm{La}(\mathrm{lac})_{2}\left(\mathrm{H}_{2} \mathrm{O}\right)_{5}\right]^{+}} & 2 \\
\mathrm{La}(\mathrm{lac})_{3}\left(\mathrm{H}_{2} \mathrm{O}\right)_{2}+\mathrm{H}_{2} \mathrm{O} \rightarrow \mathrm{La}(\mathrm{lac})_{3}\left(\mathrm{H}_{2} \mathrm{O}\right)_{3} & 3
\end{array}
$$

Table 13 contains the energy components used to predict the reaction energetics from reactions 1-3. Since calculations of the vibrational component included the SMD solvent model, the free energies were used directly without calculation of gas phase and solvation contribution components. It should be pointed out that while calculated solution free energies are not exact, systematic errors included in the values should cancel out to provide accurate reaction free energies. A standard-state thermodynamic correction term is also important to account for the standard state of liquid water. The calculated free energies of reaction for both $\mathbf{1}$ and $\mathbf{3}$ are small and endergonic, suggesting that both coordination environments are stable in solution. Perhaps this is a consequence of the hydrogen bonding issues discussed in the previous section for $\mathrm{La}$ (III)-lactate 1:1 complex. Another factor to consider is that the use of $1 \mathrm{H}_{2} \mathrm{O}$ molecule in thermodynamic calculations is not ideal for modeling water. Nevertheless, inclusion of the standard state correction yields an overall exergonic $\Delta G$ for all three reactions. Hence, the predominant species in solution is expected to be the 9-coordinate complex.

Table 13. Calculated Free Energies $\left(\mathrm{kcal}^{\circ} \mathrm{mol}^{-1}\right)$ of hydration for 1-3 in aqueous solution.

\begin{tabular}{llll}
\hline Reaction & $\Delta \mathrm{G}_{\text {solv }}$ & $\mathrm{SS} \mathrm{corr}$ & $\Delta \mathrm{G}_{\text {solv,corr }}$ \\
\hline 1 & 0.217 & -4.3 & -4.082 \\
2 & -3.253 & -4.3 & -7.553 \\
3 & 3.78 & -4.3 & -0.518 \\
\hline
\end{tabular}

a. Standard state pressure correction for $\left(\mathrm{H}_{2} \mathrm{O}\right)_{n}$ clusters is calculated to be $-4.3 / n \mathrm{kcal} \cdot \mathrm{mol}^{-1}$.

\section{Calculation of stability constants}

Successful calculation of stability constants for metal complexes remains a formidable challenge even with modern computational tools available. However, as the work below will point out, inclusion of continuum solvent models aids in providing at least a semi-quantitative description of the stability constants for lanthanide complexes. Reaction $\mathbf{4}$ provides a general description of the ligand exchange reaction for $\mathrm{La}$ (III) lactate complexes:

$$
\left[\mathrm{La}(\mathrm{H} 2 \mathrm{O})_{9}\right]^{3+}+\mathrm{xlac}^{-} \rightarrow\left[\mathrm{La}(\mathrm{lac})_{\mathrm{x}}\left(\mathrm{H}_{2} \mathrm{O}\right)_{9-2 \mathrm{x}}\right]^{3-\mathrm{x}}+\left(\mathrm{H}_{2} \mathrm{O}\right)_{2 \mathrm{x}}
$$

The reaction involves exchange of two water molecules by the lactate ligand. The corresponding equilibrium constant for $\mathbf{4}$ is expressed in equation 1:

$$
\mathrm{K}_{\mathrm{eq}, 5}=\frac{\left[\mathrm{La}(\mathrm{lac})_{\mathrm{x}}\left(\mathrm{H}_{2} \mathrm{O}\right)_{9-2 \mathrm{x}}\right]^{3-x}}{\left[\left[\mathrm{La}\left(\mathrm{H}_{2} \mathrm{O}\right)_{9}\right]^{3+}\right]\left[\mathrm{lac}^{-}\right]^{\mathrm{x}}}
$$

Taking into account the relationship between the equilibrium constant and the free energy of reaction, equation 1 is transformed into equation 2 ;

$$
\log \boldsymbol{\beta}_{\left[\mathrm{La}(\mathrm{lac})_{\mathrm{X}}\left(\mathrm{H}_{2} \mathrm{O}\right)_{9-2 \mathrm{x}}\right]^{3-x}}=-\frac{\Delta \mathbf{G}_{5}}{\mathrm{RT} \ln \mathbf{1 0}}
$$


wherein the free energy of reaction, $\Delta \mathrm{G}_{5}$, is given by equation 3 :

$$
\Delta \mathbf{G}_{5}=\Delta \mathbf{G}_{\text {solv,corr }}=\left(\mathbf{G}_{\mathbf{a q}\left(\left[\mathrm{La}(\mathrm{lac})_{\mathbf{x}}\left(\mathrm{H}_{2} \mathrm{O}\right)_{9-2 \mathrm{x}}\right]^{3-x}\right)}+\mathbf{G}_{\mathbf{a q}\left(\left(\mathrm{H}_{2} \mathrm{O}\right)_{2 \mathrm{x}}\right)}\right)-\left(\mathbf{G}_{\mathbf{a q}\left(\left[\mathrm{La}\left(\mathrm{H}_{2} \mathrm{O}\right)_{9}\right]^{3+}\right)}+\mathbf{x G}_{\left.\mathbf{a q}_{(\mathrm{lac}}{ }^{-}\right)}\right)
$$

As mentioned previously, the free energy terms were used directly from the thermal analysis without calculation of gas phase and solvation contribution components and the standard-state thermodynamic correction was applied to account for the water correction. The calculated free energies of reaction and their associated stability constants can be found in Table 14. Surprisingly, stability constants are within range of experiment with an average difference of $1.2 \mathrm{log}$ units for the predicted values. This corresponds to errors of $1.6 \mathrm{kcal} \mathrm{mol}^{-1}$ for the calculated free energies of reaction, which falls within the accuracy of DFT calculations (1-3 kcal mol $\left.{ }^{-1}\right)$. While this is a small data set, it is encouraging that a set of stability constants could be estimated at the semi-quantitative level for lanthanide complexes. Without the standard-state thermodynamic correction for liquid water, the trend for successive addition of lactate anions to a solvated $\mathrm{La}(\mathrm{III})$ center is quite good with increasing $\Delta G$ for the reactions. Addition of the thermodynamic correction stabilizes the complexes further such that DFT predicts that all three reactions would be equally stable. The calculated stability constants are largest for the La(III)-lactate 1:1 and 1:3 complexes. Possible sources for the error in the calculations include hydrogen bonding issues or the thermodynamic correction for liquid water. Overall, these results suggest that while more sophisticated calculations can be used, there is an associated cancellation of errors when using approximated free energies in solution. In systems where hydrogen bonding dictates the structure, it is imperative to include water molecules at the quantum mechanics level during structure optimization. Despite the errors in DFT and the continuum solvent models in general, obtaining a semi-quantitative value for stability constants is achievable when including the solvation effects throughout the calculation.

Table 14. Calculated free energies $\left(\mathrm{kcal} \cdot \mathrm{mol}^{-1}\right)$ and stability constants for $\mathrm{La}^{3+}$-lac complexation based on reaction 4.

\begin{tabular}{llllll}
\hline & $\Delta \mathrm{G}_{\text {solv }}$ & SS corr & $\Delta \mathrm{G}_{\text {solv, corr }}$ & $\log \beta$ & $\log \beta_{\text {exp }}$ \\
\hline$\left[\mathrm{La}(\mathrm{lac})\left(\mathrm{H}_{2} \mathrm{O}\right)_{7}\right]^{2+}$ & -2.713 & -2.2 & -4.863 & 3.56 & 2.27 \\
{$\left[\mathrm{La}(\mathrm{lac})_{2}\left(\mathrm{H}_{2} \mathrm{O}\right)_{5}\right]^{+}$} & -3.409 & -1.1 & -4.485 & 3.29 & 3.95 \\
$\mathrm{La}(\mathrm{lac})_{3}\left(\mathrm{H}_{2} \mathrm{O}\right)_{3}$ & -3.668 & -0.7 & -4.384 & 3.22 & 5.1 \\
\hline
\end{tabular}

\section{TD-DFT calculations of Eu-DTPA}

In FY-14, initial scoping calculations looked at the electronic structure of $\left[\mathrm{Eu}(\mathrm{DTPA}) \mathrm{H}_{2} \mathrm{O}\right]^{2-}$ in hopes of evaluating the TD-DFT method for open shell $\mathrm{f}-\mathrm{f}$ transitions; other M-L transitions may not be accurate based on spin contamination issues. These calculations proved to be more difficult than expected due to non-Aufbau occupation of the molecular orbitals. The "triply degenerate HOMOs" are in actually split by $<0.01 \mathrm{eV}$ and contain orbital occupations of $0.82,0.73$ and 0.45 . Until an Aufbau occupation can be converged, TD-DFT calculations cannot be performed. Calculations then shifted to using Molpro and CASSCF (complete active space-scf) calculation. However, these calculations would not converge for an Eu-DTPA system. Molcas is used by the magnetism community to calculate lowest exchange states for rare-earth metal complexes. The procedure is complicated, but easy to follow. A CASSCF calculation needs to include only the f orbitals since we are only interested in the ligand field states. Because the felements have a very strong spin-orbit coupling, a large number of the roots (from the CASSCF calculation) should include spin orbit mixing within restricted active space state interaction (RASSI-SO). Additional routines are included to calculate exchange interactions between metal centers. The $\mathrm{CASSCF} / \mathrm{RASSI}-\mathrm{SO}$ procedure should be able to predict the excited state and emission spectra for $\mathrm{f}$ element systems. These calculations should have been possible in Molpro, but Molcas has been optimized to routinely perform these calculations for lanthanide systems. 


\section{References}

1. A. Barkleit, J. Kretzschmar, S. Tsushima, and M. Acker, "Americium(III) and Europium(III) Complex Formation with Lactate at Elevated Temperatures Studied by Spectroscopy and Quantum Chemical Calculations," Dalton Transactions 29, 2014: 11221-11232.

2. G. A. Jeffrey, 1997, “An Introduction to Hydrogen Bonding," Oxford University Press.

Presentations and Publications:

Roy, L. E., N. J. Bridges, C. L. Klug, J. J. Pittman, L. R. Martin, "Experimental and Theoretical Evaluations of TALSPEAK," Presented by L. E. Roy at the Material Recovery \& Waste Forms Campaign, Working Group Meeting, Feb. 2015.

Roy, L. E., N. J. Bridges, C. L. Klug, J. J. Pittman, L. R. Martin, “Toward Understanding the Complexities of Actinide/Lanthanide Complexation and Separation for Advanced Nuclear Fuel Reprocessing," Presented by L. E. Roy at the $39^{\text {th }}$ Annual Actinide Separations Conference, May 2015.

Roy, L. E., Martin, L. R., "Theoretical Prediction of Coordination Environments and Stability Constants of Lanthanum Lactate Complexes in Solution," Dalton Trans., submitted. 


\section{Domestic Electrochemical Processing}


This page intentionally left blank. 


\title{
7. DOMESTIC ELECTROCHEMICAL PROCESSING
}

\subsection{Development of Engineering-Scale Co-Deposition Cathode}

\author{
R. Blaskovitz, T. Cruse, M. Williamson, J. Willit, ANL
}

\section{Introduction and Objective}

The co-deposition of uranium and transuranics (U/TRU) is one of the key recycle streams produced by treating used fuel with the electrochemical process. The fundamental aspects of U/TRU co-deposition have been demonstrated at the gram scale. Co-deposition of U/TRU occurs when the current density at the cathode exceeds the mass-transfer limiting current for uranium electrodeposition. The goal of this year's co-deposition activity at ANL was to develop an engineering-scale co-deposition cathode. For this work, a mixture of rare earth metals (mischmetal) was used as a simulant for plutonium to allow development work at a realistic scale. Five functional and operational requirements (F\&ORs) were identified for the initial phase of this development. These initial F\&ORs for the engineering-scale codeposition cathode were as follows:

1. The cathode design must be capable of passing current at a sufficient current density; this can be achieved by varying the current and/or the electrode area.

2. Because the cathode potential at the deposit-electrolyte interface determines what species are depositing, accurate measurement of this potential without $i R$ effects is essential.

3. The co-deposited material must maintain electrical contact with the cathode at all times to ensure that the more active metals (e.g., TRU) do not exchange with $\mathrm{UCl}_{3}$ in the electrolyte.

4. The co-deposition must only occur at the desired location.

5. The co-deposition cathode should be designed so that it is amenable to removal and harvesting in a remote operation setting.

\section{R\&D Overview}

The development work this year was carried out in an 18-in. furnace well in a large glovebox located in the Electrorefining Development Lab at ANL. The cylindrical cell was divided in two sections. One section consisted of four planar anode baskets and uranium cathodes. The other section contained the codeposition cathode. The elevation of the co-deposition cathode was adjustable via a clamp on the cathode. The cathode also featured an alumina cup affixed to the bottom of the cathode to retain the co-deposit and maintain electrical contact with the cathode. A voltage probe was placed near the cathode in the deposition region to measure the deposition potential while minimizing the iR contributions. Mischmetal, a mixture of rare earth metals $(\mathrm{Ce}, \mathrm{La}, \mathrm{Nd}$, and $\mathrm{Gd})$ was placed in a mesh basket to introduce rare earths to the electrolyte by exchange reaction with $\mathrm{UCl}_{3}$. Incremental additions were used to establish U:total rare earth molar ratios of 3:1, 2:1 and 1:1, while maintaining the U-plus-rare earth mole fraction at a constant value. Deposits were obtained at each U:total rare earth ratio. After multiple tests, parameters were identified in which the current density exceeded the mass transfer limit for uranium electrodeposition and a successful co-deposit of uranium and rare earths was obtained. Previous reported attempts at co-deposition of other metals with uranium at a non-alloying cathode were only successful at $\mathrm{U}^{3+}$ concentrations less than $1.5 \mathrm{wt} \%$. In theory, there should be no upper limit of $\mathrm{U}^{3+}$ for co-deposition. Therefore, in addition to the development of an engineering-scale design, one additional goal of this work was to demonstrate that co-deposition could occur at $\mathrm{U}^{3+}$ concentrations above $1.5 \mathrm{wt} \%$. 


\section{Accomplishments}

Several modifications to the cathode design were made in the course of this work. After several tests, a co-deposit containing both $\mathrm{U}$ and rare earths was obtained with a $\mathrm{U}^{3+}$ concentration above $1.5 \mathrm{wt} \%$. This confirmed the basic premise that the only requirement for co-deposition was to exceed the mass transport limiting current density for uranium. In terms of maintaining electrical contact between the cathode and the electrodeposit, the co-deposition cathode design was successful. One modification to mounting the ceramic catch pan on the bottom of the co-deposition cathode was needed to eliminate the electrodeposition of material on the bolt attaching the catch pan to the current lead, the modification was successful. After investigating several approaches to voltage probe design and location, a new design for the co-deposition cathode incorporating a voltage probe was developed; the new design will also allow for finer control of the cathode electroactive area and simplifies removal of the cathode at the end of a codeposition test. This unit is presently in fabrication and testing will resume in early FY-16.

\subsection{AC Voltammetry for Quantitative Analysis of Actinides in Molten Fluoride Salts}

M. Tylka, J. Willit, and M. Williamson, ANL

\section{Introduction and Objectives}

Several research groups continue to study the use of molten fluorides as an alternative to molten chlorides for the electrochemical recycle of used nuclear fuel. ${ }^{1}$ The use of molten fluorides in a fuel recycle process will require high-precision, real-time concentration measurements of actinides in the molten fluoride both for process monitoring and control as well as material control and accountability. In our previous studies,

${ }^{2-5}$ we investigated the applicability of electrochemical methods for quantitative measurements of actinide concentrations in molten chloride salts. That work demonstrated both an approach to method development and a refined data analysis method for high-precision cyclic voltammetric measurements of actinides in molten chlorides at concentrations up to approximately $2 \mathrm{wt} \%$. At concentrations above $2 \mathrm{wt} \%$ the diffusion coefficient of the actinide becomes dependent on the actinide concentration. Therefore an independent online measurement of the actinide diffusion coefficient in the high-concentration case is needed to achieve accurate concentration measurements by electroanalytical methods.

This work examines the feasibility using electroanalytical methods for quantitative measurements of actinides in molten fluoride salts. This work includes investigating methods for high-precision measurements as well as independent methods to measure diffusion coefficients in the higher concentration case. The goal of this approach is to obtain accurate, in situ concentration measurements of the actinides in molten fluoride salts without requiring any calibration curve or standards.

\section{R\&D Overview}

None of the commonly used DC techniques provides a method to measure a diffusion coefficient $\left(D_{i}\right)$ independent of the concentration of the electroactive species $\left(C_{i}\right)$ as these two terms are always present together in the equation that describes either the current or potential response of an electrochemical system. As stated above, this becomes problematic at higher concentrations. However, an electrochemical technique based on the analysis of faradaic alternating current (AC) impedance has been identified that provides much greater scope for obtaining high-quality quantitative data that gives access to additional information about electrode processes. The theoretical analysis of this technique for systems involving formation of an insoluble product has been completed recently by ANL. The theoretical analysis confirms 
that $\mathrm{AC}$ voltammetry data can be used for independent determination of $D_{i}$ and therefore can be a key tool for quantitative electroanalytical measurement of actinide concentrations in molten salts.

Evaluating the feasibility of the electrochemical techniques for quantitative measurements of actinides in molten fluoride salts follows the same approach we used in molten chloride salts by first focusing on obtaining reproducible and high-precision DC measurements and determination of the electrochemical reversibility of the system containing $\mathrm{U}^{4+}$ ions in molten fluoride salts (e.g. LiF-NaF-KF). Once reliable DC measurements are established, AC voltammetry can be used to further analyze the system by making independent measurements of both, the diffusion coefficient and the concentration.

\section{Accomplishments}

The work this year involved theoretical analysis of AC voltammetry for the systems involving the formation of an insoluble product. Two independent relations describing AC current at two frequency limits have been derived as well as the relation describing the phase angle behavior, which holds independently of the applied frequency. On the basis of the results, the strategy for evaluating the diffusion coefficient and measuring the concentration has been developed.

The experimental parameters necessary to acquire the desired information have been identified and the initial experiments on salt containing $\mathrm{U}^{4+}$ in LiF-NaF-KF (FLINAK) have been completed. The electrochemical behavior of the pure melt was observed to indicate the presence of any impurities and to examine the usable potential window. A comparison of cyclic voltammograms (CV) plotted in the pure solvent and the melt containing $\mathrm{U}$ ions is shown in Figure 84. Peaks Ia and $\mathrm{Ib}$ correspond to reduction of $\mathrm{U}^{+4}$ to $\mathrm{U}$ metal and oxidation of $\mathrm{U}$ metal to $\mathrm{U}^{+4}$, respectively, Peaks IIa and IIb have been observed by other researchers but are not conclusively explained. Lack of additional peaks in the blank experiment indicates that there are no impurities present in the salt and the experimental response of the electrochemical system behaves as expected.

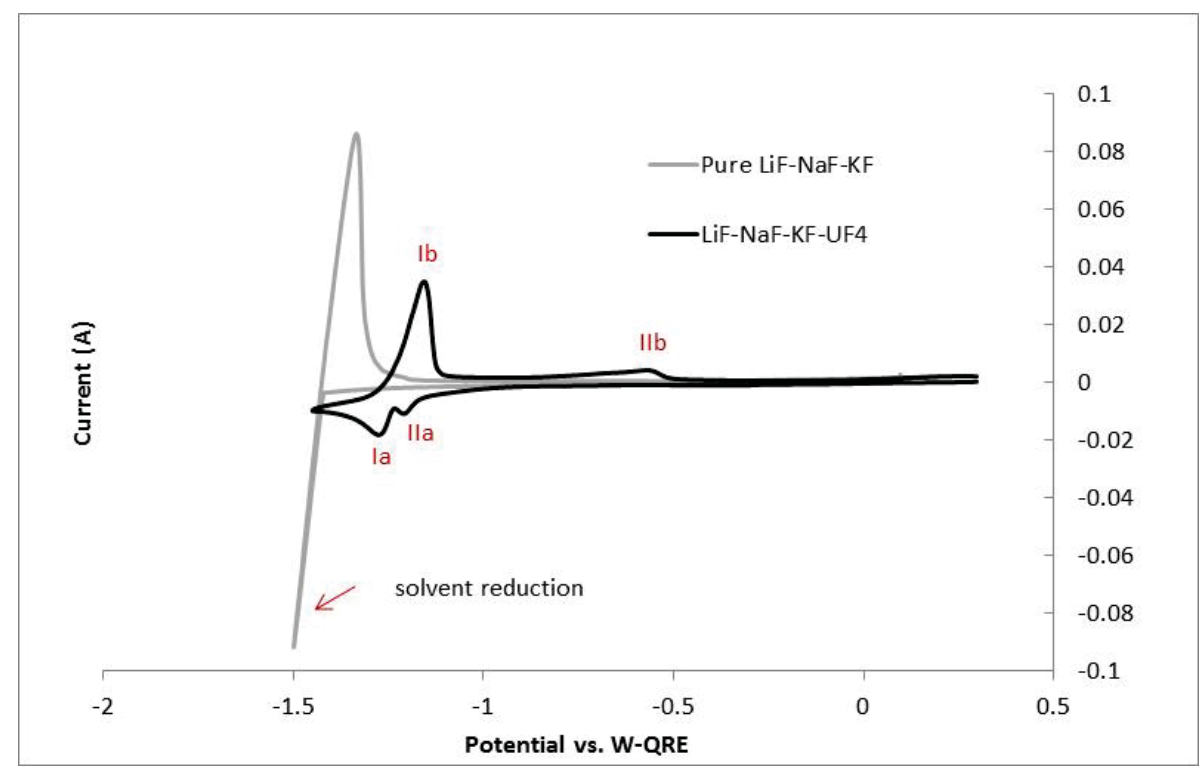

Figure 84. Comparison of cyclic voltammograms plotted in LiF-NaF-KF (grey curve) and in LiF-NaF-KF-UF 4 (1.08wt\%) (black line) at $525^{\circ} \mathrm{C}$; WE: W, CE:Mo, RE: W-QRE; $v=100 \mathrm{mV} / \mathrm{s}$.

The electrochemical behavior of the system after addition of $U_{4}$ has been examined and conditions that result in a reversible reaction have been identified. The results also have been analyzed and compared to the results reported by others in different fluoride salt solvents. ${ }^{6-11}$ Work performed at ANL this year has identified a number of issues pertaining to electrochemical techniques in molten fluoride salt media that 
still need to be fully resolved in order make high-precision quantitative concentration measurements using electrochemical techniques (i.e., solvent selection, material of the working electrode, etc.). One key item is the effect of other cations in the molten salt on the interfacial electrochemistry of uranium in molten fluoride salts. Similar effects are observed in molten chloride salts but the effects appear to be greater in molten fluoride salts. Resolution of these issues will be pursued in FY-16.

\section{References}

1. B. Abrams, S. Levy, D. Chapin, et al., "A Technology Roadmap for Generation IV Nuclear Energy Systems," 2002, U.S. DOE Nuclear Energy Research Advisory Committee at the Generation IV International Forum, GIF-002-00, available online: https://www.gen-4.org/gif/jcms/c 40481/technology-roadmap https:/inlportal.inl.gov/portal/server.pt/document/9678/generation_iv_international_forum_pdf

2. M. M. Tylka, J. L. Willit, and M. A. Williamson, "Electroanlaytical Measurements of Uranium and Plutonium in Molten LiCl-KCl Eutectic," 2012 International Pyroprocessing Research Conference; Fontana, WI, Aug. 26-29, 2012.

3. M. M. Tylka, J. L. Willit, J. Prakash, and M. A. Williamson, "Method Development for Quantitative Analysis of Actinides in Molten Salts," Journal of Electrochemical Society 162, 2015: H625-H633.

4. M. M. Tylka, J. L. Willit, J. Prakash, and M. A. Williamson, "Electrochemical Analysis of Actinides in Molten Salts," 2014 International Pyroprocessing Research Conference; Idaho Falls, ID, Oct. 1923, 2014.

5. M. M. Tylka, J. L. Willit, J. Prakash, and M. A. Williamson, "Application of Voltammetry for Quantitative Analysis of Actinides in Molten Salts," Journal of Electrochemical Society 162, 2015: H852-H859.

6. C. Nourry, P. Soucek, L. Massot, R. Malmbeck, P. Chamelot, and J.-P. Glatz, "Electrochemistry of uranium in molten fluorides," Proceedings of the First ACSEPT International Workshop, Lisbon, Portugal, March 31-April 2, 2010.

7. P. Soucek, F. Lisy, R. Tulackova, J. Uhlir, and R. Mraz, "Development of Electrochemical Separation Methods in Molten LiF-NaF-KF for the Molten Salt Reactor Fuel Cycle," Journal of Nuclear Science and Technology 42, 2005: 1017-1024.

8. C. Hamel. P. Chamelot, A. Laplace, E. Walle, O. Dugne, and P Taxil, "Reduction Process of Uranium (IV) and Uranium (III) in Molten Fluorides," Electrochimica Acta 52, 2007: 3995-4003.

9. M. Korenko, M. Straka, L. Szatmary, M. Ambrova, and J. Uhlir, "Electrochemical Separation of Uranium in the Molten System," Journal of Nuclear Material 440, 2013: 332-337.

10. M. Straka, M. Korenko, and F. Lisy, "Electrochemistry of Uranium in LiF-BeF2 Melt," Journal of Radioanalytical Nuclear Chemistry 284, 2010: 245-252.

11. M. Straka, F. Lisy, and L. Szatmary, "Electrolytic Deposition of Uranium from Molten Fluorides by Means of Current Pulse Electrolysis," European Nuclear Young Generation Forum, Praha, Czech Republic, April 17-22, 2011. 


\subsection{U/TRU Codeposition and Fluoride Salt Studies}

Guy Fredrickson, INL

\section{U/TRU Codeposition Study}

Salt from the Mk-IV electrorefiner (ER) was transferred from the Fuel Conditioning Facility (FCF) to the Hot Fuels Examination Facility (HFEF).The Mk-IV ER has been used since 1996 to treat over 1 MT of used sodium-bonded metal fuels from Experimental Breeder Reactor II (EBR-II) and the Fast Flux Test Facility Reactor. The as-received salt had a Pu:U ratio of 0.43 (1.85 wt $\% \mathrm{Pu}$ and $4.26 \mathrm{wt} \% \mathrm{U})$. The combined lanthanides (Ce, Eu, $\mathrm{La}, \mathrm{Nd}, \mathrm{Pr}$, and $\mathrm{Sm}$ ) concentration was $3.98 \mathrm{wt} \%$. The salt was loaded into a 4-in.-diameter alumina crucible and placed into the Hot Fuels Dissolution Apparatus (HFDA) furnace. Two subsequent additions of lithium metal were made to increase the $\mathrm{Pu}: \mathrm{U}$ ratio to 1.0 and 2.0, resulting in a total of three unique $\mathrm{Pu}: \mathrm{U}$ ratios. The lithium metal consumes the uranium trichoride to make lithium chloride and uranium metal.

For each of the three salt compositions $(\mathrm{Pu}: \mathrm{U}=0.43,1.0$, and 2.0), a suite of voltammetry measurements were performed, a salt sample was collected, and a uranium/transuranic (U/TRU) codeposit sample was collected. All codeposits were formed at a cathodic potential of $-2.4 \mathrm{~V}$ versus a $\mathrm{Ag} / \mathrm{AgCl}$ reference electrode; the counter electrode was a high surface area uranium metal deposit on tantalum. The salt and codeposit samples are scheduled to be transferred from the HFEF to the Analytical Laboratory in October 2015 for chemical analyses. Photographs of the three codeposits are shown in Figure 85; the mass of each codeposit is approximately $1 \mathrm{~g}$ of metal. The voltage and current trace for the codeposit formed at a Pu:U of 0.43 is shown in Figure 86; typical for all codeposits, the cathodic potential is constant at $-2.4 \mathrm{~V}$ and the current slowly increases over time as the surface area and dimensions of the codeposit continue to grow.

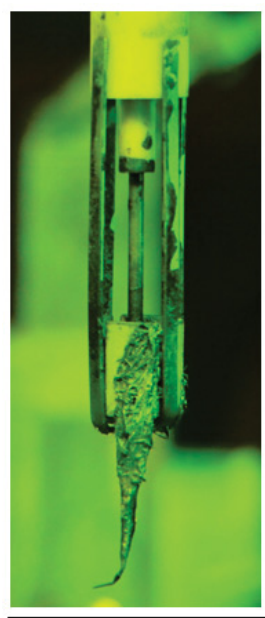

Pu: $\mathbf{U}=\mathbf{0 . 4 3}$

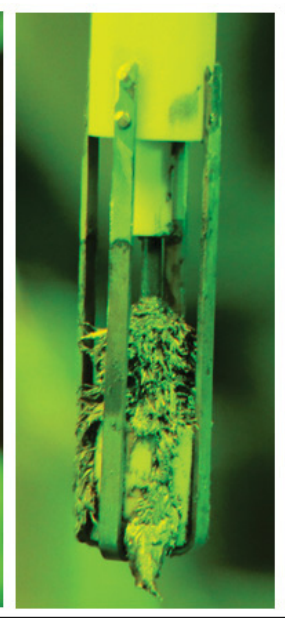

$\mathrm{Pu}: \mathrm{U}=1.0$

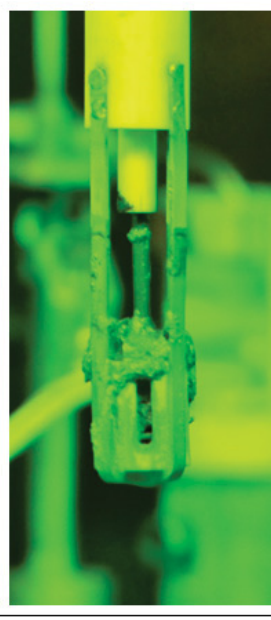

$\mathrm{Pu}: \mathrm{U}=\mathbf{2 . 0}$

Figure 85. Photographs of the U/TRU Codeposits 


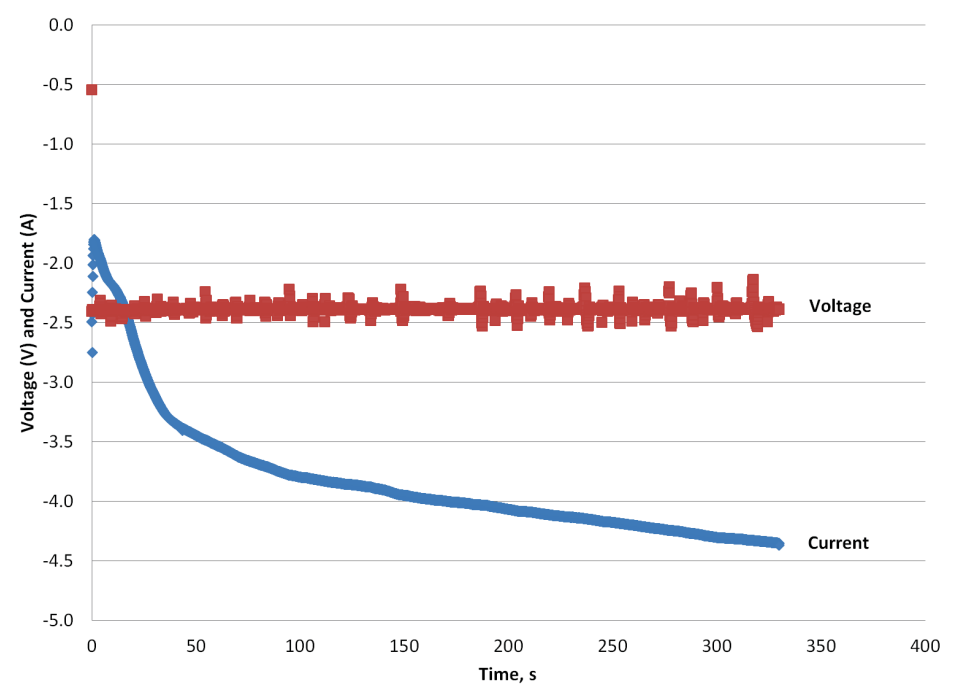

Figure 86. Voltage and Current Trace for the Codeposit at $\mathrm{Pu}: \mathrm{U}=0.43$

A series of cyclic voltammograms (CVs) are shown in Figure 87 for each of the three salt compositions. There is an obvious response of the $\mathrm{CV}$ scans to changes in the Pu: $\mathrm{U}$ ratio of the salt. Many other electrochemical measurements were performed and will be presented in the final year-end technical report.

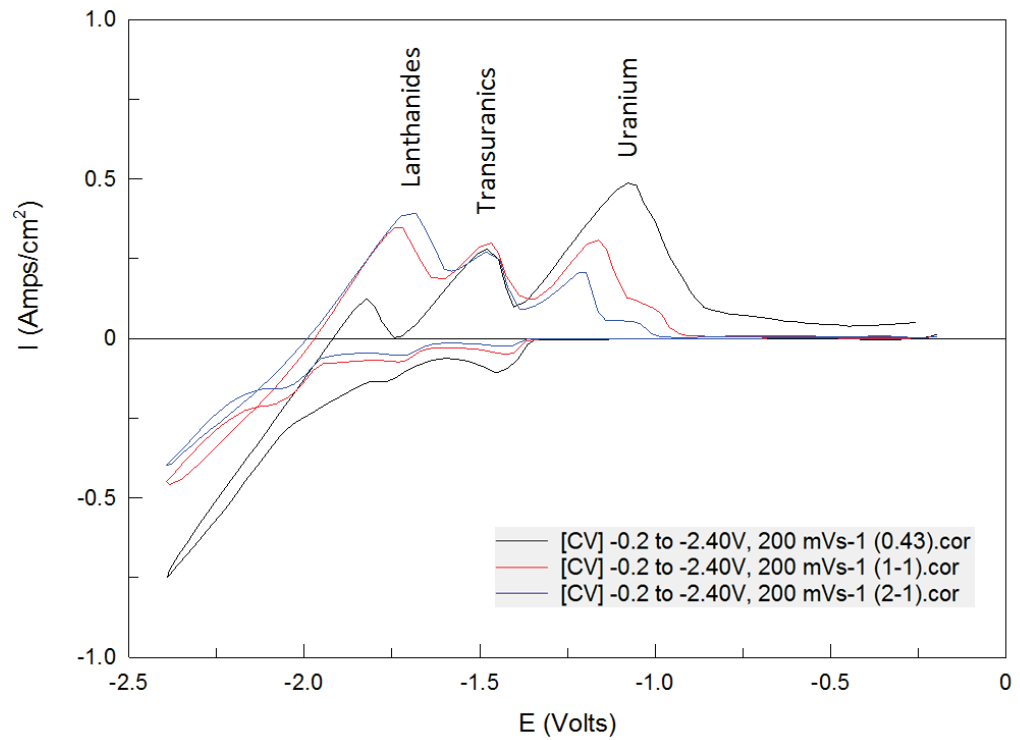

Figure 87. Cyclic Voltammograms at $\mathrm{Pu}: \mathrm{U}=0.43,1.0$, and 2.0

\section{Fluoride Salt Study}

Uranium electrorefining experiments were performed in a LiF-NaF-KF (FLiNaK) based molten salt electrolyte at $500^{\circ} \mathrm{C}$. Uranium tetrafluoride $\left(\mathrm{UF}_{4}\right)$ was mixed with the FLiNaK eutectic salt (0.465-0.1150.420 mole fraction) at $4.56 \mathrm{wt} \%$ uranium. An Inconel mesh anode basket was filled with uranium metal and submerged into the FLiNaK-UF 4 salt mixture. With contact time and multiple deposition/stripping cycles, during which uranium metal was deposited onto a solid Ni cathode and then stripped back to the anode basket, the $\mathrm{UF}_{4}$ in the salt was reduced to $\mathrm{UF}_{3}$ leading to a $6.0 \mathrm{wt} \%$ uranium content $\mathrm{FLiNaK}-\mathrm{UF}_{3}$ salt mixture. A photograph of one of the resulting cathodes with electrodeposited uranium, produced by applying $0.3 \mathrm{~A}$ for an equivalent charge of 3.0 grams uranium, is shown in Figure 88. 


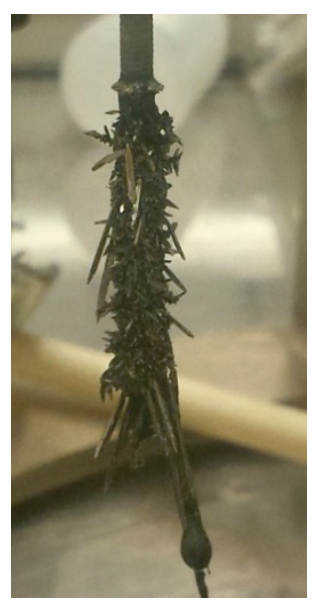

Figure 88. Photograph of Uranium Deposited from FLiNaK-UF $-\mathrm{UF}_{3}$

Following indication of complete conversion of $\mathrm{UF}_{4}$ to $\mathrm{UF}_{3}, \mathrm{LaF}_{3}$ was added to the salt (representing lanthanide chlorides in general) to create a FLiNaK- $\mathrm{UF}_{3}-\mathrm{LaF}_{3}$ mixture with a 2:1 mole ratio of uranium fluoride to lanthanum fluoride. Cyclic voltammetry (CV) was performed on each of the salt mixtures $\left(\mathrm{FLiNaK}-\mathrm{UF}_{4}, \mathrm{FLiNaK}-\mathrm{UF}_{3}\right.$, and $\mathrm{FLiNaK}-\mathrm{UF}_{3}-\mathrm{LaF}_{3}$ ) to determine the potential at which uranium and lanthanum deposition commenced and to assess the potential efficiency of separating uranium from the lanthanides.

The cyclic voltammetry was performed using a nickel working electrode, the Inconel basket as a counter electrode (containing uranium metal), and a glassy carbon rod submerged in the electrolyte salt as a pseudo-reference electrode. The resulting cyclic voltammograms are shown in Figure 89. In the FLiNak$\mathrm{UF}_{4}$ mixture, uranium deposition begins at $-0.45 \mathrm{~V}$ while in both the FLiNaK-UF 3 and FLiNaK-UF $-\mathrm{LaF}_{3}$ mixtures deposition begins at $-0.05 \mathrm{~V}$ indicating a shift in the reference potential due to the change in the electrolyte from $\mathrm{UF}_{4}$ to $\mathrm{UF}_{3}$, but little to no shift with the addition of $\mathrm{LaF}_{3}$. From the $\mathrm{CV}_{\mathrm{s}}$, the deposition of lanthanum appears to begin at $-0.43 \mathrm{~V}$. This gives a window between uranium and lanthanum deposition of $0.425 \mathrm{~V}$. This is a slightly smaller window than that in the $\mathrm{LiCl}-\mathrm{KCl}$ system at $500{ }^{\circ} \mathrm{C}$, which is reported to be $0.63 \mathrm{~V}$.

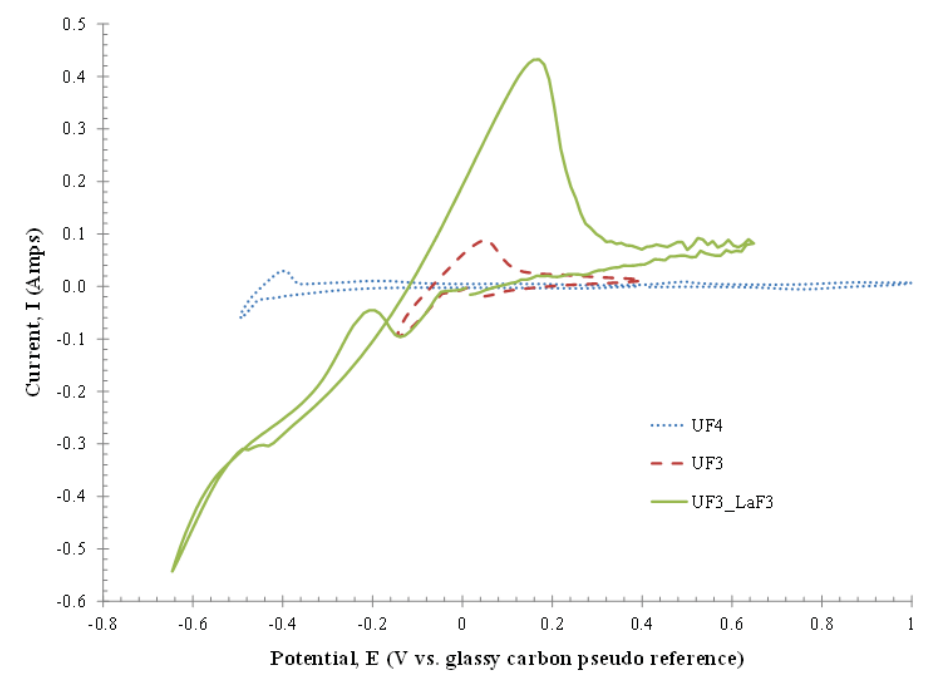

Figure 89. Cyclic Voltammograms in FLiNaK salt mixtures of $\mathrm{UF}_{4}, \mathrm{UF}_{3}$, and $\mathrm{UF}_{3}-\mathrm{LaF}_{3}$ 


\section{Molten Salt Extraction Study}

In FY-14, a series of three molten salt extraction experiments were performed in $\mathrm{LiCl}-\mathrm{KCl}-\mathrm{UCl}_{3}$ at 500 ${ }^{\circ} \mathrm{C}$ with different forms of uranium oxide fuel using the Hot Fuel Dissolution Apparatus in HFEF. The uranium oxide fuel types used in this study included fast reactor and light water reactor fuels, i.e., oxidized EBR-II fuel, crushed BR3 fuel, and voloxidized BR3 fuel. The fuel was subsequently subjected to elevated temperature and reduced pressure using the DEOX furnace in HFEF to distill away adhering salt. Time-at-temperature salt samples were taken during each run to analyze and assess extraction kinetics. Pre- and post-test samples of each oxide fuel type were taken to analyze and assess the extent of extraction. The chemical analyses of samples collected in FY-14 were completed in FY-15.

This study concluded that transuranic and reactive fission products extract from used uranium oxide fuels into molten $\mathrm{LiCl}-\mathrm{KCl}-\mathrm{UCl}_{3}$ at $500{ }^{\circ} \mathrm{C}$ by merely immersing the fuel in the salt. However, the extents of extraction varied widely between the oxidized EBR-II and BR3 fuel forms. Specifically, 92 to $97 \mathrm{wt} \%$ of transuranic and reactive fission products extracted from oxidized EBR-II fuel to molten salt compared to 14 to $23 \mathrm{wt} \%$ for the crushed BR3 fuel and 12 to $30 \mathrm{wt} \%$ for voloxidized BR3 fuel. The extraction of transuranic and reactive fission products from the oxidized EBR-II fuel to the molten salt essentially peaked after 3 hours of fuel-salt contact. In contrast, the relatively minor extraction of transuranic and reactive fission products from the BR3 fuel to the molten salt essentially peaked after 24 hours of fuel-salt contact, but the extraction continued slowly for the 50-hr duration of fuel-salt contact. This study also showed that uranium ions were free to exchange between solid oxide fuel and the molten salt phases. This was particularly manifested by the drop in $235 \mathrm{U}$ isotopic concentration in the oxidized EBR-II fuel from $57.4 \mathrm{wt} \%$ to $30.2 \mathrm{wt} \%$, while the same in the salt phase correspondingly increased from $0.36 \mathrm{wt} \%$ to 7.42 $\mathrm{wt} \%$. This equates to $60 \mathrm{wt} \%$ of complete blending of $235 \mathrm{U}$ between the salt and fuel phases. Further investigation is needed to assess the mechanisms that limit the complete extraction of transuranic and reactive fission products and complete blending of the uranium ions.

The results of the prescribed study were documented in a final report dated May 28, 2014. Following that report a sample of the pretest oxidized EBR-II fuel was subjected to additional analyses in FY-15 to address its ease in transuranic and reactive fission product extraction relative to those from the crushed and voloxidized BR3 fuels. Contrary to the assumption that the finely divided EBR-II fuel was fully oxidized, analysis results indicated that the EBR-II fuel used in this study indeed contained a substantial reduced phase of uranium. Specifically, the fraction of uranium in the metal phase was $31 \mathrm{wt} \%$. The presence of a uranium metal phase enables other reaction mechanisms that appear to facilitate a more rapid and complete extraction of transuranic and reactive fission products from the fuel to the subject salt phase. The results and discussion of the follow-on sample analysis of the pretest EBR-II fuel are documented here, as an addendum to the original May 28, 2014 report.

\subsection{Ion Selective Ceramics}

\section{Erik Spoerke, SNL}

"Ion-Selective Ceramics for Waste Separations" aims to develop an electrochemical approach to remove fission product waste (e.g., $\mathrm{Cs}^{+}$) from the $\mathrm{LiCl}-\mathrm{KCl}$ molten salts used in the pyroprocessing of spent nuclear fuel. Consolidation and concentration of contaminants such as $\mathrm{Cs}^{+}$and $\mathrm{Sr}^{2+}$ in molten salts would substantially reduce the volume of high level waste that must be packaged for disposal. We recently generated two reports describing the laboratory-scale application of ion-selective ceramics (LLTO $\left(\mathrm{Li}_{5} \mathrm{La}_{3} \mathrm{Ta}_{2} \mathrm{O}_{12}\right)$ and $\mathrm{NaSICON}$-type materials (e.g., $\left.\mathrm{KZr}_{2} \mathrm{P}_{3} \mathrm{O}_{12}\right)$ ) as "filters" to recycle $500^{\circ} \mathrm{C} \mathrm{LiCl}-\mathrm{KCl}$ molten salts and concentrate $\mathrm{Cs}^{+}$contaminants in a reduced volume of salt. ${ }^{1,2}$ Under electrochemical bias, 
$\mathrm{Li}^{+}$and $\mathrm{K}^{+}$were selectively transported across the membrane to make purified salt, while $\mathrm{Cs}^{+}$ contaminants were blocked from transport. $\mathrm{Na}^{+}$ions are also expected to be transported, while divalent contaminants, ${ }^{3}$ such as $\mathrm{Sr}^{2+}, \mathrm{Ba}^{2+}$, or $\mathrm{Sm}^{2+}$ would also be expected to be excluded, concentrated in the waste salt. Charge balance of these reactions was maintained through the oxidation and reduction of copper at the anode and cathode of the cell, respectively. This process is schematically illustrated in Figure 90 , though the copper-based charge balance chemistry is replaced by chlorine/chloride reduction/oxidation. A closed-end ceramic tube separates volumes of contaminated and non-contaminated salt, allowing selective transport of $\mathrm{Li}^{+}$and $\mathrm{K}^{+}$through the ceramic. Balancing cation transport with chlorine reduction results in increased volume of purified $\mathrm{LiCl}-\mathrm{KCl}$ salt outside the tube, and concentrated $\mathrm{CsCl}$ salt inside the tube. The focus of effort in FY-15 was to identify critical technical issues associated with scaling this approach for potential industrial use.

In considering the technical challenges of implementing this process for pyroprocessing salt remediation, a number of assumptions were

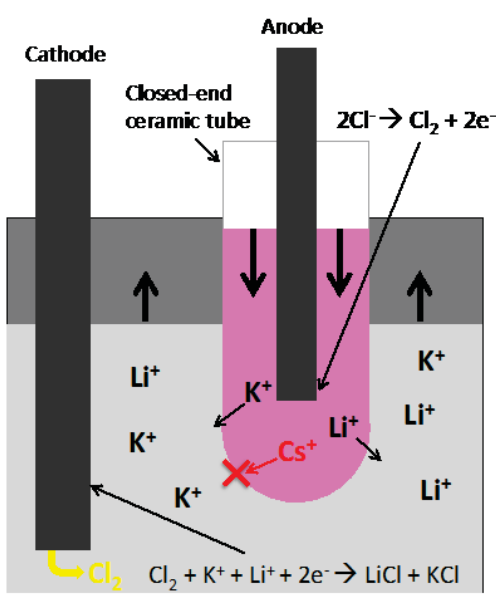

Figure 90. Schematic of process to use a closed-end ceramic tube to isolate Cs-contamination from $\mathrm{LiCl}-\mathrm{KCl}$ molten salt. made. First we assume an annual salt waste ( $\mathrm{LiCl}-\mathrm{KCl}$, containing $12 \% \mathrm{NaCl}$ ) production volume of 15 metric tons (MT), based on projections by Simpson, ${ }^{3,4}$ and this waste is conservatively assumed to have a representative (though not expressly definitive) contamination level of $2.5 \% \mathrm{CsCl}^{3}$ (accounting for other contaminants would slightly decrease the required electrochemical capacity of the system). The limit for $\mathrm{CsCl}$ concentration was determined by estimating the melting temperature $\left(<500^{\circ} \mathrm{C}\right)$ of the Cs-enriched molten salt, ${ }^{5}$ leading to an estimated target waste $\mathrm{CsCl}$ content as high as 60 mole percent $\mathrm{CsCl}$ ( $\sim 80$ weight percent). This dramatic consolidation of contaminant would require transporting more than $99 \%$ of the $\mathrm{Li}^{+}, \mathrm{K}^{+}$, and $\mathrm{Na}^{+}$ions out of the waste salt. Applying a current density of $100 \mathrm{~mA} / \mathrm{cm}^{2}$, utilizing 50 waste-filled ceramic separator tubes ( $25 \mathrm{~cm}$ long, $4 \mathrm{~cm}$ diameter), and running 12 hours daily, $15 \mathrm{MT}$ of waste salt could be treated in under 1 year (11.7 months). This timeframe is proportionately decreased if the number (or size) of ceramic tubes (and electrodes) is increased, the number of hours per day is increased, or the current density is increased.

There are several critical design elements that must be considered to effectively integrating these ceramic tubes, molten salts, electrodes, and charge compensating chemistry into a functional reactor. First, a vessel capable of maintaining an isolated atmosphere, possibly a highly corrosive chlorine atmosphere, must be created to contain the assembly. Candidate formable steel alloys may include Haynes 556 and Haynes 214, available through Haynes, International (Kokomo, IN), and reported to exhibit excellent corrosion resistance in chlorine-bearing and chloride molten salt environments at temperatures well above the $500^{\circ} \mathrm{C}$ anticipated working temperature.

Realizing large-scale salt treatment will also require the reliable manufacture of numerous formed ceramics, ideally closed end tubes. We have consulted with representatives from Ceramatec, Inc (Salt Lake City, UT), who specialize in alkali-conducting NaSICON ceramic materials, similar to the KSICON ceramics explored in this program. As shown in Figure 91, they have developed production-scale capabilities to create a range of NaSICON ceramic discs, plates, and tubes, including closed-end tubes, adhering to strict tolerances for ceramic thickness, uniformity, and phase chemistry. Ceramatec would be a logical partner in the production of formed KSICON or LLTO ceramics for use in this technology.

Another key concern is the incorporation of chemically, thermally, and radioactively stable seals, particularly if a chlorine atmosphere is to be maintained in the reactor. Seals will also need to electrically isolate the anode and cathode and effectively join reaction vessel ports with components such as salt inlet 
plumbing, thermocouples, gas inlets, overpressure relieve connections, and pressure gauges. Ultimately, selection of the appropriate glass seals with system-compatible thermal expansion, chemical inertness, and thermal stability will require specific technical study and evaluation. Phosphate, borate, and silicate glass seals used for solid oxide fuel cells may prove to be qualified candidates, as these materials are commonly used to create metal-metal and metal-ceramic seals, are suitable for temperatures exceeding $500^{\circ} \mathrm{C}$, and are stable against highly oxidizing environments. ${ }^{6,7}$

Achieving high rate electrochemical reactions will require high surface area anodes and cathodes that are stable against corrosion in chlorine and molten chloride salt environments. The corrosion resistant Haynes alloys mentioned above would logical choices, readily formed/welded and compatible with the aggressive environment and potential sealing chemistries. The cathode should also be constructed to allow chlorine gas introduction (actively or passively) to the molten salt through the electrode, maximizing reactive surface area for ideal reaction kinetics.

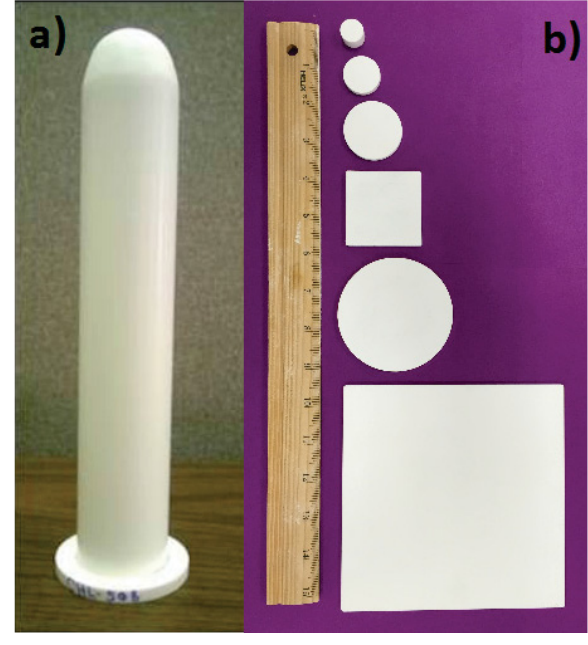

Figure 91. (a) A closed-end ceramic tube (4 $\mathrm{cm}$ diameter) and (b) sheets, discs, and cylinders made from NaSICON ceramics. Images from Ceramatec, Inc.
The technical issue of electrochemical charge compensation (e.g., chlorine versus copper or other suitable metal) should also be carefully considered. The chlorine-mediated approach does provide an elegant and relatively straightforward electrochemical strategy, and it does not stand to introduce any new chemical contaminants to the waste stream. Chlorine chemistry at $500^{\circ} \mathrm{C}$, however, challenges the chemical stability and ultimate safety of the system, impacting the selection of every component of the reactor and potentially introducing additional development and manufacturing costs. In contrast, the copper-mediated approach eliminates the highly corrosive, potentially hazardous chlorine atmosphere. It does, however, increase the chemical complexity of the system, and copper would have to be removed from the final waste salt, perhaps precipitated using lithium and potassium formates as shown previously. $^{1}$

Successful adoption of these components and processes is likely to require a graded scale-up approach. Although our researchscale efforts have demonstrated feasibility of the approach using lab-scale volumes (typically less than $100 \mathrm{~g}$ ), it would be recommended that the chemical kinetics be optimized by scaling to a $1 \mathrm{~kg}$ pilot scale, ideally utilizing as many of the large-scale components (e.g., ceramic tubes, electrodes, etc.) as possible. In addition, small scale studies of glass sealing stability, corrosion resistance of all materials, the chlorine-gas delivery, and ultimately the radiation stability of the system must all be explored prior to large scale implementation. While there is significant promise in the use of this technology to reduce waste salt volumes, significant technical development and optimization must be done before that promise can be realized.

\section{References}

1. E. Spoerke et al., 2014, "Ion Selective Ceramics for Waste Separations," U.S. DOE Office of Nuclear Energy.

2. E. Spoerke et al., 2013, "Ion Selective Ceramics for Waste Separations: End of Fiscal Year Project Assessment," U.S. DOE Office of Nuclear Energy.

3. M. Williamson, 2015, personal communication with E. Spoerke. 
4. M. Simpson, "Projected Salt Waste Production from a Commercial Pyroprocessing Facility," Science and Technology of Nuclear Installations, 2013: 1-8.

5. J. Sangster and A. D. Pelton, "Thermodynamic Calculation of Phase Diagrams of the 60 CommonIon Ternary Systems Containing Cations Li, Na, K, Rb, Cs and Anions F, Cl, Br, I," Journal of Phase Equilibria 12, 1991: 511-537.

6. Q. Zhu, L Peng, and T. Zhang, in Fuel Cell Electronics Packaging, eds. K. Kuang \& K. Easler, Ch. 2, 33-60, New York: Springer US, 2007.

7. O. Paulsen, "Rigid Bonded Glass Ceramic Seals for High Temperature Membrane Reactors and Solid Oxide Fuel Cells," Ph.D. thesis, Norwegian University of Science and Technology, 2009.

\section{Publication}

Rodriguez, M. A., J. Griego, H. J. Brown-Shaklee, M. A. Blea-Kirby, J. F. Ihlefeld, and E. D. Spoerke, "X-ray Powder Diffraction Study of $\mathrm{La}_{2} \mathrm{LiTaO}_{6}$," Powder Diffraction 30(01), 2015: 57-62.

Non-Provisional Patent

Spoerke, E. D., J. Ihlefeld, J. S. Wheeler, K. Waldrip, H. Brown-Shaklee, L Small, and D. R. Wheeler, "Electrochemical Ion Separation in Molten Salts." US Appln No.: 14/660,696. (3/17/2015).

\section{Provisional Patent}

Brown-Shaklee, H. J., J. Ihlefeld, E. D. Spoerke, M. A. Blea-Kirby, 2015, "Methods for Producing Dense Lithium Lanthanum Tantalate Lithium Ion Conducting Ceramics.” US. Appln No.: 62/110,834 $(2 / 2 / 2015)$.

\section{Presentations}

Spoerke, E. D., J. S. Wheeler, H. J. Brown-Shaklee, J. Ihlefeld, M. Blea-Kirby, L. J. Small, L. E. Johnson and K. Waldrip. "Ceramic Ion Filters for Mixed Waste Separations," Electronic Materials and Applications 2015, Orlando, FL, Jan., 2015.

Brown-Shaklee, H. J., M. A. Blea-Kirby, J. Griego, M. A. Rodriguez, J. Ihlefeld, E. D. Spoerke, "High Density Li5La3Ta2O12 (LLTO) Ceramics for Ion-Selective Fission Waste Processing," Electronic Materials and Applications 2015, Orlando, FL Jan., 2015. 
This page intentionally left blank. 


\section{Appendixes}

Material

Recovery \&

Waste Form

Development 
This page intentionally left blank. 


\section{APPENDIXES}

\subsection{Acronyms}

A\&AC Advisory and Assistance Contract

ACSEPT $\quad$ Actinide reCycling by SEParaTion

ACWF advanced ceramic waste form

AH Aagaard-Helgeson

ALSEP Actinide-Lanthanide Separation

ALTGLASS Accelerated Leach Testing of GLASS

AMUSE Argonne Model of Universal Solvent Extraction

ANL Argonne National Laboratory

ASTM American Society for Testing and Materials

$\mathrm{AU}$

Alfred University

CCIM Cold Crucible Induction Melter

CEA Commissariat à l'Énergie Atomique (France)

CECE combined electrolysis and catalytic exchange

CETE Coupled End-To-End

CIEMAT Center for Energy Investigations in Madrid

CNWG Civil Nuclear Working Group

$\mathrm{CV} \quad$ cyclic voltammogram

CWF ceramic waste form

DFT Density Functional Theory

DOE U.S. Department of Energy

-EM Office of Environmental Management

-NE Office of Nuclear Energy

-SC Office of Science

EBR Experimental Breeder Reactor

EIS electrochemical impedance spectroscopy

EPA Environmental Protection Agency

ER electrorefiner

EU European Union

F\&OR Functional and Operating Requirements

FCRD Fuel Cycle Research and Development

FCT Fuel Cycle Technologies

FR fast reactor 
FY fiscal year

FTIR Fourier transform infrared (spectroscopy)

GCM glass composite material

GCMT glass corrosion modeling tool

GM Grambow-Müller

GNEP Global Nuclear Energy Partnership

GRAAL Glass Reactivity with Allowance for the Alteration Layer

HFEF Hot Fuels Examination Facility

HEU high-enriched uranium

HIP hot isostatic pressing

HLW high-level waste

HUP hot uniaxial pressing

IWMS Integrated Waste Management Strategy

IAEA International Atomic Energy Agency

ICP-MS Inductively Coupled Plasma-Mass Spectrometry

ID inventory difference

IDIQ indefinite delivery/indefinite quality

INL Idaho National Laboratory

ISG International Simple Glass

JAEA Japan Atomic Energy Agency

JNFL Japan Nuclear Fuel Limited

LAMM Laboratory of Analysis and Material Metrology

LANL Los Alamos National Laboratory

LBNL Lawrence Berkeley National Laboratory

LWR light-water reactor

M\&S modeling and simulation

MOF metal-organic-framework

MRWFD Material Recovery and Waste Form Development

MT

metric tons

MTU metric ton of uranium

MWF metal waste form

NEUP Nuclear Energy University Programs

NMR nuclear magnetic resonance

NNL National Nuclear Laboratory (Great Britain)

NTD National Technical Director 
ORNL Oak Ridge National Laboratory

PA performance assessment

PCT product consistency test

PNNL Pacific Northwest National Laboratory

PUREX plutonium uranium reduction extraction

$\mathrm{R} \& \mathrm{D} \quad$ research and development

RF radio frequency

RR Residual Rate

RT retention time

SACSESS S Safety of ACtinide SEparation ProceSSes

S\&M Science and Methods

SANEX selective actinide extraction

SBIR Small Business Innovation Research

SEM scanning electron microscopy

SF separation factor

$\mathrm{SF} \mathrm{Eu} / \mathrm{Am} \quad$ separation factor for europium from americium

SFR sodium fast reactor

SNL Sandia National Laboratory

SNM special nuclear materials

SPFT single-pass flow through

SPS spark plasma sintering

SRNL Savannah River National Laboratory

SS stainless steel

TALSPEAK Trivalent Actinide - Lanthanide Separation by Phosphorous reagent Extraction from Aqueous Komplexes

TGA thermogravimetric

TRU transuranic

TRUEX transuranic extraction

UDS undissolved solids

UNF used nuclear fuel

UREX+ Uranium Extraction Plus

US United States

UV-vis ultraviolet-Visible

UV-vis-NIR ultraviolet-visible near-infrared

WSU Washington State University 
WTBS Waste Treatment Baseline Study

XAS X-ray absorption spectroscopy

XRD X-ray diffraction

\subsection{Chemical Compounds}

ADU

AHA

$\mathrm{Ag}^{0} \mathrm{Z}$

$\operatorname{AgA}$

$\mathrm{AgS}$

$\mathrm{AgZ}$

AgZ-PAN

BP18C6

CMPO

DAAP

DFT

DGA

DMSO

DPA

DPAH

DPTA

DTPA

EDTA

$\mathrm{H}_{2}$

$\mathrm{H}_{2} \mathrm{MEHP}$

$\mathrm{H}_{2} \mathrm{O}$

$\mathrm{H}_{2} \mathrm{O}_{2}$

$\mathrm{H}_{4} \mathrm{SiO}_{4}$

HDBP

HDEHP

HDO

HDPTA

HEDHP

HEDTA

$\mathrm{HEH}[\mathrm{EHP}]$ ammonium diuranate

acetohydroxamic acid

silver substituted mordenite

silver nitrate impregnated alumina

silver nitrate impregnated silica

silver exchanged mordenite

silver exchanged mordenite in an engineered form sorbent

$N, N$ '-bis[(6-carboxy-2-pyridyl)methyl]-4,13-diaza-18-crown-6

octyl(phenyl)-N,N-diisobutylcarbonoylmethyl-phosphine oxide

diamylamylphosphonate

Density Functional Theory

diglycolamides

dimethyl sulfoxide

dipicolinic acid

dithiophosphinic acid

1,3-diaminopropane-N,N,N',N'-tetraacetic acid

diethylenetriamine-N,N,N',N',N'-pentaacetic acid

ethylenediaminetetraacetic acid

hydrogen

mono-(2-ethylhexyl) phosphoric acid

water

peroxide

orthosilic acid

di-n-butyl phosphoric acid

bis-(2-ethylhexyl) phosphoric acid

deuterated water

1,3-diamino-2-hydroxypropane-N,N,N',N'-tetraacetic acid

di(2-ethylhexyl) phosphoric acid

$N$-(2-hydroxyethyl)ethylenediamine- $N, N^{\prime}, N^{\prime}$-triacetic acid

2-ethylhexylphosphonic acid mono-2-ethylhexyl ester 
HIDA $\quad N$-(2-hydroxyethyl)iminodiacetic acid

HMDPA hydroxymethyl-DPA

$\mathrm{HNO}_{3} \quad$ nitric acid

HTO tritiated water

$\mathrm{KOH} \quad$ potassium hydroxide

KSICON KZr2P3O12

K-TSP $\quad \mathrm{HK}_{3} \mathrm{Ti}_{4} \mathrm{O}_{4}\left(\mathrm{SiO}_{4}\right)_{3} \cdot 4 \mathrm{H}_{2} \mathrm{O}$

LA lactic acid

LBLTO $\quad \mathrm{Li}_{6} \mathrm{BaLa}_{2} \mathrm{Ta}_{2} \mathrm{O}_{12}$

LLTO structured lithium lanthanum tantalate

mor-DPA 4-morpholino- DPA

mPIP-DPA 4-methyl-piperidinyl-DPA

NaSICON Na Super Ion CONductor: NaZr2P3O12

$\mathrm{NO}_{2} \quad$ nitrogen dioxide

NTA nitrilotriacetic acid

$\mathrm{O}_{2} \quad$ oxygen

PAN polyacrylonitrile

QDPA quaternary methyl ammonium-DPA

SFM perovskite structured $\mathrm{Sr}_{2} \mathrm{Fe}_{1.5} \mathrm{Mo}_{0.5} \mathrm{O}_{6-\delta}$

TBP tributyl phosphate

$\mathrm{TcO}_{4}{ }^{-} \quad$ pertechnetate anion

TEDGA tetraethyl diglycolamide

TODGA tetraoctyldiglycolamide

TOPO tri- $n$-octylphosphine oxide

UOX uranium oxide (fuel)

$\alpha-\mathrm{Fe}_{2} \mathrm{O}_{3} \quad$ hematite

$\alpha-\mathrm{FeOOH}$ goethite

$v \mathrm{C}-\mathrm{CO}_{2} \quad$ deprotonated lactate

vC-COOH protonated lactic acid 


\subsection{Nuclear Energy University Project (NEUP) Grants}

\section{Active Projects Awarded in 2012}

\begin{tabular}{|c|c|c|}
\hline Lead University & Title & $\begin{array}{l}\text { Principle } \\
\text { Investigator }\end{array}$ \\
\hline Alfred University & $\begin{array}{l}\text { Surface Layer-Bulk Glass Interface Evolution with Aqueous } \\
\text { Corrosion }\end{array}$ & Nathan Mellott \\
\hline $\begin{array}{l}\text { Northwestern } \\
\text { University }\end{array}$ & $\begin{array}{l}\text { Novel metal sulfides to achieve effective capture and durable } \\
\text { consolidation of radionuclides }\end{array}$ & $\begin{array}{l}\text { Mercouri } \\
\text { Kanatzidis }\end{array}$ \\
\hline $\begin{array}{l}\text { University of } \\
\text { Nevada, Las Vegas }\end{array}$ & $\begin{array}{l}\text { Thermodynamic and Microstructural Mechanisms in the } \\
\text { Corrosion of Advanced Ceramic Tc-bearing Waste Forms and } \\
\text { Thermophysical Properties }\end{array}$ & $\begin{array}{l}\text { Thomas } \\
\text { Hartmann }\end{array}$ \\
\hline Alfred University & Alternative High-Performance Ceramic Waste Forms & S. K. Sundaram \\
\hline $\begin{array}{l}\text { University of } \\
\text { Nevada, Las Vegas }\end{array}$ & $\begin{array}{l}\text { Electrochemical Corrosion Studies for Modeling Metallic Waste } \\
\text { Form Release Rates }\end{array}$ & $\begin{array}{l}\text { Frederic } \\
\text { Poineau }\end{array}$ \\
\hline $\begin{array}{l}\text { Washington State } \\
\text { University }\end{array}$ & $\begin{array}{l}\text { Advanced Characterization of Molecular Interactions in } \\
\text { TALSPEAK-like Separations Systems }\end{array}$ & Ken Nash \\
\hline
\end{tabular}

Active Projects Awarded in 2013

\begin{tabular}{|c|c|c|}
\hline Lead University & Title & $\begin{array}{l}\text { Principle } \\
\text { Investigator }\end{array}$ \\
\hline $\begin{array}{l}\text { Texas A\&M } \\
\text { University }\end{array}$ & $\begin{array}{l}\text { Mixed Metal Phosphonate-Phosphate Resins for Separation of } \\
\text { Lanthanides from Actinides }\end{array}$ & $\begin{array}{l}\text { Abraham } \\
\text { Clearfield }\end{array}$ \\
\hline $\begin{array}{l}\text { Pennsylvania State } \\
\text { University }\end{array}$ & $\begin{array}{l}\text { Glass Composition and Solution Speciation Effects on Stage III } \\
\text { Dissolution }\end{array}$ & Carlo Pantano \\
\hline $\begin{array}{l}\text { University of Illinois } \\
\text { at Chicago }\end{array}$ & $\begin{array}{l}\text { Performance of a Steel/Oxide Composite Waste Form for } \\
\text { Combined Waste Streams from Advanced Electrochemical } \\
\text { Processes over Geologic Time Scales }\end{array}$ & $\begin{array}{l}\text { J. Ernesto } \\
\text { Indacochea }\end{array}$ \\
\hline $\begin{array}{l}\text { Oregon State } \\
\text { University }\end{array}$ & $\begin{array}{l}\text { Organic Speciation \& Interactions in ALSEP - } 1 \text { Step Partitioning } \\
\text { Process of Minor Actinides, Lanthanides, and Fission Products }\end{array}$ & Alena Paulenova \\
\hline $\begin{array}{l}\text { Washington State } \\
\text { University }\end{array}$ & $\begin{array}{l}\text { Managing Zirconium Chemistry and Phase Compatibility in } \\
\text { Combined Process Separations for Minor Actinide Partitioning }\end{array}$ & Nathalie Wall \\
\hline $\begin{array}{l}\text { University of North } \\
\text { Texas }\end{array}$ & $\begin{array}{l}\text { Molecular dynamics-based simulations of bulk/interfacial } \\
\text { structures and diffusion behaviors in nuclear waste glasses }\end{array}$ & Jincheng Du \\
\hline University of Idaho & $\begin{array}{l}\text { Off-Gas Treatment: Evaluation of Nano-structured Sorbents for } \\
\text { Selective Removal of Contaminants }\end{array}$ & Vivek Utgikar \\
\hline $\begin{array}{l}\text { University of } \\
\text { California, Davis }\end{array}$ & $\begin{array}{l}\text { Thermally and Chemically Responsive Nanoporous Materials for } \\
\text { Efficient Capture of Fission Product Gases }\end{array}$ & Pieter Stroeve \\
\hline
\end{tabular}




\section{Active Projects Awarded in 2014}

\begin{tabular}{|c|c|c|}
\hline Lead University & Title & $\begin{array}{l}\text { Principle } \\
\text { Investigator }\end{array}$ \\
\hline Rutgers University & $\begin{array}{l}\text { Apatite and sodalite based glass-bonded waste forms for } \\
\text { immobilization of } 1291 \text { and mixed halide radioactive wastes }\end{array}$ & Ashutosh Goel \\
\hline Clemson University & $\begin{array}{l}\text { A New Paradigm for Understanding Multi-phase Ceramic Waste } \\
\text { Form Performance }\end{array}$ & Kyle Brinkman \\
\hline Syracuse University & Sorption Modeling and Verification for Off-Gas Treatment & $\begin{array}{l}\text { Lawrence } \\
\text { Tavlarides }\end{array}$ \\
\hline $\begin{array}{l}\text { Colorado School of } \\
\text { Mines }\end{array}$ & $\begin{array}{l}\text { Controlling Hexavalent Americium - A Centerpiece to a Compact } \\
\text { Nuclear Fuel Cycle }\end{array}$ & Jenifer Braley \\
\hline $\begin{array}{l}\text { University of } \\
\text { California, Irvine }\end{array}$ & $\begin{array}{l}\text { Combining Experiments \& Simulations of Extraction Kinetics \& } \\
\text { Thermodynamics in Advanced Separation Processes for UNF }\end{array}$ & Mikael Nilsson \\
\hline $\begin{array}{l}\text { Georgia Institute of } \\
\text { Technology }\end{array}$ & $\begin{array}{l}\text { Zeolite Membranes for Krypton/Xenon Separation from Spent } \\
\text { Nuclear Fuel Reprocessing Off-Gas }\end{array}$ & Sankar Nair \\
\hline $\begin{array}{l}\text { Ohio State } \\
\text { University }\end{array}$ & $\begin{array}{l}\text { Rare Earth Electrochemical Property Measurements and Phase } \\
\text { Diagram Development in a Complex Molten Salt Mixture for } \\
\text { Molten Salt Recycle }\end{array}$ & Jinsuo Zhang \\
\hline $\begin{array}{l}\text { University of } \\
\text { Nevada, Reno }\end{array}$ & Effect of Metallic Li on the Behavior of Metals in Molten Salts & $\begin{array}{l}\text { Dev } \\
\text { Chidambaram }\end{array}$ \\
\hline
\end{tabular}

\section{Recently Awarded Grants in 2015}

\begin{tabular}{|c|c|c|}
\hline Lead University & Title & $\begin{array}{l}\text { Principle } \\
\text { Investigator }\end{array}$ \\
\hline $\begin{array}{l}\text { Washington State } \\
\text { University }\end{array}$ & $\begin{array}{l}\text { Understanding influence of thermal history \& glass chemistry on } \\
\text { kinetics of phase separation \& crystallization in borosilicate glass- } \\
\text { ceramic waste forms for aqueous reprocessed high level waste }\end{array}$ & John McCloy \\
\hline $\begin{array}{l}\text { University of } \\
\text { Nevada, Las Vegas }\end{array}$ & $\begin{array}{l}\text { Purification of Zirconium cladding using a chloride volatility } \\
\text { process }\end{array}$ & Frederic Poineau \\
\hline $\begin{array}{l}\text { Missouri Univ of } \\
\text { Science \& Tech }\end{array}$ & $\begin{array}{l}\text { Phase Separation And Crystallization of Complex Borosilicate } \\
\text { Melts for Glass-Ceramic Waste Forms }\end{array}$ & Richard Brow \\
\hline $\begin{array}{l}\text { Colorado School of } \\
\text { Mines }\end{array}$ & $\mathrm{Kr} / \mathrm{Xe}$ separation over Metal Organic Framework Membranes & Moises Carreon \\
\hline $\begin{array}{l}\text { Univ of Tennessee } \\
\text { at Knoxville }\end{array}$ & Purification of Zirconium Tetrachloride from UNF Cladding & Craig Barnes \\
\hline $\begin{array}{l}\text { California State } \\
\text { Univ, Long Beach }\end{array}$ & Elucidation of the kinetics of Advanced Separation systems & Stephen Mezyk \\
\hline
\end{tabular}




\begin{tabular}{l|l|l|}
$\begin{array}{l}\text { California State } \\
\text { Univ, Long Beach }\end{array}$ & $\begin{array}{l}\text { Building Quantitative Relationships between Ligand Structure } \\
\text { and Its Reactivity with Organic Radical Species }\end{array}$ & Stephen Mezyk \\
\hline $\begin{array}{l}\text { Pennsylvania State } \\
\text { University }\end{array}$ & $\begin{array}{l}\text { Fundamental Electrochemical Properties of Liquid Metals in LiCl- } \\
\mathrm{KCl} \text { for Separation of Alkali/Alkaline-Earths (Cs, Sr and Ba) }\end{array}$ & Hojong Kim \\
\hline $\begin{array}{l}\text { Ohio State } \\
\text { University }\end{array}$ & $\begin{array}{l}\text { Monitoring of Actinide Concentrations in Molten LiCi-KCl Salt } \\
\text { using Alpha Spectroscopy }\end{array}$ & Lei Cao \\
\hline
\end{tabular}




\subsection{FY-15 Journal Publications}

\begin{tabular}{|c|c|c|}
\hline Author(s) & Title & Publication \\
\hline $\begin{array}{l}\text { Zarzana, C.A.; Groenewold, G.S.; } \\
\text { Mincher, B.J.; Mezyk, S.P.; Wilden, } \\
\text { A.; Schmidt, H.; Modolo, G.; } \\
\text { Wishart, J.F.; Cook, A.R. }\end{array}$ & $\begin{array}{l}\text { A comparison of the radiolysis of TODGA } \\
\text { and T(EH)DGA using UHPLC-MS analysis. }\end{array}$ & $\begin{array}{l}\text { Solvent Extraction lon } \\
\text { Exchange 33:431-447, } 2015\end{array}$ \\
\hline $\begin{array}{l}\text { Mincher, B.J.; Schmitt, N.C.; } \\
\text { Schuetz, B.K.; Shehee T.C.; Hobbs, } \\
\text { D.T. }\end{array}$ & $\begin{array}{l}\text { Recent advances in } f \text {-element separations } \\
\text { based on a new method for the } \\
\text { production of pentavalent americium in } \\
\text { acidic solution. }\end{array}$ & $\begin{array}{l}\text { RSC Advances 5:27205-27210, } \\
2015\end{array}$ \\
\hline $\begin{array}{l}\text { Mincher, B.J.; Tillotson, R.D.; Law, } \\
\text { J.; Garn, T.; Rutledge, V.; Schmitt, } \\
\text { N.C. }\end{array}$ & $\begin{array}{l}\text { The solvent extraction of } \mathrm{Am}(\mathrm{VI}) \text { using } \\
\text { centrifugal contactors. }\end{array}$ & $\begin{array}{l}\text { Journal Radioanal Nucl Chem } \\
\text { DOI 10.1007/s10967-015-4397- } \\
6,2015\end{array}$ \\
\hline $\begin{array}{l}\text { K. S. Subrahmanyam, Debajit } \\
\text { Sarma, Christos D. Malliakas, } \\
\text { Kyriaki Polychronopoulou, Brian J. } \\
\text { Riley, David A. Pierce, Jaehun } \\
\text { Chun, and Mercouri G. Kanatzidis }\end{array}$ & $\begin{array}{l}\text { Chalcogenide Aerogels as Sorbents for } \\
\text { Radioactive lodine }\end{array}$ & Chemistry of Materials, 2015 \\
\hline $\begin{array}{l}\text { P. Tumurugoti, S. K. Sundaram, } \\
\text { Scott T. Misture, J. C. Marra, J. W. } \\
\text { Amoroso }\end{array}$ & $\begin{array}{l}\text { Melt Processed Multiphase Ceramic } \\
\text { Waste Forms for Nuclear Waste } \\
\text { Immobilization }\end{array}$ & $\begin{array}{l}\text { Journal of Nuclear Materials, } \\
2015\end{array}$ \\
\hline $\begin{array}{l}\text { B.M. Clark, P. Tumurugoti, S. } \\
\text { Sundaram, J.W. Amoroso, J.C. } \\
\text { Marra, K.S. Brinkman }\end{array}$ & $\begin{array}{l}\text { Microstructures of Melt Processed and } \\
\text { Spark Plasma Sintered Ceramic Waste } \\
\text { Forms }\end{array}$ & $\begin{array}{l}\text { Metallurgical and Materials } \\
\text { Transactions E-Materials for } \\
\text { Energy Systems, } 2014\end{array}$ \\
\hline $\begin{array}{l}\text { J. Amoroso, J.C. Marra, M. Tang, Y. } \\
\text { Lin, F. Chen, D. Su and K.S. } \\
\text { Brinkman }\end{array}$ & $\begin{array}{l}\text { Melt Process Multiphase Ceramic Waste } \\
\text { Forms for Nuclear Waste Immobilization }\end{array}$ & Journal of Nuclear Materials \\
\hline $\begin{array}{l}\text { M. Tang, A. Kossoy, G. Jarvinen, J. } \\
\text { Crum, L. Turo, B. Riley, K. } \\
\text { Brinkman, K. Fox, J. Amoroso and } \\
\text { J. Marra }\end{array}$ & $\begin{array}{l}\text { Radiation Stability Test on Multiphase } \\
\text { Glass Ceramic and Crystalline Ceramic } \\
\text { Waste Forms }\end{array}$ & $\begin{array}{l}\text { Nuclear Instruments and } \\
\text { Methods in Physics Research } \\
\text { Section B: Beam Interactions } \\
\text { with materials and Atoms, } \\
2014\end{array}$ \\
\hline $\begin{array}{l}\text { B. M. Clark, S. K. Sundaram, K. S. } \\
\text { Brinkman, K. M. Fox, J. W. } \\
\text { Amoroso }\end{array}$ & $\begin{array}{l}\text { Spark Plasma Sintering of Neodymium } \\
\text { Titanate Pyrochlore for Advanced Ceramic } \\
\text { Waste Forms }\end{array}$ & Ceramics Transactions, 2014 \\
\hline $\begin{array}{l}\text { P. Tumurugti, S. K. Sundaram, K. S. } \\
\text { Brinkman, J. W. Amoroso and K. } \\
\text { M. Fox }\end{array}$ & $\begin{array}{l}\text { Melt-Processed Multiphase Ceramic } \\
\text { Waste Forms }\end{array}$ & Ceramics Transactions, 2014 \\
\hline $\begin{array}{l}\text { Xu, H.; Chavez, M. E.; Mitchell, } \\
\text { J.N.; Garino, T.J.; Schwarz, H.L.; } \\
\text { Rodriguez, M. A.; Rademacher, D. } \\
\text { X.; Nenoff, T.M }\end{array}$ & $\begin{array}{l}\text { Crystal Structure and Thermodynamic } \\
\text { Stability of Ba/Ti-Substituted Pollucites for } \\
\text { Radioactive Cs/Ba Immobilization }\end{array}$ & $\begin{array}{l}\text { J. Amer. Ceram. Soc. } 2015 \text {, } \\
\text { 98(8), 2634-2640, } 2015\end{array}$ \\
\hline Mowry, C.D.; Brady, P.V.; Garino, & Development and Durability Testing of a & J. Amer. Ceram. Soc., 2015, \\
\hline
\end{tabular}




\begin{tabular}{|c|c|c|}
\hline Author(s) & Title & Publication \\
\hline T.J.; Nenoff, T.M. & $\begin{array}{l}\text { Low Temperature Sintering Bi-Si-Zn Oxide } \\
\text { Glass Composite Material (GCM) }{ }^{129} \text { I } \\
\text { Waste Form }\end{array}$ & 98(10), 3094-3104 \\
\hline $\begin{array}{l}\text { P. Tumurugoti, S. K. Sundaram, } \\
\text { Scott T. Misture, J. C. Marra, J. W. } \\
\text { Amoroso }\end{array}$ & $\begin{array}{l}\text { Melt Processed Multiphase Ceramic } \\
\text { Waste Forms for Nuclear Waste } \\
\text { Immobilization }\end{array}$ & $\begin{array}{l}\text { Journal of Nuclear Materials, } \\
2015\end{array}$ \\
\hline $\begin{array}{l}\text { Brian Westphal, JC Price, Ken } \\
\text { Bateman, and Ken Marsden }\end{array}$ & $\begin{array}{l}\text { Zirconium Determination by Cooling Curve } \\
\text { Analysis During the Pyroprocessing of } \\
\text { Used Nuclear Fuel }\end{array}$ & $\begin{array}{l}\text { Journal of Nuclear Materials, } \\
\text { Vol. 457, pp. 241-245, } 2015\end{array}$ \\
\hline $\begin{array}{l}\text { Joseph A. Macor, Jessie L. Brown, } \\
\text { Justin N. Cross, Scott, Scott R. } \\
\text { Daly, Andrew J. Gaunt, Gregory S. } \\
\text { Girolami, Michael T. Janicke, Stosh } \\
\text { A. Kozimor, Mary P. Neu, Angela C. } \\
\text { Olson, Sean D. Reilly, Brian L. Scott }\end{array}$ & $\begin{array}{l}\text { Coordination chemistry of } 2,2^{\prime}- \\
\text { biphenylenedithiophosphinate and } \\
\text { diphenyldithiophosphinate with } \mathrm{U}, \mathrm{Np} \text { and } \\
\mathrm{Pu}\end{array}$ & $\begin{array}{l}\text { Dalton Transactions DOI: } \\
\text { 10.1039/c5dt02976g, } 2015\end{array}$ \\
\hline $\begin{array}{l}\text { Casella, A. J., L. R. Hylden, E. L. } \\
\text { Campbell, T. G. Levitskaia, J. M. } \\
\text { Peterson, F. N. Smith, and S. A. } \\
\text { Bryan }\end{array}$ & $\begin{array}{l}\text { Development of On-Line Spectroscopic pH } \\
\text { Monitoring for Nuclear Fuel Reprocessing } \\
\text { Plants: Weak Acid Schemes }\end{array}$ & $\begin{array}{l}\text { Analytical Chemistry 87(10), } \\
\text { 2015: 5139-5147. } \\
\text { doi:10.1021/ac504578t. }\end{array}$ \\
\hline $\begin{array}{l}\text { G. J. Lumetta, A. J. Casella, B. M. } \\
\text { Rapko, T. G. Levitskaia, N. K. } \\
\text { Pence, J. C. Carter, C. M. Niver, M. } \\
\text { R. Smoot }\end{array}$ & $\begin{array}{l}\text { An Advanced TALSPEAK Concept using 2- } \\
\text { Ethylhexylphosphonic Acid Mono-2- } \\
\text { Ethylhexyl Ester as the Extractant }\end{array}$ & $\begin{array}{l}\text { Solvent Extraction and Ion } \\
\text { Exchange } 33,2015: 211-223\end{array}$ \\
\hline K. L. Nash & $\begin{array}{l}\text { The Chemistry of TALSPEAK: A Review of } \\
\text { the Science }\end{array}$ & $\begin{array}{l}\text { Solvent Extraction and Ion } \\
\text { Exchange 33(1), 2015: 1-57. } \\
\text { DOI } \\
10.1080 / 07366299.2014 .98591 \\
2\end{array}$ \\
\hline $\begin{array}{l}\text { Jensen, M. P.; Chiarizia, R.; Ulicki, } \\
\text { J. S.; Spindler, B. D.; Murphy, D. J.; } \\
\text { Hossain, M. M.; Roca-Sabio, A.; de } \\
\text { Blas, A.; Rodríguez-Blas, T. }\end{array}$ & $\begin{array}{l}\text { Solvent Extraction Separation of Trivalent } \\
\text { Americium from Curium and the } \\
\text { Lanthanides. }\end{array}$ & $\begin{array}{l}\text { Solvent Extraction and lon } \\
\text { Exchange 33(4), 2015: 329- } \\
345 .\end{array}$ \\
\hline Bryantsev, V. S. and B. P. Hay & $\begin{array}{l}\text { Theoretical Prediction of Am(III)/Eu(III) } \\
\text { Selectivity to Aid the Design of Actinide- } \\
\text { Lanthanide Separation Agents }\end{array}$ & $\begin{array}{l}\text { Dalton Trans. 44, 2015: 7935- } \\
7942 .\end{array}$ \\
\hline Lapka, J. L. and K. L. Nash & $\begin{array}{l}\text { Advanced TALSPEAK Separations Using a } \\
\text { Malonate Buffer System }\end{array}$ & $\begin{array}{l}\text { Solvent Extraction and lon } \\
\text { Exchange 33, 2015, in press; } \\
\text { DOI } \\
10.1080 / 07366299.2015 .10128 \\
78\end{array}$ \\
\hline $\begin{array}{l}\text { Moyer, B. A., G. L. Lumetta, B. J. } \\
\text { Mincher }\end{array}$ & $\begin{array}{l}\text { Minor Actinide Separation in the } \\
\text { Reprocessing of Spent Nuclear Fuels: } \\
\text { Recent Advances in the United States }\end{array}$ & $\begin{array}{l}\text { Reprocessing and Recycling of } \\
\text { Spent Nuclear Fuels, Waltham, } \\
\text { MA: Woodhead Publishing, } \\
\text { 2015; Chap. 11, pp 289-312 }\end{array}$ \\
\hline
\end{tabular}




\begin{tabular}{|c|c|c|}
\hline Author(s) & Title & Publication \\
\hline $\begin{array}{l}\text { Zalupski, P. R., J. R. Klaehn, and D. } \\
\text { R. Peterman }\end{array}$ & $\begin{array}{l}\text { Complete Recovery of Actinides from } \\
\text { UREX-like Raffinates using a Combination } \\
\text { of Hard and Soft Donor Ligands. II. Soft } \\
\text { Donor Structure Variation }\end{array}$ & $\begin{array}{l}\text { Solvent Extraction and lon } \\
\text { Exchange," 2015, DOI } \\
10.1080 / 07366299.2015 .10642 \\
96\end{array}$ \\
\hline $\begin{array}{l}\text { E. A. Chen, P. S. Riess, S. Y. Chong, } \\
\text { D. Holden, K. E. Jelfs, T. Hasell, M. } \\
\text { A. Little, A. Kewley, M. E. Briggs, A. } \\
\text { Stephenson, M. Thomas, J. A. } \\
\text { Armstong, J. Bell. J. Busto, R. Noel, } \\
\text { J. Liu, D. M. Strachan, P. K. } \\
\text { Thallapally, A. I. Cooper }\end{array}$ & $\begin{array}{l}\text { Separation of Rare Gases and Chiral } \\
\text { Molecules by Selective Binding in Porous } \\
\text { Organic Cages }\end{array}$ & Nature Materials: 1-7, 2014 \\
\hline Ebert, W. L & $\begin{array}{l}\text { Glass Degradation in Performance } \\
\text { Assessment Models }\end{array}$ & $\begin{array}{l}\text { Scientific Basis for Nuclear } \\
\text { Waste Management XXXVIII, } \\
2015\end{array}$ \\
\hline $\begin{array}{l}\text { X. Li, Z. Zhang, L. R. Martin, S. Luo, } \\
\text { L. Rao }\end{array}$ & $\begin{array}{l}\text { Effect of Temperature on the Protonation } \\
\text { of } N \text {-(2-hydroxyethyl)ethylenediamine- } \\
N, N^{\prime}, N^{\prime} \text {-triacetic Acid in Aqueous } \\
\text { Solutions: Potentiometric and Calorimetric } \\
\text { Studies }\end{array}$ & $\begin{array}{l}\text { Journal of Chemical } \\
\text { Thermodynamics 85, 2015: 35- } \\
41 .\end{array}$ \\
\hline $\begin{array}{l}\text { Guoxin Tian, Z. Zhang, L. R. Martin, } \\
\text { and L. Rao }\end{array}$ & $\begin{array}{l}\text { Complexation of Curium(III) with DTPA at } \\
10-70^{\circ} \mathrm{C} \text { : Comparison with Eu(III)/DTPA in } \\
\text { Thermodynamics, Luminescence and } \\
\text { Coordination Modes }\end{array}$ & $\begin{array}{l}\text { Inorganic Chemistry 54(4), } \\
\text { 2015: } 1232-1239\end{array}$ \\
\hline $\begin{array}{l}\text { Rodriguez, M. A., J. Griego, H. J. } \\
\text { Brown-Shaklee, M. A. Blea-Kirby, J. } \\
\text { F. Ihlefeld, and E. D. Spoerke }\end{array}$ & X-ray Powder Diffraction Study of $\mathrm{La}_{2} \mathrm{LiTaO}$ & $\begin{array}{l}\text { Powder Diffraction 30(01), } \\
\text { 2015: 57-62 }\end{array}$ \\
\hline $\begin{array}{l}\text { Gin, S., P. Jollivet, M. Fournie, Z. } \\
\text { Wang, Z. Zhu, A. V. Mitroshkov, } \\
\text { and J. V. Ryan }\end{array}$ & $\begin{array}{l}\text { The Fate Of Silicon During Glass Corrosion } \\
\text { Under Alkaline Conditions: A Mechanistic } \\
\text { And Kinetic Study With The International } \\
\text { Simple Glass }\end{array}$ & $\begin{array}{l}\text { Geochimica et Cosmochimica } \\
\text { Acta, 151, 2015: 68-85. }\end{array}$ \\
\hline $\begin{array}{l}\text { Kerisit, S. N., E. M. Pierce, and J. V. } \\
\text { Ryan }\end{array}$ & $\begin{array}{l}\text { Monte Carlo Simulations of Coupled } \\
\text { Diffusion and Surface Reactions during the } \\
\text { Aqueous Corrosion of Borosilicate Glasses }\end{array}$ & $\begin{array}{l}\text { Journal of Non-Crystalline } \\
\text { Solids, 408, 2015: 142-149. }\end{array}$ \\
\hline Wang, Z., J. V. Ryan, Z. Zhu, et al., & $\begin{array}{l}\text { High Sputter Rate and Accurate Interfacial } \\
\text { Chemical Information: Using Argon Cluster } \\
\text { Sputtering Source in ToF-SIMS Depth } \\
\text { Profiling of Leached Nuclear Waste Glass } \\
\text { and Functional Metal Oxide Films }\end{array}$ & $\begin{array}{l}\text { Journal of The American } \\
\text { Society for Mass Spectrometry, } \\
\text { 26(8), } 2015\end{array}$ \\
\hline
\end{tabular}

